$\triangle$ BROWN

W JUDAIC

STUDIES

\title{
Barukh Kurzweil and Modern Hebrew Literature
}

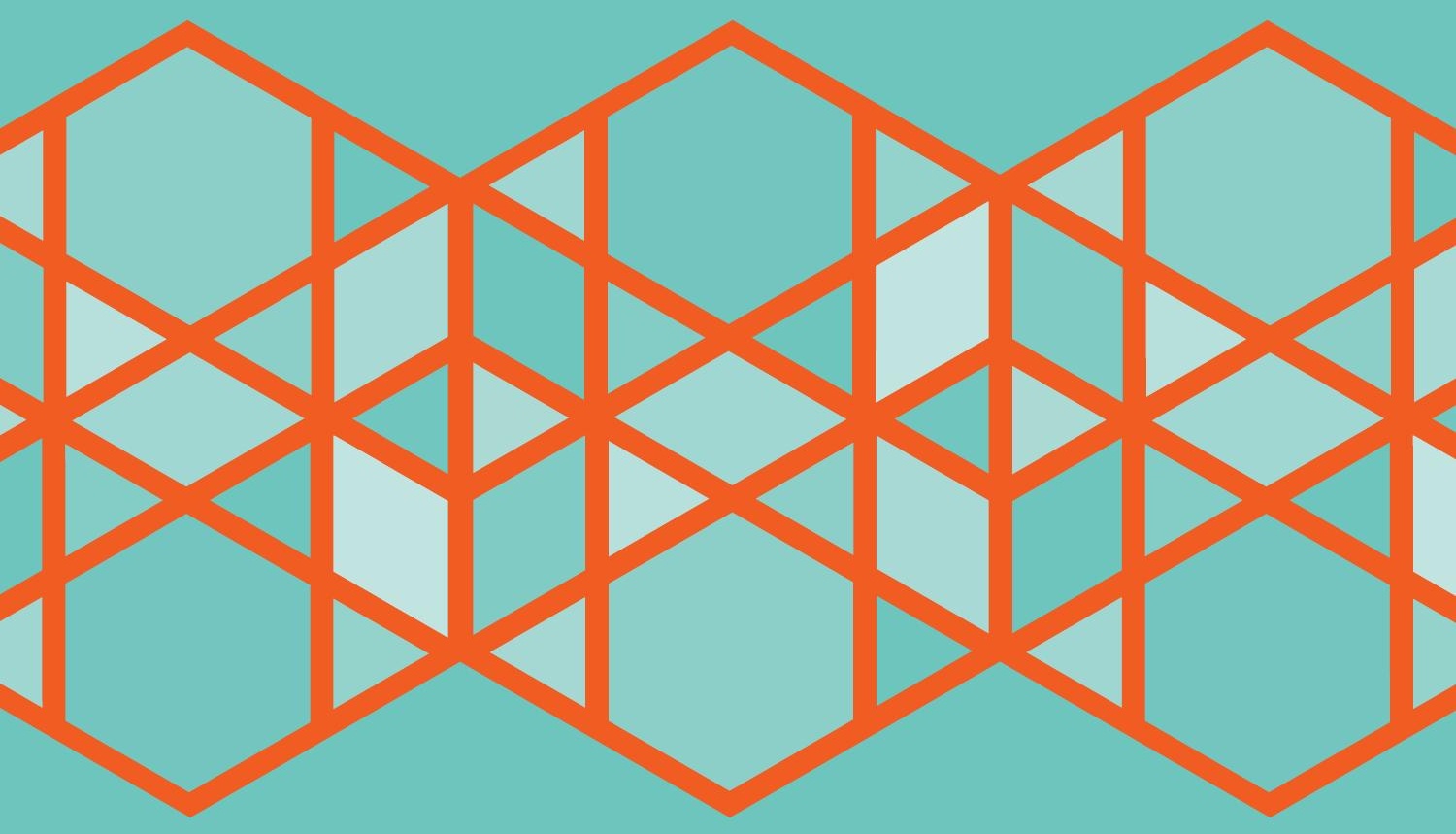

JAMES S. DIAMOND 
Barukh Kurzweil and Modern Hebrew Literature 


\title{
Program in Judaic Studies \\ Brown University \\ BROWN JUDAIC STUDIES
}

Edited by

Jacob Neusner,

Wendell S. Dietrich, Ernest S. Frerichs,

Alan Zuckerman

\section{Editorial Board}

David Blumenthal, Emory University (Approaches to Medieval Judaism)

William Scott Green, University of Rochester (Approaches to Ancient Judaism)

Martin Hengel, University of Tübingen (Hellenistic Judaism)

David Hirsch, Brown University (Modern Jewish Literature)

Baruch A. Levine, New York University (Ancient Israel)

Alan Mintz, University of Maryland (Hebrew Literature)

Valentin Nikiprowetzky, University of Paris (Ancient Judaism)

Marc L. Raphael, Ohio State University (Approaches to Judaism in Modern Times)

Peter Schäfer, University of Cologne (Ancient Judaism)

Jonathan Z. Smith, University of Chicago (Studia Philonica)

Uriel Tal, Tel Aviv University (Modern Judaism)

David Vital, Tel Aviv University (Modern Judaism)

Geza Vermes, University of Oxford (Ancient Judaism)

\section{Corresponding Editors}

David Altshuler, George Washington University

David R. Blumenthal, Emory University

Baruch M. Bokser, Dropsie University

Joel Gereboff, Arizona State University

David Goldenberg, Dropsie University

Robert Goldenberg, State University of New York, Stony Brook

David Goodblatt, Haifa University

William Scott Green, University of Rochester

Peter Haas, Vanderbilt University

Martin Jaffee, University of Virginia

Shamai Kanter, Temple Beth El, Rochester, New York

Jack L. Lightstone, Concordia University

Irving Mandelbaum, University of Texas, Austin

Ivan Marcus, Jewish Theological Seminary of America

Louis Newman, Carleton College

Alan J. Peck, Tulane University

Gary G. Porton, University of Illinois

Richard S. Sarason, Hebrew Union College-Jewish Institute of Religion, Cincinnati

Larry Schiffman, New York University

Tzvee Zahavy, University of Minnesota

\section{Editorial Committee}

Roger Brooks

Paul Flesher

Howard Schwartz

Judith Romney Wegner

Number 39

BARUKH KURZWEIL AND MODERN HEBREW LITERATURE

\author{
by James S. Diamond
}




\title{
BARUKH KURZWEIL AND MODERN HEBREW LITERATURE
}

\author{
by \\ James S. Diamond
}

Scholars Press

Chico, California 


\title{
BARUKH KURZWEIL AND MODERN HEBREW LITERATURE
}

\author{
Copyright @ 2020 by Brown University
}

Library of Congress Control Number: 2019953434

Open access edition funded by the National Endowment for the Humanities/Andrew W. Mellon Foundation Humanities Open Book Program.

The text of this book is licensed under a Creative Commons Attribution-NonCommercial-NoDerivatives 4.0 International License: https://creativecommons.org/licenses/ by-nc-nd/4.0/. To use this book, or parts of this book, in any way not covered by the license, please contact Brown Judaic Studies, Brown University, Box 1826, Providence, RI 02912. 


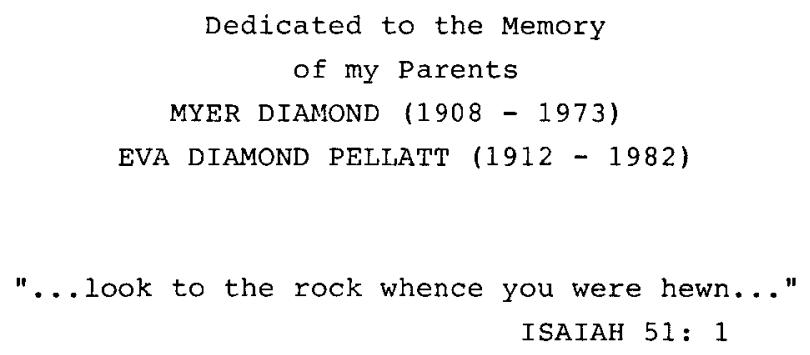



PREFACE........................... ix

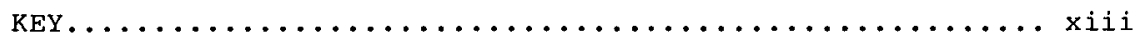

I. INTRODUCTION...................... 1

I. BARUKH KURZWEIL - A CULTURAL BIOGRAPHY......... 9

Moravia: $1907-1921 \ldots \ldots \ldots \ldots \ldots \ldots \ldots$. 9

Frankfurt: $1921-1933 \ldots \ldots \ldots \ldots \ldots \ldots \ldots, 12$

Brno: $1933-1939 \ldots \ldots \ldots \ldots \ldots \ldots \ldots \ldots \ldots \ldots$

Palestine and Israel: 1939-1972........ 15

Conclusion....................... 25

III. METAPHYSICAL POSTULATES UNDERLYING KURZWEIL'S LITERARY CRITICISM.................. 27

Religious Faith as an Ontological Absolute.. 28

Demonic Nihilism as a Modern Possibility... 29

Judaism as a Meta-Historical Religion in

Tension with History ............... 31

The Ontology of the Word: Language as the Transcendent Guarantor of Cultural Integrity....................... 36

IV. KURZWEIL'S ESTHETICS AND THEORY OF CRITICISM..... 43

The Nature of Literary Creativity........ 43

Literary Criticism as Hermeneutics....... 51

Kurzweil as a Phenomenological Critic..... 59

V. KURZWEIL ON MODERN HEBREW LITERATURE:

I. THEORETICAL STRUCTURE................ 69

Other Conceptions of Modern Hebrew

Literature...................... 70

The European Context of Modern Hebrew

Literature...................... 77

The Paradox Inherent in Modern Hebrew

Literature..................... 80

The Crisis of Language............... 83

Kurzweil's Periodization................ 84 
VI. KURZWEIL ON MODERN HEBREW LITERATURE: II. THE STRUCTURE OF THE PRACTICAL CRITICISM....... 87

The Haskalah..................... 88

The Tragic Period.................... 89

The New Vision of Jewish Sovereignty:

Uri $\mathrm{zvi}$ Greenberg........................ 101

The Critique of Post-1948 Israeli Literature.... 105

Summary Evaluation.................. 110

VII. BARUKH KURZWEIL: THE SENSIBILITY OF WEIMAR

GERMANY IN RAMAT GAN................. 115

NOTES................................... 127

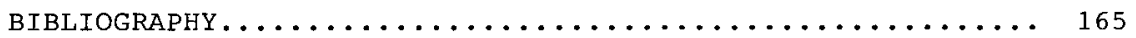

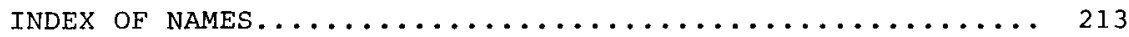

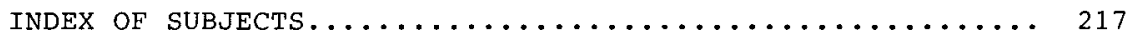


Brown Judaic Studies has been publishing scholarly books in all areas of Judaic studies for forty years. Our books, many of which contain groundbreaking scholarship, were typically printed in small runs and are not easily accessible outside of major research libraries. We are delighted that with the support of a grant from the National Endowment for the Humanities/Andrew W. Mellon Foundation Humanities Open Book Program, we are now able to make available, in digital, open-access, format, fifty titles from our backlist.

Barukh Kurzweil (1907-1972) was one of the earliest and most important critics of Hebrew literature. James S. Diamond's Barukh Kurzweil and Modern Hebrew Literature (1983) traces the development of Kurzweil's theory in the context of other contemporary literary theories and shows its impact and ramifications.

This edition contains typographical corrections of the original text.

Michael L. Satlow Managing Editor October, 2019 

PREFACE

My interest in Barukh Kurzweil flows from a variety of sources. Throughout my studies literary theory, and especially critical theory, have always been in the forefront of my concerns. Like many others, I came to Kurzweil out of my readings of Agnon but in time became as engrossed in the critic as in the novelist. I had eagerly anticipated studying with Barukh Kurzweil at Indiana University where he had been invited to teach for the summer of 1969, and I was disappointed when he did not come. Subsequently, what kept me drawn to him was not only the marvelous coherence and consistency of his method but the passion and the struggle with which he carried out the critical enterprise. In the last analysis, in spite of many generational and profound cultural differences between us, I identified with the larger existential issues that animate every line of his work. If there is any one question that has energized my interest in the humanities, especially in literature, it is the question of what the word "modern" means; I began to suspect that Kurzweil was implicitly dealing with this very question. The stimulus to do a full study of his work thus became for me an imperative.

unlike a poem, play or novel, literary criticism is not subject to the heresy of paraphrase. And indeed, in the pages that follow I have not hesitated in several places to paraphrase Kurzweil's arguments where I thought it necessary. Yet my inclination in most instances has been to quote kurzweil directly so as to let him speak in his own voice. So much have I done this that the reader may very well form the opinion that there is a surfeit of such quotation.

To such a reader I give three reasons for what I have done. First, since many of those who will peruse these pages will not read Kurzweil in the original Hebrew, and considering that this study purports to be a substantial monographic treatment of him, the first of its kind in English or any language, I have sought to give a fair sample of Kurzweil's writing in its raw--albeit translated--state, before the directness of the material would be vitiated by paraphrase or analysis. Second, to let him speak in his own voice is to help his living presence be felt actively here, an important consideration in presenting the critical personality that was Barukh Kurzweil. Lastly, though critical writing is technically not, as I have said, art, Kurzweil like any 
responsible critic, did choose his words and compose his language with utmost care and intention. Direct quotation renders visible the distinctive critical language that infuses the writing. It allows me to explicate the writing much as one would explicate a poem and, further, enables the reader to decide if there is any discrepancy between the passages in question and my explication.

The translation of all such quoted material is my own. It has not been without its difficulties. One of these is that in many cases the Hebrew Kurzweil uses is more than likely what he considered the equivalent for whatever German word or concept he had in mind. Regrettably, my German is not good enough to allow me to guess what this word might be, and I think smooth and precise translation has been impeded because of this.

The translation of one of Kurzweil's key terms--"hukiyut penimit"--has been particularly troublesome. "Hukiyut" usually denotes "regularity" or "legitimacy"; "penimit" can be rendered "inner" or "internal". But when used together in the manner he does, Kurzweil intends by "hukiyut penimit", I believe, to convey a phenomenological concept: the ineluctability of the essence (Eidos) to which a thing or a literary work is reduced by the process of intuitive communion with it that is the hallmark of phenomenological perception. Accordingly, I translate "hukiyut penimit" as "intrinsic coherence". 1

The transliteration generally follows the system used by the Library of congress cataloging service. Though I have modified this slightly, I have tried to be consistent.

This study deals with everything written by and about Kurzweil as available and collected at the end of 1976. Since then, two more collections of essays (which I have read and cited from their original places of publication) have been re-published by the Barukh Kurzweil Memorial Foundation at Bar-Ilan University. Articles about Kurzweil that have appeared since 1976 and which, at this writing, ten years after his death, continue to appear in the Israeli press and literary periodicals, are not included here.

The chapters in this book are drawn from my doctoral dissertation, "The Literary Criticism of Barukh Kurzweil: A Study in Hebrew-Western Literary Relationships", written for the Comparative Literature department at Indiana university (June, 1978). There is an important difference in scope between the dissertation and the book: whereas the former is a full treatment of all aspects of Kurzweil's critical work, this book focuses on the area 
in which Kurzweil clearly made his biggest impact--his criticism of modern Hebrew literature. The reader who wishes to learn more about the critical theory underlying Kurzweil's work, Kurzweil's criticism of European literature, Kurzweil's critique of Ahad ha-Am and Kurzweil's own attempts to write fiction is directed to the relevant chapters in the dissertation.

Many hands and minds were extended to me over the past several years, from the time this work was first conceived until this writing, when it is ready to appear in this form. This affords me the happy task of expressing here my gratitude to the people to whom these hands and minds belong: to the B'nai B'rith Hillel Foundations, for granting me a sabbatical leave in 1975-76 in order to pursue the research on this project and in particular to Dr. Alfred Jospe, Rabbi Max Ticktin and Dr. Samuel Z. Fishman, whose encouragement and astuteness have sustained and benefitted me; to the Danforth Foundation, for their generosity in awarding me an Underwood Fellowship and in particular to Dr. Robert Rankin and Sister Julia Mahoney, whose concern for the larger issues it raises have literally made this study possible; to the staff at the National and University Library at the Hebrew University in Jerusalem and in particular to the librarians in the General. Reading Room, who for several months dispensed thirty years of Ha'arets on microfilm to me daily with patience and understanding; to Mr. Ya'akov Abramson, administrator of the Kurzweil archive at Bar-Ilan University, Mrs. Margot Kurzweil, Mr. Rafi Weiser, administrator of the Agnon archive at the Hebrew University, and the staff at the Asher Barash Institute of Records (Genazim) at the Hebrew Writers' House (Bet hasofer) in Tel Aviv, who were all instrumental in allowing me to obtain a knowledge of my subject that I could never have gained from his published material alone. Further, I am indebted to three scholars who were kind enough to share with me, at various points in my work, their time, learning and insight: Dr. Arnold Band of the University of California at Los Angeles, Dr. Avraham Holtz of the Jewish Theological Seminary and the late Dr. Moshe Schwarcz of Bar-Ilan University. For their counsel. I am ever grateful even as they are not to be held accountable for what I may have done with it. To Dr. Alan Mintz of the University of Maryland go my special thanks for his 
perceptive and sensitive editorial guidance. And lastly, I cite here my appreciation to Dr. Henry Fischel and Dr. Breon Mitchell of Indiana University and to Dr. Ya'akov Mashiah, for whose patience and assistance I am ever indebted.

My particular and lasting thanks is reserved for Dr. Hillel Barzel of Bar-Ilan University. Without his steady encouragement, uncompromising standards and literary acumen this work would not have been possible.

St. Louis, Mo. January 5, 1983

20 Tevet, 5743 
MR $^{1}$ Masekhet haroman: shenei mahzorei masot 'al Shemuel yosef 'Agnon ve'al toledot haroman haeiropi [The course of The Novel: TWo Series of Essays on S. Y. Agnon And On The History of The European Novel]. Tel Aviv: Schocken Publishing Co., 1953 .

S Sifrutenu hahadashah - hemshekh o mahapekha? [Our Modern Literature - Continuity or Revolt?] Jerusalem and Tel Aviv: Schocken Publishing Co., 1959. Third enlarged edition, 1971.

BT Bialik veTshernihovski - mehkarim beshiratam [Bialik and Tshernichovski - Studies In Their Poetry]. Jerusalem and Tel Aviv: Schocken Publishing Co., 1960. Fourth enlarged edition, 1971 .

A Masot 'al sipurei Shai 'Agnon [Essays on The Fiction of S. Y. Agnon]. Jerusalem and Tel Aviv: Schocken Publishing Co., 1964. Fourth enlarged edition, 1975.

H Bein hazon levein ha'absurdi - perakim laderekh sifrutenu bame'ah ha'esrim [Between Vision And The Absurd - Essays on The Development of Our Literature In The Twentieth Century]. Jerusalem and Tel Aviv: Schocken Publishing Co., 1966. Second enlarged edition, 1973.

J Bema'avak 'al 'erkei hayahadut [In The Struggle for Jewish Values]. Jerusalem and Tel Aviv: Schocken Publishing Co., 1969 .

N haNesi'ah vesipurim aherim [The Journey And other Stories]. Tel Aviv: Am Oved Publishers Ltd., 1972.

$M^{2}$ Masekhet haroman vehasipur haeiropi [The course of The Novel And European Fiction]. Edited with an introduction by Y. Friedlander. Jerusalem and Tel Aviv: Schocken Publishing Co., 1973.

L leNokhah hamevukhah haruhanit shel dorenu - pirkei hagut uvikoret [Facing The spiritual Perplexity of our Time]. Edited with an introduction by Moshe Schwarcz. Ramat Gan: B. Kurzweil Memorial Foundation, Bar-Ilan University, 1976.

SBK Sefer Barukh Kurzweil [Barukh Kurzweil Memorial Volume]. M. Z. Kaddari, A. Saltman and M. Schwarcz, eds. Tel Aviv and Ramat Gan: Schocken Publishing House, Ltd. \& Bar-Ilan University, 1975. 

Essentially this book is a study of a critic, Barukh Kurzweil. It is also, in part, a study of a national literature, Hebrew literature. And in its larger perspective, it is an inquiry into the general problem of Hebrew-European literary relationships.

The necessity for a critical presentation, analysis and assessment of Kurzweil's work hardly requires justification. Even now, a number of years after his death, the very mention of his name in Hebrew literary circles is apt to ignite as much controversy and debate as it did at any time during his life. Both in Israel and outside it, one finds totally conflicting opinions about his worth as a critic, opinions which have only in common the passion with which they are held. In some circles, for example, there is a concensus that would deny kurzweil the very status of literary critic; at best he is seen as a cultural historian or as a sociologist of literature, at worst a "book-reviewer"--and a crabbed and arrogant one at that. 1 Those who would grant him a place within the field of criticism would extend Band's description of Kurzweil's work on Agnon to all of his practical criticism:

Most of Agnon criticism since the end of world war II
was written under the fructifying, but ultimately
destructive influence of Baruch Kurzweil's neoimpres-
sionism, which focuses not upon the work of art, but
rather upon certain general, European cultural problems
that are also manifest in Agnon's fiction. . . The
antidote to this flagrant subjectiveness must be the
analysis of the story as an organic, artistic structure
and its position within the context of Agnon's literary
career.

In other quarters a very different view obtains. Those who were closer to him personally and knew intimately both the man and the method are, though not always uncritical, more sympathetic and positive about him and convinced of his stature as a critic.

In the light of these divergent estimations, the need for a full-scale treatment of Kurzweil's criticism is clear. The Kurzweil corpus in its variegated entirety has never been dealt with in any extensive way and this book represents a first attempt 
to do so. It must however be noted that three members of the Bar-Ilan University faculty, Moshe Schwarcz, Hillel Barzel, and Yehuda Friedlander, have all written seminal pieces of Kurzweil meta-criticism. ${ }^{3}$ The following chapters, which synthesize and develop these contributions, will reveal their indebtedness to them. But let it be stated clearly: the larger aim of this study is neither to defend nor disparage Kurzweil but to try to understand and explain him. I have no illusions that the following is an "objective" treatment; meta-criticism is no less interpretive than criticism itself. ${ }^{4}$ Furthermore, if what follows is indeed a rendering, an interpretation of Kurzweil, it is clear that it could not have been undertaken without a fundamental willingness to accept his written work. Donagan's observations in his introduction to his study of collingwood is pertinent here: "If matters in which I agree with collingwood did not far out-number those on which I do not, I should not have written about him." But at the same time so is collingwood's own reminder that

it is impossible to reconstruct another man's philosophy without passing judgement on it. . . and knowledge of another man's philosophy that does not enable you to judge it critically is not philosophical, but simply a parrot-like capacity to recall what he said or wrote.

This is what I have tried to avoid.

What I have in mind when I say that the larger aim of this study is to understand and explain Kurzweil is precisely what collingwood implies here: that if we are to arrive at a proper appraisal of Kurzweil we must know his critical philosophy, that is, just what he intended by his criticism, what he sought to do. Ultimately we must measure a critic by what he asks to be measured by, not by criteria that we insist on imposing on him. Crane has put this matter very well, if inelegantly:

Any critical book or essay that makes coherent sense is a body of propositions the meaning and validity of any one of which cannot be properly judged until. we have uncovered the precise question in the critic's mind to which the proposition is intended to be an answer. This again is obvious; but what is commonly forgotten is that no question or problem, in turn, has any absolute status or isolable meaning, but is always relative, as to both its content and the conditions of its answer, to the total context of the discourse in which it occurs--a context that exists independently both of "things" and of the critic himself once he has chosen or constructed it, as a particular and finite structure of terms in which the referent of any term is conditioned by the logical relation in which it stands to all the other terms, or conceptual elements, employed in the discussion, and ultimately to the special set of assumptions 
concerning subjęct-matter and method upon which the discourse rests.

One of the functions, then, of this study is to define and present the "special set of assumptions," the "conceptual elements" and the "particular and finite structure of terms" that are operative in Kurzweil's criticism. If Crane is correct--

that literary criticism is not, and never has been, a single discipline, to which successive writers have made partial and never wholly satisfactory contributions, but rather a collection of distinct and more or less incommensurable 'frameworks' or 'languages,' within any one of which a question like that of poetic structure necessarily takes on a different meaning and receives a different kind of answer [from what]. . . it is properly given in any $g^{f}$ the rival critical languages in which it is discussed.

--if crane is correct--then one of the objectives here, in pursuit of the larger aim, is to identify and clarify Kurzweil's critical language. In doing so, we shall realize a second objective: to relate Kurzweil's work to the main bodies of modern critical theory. Only when we have done this shall we have established the ground on which any evaluation of his work can proceed.

It is impossible to discuss Kurzweil without recourse to modern Hebrew literature. A number of preliminary observations about this literature are in order. "The development of modern Hebrew literature represents an almost unique phenomenon in world literature." 8 Here is a language in which the Bible was created and yet which ceased to be a vernacular tongue from the Rabbinic period until the nineteenth century. Then, in response to certain historical developments, leshon hakodesh "the sacred tongue" ${ }^{9}$ was revivified and again a Hebrew literature, a modern Hebrew literature, began to develop. We are dealing with a literary tradition, then, that is at once both very old and very young.

It is also a literature of limited dimensions. There are today approximately three million people in the world who speak Hebrew (mostly in Israel, some in the United states and in a few other countries), but the number who are of adult age and with sufficient education to deal with Hebrew literary works in a serious way is even smaller. Modern Hebrew literature is

written and read by a society whose intellectuals belong to a variety of language cultures, and is strongly subject to multifarious European literary influences. 
The interplay of Russian, Polish, English, French and German literatures with Hebrew literature has greatly enriched the Heprew literary scope and has given it its special flavor.

From its earliest days the criticism that evolved along-side modern Hebrew literature has perceived and grappled with the diffuse issue of Hebrew--European literary relationships. In the twentieth century Joseph Klausner, Zvi Woislawski, Yeshurun Keshet, (Ya'akov Kapilowitz), Shlomo Tsemah, Eliezer Steinmann, Simon Halkin, Israel zemora, Avraham Kariv, Dov Sadan and Barukh Kurzweil have all, in very different ways, addressed themselves to this subject, sometimes explicitly, sometimes implicitly. ${ }^{11}$ To be sure, their interest in it bespeaks general ideological concerns: how to relate Hebrew literature to Jewish nationalism and its aspirations, to historic Jewish culture and the ancestral religious tradition, and to the humanistic legacy of European culture. Though most of the younger critics now writing are not so preoccupied ideologically and have chosen to concentrate on the specifically artistic and technical problems of literature, this does not mean that the larger comparative questions have been clarified and resolved. Wellek and Warren's guidelines of a generation ago still seem to me to be worth considering with respect to modern Hebrew literature:

It is just the problem of 'nationality' and of distinct contributions of the individual nations to the general literary process which should be realized as central. Instead of being studied with theoretical clarity, the problem has been blurred by nationalistic sentiment and racial theories. . . Only when we have reached decisions on these problems shall we be able to write histories of national literature which are not simply geographical or linguistic categories, shall we be able to analyse the exact way in which each national literature enters into the European tradition. ${ }_{1}$ Universal and national literatures implicate each other. ${ }^{1}$

For this reason almost all the above-named critics deserve monographic treatment, which collectively would provide a substantial filling in of the theoretical picture. This study of Kurzweil may, therefore, be seen as a step, however small, toward that ultimate objective.

From this perspective we can observe a series of other reasons for choosing Kurzweil specifically as the subject of this study. For one thing, there is the matter of critical temper. As I shall show in the next chapter, Kurzweil is a product of Western Europe, a cultural milieu very different from the East European context of modern Hebrew literary creativity. Because he is at a 
greater distance from this context than virtually all of the above-named figures he is conspicuously more sensitive to and critical of the nationalistic sentiment and assumptions of modern Hebrew Iiterature. Secondly, his German and Jewish background and training qualify him well to deal with modern Hebrew literature both in its synchronic and its diachronic manifestations. Finally, of all of the critics, his method is the clearest, the most obviously comparative, and therefore, most easily studied.

\begin{abstract}
Every inquiry into the mysteries of a work of art... must clearly delineate three different stages in approaching it. . . . The basic operations in laying bare the first dimension of the work, its intrinsic coherence, are careful and sensitive attention to images, metaphors, rhythms, rhyme-schemes and central topics. Here the poem itself stands in its unduplicated immanence. The "how" and the "what" [of the poem], form and content, co-exist in mutuality. In the second stage literary study searches for the connections, whether visible or implicit, of the individual text to its literary - linguistic tradition and to the latter's motifs, images and figurative expressions. Thus, for example, any examination of the poetry of shlonski, shin Shalom or Altermann is obligated, as one of its primary tasks, to perceive how these poems grow out of the linguistic soil of Bialik, the sacred scriptures, Jewish liturgy and liturgical poetry. Only after the exposure of this second dimension can literary inquiry proceed to its final important job: to relate this thematics to that of world literature. In other words, literary inquiry uncovers three fundamental dimensions which are always interwoven within the literary work: its unique phenomenological essence, its linkage to its national linguistic and intellectual tradition, and its integration into the general literary context of its time.
\end{abstract}

Barukh Kurzweil flourished as a critic for over thirty years, from 1941, 14 when he published his first article on Agnon, until his death in 1972. During this period he wrote nearly four hundred essays, review-discussions and causeries. The Kurzweil corpus is exceedingly rich and covers an exceptionally wide range of subjects and concerns: theoretical and practical criticism of Agnon, Bialik, Tshernichovski, Uri Zvi Greenberg, and most of the Hebrew poets and prose writers from the turn of the century until such Sabra figures of the late sixties as Amos Oz and A. B. Yehoshua; criticism of more than twenty major Europeans from Cervantes, Goethe, Stendhal and Balzac through Tolstoy, Thomas Mann, Kafka, Hesse, Broch, Camus, Frisch and Dürrenmatt; explorations of the theory of fiction, tragedy, and the modern theater; 
important critiques of modern Jewish and zionist theology and philosophy in essays on Buber, Rosenzweig, Ahad ha-Am, Yitshak Breuer and Gershom Scholem; and scores of polemical and satirical responses to the foibles, pretensions, designs and achievements of those who variously perturbed or opposed him and who he chose to attack. Of this writing, about half has been collected into ten volumes with specially written prefaces that are indispensable sources for understanding Kurzweil; the remainder lies scattered throughout various newspapers and periodicals and would perhaps fill three or four more. Implicit in all his writing are two things that are of concern to us here: a consistent, though always developing methodology, and a coherent theory of modernity. These two unite to allow Kurzweil to develop a theory of modern Hebrew literature and its relationship to the European tradition that is itself remarkably consistent and coherent. It is a serious misperception of kurzweil to ignore the unity of conception and method that underlies his disparate articles, a mistake which a number of his detractors have made. They point to the fact that he never authored a sustained discussion of a subject or a problem which was not meant to appear in piece-meal fashion in the press as evidence that he is not a bona fide literary scholar but a high-grade journalist. 15

The truth is that if Kurzweil is anything other than a literary critic, he is a philosopher of Judaism, though not a systematic philosopher and certainly not a theologian. Kurzweil can be approached in this way and, as from the esthetic standpoint, Schwarcz has laid out the first steps which any such study will have to traverse. ${ }^{16}$ Nevertheless, considering that the bulk of Kurzweil's work overtly deals with literature, it is clear to me that if we wish to do it justice, we must apprehend it through Iiterary categories.

This is not to suggest that this monograph will tell the full story about Kurzweil. As I have indicated, my prime concern is to determine how Kurzweil's critical method works, how he reads and why he reads as he does. This is, it seems to me, what an introductory study must do. My scope, therefore, is general and, even when I shall examine the practical criticism, a theoretical one. A more practically-oriented study of Kurzweil, one that tracks and analyzes in detail his readings and interpretations of specific works and figures still has to be done. 
In the passage I have quoted above (p. 5), Kurzweil continues as follows:

Any attempt to approach the literary work with a preconceived, a priori set of ideas and criticism by which to measure the object of research misses the point and is destined to fail. This was the common mistake in most of our [Hebrew] literary scholarship. No matter what the perspective was: zionist, religious, Marxist, psychological or existentialist--the main thing is that it was not a perspective intrinsic [to the literary work]. That is what happened to the works of Bialik, Tschernihovski, ${ }_{1}$ Greenberg, Agnon, Brenner, Shalom or Shlonski.... 1

This is one of Kurzweil's most interesting statements because in it he demands precisely that quality he was accused throughout his career by his contemporaries of lacking--critical detachment and objectivity. How can we reconcile this affirmation of a "perception intrinsic" to the literary text with the "flagrant subjectivism" that Band, for example, observes?

I here state my agreement in principle with strelka, Krieger and others that, even when it is deeply grounded in the text, literary criticism is performed by a person, not a machine, and thus is perforce "subjective."18 Hence I state even now my contention that the above assertion by Kurzweil of the primacy of the intrinsic quality of the literary work must be understood not within the assumptions of the Anglo-American critical tradition of New Criticism, as I think Band does, but within the framework of European phenomerology, specifically that of German phenomenological hermeneutics and its particular epistemology, which attempts, in its relation to the literary text, to transcend the accepted Cartesian subject-object dualism.

That kurzweil brought to his reading a distinct hierarchy of esthetic criteria is obvious. What needs to be brought out is that these criteria are the result of a passionate commitment to specific cultural and religious values which, I shall show, were distilled from two sources: the central European tradition, particularly the legacy of German classical humanism bequeathed by Goethe, and the German sensitivity to "Sprachlichkeit, the linguisticality of man's way of being"19; and the world-view of traditional Judaism of pre-Holocaust Central Europe, particularly, but not exclusively, the neo-orthodoxy that developed in Frankfurt. 
In the following pages I shall demonstrate how the dialectic within and between these two sources enabled Kurzweil to attain to a view of modern western literature, and modern Hebrew literature in particular, that allowed him to both explain the latter and relate it to the former in a way that, I submit, is definitive and, within its frame of reference, unassailable. Evaluations of Kurzweil like those of Band are not only inaccurate in that they seek to measure kurzweil by the wrong criteria; they are also misleading in describing Kurzweil's criticism as "neo-impressionism," its influence as "ultimately destructive," and in suggesting that an objectively "correct" reading of and approach to Agnon, or anyone else, is possible.

The succeeding chapters shall parallel the path taken by any critic as he moves toward the literary text, reads the text, and then moves away from it towards evaluation. After identifying the broad philosophical presuppositions that energize Kurzweil's criticism (Chapter III), I shall try to dig down to the epistemological bedrock upon which this criticism is founded. That is to say, I shall work towards defining his attitude to a literary text by describing his understanding of just what literature and criticism are (Chapter IV). At that point we shall be in a position to see the relationship between Kurzweil's theory and praxis as they operate in his treatment of modern Hebrew literature (Chapters V and VI). This will lead to a further evaluation and some conclusions of my own (Chapter VII). 20

But the very first undertaking is to supply a perspectival element hitherto lacking in the published work on Kurzweil--a cultural biography. 
CHAPTER II

BARUKH KURZWEIL--A CULTURAL BIOGRAPHY

"Those who are ignorant of the context of ideas are similarly destined to misunderstand them." 1 we may invoke this corollary to Santayana's familiar dictum about the necessity of understanaing the past in order to point to the biographical context of Kurzweil's life that is our subject here. In Kurzweil's case the context is clearly identifiable: the life and cultural tradition of Central Europe. Specifically we may locate it in the pre-World War I Austro-Hungarian Empire and in post-War Weimar Germany.

Two things should be borne in mind in examining this context. First, that the central European tradition is "a tradition whose assumptions for the most part have no precise equivalent in the English-speaking world." ${ }^{2}$ In fact, we may even say that as far as Kurzweil goes, the Central European stands in opposition to the Anglo-American intellectual tradition. ${ }^{3}$ second, the adjective "Central European" applies not only to general culture but has a specifically Jewish frame of reference as well. Pre-Holocaust Jewish life, like anything European, was extremely variegated and took on different textures and emphases in various countries. Indeed, the differences within Ashkenazic Jewry itself 4 are at times almost as substantial as the more fundamental and historical ones between Ashkenazim and Sephardim.

I shall discuss the salient facts of Kurzweil's life against their cultural background. I divide his life into the following formative places and periods:

1. Boyhood in Moravia: 1907-1921

2. Studies in Frankfurt: 1921-1933

3. Teaching in Brno, Czechoslovakia: 1933-1939

4. Settlement in Israel (Jerusalem, Haifa, Ramat-Gan): $1939-1972 .^{5}$

Moravia: $1907-1921$

Barukh (Benedikt) Kurzweil was born July 22, 1907, in Pirnice, Moravia, a small town in what was then western Moravia very near the border of Bohemia, and what is today west-central Czechoslovakia. ${ }^{6}$ Moravia was at that time a part of the Hapsburg Empire, which was both generally and Jewishly a unique cultural matrix. Unlike slovakia to the east, where the principal 
influence was Hungarian, Moravia lay within the orbit of Czech, Austrian and German language and culture. This was the region of Grillparzer, Stifter, Schnitzler, Hofmannsthal, Kafka, Musil, Broch, and more generally, that of Agnon and Svevo. Schocken notes the following figures who were all born in the immediate vicinity of Kurzweil's birthplace: Edmund Husserl, Fritz Mauthner, Gustav Mahler, Sigmund Freud, and Karl Kraus. ${ }^{7}$ The fact that most of the above men were born Jews testifies to the opportunities for creativity which the Hapsburg Empire afforded to Jews and to all minority groups. Moreover, the fact that most of them became assimilated Jews testifies to how advanced the process of Emancipation was in the Empire by the end of the nineteenth century. The Edict of Toleration of the Emperor Joseph II of 1782 was one of the earliest examples of the political liberation of the Jews from the medieval world order, enabling them to participate more fully in society.

Jewishly, Moravia itself was distinctive, for it was situated at the crossroads of Europe. Jews had been there since the first half of the thirteenth century. The heretic Jacob Frank had lived at the capital, Brno, in $1773 .{ }^{8}$ Because of its proximity to Vienna, Moravia became a hotbed for the followers of Herzl at the turn of the century, and we can assume the flourishing existence of many zionist groups and institutions throughout the area during the first decade of this century. "After the czechoslovakian Republic had been established in 1918, Moravian Jews frequently constituted the bridge between . . . traditionalists and modernists, Zionists and non-Zionists." 9

Kurzweil himself, in his tribute to Max Brod on the latter's sixtieth birthday, has some interesting things to say about czech Jewry and therefore, however indirectly, about himself. The Haskalah, he notes, took a more controlled, less assimilationistic course in Bohemia and Moravia than it did in Germany, and so religious tradition never quite lost its hold. Moreover, because the Jews there had to face two nationalisms--slavic and German--neither one could make an absolute claim on their loyalties. This gave Czech Jewry a sense of moderation, an ability to see the many sides of a question. ${ }^{10}$ This, in turn, engendered a skeptical outlook on life which Kurzweil feels is the most important feature of Czech Jewry. The knowledge by the czech Jew that he could not take seriously his being either a German or a slav left him with two choices: either to become a rootless cosmopolitan or to integrate his life around a specifically Jewish identity. ${ }^{11}$ As we shall see, affirmation of tradition, an attachment to Jewish 
nationalism, and a deep scepticism were all key elements in Kurzweil's own make-up. ${ }^{12}$

At any rate, all these elements were fostered in his early life. His father was a (the?) rabbi in Pirnice, and his maternal grandfather was, evidently, a rabbinic scholar of some repute. ${ }^{13}$ In his childhood, Kurzweil, like his counterparts throughout all the centuries and lands of the European Diaspora, was introduced by his father to and received a thorough grounding in the classical Hebrew texts of Judaism: the Bible, the Talmud and halakhic and midrashic sources. ${ }^{14}$ Even as a child he was a voracious reader. By the age of nine or ten he was reading Biblical narratives in Hebrew freely for his own interest. Before then he says he read stories in German and somewhat later, about the age of eleven or twelve, he discovered Czech literature. ${ }^{15}$ He also attended both local German and Czech schools until the age of fourteen, at which time his father determined that the son would leave home to study in a larger Jewish community with a major Yeshiva, as befitted his abilities. The Yeshiva of Rabbi solomon Breuer in Frankfurt-am-Main was chosen, and Kurzweil left for that city in 1921.16

Before I discuss that Yeshiva and the Frankfurt years, I ought to note one further feature about the Hapsburg environment that was deeply imprinted into Kurzweil's consciousness--its stability. Kurzweil never forgot, and may possibly have idealized, the coherence of his childhood world that was the Austo-Hungarian Empire before the outbreak of World War I. For him, as for Agnon, Musil and others, the assassination of the Archduke Francis Ferdinand in 1914 was the watershed of the cultural and political upheaval that is the hall-mark of the twentieth century. ${ }^{17}$ The implication of these events is that if man in the twentieth century has begun to put away his human kings, he has also, therefore, begun to put away Divine authority. ${ }^{18}$ This is Kurzweil's primary experiental concern and informs virtually everything he ever wrote. It is for this reason that Kurzweil hears a tone of romantic melancholy in all the literature emanating from the Austro-Hungarian Empire and from Czech-Jewish literature in particular. It is not too much to say that Kurzweil listened for that melancholy in any variation possible in every literary work he encountered. 19 
Frankfurt: 1921-1933

The climate in Frankfurt between the wars was obviously different from Moravia, politically, culturally and Jewishly. The twelve years Kurzweil spent there were seminal to his development. 20

Kurzweil began as a student in the Yeshiva of Rabbi Solomon Breuer. This venerable academy, certainly one of the major institutions of its kind in Pre-Holocaust Europe, had been founded in the nineteenth century by Breuer's father-in-law, Samson Raphael Hirsch (1815-1889).21 Here Hirsch's "neo-Orthodox" response to the Emancipation expressed itself in the Yeshiva's ideal of combining traditional Torah study with the pursuit of the secular knowledge of science and the humanities. This was quite different from East European Yeshivot, where secular learning was suspect and forbidden (though often acquired covertly), as well as from such rabbinical seminaries as the one at Breslau fostered by liberal Jewry which approached Judaica through the critical canons of the historical school, the wissenschaft des Judentums. ${ }^{22}$

Although it was a penurious life in the Yeshiva, involving eating with a different family each day, we may assume that Kurzweil fared reasonably well as a student. In time he was selected to serve for a while as Haus-bakhur (steward) to the aging Rabbi Breuer. He befriended one of the master's sons, Yitshak Brever, and the influence of this future ideologist of German Orthodoxy and major critic of secular zionism on Kurzweil is among the most important of the numerous influences that we shall identify. ${ }^{23}$ The essential thrust of the Hirsch-Breuer school was its affirmation of the independence of Judaism (and, by implication, the Jewish people) from history. The Torah and its people are seen as "meta-historical," beyond the human and subjective categories of all that lies within the realm of the historical. As we shall note, this idea became seminal to Kurzweil's world-view and is a key element in his criticism of modern Hebrew literature. 24

Contemporaneous with his Jewish studies (mostly of Talmud and poskim) in the Frankfurt Yeshiva, Kurzweil continued his secular studies on the secondary school level as a non-residential student ("Externer") at the Helmholtz Oberrealschule. This allowed him to pass the matriculation examinations so that by 1928 he was able to gain admission to the University of Frankfurt. From that time on Kurzweil no longer attended the Yeshiva regularly, although he still continued his close association with it. From 1928-1933 he 
devoted himself to doctoral studies in the humanities, with concentration on Germanics (probably literature and philosophy) and history. Here he absorbed all the dominant ideas and schools that one might expect to find in a leading German university of that time: the idealistic metaphysical tradition, phenomenology, ${ }^{25}$ existentialism, and the aristocratic esthetics of German classicism, Romanticism, and modernism, especially as embodied in the elitism of the George Kreis. The result was Kurzweil's doctoral dissertation, Die Bedeutung bürgerlicher und künstlerischer Lebensform für Goethe's Leben und Werk dargestellt Am Faust 1. Teil, ${ }^{26}$ accepted in 1933. This was among the last doctorates awarded to a Jew at Frankfurt and possibly in Germany before the onset of the Nazi regime. By this time, also, Kurzweil had received rabbinical ordination from Rabbi solomon Breuer. ${ }^{27}$

We should note, however briefly, a number of other people and institutions that were flourishing in Frankfurt at this time, which, even though Kurzweil did not have direct contact with them, were still part of the total environment in which he developed for twelve years. This was the period of the great collaboration between Buber and Rosenzweig which began to produce their new German translation of the Bible. The celebrated Freies Judisches Lehrhaus was during these years at its peak of activity. Although Kurzweil as a student of the Breuer Yeshiva was officially a part of the separatist element which, since Hirsch, had held itself aloof from the organized Jewish community of Frankfurt (Kurzweil never met Rosenzweig), it is nevertheless inconceivable that he was not in touch with what was being thought and written in more liberal circles. Similarly, Frankfurt was the seat of the Institut fur Socialforschung which produced important historical and sociological studies in the light of German socialism by such figures as Adorno, Horkheimer, 28 and Marcuse.

In 1933, having formally completed his studies, and with the spectre of Nazism becoming imminent, Kurzweil returned to his family in Czechoslovakia.

Brno: $1933-1939$

After a brief stay with his mother, Kurzweil was finally offered employment at Brno, the capital of Moravia, on the faculty of the Hebrew gymnasia there, the only institution of its kind in western Czechoslovakia. His task was an unenviable one: to teach religion to young people who were more than likely to have been negatively pre-disposed to the subject. The indications are that 
he succeeded beyond everyone's expectations, showing powers as an engaging teacher that were to be life-long. During this period, Kurzweil was also invited by the local rabbi to perform certain rabbinical functions and rites de passage in his absence. ${ }^{29}$

In January 1937, Martin Buber, who was shortly to emigrate to Palestine, had occasion to lecture at Brno on the Bible. 30 Kurzweil's meeting with him was to prove to be momentous in several respects. Kurzweil. was profoundly affected by the man and his teaching; he describes this first encounter as "a decisive turning point in my life." 31 Buber, too, was impressed and invited Kurzweil even then to come to Frankfurt to teach in the Lehrhaus. Kurzweil, however, declined, as he refused to return to Nazi Germany. It is important to note, I think, that kurzweil was not unfulfilled doing what he did in Brno. In spite of his inclinations toward Jewish nationalism, he was thoroughly imbued with a love for and a sense of the validity of Jewish life in the Diaspora, and quite probably would have been content to live out his life in that mode. Here we may answer the speculative question that cannot but be asked of kurzweil by anyone who studies his life's work: where would he have been had world War II and the Nazi Holocaust never happened? Our answer must be: most likely in a German university and without question in Europe. 32

When the situation became critical--in March 1938 the Nazis occupied Austria and several thousand Jews escaped to Brno--the only real option for Kurzweil was to go to Palestine. Accordingly, at about this time or possibly somewhat earlier, Kurzweil wrote to Buber requesting from him a certificate of sponsorship which was necessary, under existing British mandate law, in order to be permitted legal entry into Palestine. This document apparently took some time in arriving, but when it came in late 1939 after the war had begun, it enabled Kurzweil to go to the Hebrew University in Jerusalem as a research student under the aegis of Buber. ${ }^{33}$ Kurzweil, we can see, got out of Europe just in time, unlike most of his family and friends who were very soon deported to the death camps as the liquidation of Czech Jewry proceeded. Kurzweil thereafter always regarded himself as a "brand plucked from the fire," a sensibility that haunted his inner life in a way not always visible in his criticism. ${ }^{34}$

It is not exactly clear what or how much Kurzweil published during the Brno years. There are extant copies of two lectures that bespeak his teaching and rabbinical activity. ${ }^{35}$ Barzilai, in the preface to his bibliography of Kurzweil's writings up to the 
end of 1963, notes that articles in German were published in Austrian, Swiss, German and Luxembourg newspapers and journals which are probably no longer in existence. He does not, however, indicate what these articles were about. ${ }^{36}$

Palestine and Israel: 1939-1972

The first two years following Kurzweil's arrival in Palestine were spent in Jerusalem. Kurzweil was, as I have noted, a research-student of Buber, but it is not clear just what this entailed. Certainly Kurzweil attended Buber's lectures at the Hebrew University and also spent time at Buber's home, probably as part of the latter's select circle of students. There is no question that Kurzweil needed Buber at this phase of his life. The master spoke to the student's deepest perplexities and yearnings. Years later, at Buber's death in 1965, Kurzweil reflected upon this "man of the spirit, unique sage, who was the embodiment of personal tranquility, self-security and love of life. - . Individuals who were unhappy, fragmented, consumed by doubts that gnawed away at their innards--all sought Buber's presence." 37

It is important to note that at this time Kurzweil saw himself both as a literary artist in the German language and as an academician and a teacher. His deepest desire was to create in German, especially the experience of the Diaspora Jewish life of Central Europe he had so recently and so painfully left behind. During the Jerusalem years Kurzweil participated in a circle of other literati from Germany where presumably their own works as well as classics from German literature were read and discussed. The participants included Dr. Moshe Spitzer, Yitzhak Shenberg (Shenhar), Heinz Politzer, Manfred Sturmann, Jean Levinson, and Aryeh Ludwig strauss. ${ }^{38}$ At one of the first sessions of this circle that kurzweil attended very soon after his arrival in Jerusalem, something occurred that was to transform his life: a few chapters of Agnon's novel, Ore'ah natah lalun (A Guest for the Night), which had just been published, were read aloud from the Hebrew original. Kurzweil was affected to the core of his being. ${ }^{39}$ Here was the very narrative that lay dormant within him, the very thing that struggled for expression in his novel-in-progress Die sterbende Gemeinde: the pre-World war I "then" of the Austro-Hungarian town depicted over against the shattered post-war "now." It became at once clear to Kurzweil that he would never be able to write fiction like that, but the experience also spurred 
him to look more deeply into Agnon and the whole field of modern Hebrew literature. Several years previous Kurzweil had read Agnon's "Vehayah he'akov lemishor" in the German translation ("Und das Krume wird gerade") but he had not been significantly impressed. In the Frankfurt Yeshiva he had been introduced to Feierberg and Bialik by some of his fellow-students from Eastern Europe, but that, besides a few of Ahad ha-Am's essays and a smattering of Mendele, was all the modern Hebrew literature he had read. ${ }^{40}$ Furthermore, another development occurred during these years which also helped deflect Kurzweil away from literary creativity in German towards literary criticism in Hebrew: the destruction of European Jewry, about which he learned at this time. Kurzweil now made a pact with himself never again to write publicly in German. ${ }^{4}$ Privately, however, he could not relinquish the language (he continued writing his notes and probably some letters in German) nor his desire to create with it. During the period 1940-1942, with Buber's encouragement, he sporadically attempted in his own way to transmute his vision of Jewish Moravia into fiction. 42

The problem of a livelihood must by now have come to the fore. ${ }^{43}$ Whether Kurzweil formally sought it at this time or not is unclear, but the prospect of an appointment on the faculty at the Hebrew University was not forthcoming. Instead Kurzweil went to Haifa where he began teaching at the reputable Reali school, probably in the fall of 1942. After one year he was dismissed by the headmaster, Dr. Biram ("he will never be a teacher"). The next year was spent teaching in a vocational high school but this too proved fruitless since it was hardly the environment for humanistic concern. ${ }^{44}$ Finally kurzweil joined the staff of the innovative Hugim school in Haifa, and here he remained until he was called to Bar-Ilan University in 1956. The contrast in the classroom between the European, traditional teacher and his brash Sabra students must have been a challenge to both, but it was not without success. 45

Kurzweil's relationship with the Hebrew University is complex and many-sided, both from an emotional and an intellectual standpoint. There can be no doubt that he possessed the credentials that would have entitled him to a professorship there, but the question here has to be put in two ways: did the Hebrew University fail to appoint Kurzweil? or did Kurzweil fail to get appointed to the Hebrew University? Such evidence as there is indicates that at various points both formulations are correct. At the outset Kurzweil, we remember, was under the tutelage of 
Buber and, strange as it may sound now, in the early forties Buber did not carry much influence within the university. Kurzweil, in this respect, did not pick a teacher who was either willing or able to advance his career. But Kurzweil himself did not help his own cause. In some of his early critical pieces, which I shall presently discuss, he treated some of the university's leading lights, notably Prof. Joseph klausner, with something less than respect and gentleness. ${ }^{46}$ It is thus clear that in those early years the door to the Hebrew University was closed. Later in the forties and in the early fifties, Kurzweil was invited several times to come from Haifa and lecture in Jerusalem. ${ }^{4}$ In 1952 or 1953, there was an opening in Hebrew literature and Nathan Rotenstreich, who was then rector and a friend of Kurzweil, suggested that he submit his credentials, which step would, apparently, have allowed him to be considered and probably appointed to the position. Characteristically kurzweil refused to do this. He considered that his abilities and his reputation as a literary scholar were by that time beyond a process of this kind.

Nevertheless, I think it an over-simplification to say, as many in Hebrew literary circles do, that because of these developments Kurzweil bore a life-long grudge against the Hebrew University. There are more substantial issues involved here as well. The Hebrew University, especially in its Jewish studies departments, was committed to the Wissenschaft approach of the historical school. It was inevitable that on purely intellectual grounds the products and claims of that method of research would run afoul of Kurzweil, as did Gershom Scholem, Jacob Katz, and Isaiah Tishbi. 48

The Haifa years by no means marked a stagnation in Kurzweil's development, even if it is certain that a university environment would have been eminently more suitable. For one thing, kurzweil himself never denigrated what he was doing, since he considered the teaching of literature a serious task regardless of the age of the students. By the early fifties Kurzweil was also lecturing at Haifa's Teachers' Seminary and even Dr. Biram saw fit to change his mind and invite him back to do the same at Reali. ${ }^{49}$ In Haifa there was also intellectual companionship of the first order: Yehezkel Kaufmann, Yosef Schechter and the poet Shin Shalom all lived there and the relationship with them was fructifying. 50 Kurzweil himself became in time one of the prominent figures on the Haifa cultural scene, speaking frequently at literary and other topical forums. In 1943 he married Margot Gotlewsky, who 
had also come from Germany in recent years and who he had met in Jerusalem. Subsequently one daughter, Ruth, was born to them.

But beyond all this, the Haifa years began with the inception of perhaps the most important development in Kurzweil's career as a literary critic: his association with Ha'arets. This daily newspaper had been founded in 1918 by Zalman Schocken, a highly literate German Jew who became Agnon's patron and one of the leading publishers of the incipient Jewish state. Halarets was unique among the Yishuv's dailies--it remained independent of any political party. In addition it established itself journalistically as the most substantial and authoritative of the Hebrew newspapers and came to occupy a role in Israel commensurate with that of the London Times or the New York Times. Sometime in 1941 Kurzweil was asked by schocken to become a regular contributor to the newspaper's weekly literary supplement. ${ }^{51}$ The match was a fortuitous one. The newspaper acquired a young critic who was superbly equipped and poised for a fundamental encounter with modern Hebrew literature. And the critic now would have access to a far wider audience than any lecture hall could give him, especially considering the paucity of well-developed literary periodicals in the emerging state as well as the fact that Ha'arets served as a major organ of the intelligentsia, a role it has never completely relinquished even with the subsequent proliferation of quarterlies. Moreover, the independence and integrity of the newspaper stood Kurzweil in good stead, for he had harbored a suspicion of all journalism which traded on the transitoriness of the word. Thus from the time his first piece appeared, on January 30, 1942 (on Agnon's Elu ve'elu until his last, on July 14, 1972 (on the use of the computer in literary studies) we count perhaps three hundred fifty essay-reviews and critical articles. To be sure, Kurzweil's long relationship to Ha'arets was not without its problems. There were times when the violence of his polemic strained the limits of understanding between publisher and critic; and there were also instances when kurzweil, rightly or wrongly, felt manipulated and condescended to by younger, enterprising editors of the literary supplement. For a while in fact, in the early sixties, Kurzweil sharply reduced his contributions to Ha'arets and saw fit to appear in Davar. But always the disagreements, which bear resemblances to a family quarrel, were patched up and Kurzweil returned to schocken's daily. Indeed, it is not too much to say that over thirty years of appearing in the same place on Fridays turned Kurzweil himself into something of a fixture among various sectors of the Israeli reading public. ${ }^{52}$ 
From the outset, the articles on Agnon and European fiction were, in general, received with respect, even acclaim. In 1953 they were collected by the schocken publishing house into Kurzweil's first volume, Masekhet haroman. 53 More controversial was Kurzweil's treatment of the budding Israeli writers. He had judged their work mercilessly, found it wanting artistically, and thus had trampled upon the national pride of the new state, which regarded its literature as something more to be read in celebration rather than to be critically evaluated. 54

In general, the earliest responses to Kurzweil's arrival on the literary scene in the years that preceded statehood (1942-1948) are instructive. Hebrew literary criticism had never seen a critic possessing anything quite like kurzweil's central European background combined with such independence, fastidiousness and such an implacable and explosive temperament. It is interesting to see how the various doyens of the intellectual life of the Yishuv tried to come to terms with him. Klausner, as the title of his only response indicates, "A Little Less carelessness and a Little More Humility," scores Kurzweil for his sweeping overstatements and his braggodacio, though he is not without admiration for what he notes as Kurzweil's courage and his literary sensitivity. ${ }^{5}$ Ernst simon chided kurzweil for his

\begin{abstract}
unrestrained impulse to polemic, the obvious glee of his sarcastic utterances, and also his posing as a kind of Karl Kraus in Hebrew garb. . . . It is forbidden to him to enjoy the blows he must so frequently inflict on the unsuccessful. It is just this part of his work that should be done in fear and trembling and not in what is almost delight.
\end{abstract}

Rabbi Binyamin went even further. Kurzweil, he says, makes the fundamental mistake of judging modern Hebrew literature by the standards of European literature, which are inapplicable to a literature less than two centuries old. Such criteria will, of necessity, bring about a superficial reading of modern Hebrew literature; it will only be known "from the outside." 57

Kurzweil's counter-reaction came in each case swiftly and forcefully. Klausner was rebuked as a popularizer and panderer who has distorted Jewish history, especially Biblical history, to conform to the demands of secular Jewish nationalism. His work is not criticism but dilettantism. The true critic must oppose the popular will and its taste, for his vocation is an aristocratic, lonely one. 58 Simon was answered by similar asseverations of the total independence of the critic, for whom irony and satire are legitimate weapons in the fulfillment of his duty to art and to 
society. 59 As for Rabbi Binyamin, Kurzweil did not so much refute as corroborate him. Picking up on the former's distinction of reading modern Hebrew literature "from the outside" as opposed to "from the inside," Kurzweil makes out Rabbi Binyamin to have meant not that Kurzweil read superficially but that he is "an outsider" to the Hebrew literary community. Such a designation is quite acceptable to Kurzweil. From the outset of his life as a critic he held himself separate from all political parties and literary cliques. ${ }^{60}$ In fact, one of Kurzweil's favorite targets was the "you scratch my back, I'll scratch yours" syndrome that he saw energizing the Israeli literary scene.

It should thus be clear that almost from its beginning Kurzweil's literary career was marked by controversy, rancor, and misunderstanding. This is not to suggest that Kurzweil was taken lightly. As early as 1948 he was asked to serve as one of the judges for the Ruppin Prize. ${ }^{61}$ In 1954 he was himself awarded the Holon Prize in recognition of his critical labors. ${ }^{62}$ But we do not need to cite these facts to prove that by the mid-fifties he was taken very seriously. Even his most hard-bitten critics admitted that he had major critical powers. It was thus natural that when Bar Ilan University was founded in 1955 at Ramat Gan, Kurzweil was asked to chair both the departments of Hebrew Literature and World Literature. Agnon and the renowned Talmud scholar Shmuel Bialoblotzky were largely responsible for the invitation.

Kurzweil began teaching at Bar-Ilan in 1956. The university was in many ways a very congenial arena for his endeavors. Here Jewish culture was openly affirmed as religious in nature and the tradition as something to be lived out rather than relativized as an object of historical research. Here, a century later, was the Hirsch synthesis between Torah and secular culture in the context of an Israeli university. Moreover, being a new institution, Bar-Ilan offered no precedents that Kurzweil would have to contend with in shaping his departments. ${ }^{63}$ From its inception Kurzweil was, along with Bialoblotsky, probably Bar-Ilan's scholar of highest stature in the humanities and, upon the latter's death in 1960,64 he succeeded him as chairman of the University senate.

He did not come to the new institution from another university, and so did not bring with him the glamour and the recognition of more established centers of research in Israel; he brought [instead] his personality, his authority, and his experience in scholarship and teaching. Other institutions and agencies in the country recognized only later on (largely because of his own efforts) his achievement and labors in the now university, and they were forced to acknowledge them. 
Because of his position in the university, Kurzweil was embroiled in a number of crucial battles in those first years of existence. Bar-Ilan as a religious university was frequently eyed as a sphere of influence by the Israeli religious establishments--the National Religious Party and the Chief Rabbinate. Kurzweil fought vigorously and ceaselessly against their encroachment, which apparently became an issue during the period of his chairmanship of the University senate (1960-62). In addition Kurzweil was appointed by the President of Israel, Yitshak ben Zvi, to the country's first Commission on Higher Education. This involved him in several battles for the accreditation of Bar-Ilan. Although his own departments were recognized immediately, he took the status of the entire university personally. He construed the delays in getting official recognition of Bar-Ilan's advanced degrees (as well as those of newly-founded Tel Aviv University) as an attempt by the Hebrew University to monopolize all graduate study in Israel. 66

It was as a teacher, though, that Kurzweil triumphed at Bar-Ilan. Soon after its opening

the university could not handle the applications of all who sought to be accepted as Kurzweil's students. Many students from older universities came over to him and asked him to direct their theses and graduate work until he was unaple time-wise and energy-wise to accommodate them all.

By 1964 Kurzweil notes a total of three hundred students in his twin departments, an impressive number by any standards. 68 There is ample testimony from those who attended his classes--it is clear that these were lectures and not discussions--that they were a singular experience. Kurzweil pronounced in an inimitable way not only on the literary work or topic of the day but upon various aspects of current events and personalities. ${ }^{69}$ The venerable professor could be cruel in cutting down wrong-headed or pretentious students, but he was also known to be the one to see if a student needed any kind of personal assistance. ${ }^{70}$

off-campus Kurzweil was very much the bon vivant who enjoyed good brandy, good conversation and good music. He presided over a curious, semi-secret society for the restoration of the Hapsburg monarchy, and took pleasure in inducting his colleagues into it, an academic prank that became something of a tradition. ${ }^{71}$

The Bar-Ilan years witnessed the successive publication of five volumes of Kurzweil's critical essays. In 1959, a number of his major utterances of the previous twenty years were collected: the discussions of Mendele and Feierberg, the trenchant critique 
of Ahad ha-Am, the comprehensive four-part treatment of the influence of Nietzsche and Lebensphilosophie on modern Hebrew literature, the analysis of the canaanite movement, and the luminous exposition of the metaphysical and existential bases of the idyllic. All these, introduced by an expansion, written specially for this volume, of an earlier seminal essay on the nature of modern Hebrew literature, resulted in Sifrutenu hahadashah: hemshekh o mahapekhah? lour Modern Literature: Continuity or Revolt?]. Surprisingly, although this book contains some of Kurzweil's most original and important work, it was received in relative silence. 72

It was followed within a year by Bialik veTshernihovski mehkarim beshiratam [Bialik and Tshernichovski - studies in Their Poetry]. Here all Kurzweil's previous essays on the two major poets of modern Hebrew were brought together, and the results could be seen as a vigorous application of the theory laid down in the previous volume. 73

Kurzweil's next project was to collect all his work on Agnon. Part of this, we recall, had appeared in 1953 as part of Masekhet haroman, but the book had gone out of print. In 1963, Masot 'al sipurei Shai 'Agnon [Essays on the Fiction of S. Y. Agnon], was published. This was one of Kurzweil's most acknowledged achievements and was influential in getting Agnon nominated for the Nobel Prize in 1966, the process of which Kurzweil himself helped initiate. 74

By now, Kurzweil was clearly established as a major figure, some would say the major figure, in Hebrew literary criticism. This was, of course, a matter of opinion, but in early 1964 it was expressed in more or less official terms: Kurzweil was awarded the Bialik Prize by the City of Tel Aviv for belles lettres, the most prestigious honor conferable upon a Hebrew writer. He who had opposed, if not ridiculed, the awarding of literary prizes in a country as small as Israel as nepotism and against the true interests of art, now was constrained to accept one himself. ${ }^{75}$ It is worth noting that the Bialik Prize was awarded to kurzweil not for his work on Agnon, as we might have expected, but for the revision he had forced in the understanding of Bialik and Tshernichovski. The judges' citation at the awarding of the prize said in part:

Barukh Kurzweil is one of the most important critics of Hebrew literature in our time. Equipped with a wide and profound knowledge of world literature and the literature of Israel, he knows how to relate the two into one entity in his critical writings. He investigates the 
purpose of Jewish existence and fights for it in eygry fibre of his being and with every stroke of his pen.

In the fall of 1964 Bar-Ilan University matters took Kurzweil on his first and only trip to the United states. After a brief stop in Europe, Kurzweil spent several weeks in the New York City area. During this time he gave several well received lectures in Hebrew on modern Hebrew literature at New York University, Rutgers, the Hebrew P.E.N. Club, and at the Jewish Theological Seminary. At the Leo Baeck Institute he lectured in German on the relationship between Jewish identity and language in Kafka, Karl Kraus and Hermann Broch. 77

The fall of 1966 saw the publication of Bein hazon levein ha'absurdi [Between Vision and the Absurd]. This was a continuation of the Kurzweilian thesis and method applied to other key figures in modern Hebrew prose and poetry, but with visibly deepening enrichment of critical theory. The first hundred pages, comprising nine essays on Uri Zvi Greenberg, constitute a miniature study of that poet. This is followed by sections on the poetry of Lamdan, Shin Shalom, Shlonski, and Altermann, and the prose of Brenner, Gnessin, and Shenhar. The volume concludes with a few of Kurzweil's many essays on the fiction of the sabra writers, notably his much-disputed treatment of Yizhar's Yemei tsiklag. 78

In 1969 the collected Kurzweil corpus was significantly enriched by the appearance of Bema'avak 'al 'erkei hayahadut [In the Struggle for Jewish Values]. Here we find the quintessential Kurzweil--literary criticism alongside Jewish philosophical concern and both interpenetrated with the question of values in both their general and Jewish manifestations. Some of the literary essays, especially the preface, are distinctive in that we see in them a shift of emphasis away from the practical toward theory, as Kurzweil, feeling more and more misunderstood toward the end of the sixties, strove again and again to clarify his position. In this volume, too, are the celebrated and important critiques of Gershom Scholem and the scientific treatment of Jewish studies, as well as some of the most recent statements on Jewish education and Israel-Diaspora relationships. 79

In actuality the latter half of the sixties were not easy or pleasant years for Kurzweil. The larger cultural and religious problems that obsessed him were never mere intellectual constructs but crises that he lived out in uncommon experiential intensity. (It is quite possible that in all his writings no noun appears more often than "crisis.") Thus, apart from any constitutional or 
psychological reasons, about which we can only conjecture, the continued failure of reality to attain to his expectations predisposed Kurzweil to chronic pessimism and depression. Those who promised and believed in progress and even redemption were among his favorite targets; all man can hope for, he felt, is the least possible evil. 80

Towards the end of the sixties these tendencies became more pronounced in Kurzweil's essays. The tone of the polemic is not so much biting and sarcastic as hostile and shrill. Internal considerations for this aside, there were a number of external factors that might have been influential here. The six Day war of 1967 and its resulting re-unification of Jerusalem precipitated what must have been a severe challenge to Kurzweil's world-view: secular zionism and the processes of history had seemingly intruded into the realm of sacred meta-history. Kurzweil could only oppose, however vainly, what in retrospect can be seen as an ill-founded euphoria and even, in some extreme cases, pseudo-messianism. ${ }^{81}$ Furthermore, the literary and critical pendulum in Israel had begun to swing in those years away from the taste and esthetic criteria that Kurzweil and his generation represented. Whereas Hebrew literature and criticism had since their inception been tied in some way to the Jewish problematic, whether that was construed religiously or nationalistically, now the younger writers and critics overtly severed the links between literature and ideology and preferred to inhabit a wholly esthetic domain, the autonomy of which they affirmed. In short, it is possible that, allowing for exceptions, Kurzweil discovered that he had lost much of his audience. The rapid development of literary studies at Tel Aviv University under Benjamin Hrushovsky, where formalism and structuralism were the regnant critical approaches, controverted all that kurzweil had written and taught. It was to him but one more manifestation of the deepening "crisis in culture" that threatened Jewish and human apocalypse. It is possible that Kurzweil founded Bar-Ilan's journal of criticism, Bikoret ufarshanut [Criticism and Interpretation] in 1970 to counter the influence of Hrushovsky's hasifrut [Literature] which had begun publishing in $1968 .{ }^{82}$

Barukh Kurzweil died on August 24, 1972, by his own hand. Press reports described his death as due to "a protracted illness" or "a heart attack at his office." 83 The funeral was attended by a large crowd of mourners, including many of the prominent members of Israel's academic community and government. 
Five volumes of Kurzweil's work have been published posthumously. havesi'ah (The Journey), which came out in the fall of 1972, contains the three stories by Kurzweil. Though two of these had appeared previously in the press, the work as a whole came as a revelation of the interior landscape of the recently-deceased critic to readers, who were probably adjusting to the relative quiet that had settled over the Israeli critical scene, however temporarily. ${ }^{84}$ In 1973, a major service to the Kurzweil corpus was rendered by Friedlander, who collected virtually all Kurzweil's essays on European fiction, some of which had appeared in Masekhet haroman in 1953, and published them as Masekhet haroman vehasipur haeiropi The Course of the Novel and European Fiction].

In 1975 Sefer Barukh Kurzweil IThe Barukh Kurzewil Memorial Volume] appeared. Originally intended as a Festschrift to be presented on the occasion of Kurzweil's sixty-fifth birthday, it served instead as a posthumous testimony to him and to his wide range of interests. Bar-Ilan University has also initiated the Kurzweil Archives (Yad Kurzweil) which will re-publish several of the hitherto uncollected essays as well as prepare a complete bibliography. In 1976 the first of these appeared. Entitled leNokhah hamevukhah haruhanit shel dorenu [Facing the spiritual Perplexity of our Generation], this volume collects Kurzweil's major essays on Jewish thought and figures. 85

\section{Conclusion}

Kurzweil's life is in several ways paradigmatic of the European Jewish experience of the twentieth century. Geographically and culturally, it traverses the course followed by those who were forced to uproot themselves from the European context of several centuries of continuous, coherent, if not always secure, Jewish life and re-locate themselves on a different soil, where life, though no less precarious, had already begun to develop in a way very different from the abandoned and decimated Diaspora. Experientially, Kurzweil saw himself and, we can now see, must be seen by us not so much as an emigrant as a survivor. Intellectually his life is an expression of the larger struggle to interrelate Jewish and western cultures or, more accurately, to come to terms with the purpose and meaning of Jewish existence amid a society of secularized consciousness that challenged, when it did not refute, the transcendent basis of the ancestral religious tradition and its norms. 
Gershom Schocken is, thus, perceptively correct, I believe, in accentuating Kurzweil as an "outsider" to the society he lived in for almost exactly half his life. ${ }^{86}$ For, unlike most of his counterparts, Kurzweil did not accede with his whole being to the new Jewish reality that was taking shape in Israel. To be sure, he accepted it in principle, but I do not think he ever made his peace with its visible manifestations. Unlike all other major critics, Kurzweil "did not grow up inside the movement of our national revival . . . "87 This perception of him as an "outsider" thus coincides with his own perception of himself. kurzweil's temperament, some of the features of which are implicit from the foregoing, did not ameliorate this view. I have no intention of painting an in-depth psychological portrait of Kurzweil. Suffice it to say that those who knew him testify to an unusual capacity for impatience and a rather well-developed ego; those who knew him very well speak of paranoid inclinations in certain situations. ${ }^{88}$

one trait, however, comes through as clearly on the printed pages as, apparently it did in real life, and it is this that is of relevance here: Kurzweil's visceral inability to tolerate even for a second anything that smacked to him of inauthenticity and pretentiousness. "Refusal to acknowledge limitations engenders phoniness." 89

This was the principle which animates every line Kurzweil ever wrote. His ruthless application of it over the years made him many enemies and did not endear him to those, however benevolently disposed, who were less consistent and sensitive than he.

In this perspective we may say that Kurzweil was not an "outsider" to the society in which he lived as a critic but in truth an "outsider" to all the imperfect reality of this world. He beheld this imperfection with more pain than most men, a pain that was exacerbated by his fear that for man the worst was yet to come. The fruit of that pain and that fear is the literary criticism that I shall now proceed to examine. 
CHAPTER III

METAPHYSICAL POSTULATES UNDERLYING

KURZWEIL'S LITERARY CRITICISM

Metaphysics in the central European tradition is not "a professorial philosophy, which compartmentalized knowledge [but] a 'total' system of truth about the world."I such philosophical all-inclusiveness is foreign and sometimes distasteful to the more empirical and pragmatic Anglo-American mind. But if we seek to show the philosophical underpinning of Kurzweil's work; if we want to set forth the ideas that energize his criticism, then we cannot but describe them as what in fact they are: metaphysical postulates. It is only necessary to add that while metaphysics is usually dissociated from religion, this cannot be done here since for Kurzweil both are intertwined as expressions of the absolute. In the same way, although a metaphysical truth is generally something different from one existentially known, in Kurzweil's case the boundaries between them are blurred. The legacy of nineteenth century German idealism is as much the source for the following root-ideas as is Jewish religion.

Kurzweil himself was neither a philosopher nor a theologian, systematic or otherwise, and it is not my aim to present him as such. He never formally enunciated the following postulates. Nevertheless his work, like all literary criticism, reaches out in a natural way to other disciplines and areas of concern.

As a student of literature I regard problems in philosophy, aesthetics and history as integral to my work. Whoever knows my books.. . or any critical article I have written will be able to observe my method, which is an inter-relating of matters that are beyond literature, such as social and religious questions, with discussion of the literary text.

What follows has been extrapolated from Kurzweil's writings and organized in a fairly sequential way. Attempts in this direction have already been made by Schwarcz and Barzel. ${ }^{3}$ Schwarcz focuses primarily on the philosophical and Barzel on the literary aspects of Kurzweil's thought. While I shall not substantially disagree with their important analyses, I shall seek to integrate them and to extend the discussion in such a way as to attempt to deal with the totality of Kurzweil's literary criticism and its ramifications. Accordingly, I propose here a scheme of exposition that sets up four fundamental metaphysical postulates that $I$ see underlying Kurzweil's criticism. 
Religious Faith as an Ontological Absolute

One of Kurzweil's most frequently used terms is "vada'ut kama'it" (primordial certainty) or "hazut kama'it" (primordial vision). This refers to his idea and conviction that the only absolute in human life, human history and human culture is faith in the living, transcendent God. This notion, at once simple and profound, can be seen to stand as the cornerstone in the foundation of Kurzweil's thought.

It should be emphasized here that when Kurzweil speaks of religious faith he is not referring to theology, morality, observances or institutions but to the untrammeled relationship between man and God that must precede these. It is the Divine side of the relationship that is absolute, not the human side which, after all, is liable to imperfection and inauthenticity. ${ }^{4}$ Hence it is belief in God that is primary.

Religious faith is thus construed as the only means which furnishes man with an adequate perspective on himself as a finite creature in the cosmos. All attempts to explain religion historically or psychologically, while interesting, err in seeing religion as a secondary principle when it is in reality a primary one. 5 The issue is essentially an anthropological one, specifically that of philosophical anthropology as propounded by scheler and Buber. Kurzweil found a great deal in the thought of both these men which conceptually spoke to his own existential searchings, and for this reason the period of study with Buber must not be regarded merely as a formality. That belief in God is a function not of dogma or of rational philosophical argument but of a living relationship--this is what Kurzweil learned from Buber, even if he later came to question whether, because it is inherentIy subjective, the dialogical principle could ever be transferred from the individual to the collective sphere, and whether it in itself without objectivations was adequate as a foundation for concrete, lived life.

In its fullness, religious faith constitutes the world in its primordial unity. The good, the true and the beautiful--ethics, philosophy and esthetics--are integrated. ${ }^{6}$ The further back we go in history the closer we come to this primordial vision of a sacralized universe. Similarly, within the individual, ontogeny re-capitulates phylogeny. "In truth it has been said that a person sees and perceives but once in his life." 7 Religious certainty is part of the ineffable splendor ("zohar") of childhood, and it is Kurzweil's intuitive understanding of this 
splendor that enables him to lay bare its manifestation in Bialik, Uri Zvi Greenberg and Agnon. ${ }^{8}$ The crisis of modernity, therefore, is precisely the result of "growing up", of moving away from the certainty of the Absolute, the ontological Absolute.

Demonic Nihilism as a Modern Possibility

Another word that occurs regularly in Kurzweil is "demoni", "the demonic". We may regard it as denoting the antithesis of the primordial religious vision. Kurzweil uses it with a rich series of over-tones and implications in mind.

The momentous movement in western civilization has been out and away from the primeval paradise of certainty that ancient man (or the child) inhabited towards a reality from which all clouds of glory have departed. Secularization is, of course, the name we know for this process, but its "demonic" nature is our concern. For Kurzweil the essential point in western history is the transition from a theocentric to an anthropocentric world-view. The pristine wholeness which encompassed the man-God relationship has been exploded with the historical sundering of the two parties from each other. In the beginning there was Anschauung

a Goethean word . . [connoting] the menta] process by which we spontaneously grasp, through observation and by intuition, a thing in itg wholeness. Goethe uses it as the opposite of analysis.

But now, after the waning of the sacral middle ages, ${ }^{10}$ dichotomy has entered human cognition: science and analysis on one side, art and feeling on the other. ${ }^{11}$ Each in its own way is an attempt to re-constitute the now fragmented universe and thus re-acquire for man the lost unity. While neither one succeeds, Kurzweil is clear that art stands a much better chance of doing so than science. Both, however, are substitutes for wholeness, and even "religion" in its modern manifestation is a relatively self-conscious, specialized enterprise that bears little resemblance to its all-embracing past.

In this new setting man is thrust into a cosmos bereft of certainty. He lives now not in the presence of God but of the abyss, of Nothing. ${ }^{12}$ The individual ego becomes the center and gradually enlarges to fill the void. Man for the first time conceives of himself as an autonomous being who is self-sufficient. There is no transcendent source for values and morality, nothing to hold in check man's instinctive capacity for self-aggrandizement, hubris, domination and destruction. The 
seductions of these dark powers, the demons within, prove irresistible and a new domain, the demonic, proffers itself. Now man is utterly alone, beyond all values and all relationships with society or his fellow-men--and yet he is unsatisfied. He has lost his soul but failed to gain the world, for the demons are insatiable. Eros as a force relating him to anything outside himself has disappeared; Thanatos now comes to the fore. Life itself is renounced, either passively as absolute silence envelopes him, or actively through suicide. A final, ultimate certainty is attained--the certainty of death; and a final, ultimate relationship is consummated--with the grave.

That is the dynamic of modernity. ${ }^{13}$ I have stated it here in a somewhat inchoate way. Kurzweil discerns its pattern in detail in history and various aspects of it in any literary work he examines. The essay "The Faustian Problem and Its Influence on the European Spirit" is central here. Likewise, the phenomenon of Hitler's Nazism is for Kurzweil not accidental but the inevitable consequence of modernity and its new anthropology. 14

It is, therefore, not difficult to understand why Kurzwejl is so imbued with a sense of crisis. The dilemma of modern, secularized culture has been precipitated by a twofold collapse: of fundamental, traditional religious belief on the one hand, and of the rationalist humanistic culture on the other. The decline of culture as it submits to all that is left--demonic nihilism--is the only possibility Kurzweil sees, a possibility that is one of the foundations of his world-view. 15

The question is: is this process truly inevitable? If man has indeed lost his place in the cosmos and no longer knows who he is as man; if two world wars and the possibilities for a third have confirmed this anthropological problem, is there any hope? Is this metaphysical entropy at all reversible?

My understanding of Kurzweil leads me to conclude that his pessimism was absolute. His antipathy to any notion of progress was deep. To be sure he knows and speaks of the desire "to return" to the past and its certainties, but it is always a "late return" (shiva me'uheret") and it is destined to fail. Kurzweil knows that real time runs in one direction only. A person like Buber radiated the possibility that Geist and Leben could again be organically reunited and harmonized, and intimated out of his very being the primordial wholeness, but, as we have noted, Kurzweil regarded these as God-given qualities not objectively transferable. 16 
This pessimism and the elitist distrust and fear of the masses impart to Kurzweil's criticism two distinct features that did not stand its reception in good stead. The first is an aristocratic posture and tone that was construed by most readers as arrogance. The other is a general thanatopic tenor. Kurzweil not only excels at showing the spiritual nakedness of modern man; he is equally adept at breaking down all attempts at reclothing and exposing them as pretentiousness and hollow presumption. Death is the only unassailable Absolute beyond God.

\section{Judaism as a Meta-historical Religion} in Tension with History

Kurzweil's writings rest squarely on the belief that Torah (Jewish religious tradition) is God-given, a timeless absolute that transcends the limitations of human history. The Jews, therefore, exist for the sake of Judaism; Judaism does not exist for the sake of the Jews. Furthermore, the Jews are different--not better--than other nations precisely because their peoplehood derives from a religious basis. "Jewish existence without God is the Absurd with a capital 'A'."17 Kurzweil speaks often of "ye'ud le'umi", a "national purpose" that impinges on every generation of Jews.

The primacy of the religious element is asserted on non-theological grounds as well. Kurzweil at one point argues that because nations change and develop within the flux of history we have no empirical criteria for determining what is the essence of Jewish culture other than that which is a meta-empirical constant, i.e., Jewish religion. ${ }^{18}$ This approach is distinctly phenomenological; it seeks to discover the objective, indivisible essence of a phenomenon by descriptive reduction. ${ }^{19}$ As such it has affinities and may even have been influenced by Yehezkel Kaufmann, especially by his Golah venekhar [Exile and Alienage], which was conceived as "a sociological history [of the Jews] devoid of metaphysical assumptions." 20 Silberstein has amply documented Kaufmann's relationship to Dilthey's thought 21 and his even stronger one with Husserl's phenomenology. 22 These are the same connections that we shall discover in Kurzweil's work, and I cannot overemphasize their importance.

In this way the subjectively theological and the objectively phenomenological ${ }^{23}$ unite to produce in Kurzweil an overarching, synoptic view of Judaism and the Jewish people. Both are seen as beyond the ravages and uncertainties of history; past, present and 
future are contemporaneous, bound together into a seamless whole; and Jewish time can furnish certainty:

What will be in the end has already been in the past. And what has never been will never be.

Therefore do I trust in the future, for I have set the face

of the past before me; this 4 is my vision and my song. Selah. Hallelujah. Amen.

These words of Uri zvi Greenberg, perhaps more than any other utterance, constitute Kurzweil's credo as a Jew. Kurzweil was aware that such a position represented an acceptance in Jewish terms of the very "mythos" which he regards as dangerous. I shall deal more fully with his attempts to come to terms with it in the discussion of Kurzweil's reading of Greenberg (Chapter VI). Suffice it to say for now that kurzweil knew that the dilemma was unavoidable, and that it could not be solved by denying the irrational but rather by invoking rational, humanistic categories as well. 25

The "meta-historical" view of Judaism has its roots in nineteenth century German idealism and is represented principally by the thought of Samson Raphael Hirsch, Yitshak Breuer and Franz Rosenzweig. ${ }^{26}$ Hirsch developed it in protest against the rise of the historical school, the Wissenschaft des Judentums, the effect of which he saw as relativizing what had been absolute. In seeking to show with declared scientific detachment that Judaism, and especially Jewish law, were not static entities but evolving products of historical process, and thus amenable to modification for modern conditions, the Wissenschaft, in the view of Hirsch and his followers, actually was dismantling the transcendent basis of the Torah.

The implication of this line of thought is a rejection not only of historicism in Judaic scholarship but of all Jewish nationalism that lacked this ontological basis. "The Jewish rebirth, with its aim of 'normalizing' the people along historical lines is achieved at the price of relinquishing its timelessness, the guarantor of which is Divine history." 27 The chief exponents of the meta-historical approach in the first part of the twentieth century, Breuer and Rosenzweig, were thus, not surprisingly, identified with an opposition or at best a neutral attitude to zionism. Breuer was not without an understanding of the essential polity of the Jews las opposed to other more assimilationist varieties of anti-zionism which saw the Jews strictly as a religious group) and kurzweil points to his excellent treatment of Herzl. 28 On the other hand he could describe zionism as "the 
worst enemy the Jews ever had" 29 because in divorcing religion from nationalism it made the former into a matter solely of personal concern. In his trenchant essay on Rosenzweig Kurzweil observes:

Not only was Rosenzweig "the quintessential aristocrat"; he also saw in zionism rightfully [emphasis mine, J.S.D.] "a movement that was pro-socialist, progressive and at times proletarian." The main thing, it appears, was his opposition to the kind of modern nationalism that lay at the core of zionism. . . Rosenzweig, and also yitshak Breuer, between whom, in spite of all their differences, are some interesting points of contact, both understood the danger of modern nationalism and its progeny, the fetishism of a sovereign state. For this reason both Rosenzweig and Breuer distanced themselves from Zionism, which was by nature a secular movement but was particularly dangerous when it cloaked itself in the mantle of the spiritual, as for example in the teaching of Ahad ha-Am.

Here to a certain extent Kurzweil tips his hand. His own affinity with the meta-historical approach necessitates our determining that he shared its reservations about zionism. Most of his observations on Breuer and Rosenzweig serve not to tell us definitive things about them but about Kurzweil.

The Jewish state is not Judaism's last word. He who links the fate of the Jewish people and the fate of Judaism to the state alone renounces the eternal in the life of the eternal people. . . . The state of Israel has not solved and will never solve the problem of the Jewish people, neither its physical problems and certainly not its spiritual problems.

More explicit departures from the classical zionist line would be hard to find.

It is important, however, to note that these reservations--actually they are strictures--were aimed at zionism in its purely secular manifestation. They are not so much moral strictures and are certainly not political ones, ${ }^{32}$ but cultural ones, for Kurzweil was concerned primarily with Jewish cultural authenticity.

I do not wish to determine what is possible among other nations, but it seems to me that we shall never achieve cultural independence if we fail to find the genuine link to our religious tradition. We must not allow the idea of the state to take the place of the absolute of Judaism, of God. There are visible tendencies among us 3 to endow the state with all the attributes of Divinity.

Nevertheless--and here the wheel of the dialectic swings round--Kurzweil knew that Judaism and the Jewish people also exist within the finite parameters of human history. He could not deny 
the validity of a nationalistic enterprise which saved him from the certainty of Hitler's gas chambers. And, with the decimation of the European Diaspora he so loved, he envisioned no place where Jewish culture could now develop other than Israel. Accordingly, we find throughout Kurzweil's writings, side by side with the critical perspective, a basic acceptance of the 2 ionist idea and a clear sense of pride and respect for the Jewish state. ${ }^{34}$ He concludes his assessment of Breuer by pointing to what he calls the static and ultimately tragic nature of his thought which, he feels, evidences the same lack of attention to modern historical realities that characterized all of German orthodoxy. ${ }^{35}$ Too, the essay on Rosenzweig contains several demurrals that clearly show that kurzweil must not be understood solely from the standpoint of the meta-historical approach:

Zionism was an expression of the instinctive will of the masses. It, and in a larger sense the establishment of the [Jewish] state, were the result of a necessary process which fate forced on our people in a cruel historical situation that did not ask for abstract intellectual arguments. But, on the other hand, we should certainly not exaggerate maţ̌ters by apotheosizing a narrow materialistic secularism.

On the surface this statement would seem to appeal to the collective will as a determining factor in Jewish history and survival, in which case Kurzweil would be adumbrating Ahad ha-Am's position (which he repudiates), thus contradicting himself. ${ }^{37}$ yet I believe that to charge Kurzweil with inconsistency here is to miss the point. He did not approach the issues of zionism and the Jewish state solely from the standpoint of pure ideology but from out of life--and life is stronger than logic. ${ }^{38}$

Thus the events precipitated by the Six Day war of 1967 were no less perplexing to Kurzweil than to any other intellectual who tried to make sense of what had transpired. Here, with the unanticipated reunification of Jerusalem and the dramatic return to the Western Wall, Jewish nationalism had seemingly achieved in history the beginnings of what was supposed to take place only in the final, sacral meta-historical redemption. Such developments only exacerbated the inappropriateness and confusion caused by the assumption by zionism, a secular movement that had ostensibly broken with the Jewish past, of an increasingly spectacular role as purveyor of Jewish continuity. Kurzweil now saw zionism as "trapped by its own achievements", but it is hard to tell whether he is bitter or gratified at this fact. ${ }^{39}$ The conclusion he comes to at the end of one of his most penetrating discussions of the 
new situation created by the Six Day war can serve to help summarize this attempt to define his perception of the tensions between Jewish history and meta-history.

Perhaps we have no choice other than to live out Jewish being within the Absurd, within the complete incongruity between a post-human technological reality, a time when man cowers in vain behind his tools which control him--and the living Torah of a living Judaism. . . The secular state is not Judaism or its replacement. The secular redemption is not the messianic redemption. The secular state has a crucial role. Religious commitment is the private affair of each Jewish person. And there is no better place for an authentic Jewish existence $0_{0}$ than in this state. Anything more is not given to man.

But it is in his criticism and not in his philosophical or occasional essays that we find a clearer indication how kurzweil envisions the reconciliation of these tensions, specifically in his interpretation of Agnon and Greenberg. The paradoxes borne of the discontinuity between Jewish history of the modern present and the meta-historical transfiguration of the ancestral past are resolved in a daring act of poetic vision in which, almost miraculously, that past is reclaimed.

This is not the vision of a simplistic faith but the volitional decision to [attain to] a unified perception of the then and the now, the there and the here, in the spirit of the categories intrinsic to the past itself.

Here the historic and the meta-historic coalesce into what Kurzweil later calls a "new continuum." 42 Because it is only Agnon and Greenberg who have thus far construed this continuum poetically, Kurzweil sees in them not only the culmination of modern Hebrew literature (as we shall see further in chapter VI) but the only satisfying solution to the impasse of Jewish modernity.

I have dwelt in some detail on this aspect of Kurzweil because it is crucial. We cannot possibly understand his perception and criticism of modern Hebrew literature which, like Russian literature, arose and developed as a handmaiden to ideology, without knowing his relationship to that ideology. Kurzweil's commitment to a meta-historical fideism is antipodal to the perspective from which most Hebrew literature in the twentieth century, especially that of the sabra writers, was created. 43

We may infer from all that has been presented here that the most important operative idea in Kurzweil's Jewish world-view is that a secular Jewish culture is both a contradiction and an 
impossibility. Yet, having seen the complex dialectical and phenomenological elements that underly this position, irrespective of its theological grounding, we must be careful not to make the common mistake of tagging Kurzweil with such simplistic labels as "Orthodox" or as a "religious zionist." Moreover, his opposition to such humanistic substitutes for the classical halakhic tradition as Ahad ha-Amism or Reform Judaism did not interfere with his enjoyment, appreciation and evaluation of artistic expressions of such a secular humanism as that of Shlonski, Altermann and Yizhar. Paradoxical as it may sound, there is in Kurzweil a liberal, humanistic streak which co-exists with (but does not supersede) the meta-historical fideist. 44 In literature ideology is ultimately not the issue, but art. ${ }^{45}$ Both, as we shall now see, have to be measured by the way in which they stand in relationship to the spoken and written word.

The Ontology of the Word: Language as the Transcendent Guarantor of Cultural Integrity

Throughout his criticism Kurzweil constantly examines and evaluates the language of the literary artist in question. He does this not as a formalist interested in sound patterns or semiotics or as a structural linguist but out of metaphysical considerations of a completely different order. Clarification of these considerations will serve to illuminate a fourth foundation of Kurzweil's work.

In general we may say that Kurzweil's attitude to and treatment of language, i.e., the poetic language of literature regardless of genre, fits in to a specifically German tradition of Sprachphilosophie that goes back at least to Herder and Novalis and runs down the backbone of German philology in the nineteenth century, through schelling, Humboldt, Droysen, Steinthal (who edited Humboldt's writing on linguistics), Schleiermacher and Dilthey. It continues in this century in such diverse activities as German stylistics ${ }^{46}$ (Vossler, Spitzer, Auerbach), representational symbolism (Cassirer), metaphysical hermeneutics (Heidegger, walter Benjamin) and the "language mysticism" of Karl Kraus. 47 Buber and Rosenzweig belong to these latter two groupings and, as I shall now show, so does kurzweil.

Heidegger's development of the idea--no, the experience--of language as a response to and, therefore a discloser of a metaphysical reality is seminal here. In his attempt to understand life from out of life itself, as Dilthey and German 
Lebensphilosophie had begun to do, Heidegger went behind existence, so to speak, and, with the aid of Husserl's phenomenology, came upon what we may call the given substructure or pre-structure of existence, the ontological category of Being. ${ }^{48}$ As his thought progressed Heidegger came more and more to focus on the unique role and power of language to disclose Being. "There is no being without language and no language without being."49 Language, as Humboldt had observed, is thus not only an instrument for presentational thinking or for relaying information, but something that derives from beyond man, from existence or Being itself. Man does not invent language any more than he invents time or being itself. 50

Kurzweil essentially holds to this view. In his important essay "Between Anthropology and Literature" he quotes Heidegger's statement in Unterwegs zur Sprache: "If it is true that man finds the proper abode of his existence in language--whether he is aware of it or not--then an experience we undergo with language will touch the innermost nexus of our existence."51 Language, then, for Kurzweil is ipso facto an aspect of man and the anthropological problem as discussed above. ${ }^{52}$

Language flows from out of the deep of human consciousness and reaches up or back to the pristine sphere of primal wholeness. Rosenzweig, too, speaks of silence in similar terms and Schwarcz insightfully finds

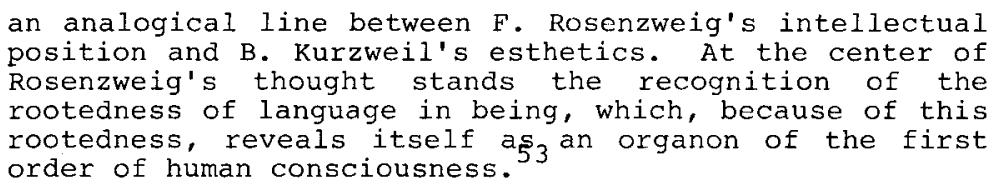

Language as the vehicle of Revelation is the particular strand Kurzweil drew from Rosenzweig's meta-historical theology. It is a most important strand for it illuminates the sacral nature of the Hebrew language. Rosenzweig had written about Hebrew as a meta-historic language in these terms:

Since time immemorial the Jewish people's own language has ceased to be a language of daily life and yet. . . it is anything but a dead language. It is not dead but, as the people themselves call it, a holy language. The holiness of the people's own language has an effect similar to that of the holiness of its own land: it does not allow all their feeling to be lavished on everyday life. It prevents the eternal people from ever being quite in harmony with the times. By encompassing prayer, the ultimate, loftiest region of life, with a holy region of that language, it even prevents this people from ever living in complete freedom and 
spontaneity. For the freedom and spontaneity of life rest in the fact that man can express in words all he thinks, and that he feels he can do this. . . As a result he cannot speak to his brother at all. He communicates with him by a glance rather than in words, and nothing is more essentially Jewish in the deepest sense than a profound distrust of the power of the word and a fervent belief in the power of silence. The holiness of the holy language which the Jew employs only for prayer does not permit his life to put out roots into the soil of a language of its own. So far as his language is concerned, the Jew feels always he is in a foreign land, and knows that the home of his language is in the region of the holly language, a region everyday speech can never invade.

It is precisely this relationship to Hebrew as a meta-historic language that energizes Kurzweil's criticism of modern Hebrew literature and sets up special criteria for its evaluation that we shall have to consider. 55

But now we encounter a familiar dialectic: language (all language, not only Hebrew), even if it flows from the transcendent, exists within history. ${ }^{56}$ As such it is the conveyor not only of facts but, more important, of all shifts in man's consciousness and his percoption of himself as a cosmic being.

With the loss of simple religious faith it is no longer possible to talk of the Divine source of language. . . . In the wake of man's increased scepticism the universe of language has shrunk. Its sphere of authenticity has been limited. It now turns man back to his wretched self. It no longer redeems mar and can no more open him to worlds beyond. Language can now pring man only to
the borders of the chaotic void. . . .

The very authority of language is thus now in doubt. 58

Because this process happens not only to an individual but to a nation or a society, ${ }^{59}$ language becomes the yardstick of culture, morality and values. Here Karl kraus is important, both as an example of an unsparing application of the yardstick and as perhaps the most important of all the many influences on Kurzweil. In Kraus we have the supreme case of a critic who lived in perpetual tension with his society precisely because he knew that all its inconsistencies, self-delusions and hypocrisies and, therefore, its immoralities, were related to the way in which the word was related to and used. "No word is primitive and unspoiled enough to describe the almost frightening directness, spontaneity and naivety with which he [Kraus] himself experienced his calling."60 Language and moral values are inextricably linked--that is the root idea of Kraus's work and mission, extending through nine hundred twenty-one issues of Die Fackel from 
1899 to 1936, of mercilessly exposing all attempts in his culture to separate the former from the latter.

Kurzweil's defense of the use of polemic in criticism, which we shall consider below, is distinctly Krausian, as Ernst simon sensed. ${ }^{61}$ So is his declared animosity toward the press. ${ }^{62}$ At times Kurzweil could abandon the restrained discursiveness of the critical essay and instead move to overt satire where he plainly follows the technique, used by kraus in his stupendous the Last Days of Mankind, of a dramatic dialogue between thinly disguised characters in which their words are nothing but their own actual utterances quoted verbatim from the newspapers. ${ }^{63}$ Most instructive here, however, is Kurzweil's own discussion of Kraus. He attempts to show that, less than either Brenner, Weininger or Kafka, Kraus is not to be understood, as he commoniy is, as a "self-hating Jew." but as one whose rejection of the imperfect and counterfeit Jewish present was necessitated only because of his memory of and yearnings for the pure and authentic Jewish past. At the base of Kraus's world-view Kurzweil finds a commitment to culture and to language that bespeaks an acceptance of a transcendent source of values that to him is ultimately religious.

Kurzweil claims for Kraus vis a vis the German language the same meta-historical relationship Rosenzweig described between the Jews and Hebrew. ${ }^{6}$ whether kraus came to this because of his Jewish roots or whether it was his erstwhile conversion to Christianity that made him understand language as "Logos", Kurzweil cannot say; he is clear that kraus must be seen within his Judeo-Christian framework and

what appears as "Jewish self-hate" is actually the
fundamental unwillingness of Kraus [to partake of] a
Jewish existence that was absurd and to perpetuate it
through false ideologies on both the Right and the
Left.

What I think we have here is not influence nor even emulation of kraus by Kurzweil but identification with him. Like Kraus, Kurzweil's main sensibility is that of living in "the last days of mankind" as culture wanes and the word retreats into silence. ${ }^{66}$ If such ideological criteria as "progress" and "reaction" were foreign to Kraus because "what he construed as progress frequently necessitated falling back to secure and genuine cultural positions", 67 Kurzweil himself came to enunciate the same attitude:

It is necessary also to re-examine, in a fresh way, the humanistic content of western culture. I know that such a demand is suspect as being reactionary. But all true progress is the result of a dialectical process which 
knows how to encounter anew the tradition of the past in order to bring it to a new integration into changed conditions.

Janik and Toulmin, largely following the work of Carl Schorske, regard the crisis of language as the bellwether of the widening rift between fantasy and reality that they define as the central problem of twentieth century culture. ${ }^{69}$ Kraus is central to their thesis, because the language crisis first surfaced in Hapsburg Vienna and Kraus's awareness of it was the most acute and influential.

In general I would say that this thesis is preceded, corroborated and extended by Kurzweil's work. He defined the crisis of language as the indicator of the crisis of modernity well before Janik and Toulmin, and he wrote about Karl Kraus in very similar terms a decade or more before them. ${ }^{70}$ Likewise, his studies of Agnon, Musil and Kafka brought Kurzweil to the idea well before the authors of Wittgenstein's Vienna that it was in the late Austro-Hungarian Empire that the sensibility of the crisis was germinated. This is because Kurzweil understands this crisis in spiritual terils, as a loss of the Absolute of religious certainty. Here I would say that he provides an all-embracing explanation for the crisis that Janik and Toulmin never do. While they indicate a clear grasp of the problem, at no point do they suggest any specific reason why language failed when it did, and why reality and fantasy became dissociated in Viennese society. True, they speak of "a consideration of values and of the meaning of life, on an existential plane" and of "the most pressing questions about life and society" as the dilemma of Hofmannsthal and his intellectual contemporaries. ${ }^{71}$ But essentially their analysis is, as they intend it to be, on the historical plane. Kurzweil couches the entire issue in metaphysical terms and that, I would say even now, is his distinction and his main contribution. He provides a metaphysical answer to a metaphysical problem.

That is why he identifies with Kraus and emulates him so completely. Experientially he is in the same place: a child of the Hapsburg Empire of pre-World War I, where

\footnotetext{
the problem of authority was manifested by the image of the Kaiser, and his monarchial order reflegted in miniature the cosmic order of the king of Kings.
}

That is why he construes Kraus's critique of language and society as an essentially religious one. "The denial of God and sacred history gives birth to doubt and to the denial of the authority of language." 73 Kurzweil starts out from the sacral realm, embodied 
by the Hebrew language, and he is even more vulnerable than Kraus to the spiritual corrosion of modernity. "The sacred tongue, its images and concepts, can communicate the complexities of secular reality only in a strange and absurd way. The words become ghostly."74 This in turn leads to one of Kurzweil's major theses: that it is precisely Hebrew language and its modern literature, beginning with Feierberg and Gnessin and culminating in Bialik, 75 Agnon and Uri zvi Greenberg, that display the first adumbrations of the crisis in language and culture that would ultimately engulf all the literatures of Europe in the twentieth century.

But we get ahead of the story. My intention here has been to set down the main features of the Kurzweilian world-view and to show their remarkably coherent inter-relationships. It is a coherence born of a deep capacity for dealing with reality dialectically, a capacity that Kurzweil comes by honestly from the two traditions he seamlessly integrates--the Jewish and German. It is superfluous, I think, to establish Kurzweil's "Jewishness", but in regard to his "Germanic" quality the following generalization of wellek seems to me to be wholly to the point:

Germans operate, or rather operated, with dichotomies, thesis and antithesis, vast contrasts such as idea and form, idea and experience, rational $j_{6} 5 \mathrm{~m}$ and irrationalism, perfection and infinitude, etc. 

We are now ready to examine Kurzweil's understanding of art, for it flows directly from his understanding of language. Then we can turn to his notion of what literary criticism is and how it is to be performed. Here, too, we are dealing with a definite poetic and esthetic theory, but it is one that has not been clearly articulated; rather it has to be fleshed out from a number of statements and a few suggestive hints scattered throughout Kurzweil's writings.

The Nature of Literary Creativity

In both the Critique of Pure Reason and in the Handbook to his lectures on logic, Kant notes that the fundamental questions of philosophy in its widest sense are three: what can I know? what ought I to do? what may I hope? In the latter work he establishes a fourth question as basic to these three: what is man? ${ }^{1}$ This is the "anthropological" question. It is anthropological because Kant assigns metaphysics to answer the first one, ethics the second, religion the third and anthropology the fourth. "And Kant adds: 'Fundamentally all this could be reckoned as anthropology, since the first three questions are related to the last. " "2

To answer Kant's fourth and most basic question, "What is Man?" requires for Kurzweil a completely different way of searching than what he saw in Buber, Heidegger and Scheler, one that employs no method and uses another medium--language. This way is the way of art, specifically literary art. ${ }^{3}$

More than anything else it is language that defines man, and so when we are examining language we are examining man. I have noted in the preceding chapter the bases for this view. If language, in Heidegger's words, is truly "the home of Being," then Kurzweil believes that

Poetry and the literary work to the extent that it is a true work, returns man to his dwelling place, to language. And to the extent that we have a deep experience with it, language discloses the nature of our being.

Literature, therefore, is the locus classicus of the development of the anthropological question and that is the perspective in which it is to be read: 
It is the language of the poets that knows how to determine man's dwelling place, that penetrates most deeply into the problem of man. . . Man and his perplexities--that is the historical trajectory of literature. Stylistic questions are certainly important, but they are secondary to the anthropological ones relating to the presentation of the image of man in all periods. That "the style is the ${ }_{5}$ man" is indeed true; but without man there is no style.

We recover here a most important foundation for Kurzweil's esthetics from which a number of equally crucial corollaries follow. First is the notion that, because it is essentially a holding up and a showing forth of the human, literary language and literary art are by their very nature communicative. Art which is non-communicative is, in this sense, a contradiction in terms.

The creative act [itself] is always an act of relationship. Unlike the scientific process, artistic creativity involves demolishing the barrier between subject and object. It brings about and illuminates what did not exist beforehand. . . something beyond subject and object, a third entity which encircles the poet and the substance of his poetry. And so for this reason the creative act establishes the yearned-for unity which we have lost. It is that new thira entity, beyond and above subject and object. It is "I", but at the same time it is both less and more than "I"; it is "Thou", but at the same time it is both less and more than "Thou". 6

The context of these words, a discussion of those issues in relation to Tshernichovski's poetry, should not keep us from recognizing how closely they relate to Kurzweil's critique of Buber. Here we can see not only how much Kurzweil accepted the realm of "between" as "the real place and bearer of what happens between men" 7 but also that for him art provides precisely that which "the philosophical science of man, which includes anthropology and sociology" 8 cannot: a concrete, available "third entity" that can recover for man his lost sense of primal wholeness. To be sure, Kurzweil here talks about the creative "act", but the referent is really to the work of art itself that the act brings into being, for it is in the work where the artist and the reader meet, where comunication takes place.

second, such a poetics holds itself always in readiness for the instances when language is not related to Being; when words manipulate and do not disclose; and when what is created reflects not man in his relatedness ("man as man" in Buber's words) but presumptuous narcissism. In all these instances what passes for literature is not art. ${ }^{9}$ Better silence than such presumptuousness, as Bialik, Hofmannsthal and Kraus understood. 
But that is not the half of it. The real question such a poetics asks is: considering what has happened to man in the twentieth century, is art even possible now? In the light of man's increasing detachedness, his continued withdrawal from the sphere of "between", be it between man and man or between man and God, into the sphere of "within"; as man has become increasingly problematic to himself, can language still serve as the vehicle for artistic communication? ${ }^{10}$ These doubts inform all of Kurzweil's criticism. I state them here in general terms and shall explore them further below when I shall consider the particulars of Kurzweil's literary theory.

All this would appear to imply that when Kurzweil talks about art he is really referring to literature. What about other esthetic expressions as music, painting and sculpture? Kurzweil does not deal with these, though he is aware that they too are related to the human situation. ${ }^{11}$ It is certainly possible to incorporate them into the larger contours of the esthetic theory I have here described. "Without belief in man and in his uniqueness no art is possible." 12 Nevertheless, since it is rooted in language, literature is clearly the focus of this theory.

Literature as art, then, by its very nature, involves relationship, or a striving for relationship, with the absolute, with the Divine, with that which transcends the self. In this sense is art ideally encompassed within the sacred and beauty an aspect of the holy. ${ }^{13}$ To put it in the terms of the Kantian trinity, the beautiful exists co-terminously with the good and the true, at least it did when the cosmos was perceived in its transcendental wholeness. 14 When, however, man loses this perception, as he has over the last five centuries, then the process of differentiation occurs: the beautiful is dissociated from the true and the good, and a new realm, the esthetic, takes on its own autonomous existence as an absolute in and of itself. Kurzweil points to Benn, George, and Valéry as the leading exemplars of this process since Beaudelaire. ${ }^{15}$ Nevertheless Kurzweil is clear that, as Schwarcz aptly puts it, "all authentic art serves as a trustworthy record of the artist's striving to realize anew the unimpaired reality" of what he felicitously calls "the beauty of the pre-esthetic".16 This may take the form of an attempt to recover the primal vision of childhood or to re-constitute the collective consciousness of his nation or to recover the unassailable certainty of religious faith. 17 In any case, all great art comes about after its creator has been carried "back to the depths of the deep, to the flux of the irrational, beyond the moral, to the mythological". 18 
This means that all great literary creativity is for Kurzweil an inherently irrational process, resulting from the artist's encounter with the infinite as he stands before the depths of the abyss.

Any tendency toward unequivocal clarity, toward artistic
expression which resists the seductions of unfathomable
ambiguity, will circumscribe the limits of esthetic
possibilities for developing the multivalent, the
undefinable, the variegated, the irrational--the very
mysteries of the work! $\cdot$. The irrational and the
realm of the unspecifieg together constitute the womb of
the great work of art. Reality by its very infinity is ambiguous, dialectical, chaotic, confusing and threatening. It is the poet who perceives it thus as he stands in his solitary-ness before it. And here, precisely as a poet, he is spurred to create in the face of the void of the cosmos, a miniature world that, while evoking the larger boundlessness, still, because concrete, rational form is imposed by him on it, brings to its human creator a measure of wholeness, security, truth and beauty. This miniature world is the work of art, which represents at one and the same time both a yearning for and an illusion of the re-integration of diffuse and problematical reality. In his original formulation of this, the metaphysical basis of esthetic creativity, Kurzweil, following schiller and Schopenhauer, points to the "idyllic" as its essential aspect. 20 This is because the idyllic, in that it captures the world as a totality, does so in miniature, from a distance. Hence comes its charming, pleasurable and reassuring qualities. Were that same world reflected up close, in all its vastness, it would be terrifying. ${ }^{21}$ The idyllic, therefore, performs the same function as religious ritual.

Ritual teaches man how to meet the forces of the Divine, the transcendent and threatening numinous (Otto), the incomprehensible eternal "Ein sof". But the idyllic, as the heart of poetry, is also an attempt to root man in his little place in the face of the terrors of the formless void. The idyllic thus brings to light what in actuality is the implicit or explicit concern of all true art, namely the connection of the work to the hieratic-religious sphere.

Late in his life (1968) Kurzweil came to emphasize the wider perspective this passage only hints at.

More than twenty years ago, in my essay "The Existential and Metaphysical Roots of the. Idyliic" I tried to illustrate, through the idyllic element, the consoling and tranquillizing function of the work of art. The idyllic appeared to me as "the important and even 
central element of every work of art. . . ." Today I know that art in general performs the task of serving as a life-buoy against the formless void of sphinx-like, inscrutable, external reality, the objeçtive meaning of which we shall never be able to fathom.

Here we feel the full thrust of Kurzweil's esthetic theory. Art in its most sublime manifestations strives after the same primordial wholeness and certainty that religion once gave. It is both an intimation and yet an illusion of such certainty. The consciously applied, rational laws of form and proportion concretize and organize polysemous reality into a deceptive, pleasing coherence. As the vestiges of the Absolute of religion vanish,

artistic analysis, art itself can serve both as a refuge and as a revenge. All that is left is artistic form, and it is a kind of $2 \mathrm{~g}^{\mathrm{ad}}$ catharsis--without God, without gods, without grace.

The centrality of the artist's experience in this poetics is apparent. The work is an objectivation of an inner experience. As such the conventionally used term for poetic creativity--mimesis--becomes problematical. Mimesis is an Aristotelian concept predicated on the subject-object dichotomy, and the artistic act as Kurzweil construes it transcends this dichotomy. "The arts and literature do not 'imitate' reality. They evoke it in their language. Reality itself remains 'as it is'--ever shrouded by a veil of mystery."25 Such a poetics should be seen within the context of a German intellectual configuration, specifically the philosophy of life (Lebensphilosophie) as developed from German Romanticism into phenomenology.

Two figures in this tradition, although by no means the only or even the main figures, I have already mentioned: Schiller and Buber. To them we need add Buber's teacher, wilhelm Dilthey (1833-1911). Schiller's understanding of artistic creativity is the foundation here, especially his notion of how "life" and "shape" inter-penetrate as the products of the two essential impulses of man, the "sensuous" and the "formal". "Life" for Schiller is "the object of the sense impulse.. . a concept which expresses all material being and all that is immediately present in the senses". "Shape", on the other hand, is "the object of the form impulse, expressed generally . . both in the figurative and in the literal sense. . ."

From the interaction of [these] two opposing impulses... we... see.. the origin of the Beautiful, whose highest ideal is.. . to be sought ${ }_{6}$ in the most perfect possible union of reality and form. 
That Kurzweil appropriates this should be clear from the foregoing, but between Schiller and Kurzweil comes also the decisive contribution in this area of Dilthey. The essential aspect of Schiller's theory was, for Dilthey, that it defined the creative act as a continuous process of transference from "lived experience" (Erlebnis) to artistic form (Gestalt) and from artistic form to "lived experience". ${ }^{27}$ This allowed Dilthey to develop his own concept of Erlebnis as the seed of the poetic process, a concept that has not fared well among American theorists but which is, beyond its importance for understanding Kurzweil, crucial to the development of any epistemology of literature. It is not that the Erlebnis idea is unknown or unrecognized. Wellek, for example, in his rather inadequate treatment of Dilthey, does note it as one of his principal terms and correctly describes it not just as unspecified experience--anything can become an Erlebnis to the poet--but as experience in its totality, an event or a thing that engages the total person. ${ }^{28}$ But wellek seems to construe this experiential basis of literature primarily as Stoff, and he is led to regard Dilthey as having been interested almost exclusively in content and in literature as the expression of the "life-ideal of an age". 29

More recent studies of Dilthey have attempted to correct this erroneous perception. They emphasize that the totality of poetic Erlebnis, as Dilthey understood it, lies precisely in its immediacy, in its anteceding the Cartesian dualism and reflexive thought. "Experience does not and cannot directly perceive itself; . . it exists before the subject-object separation." 30 Is is not the content of consciousness nor a psychological construct but the "total structural coherence of the psyche" which seeks "to comprehend the relationship between the historical and the existential, the universal and the particular, the biological and the ontological aspects of human life". 31 It is the very opposite of the anatomized consciousness of I. A. Richards ${ }^{32}$ and the philosophical legacy of Locke, Hume and Kant which separated cognition from feeling and will and equated it alone with "knowing". 33 Palmer assesses Dilthey's concept of Erlebnis in these insightful words:

Just this realm of prereflexive consciousness is that staked out by Husserl's and Heidegger's phenomenology. As Dilthey seeks to implement his methodological project in close coordination with his life philosophy, as he makes a clear separation between mere "thinking" and "life" (or experience) he is laying the foundations for 20 th century phenomenology. . . . Yet it would be a grave mistake to think of experience as pointing to some 
kind of merely subjective reality, for experience is precisely the reality of what is there-for-me before experience becomes objective (and therefore admits of a separation from the subjective). The prior unity is that out of which Dilthey tries to forge categories that will contain rather than separate the elements of feeling, knowing, and will, which are held together in experience--such categories perhaps as "value", "meaningfulness", "texture", and "relationship".

It is on this epistemological foundation that we must understand the ontological status Kurzweil grants to a literary work and his statement that such a work is at once subjective and objective. Similarly, it is on this foundation that we must see resting the mode of interpretation it necessitates--hermeneutics-- ${ }^{35}$ and Kurzweil's relationship to that mode. As I have indicated, I shall explore this subject more fully below when I shall examine another feature of poetic experience as Dilthey conceives it that has a direct bearing on and unites both the creative and the interpretive aspects of literature: its temporality, the fact that such experience always exists within a specific historical context.

As far as the consideration of Erlebnis here goes, it remains only to note the distinctive way in which Dilthey advocated works of art were to be perceived: "as individual manifestations. . . belonging to an ordered or structured whole" and not in accordance with the canons of "the positivism of the natural sciences [which] tended to regard them as exemplifications of a general rule". 36 The goal is a holistic perception of reality.

This, I would suggest, is the "wholeness" that Kurzweil and Buber refer to. Dilthey's hopes for scientific rigor aside, it is a spiritual category and can be traced back to the monistic epistemology of the German tradition that runs back to Goethe. ${ }^{37}$ The struggle is on behalf of a vision that would integrate all reality, Anschauung, 38 and against the increasing inroads not of science but of scientism, which sought to abolish the mystery of life and to dismiss "a priori as invalid all ontological assertions, i.e., assertions about the nature and meaning of Being" in favor of a strictly causal explanation of phenomena. ${ }^{39}$ Essentially this is a struggle between analytical reason and creative imagination, the balance of power between which Goethe tried to maintain, 40 but ultimately it becomes an assertion of the priority of art over science. That, at least, is where Kurzweil enters the lists. It is a facet of his esthetics that pervades all his criticism. 
Now if the basis for Kurzweil's esthetic and poetic theory is metaphysical, it is predicated upon an epistemology that I identify as phenomenological. ${ }^{41}$ specifically, it is akin to the "transcendental subjectivity" that Husserl developed, whereby reality only exists to the extent that it is intentionally constituted by the Ego.

The upshot of the "transcendental subjective" mode of perception is that it does not admit of any truth that calls itself completely "objective". This is the driving force behind Kurzweil's sustained assault not only against the scientific method but against the manifestations of this method in the humanities. The assault is concentrated specifically against all claims of scientific objectivity in the fields of historical and literary scholarship, against all attempts to controvert the inscrutably human in the humanities.

The painful recognition of the inherent subjectivity of my discipline, which is one of the humanities, brings me to be sceptical about the humanities in general and history in particular. To put it simply: I can find no "truth" in the humanities. It is possible only to reach the maximym proximity to "the inner truth" of a text and no more.

All reality is thus a text to be interpreted and not analyzed. "If we extend this notion beyond literature, it merely confirms that the bases for historical knowledge are not empirical facts but written texts, even if these texts masquerade in the guise of wars or evolution." 43 De Man is concerned with the problems of literary history but his observation holds, I think, for all history as Kurzweil perceives it.

More precisely, it is not history per se that is the target 44 but historicism, the reduction of amorphous reality to definite laws. It is against historicism in a specific framework that Kurzweil fought--"mada'ei hayahadut," "Jewish sciences", the offspring of the nineteenth century Wissenschaft des Judentums, particularly as it is exemplified in the work of Gershom Scholem. kurzweil's critique of scholem--actually there are several separate critiques that coalesce into one extended repudiation of the work of perhaps the most celebrated Jewish scholar of our time--is voluminous and bitter. From the standpoint of literary criticism, which is our standpoint here, the critique is tangential. It is not, therefore, my intention to analyze it in any detail and, in any case, it can be readily understood in the light of the metaphysical postulates discussed in the preceding chapter. ${ }^{45}$ 
Suffice it to say that scholem is condemned for contravening the absoluteness of Jewish religious faith by relativizing it through the process of historicism.

Science cannot replace religion, and a scientific
approach to Judaism has no authority as far as Judaism
as a living substance goes. The Judaic sciences are
concerned with the anatomy of a Judaism which has ceased
to be "Torah" . . It is possible to say that, paradox-
ically, a mathematician or a physicist is more
authorized to appear as spokesman for Judaism than
Messrs. Baer, Baron or G. Scholem, just as a gynecolo-
gist, gua gynecologist, is unable to evoke the mysteries
of Eros, even though he is familiar with every aspect of
the female body. The poet and the lover, without their
ever having known woman, know a great deal more about it
[Eros] and love than any gynecologist. And if the
latter should become a lover, it will not be due to his
professional expertise but in spite of it.

Here again we can sense Kurzweil's utter unwillingness--perhaps it is an inability--to concede any value to "realistic" epistemology.

Kurzweil's critique of scientism in the humanities was launched not only against scholem and Jewish historical scholarship but, with equal force, against all attempts to cast literary criticism into a scientific discipline. Kurzweil's attack on these attempts, specifically his life-iong polemic against formalism and structuralism, takes us to the heart of his view of what the critical enterprise is.

\section{Literary Criticism As Hermeneutics}

One of the central terms in Kurzweil's critical language is "values". There is, it is clear to him, a whole world of values outside of and around it that are reflected in and that impinge on the literary work itself. Considering the link he makes between philosophical anthropology (of which Scheler's in particular emphasizes man as a value-creating being) and art, it is hardly surprising that this is the aspect of literature on which kurzweil focuses a good part of his attention.

Kurzweil never articulates exactly what he means by "values". In general, though, the term as he uses it points back to the realms of the "true" and the "good" of which the "beautiful" ideally partakes.

In all true art the ethical, even the religious, is the soul of the esthetic, for no matter how apostatizing and rebelilious it is inform, its pulse can still be felt in the true esthetic. 
Values, therefore, are moral, religious and social categories, and if they were once absolutes--"Divinity alone can be the guarantor of absolute truth"--in the secularized world of the last two hundred years we can only speak of relative values. Still, "it is absurd to assume the existence of a reality entirely devoid of values". 48 This position agrees with that of Wellek who also stresses that

a work of art is a totality of values which do not adhere merely to the structure but constitute its very essence. All attempts to drain value from literature have failed and will faill because its very essence is value. Literary study cannot and must $49 \mathrm{t}$ be divorced from criticism, which is value judgment.

But whereas with Wellek we get the feeling that values, crucial as they are to literature, are an axiological construct, with Kurzweil, his own discursive treatment of the subject notwithstanding, they are a matter of deep personal concern, unashamedly espoused, in spite of the fact that by the late sixties he knew that he would be scorned as "old fashioned" by the younger Israeli critics who fiercely opposed any attempts to undermine the strict autonomy of the literary work. 50

Such a position would seem to necessitate examining the "what" of literature, its content only, leaving aside the formal aspects. Kurzweil regards this as an impossibility, as it negates the very nature of literature. Content only exists in the work to the extent that it is encased in form. Form and value are as inter-related as are content and value, and all three co-exist within a literary work. Hence not only is it impossible for criticism to concentrate on content alone but, Kurzweil concludes, all approaches that examine only form in its "purity" betray the very nature of form itself. 51 Again we see his deep-seated aversion to all "purity" that is antiseptically isolated from the ultimate questions of human reality. We may also note that by "form" Kurzweil means all aspects of the "how" of literature comprised by style and technique.

Now, since "the primary basis in the act of creating a work of art is the tension between the artist and the world", 52 and since the content and the form of the created work reflect values as artistic tension presents them, the subject and goal of literary criticism emerges: the world of values as communicated by the work of art or, to put it more accurately, by the form of the work of art. For, because of their inter-relationship, any changes in the perception of the world by the literary artist, that is, any shift in values, of necessity causes changes in his 
rendering of that perception, in the "how" of literature. "The concept of form has to be functional because it changes in accordance with the progressive alterations in man's Weltanschauung." 53 The larger task of the critic, then, is to examine the incessant shifts in the link between the work and the world. 54

All this is what Kurzweil means when he says that without values there can be neither literature nor criticism (i.e., literary evaluation), that "literary problems are much more than literary problems alone; otherwise they are not even literary problems". 55

Kurzweil's militant indictment of formalism and all critical methodologies that purport to treat poetic questions scientifically is ineluctable and now stands clearly visible. Those who deal only with the formal and structural elements of the work of art are guilty of reducing the dimensions of literature, of asking small questions of it, questions that, of necessity, will yield answers of comparable size.

Isolating the literary work, removing it from its world and from its intellectual, linguistic and social tradition is a hopeless and wilful act, the Eruit of a contumacious generation which parades its nakedness as the expensive finery of the very latest fashion. . . . From time immemorial poetry has been linked to the life of man, and the problem of man is its very soul. The human spirit is no more nourished by ${ }_{56}$ structuralist formulas than the body by a printed menu.

Professions that because of the spiritual crisis engulfing culture and the arts "literature desires nothing other than itself and has no reference to values of any sort" are nothing other than the suspicious modesty of a criticism that is satisfied "to detach every poem, every story fragment and certainly every work of fiction from its living link to the environment from which it sprang" and anatomize it methodically. 57

Moreover, the presumption that the dissection will be performed with scientific precision and will yield objectively valid results is totally repugnant to Kurzweil. All the remonstrations we have noted against historicism apply as well to the various attempts to establish an empirical, systematic method of arriving at the truth of literature. "Let it be noted, incidentally, that 'pure science' in the humanities is the kith and kin of 'pure poetry'; both dwell together at the threshold of nullity."58 Except that literature is, if possible, even more overtly antithetical to science than history.

The way of thought [of the sciences] is not the only way; there is another mode of thinking which is closer 
to [that of] poetry, religion and certain kinds of philosophy, all of 5 ghich are repulsive to [certain] types of scientists.

It is important to note, however, that this polemic against all formalist esthetics (not just Russian formalism or French structuralism, for example) was probably called forth by some specific developments within the field of criticism in Israel in the latter half of the sixties. The movement away from moral and ideological pre-occupations in criticism in favor of more "intrinsic" and inherently literary concerns, a movement which had occurred decades earlier in Europe and America, now began to stir in Israel. It is even possible to generalize, I think, that Kurzweil, having dominated Hebrew criticism for the previous quarter century, was a catalyst, or perhaps even the catalyst, for this shift. In a negative way we may gauge the strength of his influence precisely from the vigor with which the younger critics embraced the "new" methodologies of Benjamin Hrushovsky and his quarterly hasifrut. The positive result of this process, though, we may say, is that it forced kurzweil to produce such late statements as "Literary Evaluation and the world of values", "Between Anthropology and Literature", and "The Principles of Literary Interpretation", which are all prerequisites for digging out the roots of his critical theory, as this entire discussion testifies.

Nevertheless we ought not to lose sight of the fact that in its larger perspective Kurzweil's attack on the scientific aspirations of criticism (and, if I may so say it, the resultant antagonism, now more tacit than verbal, between the kurzweil "school" at Bar-Ilan and the Hrushovsky disciples at Tel Aviv and the Hebrew Universities) is simply modern Hebrew criticism's version of a long-standing and still ongoing debate among all critical theorists over the nature of literary study.

In one of the most revealing statements of his critical position, Kurzweil says:

I have no doubt that hermeneutics, that is the art of literary interpretation, which is always essentially understanding and not recognition, is the heart of literary scholarship. Recognition is characteristic of the exact sciences. Understanding is the foundation of the humanities.

How does the critic "understand", "interpret", and "evaluate"? How does he go about, as Kurzweil mandates him to, encountering the world out of which the work springs and to which it, however tenuously, has reference? 
Not, says Kurzweil, by imposing the facts or the methods of that world which lies beyond the work itself. Kurzweil repudiates what the practitioners of Geistesgeschichte do no less than he repudiates Marxist, Freudian or Jungian criticism.

Literary evaluation betrays itself when it overlooks the uniqueness of the artistic-esthetic phenomenon; it strays from its task completely when it reduces the literary text to a kind of laboratory for the testing of social, national, psychological, ideational, historic or biographical truths. Such elements are doubtless present in the literary work, but in and of themselves they do not comprise its distinctive essence and total value. [In the same way] the biased application of the historic-biographical approach, for example, or the method of reconstructing the experiential basis of poetry and literature precipitated an exaggeration of the opposite kind which separated, in an unnatural way, the literary work as a concrete esthetic phenomenon and its totality as a second [i.e., miniature] reality whigh always reflects the primary, external reality... .

In other words, Geistesgeschichte, psychologism and the other approaches that Wellek calls "extrinsic" are, in themselves, as inadequate to the critical task as are the "intrinsic" ones in themselves. What is wanted is an approach where the reader-critic puts everything else out of mind and encounters the text in its fullness as a "unique esthetic phenomenon". Kurzweil's terminology here is instructive. His description of the work as a "phenomenon" confirms the essentially Husserlian manner in which he relates to the literary text. The basis of Husserl's phenomenology is that it sought to gain an absolutely valid knowledge of things by suspending all pre-conceptions about them and putting all reality into brackets, as it were, so that the only manifestation of things that is given--their manifestation as phenomena--is confronted. 62 Kurzweil's emphasis on the distinctive nature of the literary work presupposes a radical taking into account of its genesis and ontological status. We are, then, led back to some of the concerns raised above, and here again Dilthey is a key figure. Dilthey's point that the methods of science are not appropriate to the humanities is to Kurzweil in dire need of reiteration, and so is the path Dilthey laid open to literary critics--hermeneutics.

We may put the matter thus: if Erlebnis is the source of a literary work, then hermeneutics is the method of receiving, reading, interpreting and evaluating that work. Just as the former is an ontological and not a psychological experience, so the latter is not an intellectual or an analytical operation but a response out of one's whole being. The terms which contain Dilthey's conceptualization of the hermeneutic process are 
Nacherleben and Verstehen. Palmer describes Verstehen as "the operation in which the mind grasps the 'mind' (Geist) of the other person". 63 There can be little question that Dilthey's Verstehen is what Kurzweil is referring to and openly advocating in the important passage I cited above. (p. 54 , bottom).

Poetic Erlebnis, for Dilthey, does not take place in a vacuum but in history, and the same is true of Verstehen. "Meaning always stands in a horizontal context that stretches into the past and into the future"; ${ }^{64}$ therefore meaning is created and understood from under a specific horizon. The consequent Geschichtlichkeit of literature allowed Dilthey to hope that through the hermeneutic process the critic would be able to arrive at "an objective relation between data (e.g. works of art) and the history of the human spirit". ${ }^{65}$ The literary work would thus be able to be seen as an individual manifestation of the socio-historical reality it reflected. A larger "hermeneutical circle" could thus be drawn between the work as the part and the age as a whole.

This idea was very quickly taken up by humanistic scholars in German universities in the decades following Dilthey's death--but in a way that Müller-Vollmer believes was completely untrue to what Dilthey himself intended. Of course, part of the reason for this is that Dilthey never wrote a complete treatment of any of the many subjects on which he wrote, and so his writings on literary theory, like everything else, exist only as "a grandiose collection of.. . fragments". ${ }^{66}$ The piecemeal manner in which his Gesammelte Schriften were put out (1913-1967) did not help either.

Muller-Vollmer suggests a deeper reason why Dilthey was misappropriated that is of interest here. In their attention to the parts, the nature of the whole--the philosophical basis underlying all Dilthey's work--was neglected by those who considered themselves his followers. I have already identified this basis as an adumbration of Husserl's phenomenology whereby Erlebnis and Verstehen must be seen to take place within the totality of a Gestalt that is formed by the artist, or the critic, before and beyond the traditional Cartesian dualism of the external world into subject and object. The literary work is seen as a total artistic structure composed of distinguishable elements of different strata, a view which Müller-Vollmer correctly says anticipates the phenomenological configuration later worked out by Husserl's pupil, Roman Ingarden. ${ }^{67}$ That is why in this view the dichotomy of literary study into "intrinsic" and "extrinsic" 
approaches "without a prior investigation of its position in and relationship to the world of human experience" is fallacious. 68 Moreover, Dilthey held no concept at all of "an all-powerful and ubiquitous spirit of the age" but instead was clear that "literary works do not derive their 'historical content' from the spirit of the age; it is rather through them and their creators that this spirit comes first into being". ${ }^{6}$ And "his [Dilthey's] own explicit warnings to apply the concept of 'world-view' with caution, if at all, to literature remained unheeded." 70

I dwell on these clarifications of Dilthey because they are, in a sense, a clarification of Kurzweil. Whatever else it is, hermeneutics is not Geistesgeschichte or the history of ideas but interpretation grounded in the concreteness of the literary text. This entire discussion, then, should shed light not only on Kurzweil's statement cited above but also on the following rejoinder he delivered to the ha-Sifrut coterie:
It is worth reminding these "innovators" of the work done from Dilthey and Schleiermacher through 19th century scholarship until Wolfgang Kayser, Staiger, Heidegger, Auerbach, Ingarden, Gadamer and others. And here in Israel also things have been done, especially in the most difficult domain of all, the domain of her- meneutic interpretation.

Kurzweil here leaves no doubt not only about whom he is talking but also about where he sees himself, correctly we are beginning to see, belonging as a critic.

criticism is a creative act and, therefore, true criticism can only flow from a deep love of the created work. It is a giving of one's total self to art. This means that art and its interests transcend even human relationships. As Kurzweil answered Ernst Simon:

\footnotetext{
Neither you nor I is of importance. . . important only is the work of art; we simply do not count. Only the [artistic] undertaking itself is of interest, and if it is [judged to be] superfluous, its sentence should be summarily pronounced with every legitimate weapon.
}

Should rational argument prove inadequate in serving art by exposing presumption, hollowness and falsehood, then the critic is certainly mandated to unsheath irony and satire and do the job with them.

In this way Kurzweil comes around, in spite of the very different philosophical base on which his criticism rests, to the same view of the critic as a custodian and shaper of society's values that animates the work of such Anglo-American figures as 
F. R. Leavis, Ivor Winters, Robert Penn Warren and Lionel Trilling.

Criticism, therefore, is at the same time both a static, conservative enterprise and a dynamic, revolutionary one. The critic "must preserve the eternal possessions of humankind, the moral values of the nation, from the din of political clamor", but he must also be resilient enough to be able to hear and identify new modes of artistic expression. It is just this dialectical nature of life that he must promulgate: that

revolution and a conservative traditionalism are not in contradiction. . . [but] appear as two vital sides of a larger, unified event--the human spirityin its faltering movement toward the wholeness of life.

But in doing all this the critic must have no illusion that he will succeed or that his influence will be very great. In the current crisis of culture he should not hold to a false optimism that parasitically lives off the future to pacify the furies of the present; let him rather be committed to the true optimism--a pessimism that hopes only for the least possible evil. ${ }^{74}$

such a stance clearly predicates the autonomy of criticism and, what is more, the strict independence of the critic from all "isms" be they political or philosophical.

Those who examine intellectual matters from under the secure shade of the political tree can be sure that whatever they discover will be affected by the kind of shade put forth by that particular tree. They forget that the tree is not the forest and that beyond its cover is a rich and variegated world, full of both light and shade. Sometimes the sheer fragrance of the tree is so intoxicating to those who sit under it that any new, strong scent different from the official, parochial one is considered putrid.

This statement has specific Israeli overtones, for until recently Israeli criticism was politicized to a much greater extent than in the United states. But the statement is valid as a general principle for Kurzweil: the subjectivity of criticism should not be dictated by mass or institutional criteria but by those determined by the free, responsible and sensitive individual.

This individualistic basis for criticism leads us to a final implication of the Kurzweilian view of criticism: it is inherently a lonely vocation. 76 The true critic shares the fate of the true poet or novelist; as Thomas Mann puts it, "having pledged his allegiance to the word, the artist cannot dissociate himself from a certain opposition to reality, to society, to life". 77 Even his bitterest enemies would not deny that Kurzweil attained to this. $\mathrm{His}$ utter isolation within the context of Israeli literary life, 
particularly in his last years, is manifest even now to anyone who studies the press and periodicals of the time.

Kurzweil himself probably viewed this with more equanimity. He might have regarded his marginal position as the fulfillment of the ideal Nietzsche set up for the critic. To Nietzsche, the critic

is not a skeptic but has "a certainty of standards, a conscious unity of method, sophisticated courage, loneliness, and the ability to account for himself". - . He teaches us to take time, to become quiet--to become slgy--as a goldsmith's art and connoiseurship of the word.

Kurzweil as a Phenomenological Critic

In the preface to his second book of collected essays, Sifrutenu hahadashah: hemshekh 0 mahapekha?, as in all the illuminating prefaces to all the volumes, Kurzweil tries to establish that which unifies the various essays:

This book comprises a summary of my ideas regarding the history of the problematics of modern Hebrew literature. For as long as I have been involved in literary research I have regarded historical-biographical discussions strictly as preparation for the main and decisive task of the scholar: the attempt to reveal the intrinsic coherence of the work of art, that is, to penetrate into its esthetic and intellectual experience. Since every true work of art is a phenomenal vision of a certain reality, it is perforce imbued, either knowingly or unwittingly, with problems characteristic of that reality which is disclosed. And since reality is not a stable construct but one that changes from period to period as each generation perceives it differently, so similarly do artistic presentation and depiction of it change in time.

The foregoing should sensitize us to the existence of a sub-stratum of literary theory that lies beneath these compact sentences. They ought to help prevent us from overlooking a fundamental principle of Kurzweil's criticism that is here only tacitly assumed: that the "intrinsic coherence of the work of art" is yielded only by the text of that work. If the "unique phenomenological essence" that is the literary work is to be "uncovered" or "penetrated into", the point of departure for these operations is the text itself. 80

What is of interest here is the sense of the term "intrinsic coherence" or "immanent coherence".81 It, too, is one of Kurzweil's most frequently used critical terms, and no under- 
standing of him can be complete without penetrating to its essence. Its implication is, if taken at face value, liable to mislead. Consider, for example, the following observation from Kurzweil's discussion of Bialik:

The preceding chapters of my treatment of Bialik have already posited a fundamentally new approach. . . . Our discussion of the personal poetry renders in an analytic-intuitive way all the traditional methods of explaining his poetry completely antiquated. our analysis obeys but one command: to be faithful to the intrinsic coherence of the poeftry, which appears to us as a living and whole organon.

Such a statement of critical principle has overtones that seem very similar, if not identical, to New Criticism as Tate or Ransom formulated it. Indeed, setting aside for now the suspicious juxtaposition of the terms "analytic-intuitive", it is hard to escape the conclusion, both from this passage and from much of the Kurzweil corpus, that in his asseveration of the organic nature of the literary work and of the primacy of the text itself Kurzweil is the "new critic" of modern Hebrew literature. 83

Nevertheless, I believe we err if we perceive Kurzweil in these terms and leave it at that. While it is more than likely that he was completely conversant with the methods of New Criticism, particularly with I. A. Richards, and while we cannot rule out its close attention to the text as one of the many influences on him, it is clear to me that ultimately kurzweil takes his stand in an approach that has some serious disagreements with Richards, namely that of phenomenological hermeneutics. For one thing, though hermeneutics agrees with New Criticism that the individual work must be the starting point of any literary analysis, it emphasizes the contextual relation of the parts to the whole, and it seeks to read the work in relation to the rest of the author's corpus. Second, there is a difference between the two approaches over the autonomy of the individual work in relation to everything around and outside it, i.e., the reader, the artist, the external world and values. 84

This dissimilarity relates to an underlying perceptual difference over the very "mode of existence" of the literary work. And this in turn flows from a fundamental difference in epistemology. 85

Oxenhandler has documented this in an excellent brief study of the varying philosophical foundations that underly American New Criticism and French phenomenological criticism. He notes that New Criticism, to the extent that it has worked out a clear 
philosophical basis in response to Ransom's call for ontological criticism, has done so largely in Aristotelian and Thomistic terms. Oxenhandler calls this basis "realism" 86 because it construes reality, i.e., the real world, as composed of nothing other than real objects. What energizes the work of such critics as Ransom, Tate, Wimsatt and Brooks is the perception of the literary work primarily as an object. That it is an object sui generis and how it attained this status are relatively unimportant considerations; what is important is precisely its existence as object with, like all objects, its own properties. In this case the properties are such concrete things as structure, images and symbols. The task of criticism is to see how the work is put together and held together, and that is why, to perform its task, New Criticism dissects the "verbal icon" with close, astute textual analysis that has no recourse to anything other than "the work itself". This is the only method that is adequate and faithful to the work as an autonomous object.

In phenomenological criticism the emphasis is on the work as an intentional work. It is a human creation to be interpreted and heard, not an object to be dissected and analyzed. Art is not so much craft as disclosure. ${ }^{87}$ This is because

For the phenomenological critics, the poem does not have an independent existence. It is simply part of consciousness; and in the measure that it appears to us, within consciousness, it has being--it is.

The critic's relationship to the text, then, is not as an "I" to an "It" but very much as an "I" to a "Thou", to put it in Buberian terms. The work

does not speak by being cut to pieces in order for the analytical reader to see how and why it is made as it is; one must enable a work to speak by knowing how to listen, both to what is spoken in the words ang 9 what is left unsaid but still present behind the words.

This means that what obtains between the critic and the text is no less important than that between the artist and the text. The distinctions between author, critic and text, so important to Anglo-American criticism are, to the phenomenological critic, "artificial and untenable", and "unverifiable within [t]his frame of reference". 90 In fact, criticism itself in this perspective is an unverifiable act. It strives not for a demonstrable, empirically arrived at explication, "the correct reading", but for a creative experience no less profound and engaged than that of the poet or novelist. Such criticism eschews "the heresy of 
paraphrase" no less strongly than New Criticism, but at the same time it unabashedly scorns the latter's pretensions at "objectivity". 91

I cannot maintain that Kurzweil carried out all his criticism with full consciousness of this epistemological differential. On the whole, though, it is within the cognitive structure of phenomenology that Kurzweil implicitly relates to the works he discusses. The emphasis on the "analytic-intuitive way" noted above $^{82}$ now comes to the fore. If the experience of the poet, while not identical with the poem, is nonetheless related to the poem, it can only be recovered by a subjective act of intuition. This is what Kurzweil means when he says that the real challenge of criticism is "to grapple with the demands of literary interpretation in the true sense of hermeneutics". 92

Intuition means subjectivity but, for kurzweil, it is the subjectivity borne of an attempt to penetrate to an objective knowledge of things. That is the whole point of the phenomenology that Husserl developed. Believing that Kant's hope of attaining to a knowledge of "the thing in itself" was still unrealized, and convinced that all we really have to go on are phenomena, Husserl tried to institute a method that would enable the Kantian dream to be fulfilled. All reality would be doubted, just as Descartes had begun; all metaphysical and other prior definitions and qualifications of the nature of things would be suspended; existence, in short, would be "put into parentheses"--until only the aspects of things that are perceived by consciousness, constituted "by consciousness, are true and immediately valid". In other words, reality is reduced to its most undeniable nucleus: the knower to pure consciousness ("transcendental subjectivity") and the known to its purified essence as intuited by the knower. ${ }^{93}$ Husser 1 speaks specifically of "the intuition of essences" (Wesenserschauung), 94 and it is highly likely that Kurzweil's use of the term "intuition" in his declarations of critical position connotes and implies the process of phenomenological reduction (Epoche).

The interesting feature of this method is its claim that such intuitive knowledge, subjective as it is, is at the same time objective, as objectively valid, in fact, as any cognition of the natural sciences. This claim is made not only by Husserl, who put forth phenomenology as a discipline of scientific rigor, but even by his pupil Heidegger and other followers who abandoned all scientific pretensions. 95 The knowledge is objective because things can only be known to the extent that they are intentionally constituted by consciousness. 
If an object is genuinely given as object, it is given as object for a subject; and thus the subject, too, is given; it is a datum of consciousness. Just as there is no consciousness (act of consciousness) without its objective reference, so there can be no object without its subjective reference.

Kurzweil knows this, which is why he both never denied the inherent subjectivity of his readings and at the same time resolutely proclaims them as a "penetration to the essence of the work". This is what he means when he says that it is possible to find no absolute "truth" in a text but rather "it is only possible to reach the maximum proximity to the inner truth of a text and no more". 97 Friedlander observes that in Kurzweilian criticism one "draws near to the work", one does not "master it", and on this basis he suggests that we must understand and appreciate the intellectual responsibility of Kurzweil's life-long practice of titling so many of his critical essays "Notes on . . ."98

Friedlander documents what Kurzweil was wont to say to his students: "The literary interpreter must enclose himself in parentheses and listen with maximum acuteness and alertness to the sounds that well up from the work." 99 The indispensibility of this basic methodological step--it is better described as a mental act--is repeated frequently throughout Kurzweil's writings. In reading Bialik's crucial poem "Metei midbar", for example, after all biographism and psychologism have been purged

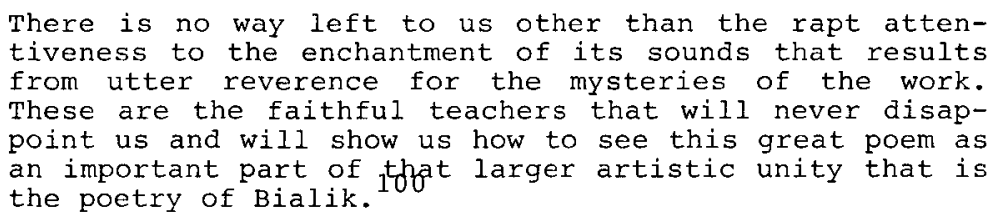

In this way the work is penetrated--not by brusquely pushing into it but by allowing it to disclose itself. Such "penetration" should be seen as Kurzweil's appropriation, in however inchoate a way, of the phenomenological reduction in which the irreducible essence of the work is intuited. It is in this framework, after the essence has been apprehended, that the "analysis" Kurzweil speaks of takes place. This involves the whole panoply of critical concerns: for theme and motif, style, image and symbol. Kurzweil examines them all. But in any case analysis is not done to carve up the work but to relate the elements investigated to the intuited essence. In this way is the "intrinsic coherence" of the work illuminated. 
The hermeneutic nature of this operation now becomes apparent. The mysterious process that is understanding comes about in the dialectical, circular way that schleiermacher described. The intuitive "grasp of the whole" throws light on the parts, yet we never really know the whole before we know the parts. An early aphorism of Schleiermacher states that understanding replicates precisely the way a child grasps the meaning of a new word: the sentence structure and the total context of meaning are the guides for the child and are the systems of interpretation for a general hermeneutics. 101

But for Kurzweil the boundaries of the "hermeneutical circle" are never circumscribed by the individual work under examination. The very end of the two sentences cited above about "Metei midbar" hints at this. ${ }^{99}$ Kurzweil, I have determined, is not a New critic.

Literary criticism [needs to] attain to that approach necessary for a true understanding of a work of art [by seeing it] within the totality of every great writer's work. . . that is, to see the individual artistic phenomenon also synoptigally in the context of the oeuvre in its wholeness.

This is a great methodological principle of all of Kurzweil's criticism. ${ }^{103}$ It is here enunciated in regard to Agnon but it is valid for every novelist and poet Kurzweil chooses to discuss. Just as the sefer hama'asim sheds light on the entire Agnon corpus, so the seemingly different "personal poems" of Bialik can and must be integrally related to the earlier "national" poems; and, in the same way, such disparate works of Tshernichovski as the sonnet cycle 'Al hadam and 'Ama dedahava can be shown to be parts of a larger whole.

Nor does the application of the principle stop here. "In grasping the artistic phenomenon, as in the apprehension of all the events of life, the Gestalt, holistic approach to things is

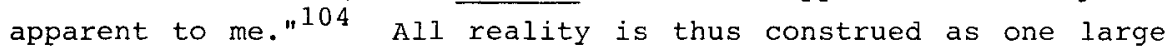
Gestalt. Therefore, what Kurzweil calls the individual figura, be it the image or symbol in a poem or a novel, be it the single poem, play or novel, or be it the entire corpus of the poet, playwright or the novelist--all cannot but be related to their context, to their cultural field, to the larger whole to which they belong, ${ }^{105}$ like the words of a sentence. Here we see, from another angle, why kurzweil feels that modern literature presages the decline of culture. In its increasing tendency to turn in upon itself, modern literature breaks down the distinction between individual image and the holistic background. ${ }^{106}$ It offers, in 
other words, no hermeneutic circle to the critic. Since it refers to nothing other than itself, culture and values have ceased to exist for it. Mallarmé has been corroborated: "The words are all there is", and a century later, art has actualized what Flaubert envisioned in his own Bouvard et Pecuchét: "Je prépare mon vommis sement."107

We have thus arrived at a determination of the rudiments of Kurzweil's attitude to the literary text and how he reads that text. Its hermeneutical as well as its phenomenological nature should be clear. The conjunction of the two in his criticism now enables me to state what I see lying at the heart of all of Kurzweil's work. The intuition that penetrates to the essence of a literary work, its transcendental reduction, is, because that work is part of a total culture, ipso facto identical with the intuition of the essence of the total culture, its transcendental reduction. Reality as a total Gestalt is in effect reduced phenomenologically, and its parts are all understood and interpreted in accordance with this reduction. The "intrinsic coherence" of a single work thus partakes of the "intrinsic coherence" of all culture. Here we may pull together virtually everything set forth in this chapter. Barukh Kurzweil intuited that the essence of man, as man, is to live as a created being in relation to the Absolute of a concerned God. Modernism in western culture, therefore, is essentially the crisis in belief and in values that the breakdown of this relationship has precipitated. A work of modern literature, for this reason, reduces itself to being or showing some aspect of this breakdown. These are the foundations of Kurzweil's critical monism.

To be sure, this approach to the literary text and the cultural theory that underlies it are not original with Kurzweil. They connect securely to the critical work of such European figures as Erich Auerbach, Nikolai Hartmann and the theoretical positions developed by Roman Ingarden and Hans-Georg Gadamer. Were I to pursue this matter in ever wider circles, I would be able to show broad resemblances between Kurzweil and a host of other kindred spirits in European criticism: Emil staiger and Max Kommerell; Georges Poulet, Gaston Bachelard, Sartre and other "critics of consciousness". This would run the risk, however, of obscuring Kurzweil's own uniqueness. The influences of the Israeli milieu in which he flourished as well as the Hebrew literary tradition in which he was so deeply involved must be regarded as decisjue in the shaping of this uniqueness. 
Now, if this is the cognitive structure within which his work takes place, it should be read and evaluated in the same context. This implies that we must learn to know quite precisely what to expect from such work, what kind of questions to ask of it and, conversely, what not to look for in it. Not having looked yet at the practical criticism, I can here state what the expectations and questions are only in general terms.

For one thing, we must be prepared not to be put off by the grandiosity of the claims Kurzweil makes.

With the bracketing or doubting of reality, the critic's language acquires a new mission. There is less need for the critic to be humble, since he is, in a very real sense, co-creator of the literary work. Phenomenological criticism : . . manifests a kjnd of Hegelian pride, a belief in its own omnipotence.

For this reason such ingredients of realistic cognition as meticulous research, elaborate documentation, analytical footnotes are all outside the purview of such criticism. One looks in vain for them in Kurzweil. Rigor is an aspect of passion, not vice versa. This is something that very few of Kurzweil's critics understood.

More importantly, it is quite beside the point to accuse Kurzweil, as many do, of ignoring the text, of not getting "the correct reading", or of not analyzing the literary object. For Kurzweil there is no object to analyze, no distinct "correct reading" to get; there is only knowing how to "read correctly". Like Gadamer, he "is concerned not so much with understanding more correctly (and thus with providing norms for valid interpretation) as with understanding more deeply, more truly."109 I would add "more authentically". Criticism as hermeneutics is, for Kurzweil, not "the logic of validation" but a "theory of understanding". 110 Its energy is directed at providing not the "truth to reality" but "truth about reality". 111

This being the case, the limitations of this approach, what it cannot do, are now properly seen. The basic problem is one not of validity--that is now construed in existential terms--but of verification. This is the fundamental weakness of all phenomenology. "Transcendental subjectivity" comes perilously close to "transcendental solipsism".112 What guarantee is there that the essence of a work as intuited by one critic, however supervised he may be by thorough training and wide reading in the humanities and social sciences, will be the same as that intuited by his equally responsible and experienced counterpart? It is as impossible to achieve an analysis "free from suppositions", as Husserl had hoped, as it is to put the world (including oneself as critic) 
into parentheses as one confronts that world's other beings and things (including a literary text). When all is said and done, in literary criticism as well,

the phenomenological method .. . is not one of "proof"; rather it is one of description, wherein it is hoped that others will see things the same way-iknowing subjectively that they are wrong if they do not.

The only possible basis for verification--and it is a dubious one for criticism--is a replication of the same reductive process within the framework of the phenomenological method. We can appreciate the claim of Eugen Fink, who Husserl himself regarded as among his best interpreters, that "it is impossible to understand what phenomenology is without being oneself a phenomenologist". 114

This is hardly to suggest that the results of such criticism, Kurzweil's in particular, are to be dismissed out of hand. What they might mean and what this body of criticism "accomplishes" I shall be better able to speak of only at the end of these deliberations. 

CHAPTER V

KURZWEIL ON MODERN HEBREW LITERATURE:

I - THEORETICAL STRUCTURE

Kurzweil's work on modern Hebrew literature represents the synthesis and fruition of all the strands of his thought and method. Here we find a theoretical as well as a practical fullness lacking in the criticism of European literature. There is a much more carefully worked out conception of Hebrew literature as a national literature and greater attention is paid to individual figures and their specific works.

Indeed, I have so anatomized the Kurzweilian approach and framework that we may properly regard all the preceding chapters as an extended introduction to his criticism of modern Hebrew literature. The denotations of this oft-used term "modern Hebrew literature" are now quite evident. "Modern" for Kurzweil means specifically the loss of religious faith in the transition from the integral past to the fragmented present; "literature" refers to the esthetic response of man-as-artist or artist-as-man to the uncertainty and chaos that swirl around him; and "Hebrew" implies a linguistic tradition rooted in a sacred world-view. In a sense it is the relation of this latter element, Hebrew, to the other two that Kurzweil seeks to achieve. Is "modern Hebrew Iiterature" modern literature written in Hebrew or is it Hebrew literature written in the modern mode? Or, to put it in Kurzweil's own terms, does modern Hebrew literature represent a "continuity" of past Jewish culture or is it a "revolt" against it?

Kurzweil's notion of the impossibility of tragedy in the Biblical world hints at a larger network of ideas about the sacred and the secular as they pertain to art. There is a basic distinction here between sacral and secular art. The important point about this distinction is that it refers not to a difference in subject matter but in the world-view that energizes these respective esthetic manifestations. Thus, paradoxically,

sacral art does not know religion as a subject because its entire reality and world is--holiness. The religious subject [i.e., theme?] as one subject among others is the distinctive feature of secular art, of fictionalized art which springs out of an autonomous world.

Undergirding all this are the metaphysical postulates Kurzweil holds about Hebrew as a sacred tongue and Jewish polity as a 
sacred category. It is the connections between these postulates and modern Hebrew literature that I propose to illuminate here, for they lie at the heart of Kurzweil's contribution.

It should, however, be quite clear that the value of this contribution is not its originality. The ontological status of the Jewish people, their culture and their language is a given in classical Jewish theology, and secularism as the hallmark of modernity is widely recognized. Rather, it is the application of this given and this recognition to belles lettres created by Jews in Hebrew in the last century and a half that is Kurzweil's achievement. As Barzel has astutely observed:

Actually it can be said that intellectual life is propelled forward precisely by proponents of one principle, who confront every thinking person with their root idea. The idea itself need not even be new. In the last analysis Marx did not invent the notion of the material, Freud eros, and Bergson intuition. Hillel the Elder did not discover the principle "What is hateful to you do not do to your fellow-man" and Rabbi Akiva did not formulate the dictum "Love your neighbor as yourself."

Application is the key.

In order more fully to understand and appreciate what Kurzweil sought to do as he developed his theory of modern Hebrew literature, it is first necessary to survey, however cursorily, the state of critical thought up to and including his time.

\section{Other Conceptions of Modern Hebrew Literature}

The two most influential histories of modern Hebrew literature, those of Lachower and Klausner, are in agreement on what this literature is and when it can be said to have begun. In their wake one finds not so much differing opinions as refinements and developments of their views. Both Lachower and Klausner focus their histories on Hebrew literature as it began to be written in Europe in the eighteenth century. Lachower starts in the second quarter of that century with Moshe Hayim Luzzatto, who he sees as the spiritual descendent of the Italian Hebrew humanists of the sixteenth century. ${ }^{3}$ Klausner, however, begins with the German Haskalah of the latter half of the eighteenth century, specifically with Wessely. ${ }^{4}$ The recognition implicit in both treatments is that these are the respective points at which the "new spirit" enters Hebrew literary creativity. 5 Both Lachower and klausner specify "secularism" as the distinctive feature of this creativity, ${ }^{6}$ but neither one develops this into an explicit literary 
norm. What "secularism" is and how modern Hebrew literature is related to the Hebraic literary tradition of the past we are not told by either Lachower or Klausner.

In any case, both include the philosophical literature of the Wissenschaft des Judentums along with belles lettres within the purview of modern Hebrew literature. Inasmuch as the purpose of this literature, as Klausner sees it, was to "enlighten" the Jews, such philosophical works are, in his opinion, an integral part of it, since they, too, were written to propagate Enlightenment ideals. ${ }^{7}$

The two differ in their periodization. Lachower begins with a geographical-chronological scheme but shifts to a more conceptual one. Whereas the first two volumes of his history deal with Hebrew literature "From the Growth of the New Literature in Italy Until the Decline of the Haskalah in the West" and "From the Early Days of the Haskalah in the East Until the Close of the Haskalah Period," the third volume covers the period "From the Awakening of the Jewish National Ideal Until our Own Times." Klausner super-imposes more literary categories on those of time and place, but he is only willing to offer a configuration of the century of Haskalah literature. This he divides into three periods: the rationalistic, when the German Enlightenment was defended against the attack of the Traditionalists (1781-1830); the romantic, when religion and the Enlightenment were reconciled in Galicia (1830-1860); and the realistic, when the Enlightenment went on the offensive against religion in Russia and Poland (1860-1881). Though periodization is, to be sure, a highly problematical matter, and is a function of one's conception of the nature of the literature itself, a detailed discussion of these schemes is beyond the scope of my concern here. Suffice it to note spicehandler's comment that

the schemes of Klausner and Lachower are faulty because they treat early modern Hebrew literature as a mature literature when in reality it possessed little esthetic value prior to 1881 .

The most important alternative definition of Hebrew literature is that of Dov Sadan. Sadan holds to a catholic, inclusivistic view whereby modern Hebrew literature is seen to embody the totality of literary creativity in that language in the last three centuries. He includes, besides belles lettres, all Hassidic and Mitnagdic writings. In fact, sadan's literary holism brings him to consider together everything of Jewish content and concern written by Jews not only in Hebrew but in Yiddish, Ladino and 
various European languages. Sadan, too, notes secularism as the distinguishing feature of much of this literature, but he is more interested in its underlying unity. ${ }^{9}$ unlike most of his critical counterparts, Sadan is much less exercised by the literature of the Haskalah. It is simply one aspect, the "conscious" aspect, of a new development in Jewish life; underneath the "sub-conscious" well-springs of normative Jewish creativity continue to flow, as the rabbinic and other non-imaginative writing indicates. ${ }^{10}$

Now in regard to the terminus a guo of Jewish modernism, the opposing view to those who locate this in the eighteenth century Enlightenment is held by those who follow Gershom scholem in regarding the sabbatian heresy and the movement it engendered as the first stirrings of the challenge to the Jewish past. ${ }^{11}$ Jewish modernism is thus pushed back to the seventeenth century and, more importantly, is now seen to be a development indigenous to the Jews rather than a response to external influences from European culture. In terms of modern Hebrew literature this view is of importance for two critics, H. N. Schapira and simon Halkin.

Schapira uses it to buttress his contention that modern Hebrew literature is an "organic link" in the unbroken chain of Jewish culture, and is but a manifestation of an age-old tendency in Jewish life to affirm the concrete reality of the terrestrial world over the etherealized reality of the spiritual world. What is more, Schapira holds that such literature affirms this new reality as it is expressed in the collentive Jewish will, whereas the old reality was lived out solely on the basis of an impotent individualism. Such generalizations come from Schapira's notion that all Jewish history is a dialectic between these two sets of antithetical forces. Modernism for him begins when Jewish landlessness and spirituality reached their nadir after the expulsion from spain in 1492 and the pendulum began to swing back toward the earthly, toward concern for corporate Jewish existence rooted in territorial realities. ${ }^{12}$ The sabbatian heresy thus signifies a powerful impetus toward and an indicator of the new direction. The Haskalah, the literature of which is his main interest, represents an intensification of the process, but not its culmination--that schapira sees in the zionist movement. What triumphs in the latter half of the eighteenth century, then, is not secularism--religious and secular elements were, in his view, always inter-woven in Jewish Iife and literature--but the impulse to the terrestrial. In other words, Schapira subordinates the secularism that Klausner sees as the distinctive feature of the new Hebrew literature to his own notion of the "terral", which in 
the Haskalah is not a novum but a recurrence. What is new for Schapira in the Haskalah, what was taken in from the outside, is rationalistic empiricism. 13

Accordingly, the periodization that Schapira embraces is keyed to the organizing principle that he sees within the process of Jewish modernism. He rejects the categories of Lachower and Klausner and, in tones reminiscent of Kurzweil, inveighs against purely esthetic criteria: Hebrew literature must be connected to Jewish life, and its periods must be related to historical developments. ${ }^{14}$ Schapira comes to discern three general stages of modern Hebrew literature about which he, by his own admission, is imprecise in regard to dates. The Haskalah period marks the phase at which "terralism" became the predominant force in Jewish life, and it runs from the first issue of haMe'asef (1784) until the eighteen-eighties. The period of Shivat Tsion that follows shows the gradual transition from "terralism" as an idea and a force into the reality of political zionism, and this period ends with the institutionalization of this reality in the Balfour Declaration of 1917. The third phase is the Erets Yisrael period and it lasts until the present (1940).15

Simon Halkin's views are in general similar to those of Schapira. While he does not purport to write a literary history, and while he is clear that "modern Hebrew literature is the product of the last two hundred years of Jewish life," Halkin nevertheless, like Schapira, finds in the Sabbatian movement as Scholem has depicted it, the precursor of the "hunger for a fuller human life in the heart of the simple Jewish folk" that animates modern Hebrew literature from its beginnings. ${ }^{16}$ But is is hard to find an overall, clearly defined idea of Hebrew literature in Halkin, for he touches all the bases without indicating what he thinks is primary and what of secondary importance. Sociological insights and historical events that have shaped the modern Jew are adduced in the same way as interior developments within the Jewish soul. Halkin is certainly alive to the larger questions posed by "the disharmonies in modern Hebrew literature.. . between this new body of Hebrew letters, mainly secular in character, and the religious Jewish folk life from which it sprang," but, outside of the tacit assumptions of normative political zionism, I do not see any particular critical or otherwise esthetic perspective that he brings to bear on these questions that I might note here. 17

The only other view of modern Hebrew literature immediately relevant is that of Avraham Kariv. His approach is not one that seeks to apprehend this literature in terms of its modernism or 
out of any esthetic categories. Kariv's focal point is the direction of Jewish national life. He mystically postulates a "spirit of the people" that includes its "eternality". He speaks of a "secret" in the depths of its existence. This has all the trappings of a religious postulate except that Kariv does not identify relifion per se as the subject for Hebrew literature. Still, his position leads to a sharp critique of modern Hebrew literature: it has presented only the surfaces of Jewish life, and has done so in a wholly negative way, and so it has ignored the depths. This literature has, therefore, contributed nothing to the advancement of Jewish national life and it must be rejected. Kariv evidences a familiarity with and a cultural outlook similar to what one finds in Russian literature. He cites Dostoevski and Blok as examples of artists who loved their people and so were capable of evoking its luminous and its simple human aspects in addition to the dark and despicable. But such Hebrew writers as Y. I. Gordon, Mendele and Brenner knew only how to satirize the foibles of their people; to treat literarily, for example, its martyrology, he charges, is beyond their capabilities. We may regard this unsparing judgment as Kariv's particular appropriation of secularism as the salient feature of modern Hebrew literature but his critique also implies a repudiation of normative zionism's notion of shelilat hagalut ("negation of Diaspora"). Running through all Kariv's criticism is the distinction between the sacred Hebrew writings of the Jewish past and the modern Hebrew literature that he describes as "the fruit of a Jewish decadence that has overtaken us", "a self-hate" that has resulted from a casting of of the ancestral past. 18

Kurzweil's theory and criticism of modern Hebrew literature must be seen to be variously shaped by and related to all six of the above figures. He takes account of all of them, taking certain elements from each and developing them, while rejecting others.

The case of Sadan is clear. Kurzweil is emphatic that Hebrew belles lettres as an esthetic category need to be separated from other kinds of non-imaginative literature and dealt with on their own terms.

It appears to me that sadan's approach has no support, for it completely ignores the methodical need to define the limits of one's scientific [sic!] discipline. It is convenient for sadan to set himself up as [the epitome of] associative omnipotence who can thus hover above and beyond the root problem [of modern Hebrew literature]. 
Indeed, he gives the impression not only of being at home in all the literatures in which Jews have ever had a shareg but also of being the owner of the home itself.

on the other hand, Kurzweil does not deny the validity of looking for the Jewish problematic in other languages besides Hebrew. He does just this in his comparative study of Brenner, Weininger, Kafka and Kraus, 20 and in his uncovering thematic similarities between Bialik and Kafka. 21

A selective eclecticism of a similar sort obtains with respect to Kariv. As Hebrew critics the two are remarkably similar, as Kurzweil himself understood, except that what Kariv calls "the spirit of the people" Kurzweil identifies as Jewish religious faith and practice, which he puts forth as a more concrete, objectively usable cultural criterion. ${ }^{2}$ The chief distinction between them lies in the willingness of each to grant esthetic value to modern Hebrew literature. Bakon puts it well:

Kurzweil departs from literature in order to return to it; literature is the necessary ground of his discussion. Kariv, however, comes to literature from life and then returns 3 to life in order to draw conclusions about literature.

Kurzweil finds in Kariv the very inadequacies that others find in him (i.e., Kurzweil). Kariv's value judgments cause him to miss the art in certain writers, e.g., Mendele and Brenner; on Y. L. Gordon's position as an inferior poet they are apparently agreed. Kurzweil feels that Kariv would deny the historical dimension of Jewish existence, for the logical outcome of his approach would have to be a denial of the modern secular Jewish state, to which Kurzweil knows Kariv really will not agree and which he himself certainly refuses to do. Most interestingly it is Kariv he sees as forgetting that the clock of history cannot be turned back! But what he openly says he took from Kariv is the latter's distinction between sacral and secular literature, a distinction he notes as instrumental in forcing the necessary revision in the reading of modern Hebrew literature. 24

The revision Kurzweil has in mind is that which challenged the accepted view that modern Hebrew literature is a "literature of revival" that parallels and reflects the reawakening of Jewish national ideals. Seeing the juxtaposition of Sadan, Kariv and Kurzweil we can understand why Kremer groups the three together in his outline of modern Hebrew criticism. All three, in his view, collectively brought about a second revision in the theory of modern Hebrew literature by judging it not on the basis of the 
individual work but in the light of the total Hebrew literary tradition. ${ }^{25}$ All three, I would add, implicitly or explicitly follow Klausner and Lachower in regarding secularism as the dominant value of the new Hebrew literature. As sha'anan points out, "the argument begins with the clarification of the nature of the secularism." 26 Sadan sees it as only one aspect of Hebrew letters and is in the long run satisfied that there are other aspects to be studied also. Kariv sees it as the betrayal of the Hebraic spirit and is ultimately content to dismiss all the Hebrew literature in which it is manifested. Only Kurzweil sees this secularism as more than a surface phenomenon, a mere "topic" for literature, but as an all-pervasive new content of consciousness which transforms human life and values.

The secularism of modern Hebrew literature is a given in that it is for the most part the outgrowth of a spiritual world divested of the primordial certainty in a sacral foundation that enyelopes all the events of life and measures their value.

Modern Hebrew literature is thus seen as a radical break with the Jewish past and not a continuation of it, and for this reason Kurzweil, unlike sadan, is deeply troubled by it. But because it is literature--and here we do well to recall the details of Kurzweil's poetics-it cannot be merely condemned as Kariv condemns it but read correctly and contemplated, especially so because the secularism and the human condition it reflects are but the Jewish expression of a general human problematic. Accordingly, Kurzweil is satisfied only to track the process of secularism as he understands it by examining its concretizations in modern Hebrew belles lettres, and thus to expose the hollowness and self-deception of seeing it as a "revival" or a "continuity".

In general terms, then, I believe we can see Kurzweil as adding to the foundation laid by klausner and Lachower. ${ }^{28}$ This perception of him allows us now to understand in a new way his extended polemic against Gershom scholem and to regard it as an integral part of his literary work. Just as Klausner and Lachower included the Wissenschaft figures within the scope of their work, so does Kurzweil see fit to treat in his own way the leading representative of that approach of his time. Finally, his acceptance of Klausner's view of the European Enlightenment as the source for Jewish modernism necessitates his disputing the approach of Schapira and Halkin. 
The European Context of Modern Hebrew Literature

If Klausner and Lachower treated the Haskalah in the historical-biographical terms of nineteenth century criticism, Kurzweil does so in terms of the phenomenological hermeneutics of the twentieth that I have discussed. Modernism is for him a general cultural phenomenon the essence of which is quite familiar to us by now. What I want to show now is how Kurzweil sees modernism operating on the Jews in particular and why he feels it was so especially traumatic to them. 29

The decisive difference between the nations of Europe and the Jews as they experienced the dynamic of modernism lies in the place of religion in their respective cultures. In christian Europe religion was not the sole component of culture and when it declined that culture had other value structures to fall back on, specifically those of secular humanism and nationalism. When an Englishman, a Frenchman or a German lost his faith, his own existence gua Englishman, Frenchman or German was still unimperilled and had by no means lost its raison d'etre. A secular Iiterature was possible in such languages, for

the absence of belief in God did not precipitate in
world literature the same changes and mutations it did
in modern Hebrew literature, for the simple reason that
Jewish existence is linked to religion in a completely
different way than is the existence of all the other
nations. Already in the first half of the eighteenth
century Being without God was a basic pre-supposition of
a large part of European literature without this shift
causing such a profound shock in the conception of life,
suffering and existence in general. The bulk of the
culture of the nations of Europe was already then
secular and they lived on their land and in their
states. In other words, their existence was not absurd.
With the Jewish people the situation is different. And
so there are certainly distinctive, different and
fateful implications for modern Hebrew literafure of
this process of the rupture of religious faith.

Indeed it is in theory well-nigh impossible to create a Hebrew literature reflecting the new consciousness inasmuch as the language only operated in the sacral sphere of the synagogue and Bet Midrash. 31 This sacral sphere and sacral world-view infused and structured Jewish life as long as the Jews were insulated politically and sociologically within the Ghetto. When, however, the barriers between Jews and Gentiles were broken down; the moment the Jew came into unconditional, unrestricted contact with the outside world and imbibed the Enlightenment ideals then in play, at that moment his religious faith began to crumble and 
Jewish modernism began. For Kurzweil this decisive moment can only be the end of the eighteenth century.

In reaching this analysis Kurzweil was guided not only by his own understanding of European and Jewish life and history but by the important work of Max Wiener, Jüdische Religion in Zeitalter der Emanzipation. ${ }^{32}$ wiener's achievement is that he deals with the Emancipation not in terms of what it meant for Jews externally--such historical studies have been done in abundance ${ }^{33}$--but what these cataclysmic changes in their external lives did to them internally.

\begin{abstract}
Here the focus will be concentrated on the Jewish religion. The fact that this religion is inter-woven into the external aspects of the generations of the Emancipation, into the political, social and economic history of the period, will certainly prevent [us] from constructing . . a thought-world removed from concrete realities. . . [But] even after taking these factors into consideration, it is worth attempting to draw a picture of how the Jewish spirit saw itself from within, out of the context of its religious life.
\end{abstract}

Wiener's conclusions are confirmed for Kurzweil from another quarter, Natan Rotenstreich's authoritative study Jewish Philosophy in Modern Times From Mendelsohn to Rosenzweig. ${ }^{35}$ The "transvaluation of values" within European Jewry came not with Berditchevski at the end of the nineteenth century but a century earlier with the haskalah. What before had been absolute was now relativized and the fateful dichotomy between "religion" and "life" was now in evidence. Kurzweil is clear that such a process could only have come from outside the Jewish sphere since internal Jewish values were unambiguous and all-embracing.

From this position Kurzweil is able to discern the claim of Scholem that the Sabbatian movement is the watershed of Jewish modernism as erroneous and tendentious. Scholem's error is that he exaggerates the importance of an exotic, transient event in Jewish history and over-estimates its historiographic weight. The fact is that

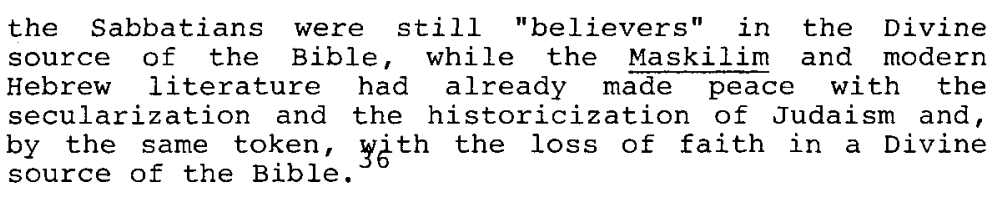

The real meaning of the Sabbatian movement for Kurzweil is its attempt to throw off the rationalizing influence of halakhic norms in favor of an ecstatic return to the instinct and myth of pre-culture, and he cites Huizinga's observation that "when Mythos 
triumphs over Logos, barbarization enters."37 The sabbatian heresy is thus testimony to a sickness in Judaism, but it is a sickness from which it recovered, for sabbatianism and the later Frankism never really took permanent hold over the Jews. Furthermore Kurzweil points to the conspicuous lack of any documentary evidence in the rationalistically-oriented literature of the Haskalah of influence of the mystical sabbatianism. There is, however, a great deal of evidence of the influence of such Enlightenment figures as Lessing, Herder, Schiller, Kant and Hegel. 38 The two most revealing autobiographies of the period, those of Solomon Maimon and Moshe Leib Lilienblum, show no traces whatsoever of Sabbatianism, and Kurzweil concludes

A meticulous examination of the text allows us to observe the causes that precipitated the collapse of the world of traditional Judaism. The spiritual impetus came to Lilienblum as to all the Maskilim entigrely from the outside--from the European Enlightenment.

The rejection of the approaches of Schapira and Halkin follows directly. In that both of them follow scholem's historiography in their approach to Haskalah literature, both are accused of failing to comprehend fully the significance of the new secularism as a radical discontinuity with the Jewish past. Schapira's attempt to impose the dialectic of "terralism" versus spirituality on all Jewish history is shown to be a wilful construction which ends up in a confused, self-contradictory view of modern Hebrew literature as an undeniable break with the past but really of a piece with it. Such a view for Kurzweil is in the final analysis meaningless. ${ }^{40}$ similarly, Halkin makes the same mistake of seeing secularism as only a matter of surface detail:

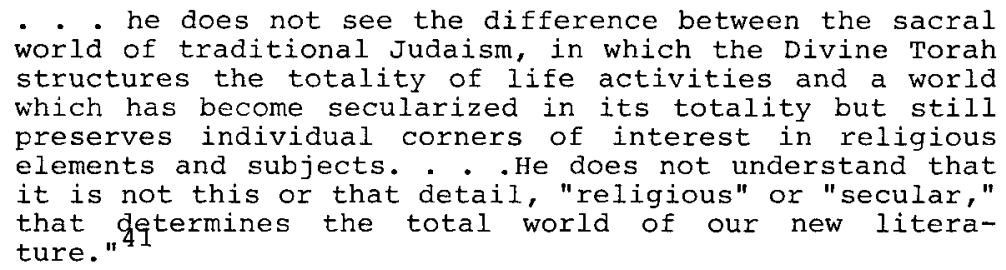

The real motivation of Scholem, Schapira and Halkin in Kurzweil's view has nothing to do with modern Hebrew literature as such. It is rather to serve the interests of Jewish nationalism. In according Sabbatianism the significance they do, the Haskalah, modern Hebrew literature and the zionist movement can be proclaimed not as the unprecedented revolutionary developments they are but as organic links in a process that arose from within 
Judaism. In this way is Jewish secularism legitimized as the natural, inexorable and lawful heir of Jewish history and polity, when in fact it is a negation of them. This is essentially the same critique levelled against Ahad ha-Am. But with Scholem the redemptive pretensions of secular zionism, which are daring and dangerous, are made to seem less so when they are presented as the resumption of forces that asserted themselves ir. the Sabbatian and Frankist movements, and the same is true of the antinomian thrust of secular zionism. 42 Here all that I have noted earlier about Kurzweil's opposition to zionism in its purely secular form comes into play. Kurzweil plainly accepts Yitshak Breuer's views on this matter; "the most profound analysis of secular Jewish nationalism is to be found in Yitshak Breuer's excellent and important book, Judenproblem." 43 The question posed by the title Modern Hebrew Literature: Continuity or Revolt? is rhetorical. It is not that Kurzweil denies the material reality of the biological continuity of the Jewish people or the formal similarity between modern and classical Hebrew; he is simply unimpressed by these things. ${ }^{44}$ This elemental fact was lost on those who attacked Kurzweil's view of modern Hebrew literature out of a secular zionist stance.

I pass over for now the larger questions posed by this view. Suffice it to note that it rests on a number of assumptions and articles of faith about the Jews and Judaism which I have already described. Beyond this I think it is possible to find in the Kurzweil-Scholem argument over the genesis and nature of Jewish modernism a tacit debate over the venerable question of just what is a literary and a cultural influence. Kurzweil seems to admit only that which can be documented and, in taking this position, stands on solid critical ground. On the other hand, if there are subtler, non-literary aspects to be taken into account when determining influence, then scholem is surely to be credited with doing something more than serving partisan zionist causes in his interpretation of the sabbatian movement. 45

The Paradox Inherent in Modern Hebrew Literature

Now in seeing the development of modern Hebrew literature in this way, Kurzweil comes to posit a paradox--what he will call a tragic paradox--at its root. The paradox runs through the entire literature and is manifest in one way or another in virtually every one of its works. Let us see how Kurzweil arrives at such a sweeping claim. 
It is clear, on the one hand, that in beginning when and where it did, modern Hebrew literature is very much a European development. A good share of its attitudes and values are those of the European Enlightenment. If the creators of the new Hebrew literature perceived Jewishness in nationalistic and not, as did the early wissenschaft figures, in religious terms, this was already a nationalism of a secular European nature. ${ }^{46}$ Further, if in this literature a rationalistic, sceptical approach to religion and the Bible co-exists dialectically with a Romantic attitude to the Jewish past--Kurzweil is insistent that it is a distortion of the nature of modern Hebrew literature to separate the two elements chronologically as Klausner and sha'anan do--in any case both rationalism and Romanticism pre-suppose a dislocation from "naive" pristine religious faith. 47

on the other hand, until the end of the eighteenth century, Jewish peoplehood and its culture were inherently grounded in religious faith. There was no available source for Hebrew literary creativity and cultural values other than the Bible and the religious tradition it engendered. When the force of the Emancipation hit, the shock was greatest in Eastern Europe, where the distance between the Jews and Gentiles had always been greater than in the west and, consequently, the hegemony of the sacral world-view had been unchallenged. And the new Hebrew literature arose precisely in Eastern Europe. 48

Hence the paradox at the heart of this literature:

This dialectical tension constitutes the tragic element of our literature. It is the fruit of the historic paradox that just at the moment when religious certainty ceases to be its most sublime asset, this people identifies with its past and affirms the priority of its essence--even as it is no longer able to live this past and this essence according to the accepted categories. For this reason the people gropes out of its own will-to-live toward a past that now requires a new understanding and explanation. This task, Herculean and tragic, is an almost super-human one.

A number of implications flow from this paradox, and Kurzweil seemingly never tires of re-formulating them throughout his career. They are, in a sense, permutations of the central thesis, appositive conclusions held applicable to the entire body of modern Hebrew literature throughout the course of its development. For one thing, the paradox generates the grand theme, the central problematic of modern Hebrew literature: religious faith and its diminution in general, Judaism and its tradition in particular. Intellectually and spiritually these were the core issues for the 
Jewish intelligentsia in Eastern Europe; one hundred and fifty years later they are still the core issues for their successors in Israel. Kurzweil emphasizes that this is not a subjective judgment but an objective fact. It is, we might say, the "transcendental reduction" he performed on modern Hebrew literature.

To the extent that every literature worthy of the name is a testimony and a revelation of the spiritual destiny intrinsic to the nation in the name of which it speaks--and any literature which is not can at best be nothing more than formalistic acrobatics, purely esthetic-- [to that extent] is nothing else possible other than what we have proved about our literature.

This does not mean that modern Hebrew literature is forced to "be religious" and must approximate religious content. On the contrary, a distinction must be made between a religious literature and a literature about the religious problem. Modern, secular Hebrew literature is the latter. 51 It is not subject that is important but attitude and treatment. Hazaz and Tshernichovski are as much concerned with the problem of "religious perdition" as are Agnon and Bialik. They differ only in regard to their attitude to the sacral Jewish past and its tradition. Kurzweil comes to discern two opposing streams in modern Hebrew literature: those poets and prose writers who in principle accept the primacy of tradition in defining the Jewish "national purpose" and who long for it when it is gone (e.g., Feierberg, Bialik, Agnon, Lamdan, Peretz and Greenberg); and those who blithely reject tradition and search for new definitions of "national purpose" (e.g., Gordon, Berditchevski, Brenner, early Tshernichovski, Schneour and Hazaz). In all cases, though, there is a struggle to re-acquire a certainty that has been lost--that is Kurzweil's essential point. 52

The paradox can, therefore, be re-stated in terms of its implications for literary creativity. An artist who designs to write in Hebrew in the modern period rightfully can and must relate to the sacral literature of the past as his legitimate, exclusive and treasured cultural possession. But at the same time, because it is a sacral literature, it must of necessity constitute a problem for him. The authentic Hebrew artist will realize and act on both these imperatives in his writing. He can do no other, and when he does he is both fooling and denying himself. The "national truth", as yalakov steinberg noted, is "enshrined" in the twenty-four ancient books of the Bible, but it is as impossible to ignore this fact as it is to pretend that the Biblical world is coeval with the modern one. ${ }^{53}$. That is why the 
paradox is both inescapable and tragic. It is this point that informs Kurzweil's negative appraisal of the younger sabra writers.

The ludicrousness of the conventional definition of modern Hebrew Iiterature as one of "revival" or "redemption" is, from Kurzweil's viewpoint now apparent.

What . . most people in the zionist movement call national "revival" is a secular process through and through which logically gave birth to a secular state, between which state and the belief-world of Judaism an absolute distinction must be made. ${ }^{5}$

Lastly, the paradox has implications, beyond those for the literature and its creators, for the critics, too. It leads Kurzweil to the conclusion that modern Hebrew literature cannot be read simply out of the canons of "American New Criticism". 55

The Crisis of Language

I have already shown how Kurzweil follows Heidegger in holding that language flows from Being. The ontological status of the Hebrew language necessitates that it is rooted in the sacral sphere and, in line with Rosenzweig, in the meta-historical realm. For this reason Kurzweil, as his treatment of modern Hebrew literature progresses, is increasingly attentive to the way in which the tragic paradox manifests itself in language.

The transition from a literature that was for the most part sacral into a modern one, secular in nature, occurs with such rapidity that it leaves the language no alternative other than to be used as a general metaphorical discourse. All the meanings of words, images and similies continuously change.

Kurzweil seeks to trace the trajectory of this process from the earliest texts of the Haskalah until the most recent Israeli literature. In this way can the full effects of the secularization of modern Jewish consciousness be revealed. Haskalah literature, for example, because it is tendentiously antagonistic to religious tradition, is esthetically deficient, and its language is more feuilletonistic than literary.

There is a tremendous difference between publicism and that true artistic creation which always transcends the bias of the moment. . until it attains to an objective approach to the subject of its material.

This is what happened in the course of the nineteenth century as the ideals of the Haskalah faded and their values were more and 
more understood as inadequate substitutes for faith in the living God. The Haskalah had disappointed and the result was that at the end of the nineteenth century a more objective attitude to the religious problem, which was still unresolved, does emerge, and an authentically imaginative literature begins. In prose Feierberg and Mendele are the first indicators; in poetry it is Bialik.

But this new engagement with the tradition is not and cannot be a full return to it. "It is a late return and its failure is foreseen from the beginning." 58 This is the fundamental meaning of Agnon, who brings the tragic paradox of Hebrew literature, and with it the literature itself, to its early full flowering. From this point on the entropy of art begins to operate in Hebrew linguistic terms. "The language which arose in revival was transformed into a secular tongue and the holiness at its source disappeared from the consciousness of the new generation in Israel."59 kurzweil talks of the "raping" of the Hebrew language as the normalization process it undergoes proceeds concomitantly with the normalization of the people for which secular zionism strove. He asks:

To what extent can the normalization which speaks clearly out of Hebrew poetry today remain within the limits of what the Hebrew language can absorb without losing its soul? This is a view with which you may disagree; to me it $6 \theta^{i s}$ apparent that the Hebrew language has a unigue soul.

Indeed, it is all too easy to disagree. A language, like the people who speak and write it, develops within history regardless of its changeless meta-historical status. Kurzweil certainly knew this with respect to the Jewish people, but he was unwilling, and perhaps unable, to come to terms with this reality as it relates to Hebrew in its increasingly modern literary garb. This is the deficiency of Kurzweil's view of modern Hebrew literature, but I shall return to consider it only after investigating the main features of what this view enabled him to do--and not to do--with some of that literature's major figures.

\section{Kurzweil's Periodization}

His theory of modern Hebrew literature brought Kurzweil to formulate a periodization scheme of his own. It is the logical result of his development of the theories of Lachower and Klausner, whose periodizations Kurzweil feels impose categories that are derived from European literature and do not take into account the unique character of modern Hebrew literature, which 
underwent in fifty years what European literature did in two hundred. 61 Kurzweil's scheme encompasses four periods:

1) the period of the "simplistic Haskalah", when the naive hope was that progressive Enlightenment humanism would be quickly reconciled with an enlightened Judaism purged of its anachronistic superstitions;

2) the period of the "militant-reformist Haskalah", wherein the "transvaluation of values" was struggled for in the certainty that universalistic Enlightenment humanism would inexorably replace particularistic Jewish religion as the new basis for Jewish existence;

3) the "tragic period", when disillusionment with the Haskalah and the shock of recognition that the Jew would never be permitted to neutralize his uniqueness in the ideal of secular humanitas were compounded by the realization that neither did he possess any longer the religious faith necessary to re-affirm that uniqueness;

4) the period of the apocalyptic "vision" of the re-constitution of the Jewish kingdom, when the tragedy of the modern Jewish situation is overcome in the merging of the meta-historic with the historic; Jewish existence in the present regains the primal wholeness of its past as the mythic basis for that past is re-established in the emergence of Jewish sovereignty over the land of Israel. 62

of such a scheme spicehandler has said: "His periodization of the East European era of Hebrew literature is vastly superior to any of the rather contrived schemes suggested by Klausner, Lachower or Schapiro." The qualification here is important: he finds Kurzweil's argument for the fourth period unconvincing, since it applies only to the poetry of Uri zvi Greenberg and nothing else. 63 Inasmuch, however, as the criteria for this fourth period are the same as those used for determining the first three, questions must be raised about all of them, particularly in view of the fact that Kurzweil gives no place to Israeli literature of the post-1948 years. But, as I have already indicated, we will be in a better position to deal with these questions after we will have seen just who kurzweil treats within these periods and why and how he does so. 

KURZWEIL ON MODERN HEBREW LITERATURE: II--THE STRUCTURE OF THE PRACTICAL CRITICISM

Kurzweil had no interest in writing a history of modern Hebrew Iiterature. "The very fact of my scepticism of the objectives and presumptions of history in general is sufficient to keep [me] from writing a history of literature, even of the most specific period." 1 Yet his commitment to the hermeneutic approach of necessity is a commitment to the historicity of a work of art. The much maligned term zeitgeist suggests itself here, and it is admissable as the real object of Kurzweil's interest, but only as Muller-vollmer defines it:

\begin{abstract}
A Zeitgeist is not . . the effect of mechanist or unconscious forces. It is the creation of the philosopher, the artist and the poet who realize that a "potential unity" . . exists among the stubborn facts of the age and who co-ordinate them into a coherent and unified world-view. - . Literary works thus do not derive their "historical content" from the spirit of the age; it is rather through them and their creators that this spirit comes first into being.
\end{abstract}

Additionally, the fact that Kurzweil is led to his own periodization is testimony to the essential inseparability in literary study between theory, criticism and history. ${ }^{3}$

Such considerations supply the perspective I think is needed in Kurzweil's periodization. It is not a system of chronological categories rigidly applied, but a device that simply structures in a general way his practical criticism of the scores of poets and novelists of modern Hebrew literature. It is even possible to say that in the course of time Kurzweil lost sight of the discriminations inherent in his periodization. An example of this is his late discussion of Josef Perl, where we are never told exactly whether Perl belongs to the "naive" or to the "militant" phase of the Haskalah, or even whether he is some sort of a bridge between them, as Kurzweil seems to imply. ${ }^{4}$ Minimally, however, I shall utilize this structuring function of Kurzweil's periods to take hold of the practical criticism. In terms of my overall purpose here there is no other way. To provide a detailed analysis of Kurzweil's treatments of particular figures and his interpretations of individual works is beyond the scope of this study. To examine this criticism by genre is equally impossible; Kurzweil deals only once with the Hebrew drama, 5 and his treatment of 
poetry and prose is, on balance, all of one piece--both are seen as aspects of a larger problematic. Accordingly, the following discussion follows the contours of the thematics, motifs or, more correctly, the hermeneutical "historical content" that kurzweil sees in modern Hebrew literature as it develops.

\section{The Haskalah}

Kurzweil is essentially not interested in the Haskalah per se. Of its first "naive" phase we hear no more than a brief description, and of its second "militant" phase there are but two essays on Perl and one on Mendele. There are extended references to Lilienblum, Y. L. Gordon, Smolenskin and Berditchevski, ${ }^{6}$ and nothing at all, beyond a few mentionings of some of their names en passant of Wessely, Letteris, the Lebensohns father and son, Erter, Mapu, Broides or Bershadski. The period as a whole is important for Kurzweil only insofar as it contains the seeds of the more complex ones that follow. The issue, in fact, is not whether the struggle against the tradition is waged in "naive" or "militant" terms but the shift Kurzweil sees at its end from a critique of Judaism out of rationalistic humanism to a critique grounded in the irrationalism of Lebensphilosophie. ${ }^{7}$ The influence of Nietzsche on Hebrew literature at the end of the nineteenth century, which Kurzweil traces very skillfully, is obviously of more import to him than that of voltaire at the end of the eighteenth.

This is the same tendency discernible in the criticism of European literature, where kurzweil is much more interested in Rastignac and Julien Sorel than in wilhelm Meister. In general Kurzweil finds a replication in modern Hebrew literature of the same de-mythologizing of religious belief and its sacred texts he observes in European literature. The relationship, for example, to the miraculous claims of the Baal shem Tov that obtains in Perl's Megaleh temirin is seen as of the. same order as the relationship to the supernatural of the medieval chivalric romance in Don Quixote, ${ }^{8}$ although there is no implication at all of an influence. Mendele's language represents a continuation of this process, for his juxtaposition of sacral and secular connotations generates ironic incongruities. ${ }^{9}$

But in both cases, of Perl and Mendele, we are dealing with fragmentary treatments. Kurzweil's essays on Perl I judge to be the more valuable both because they concentrate on a single work 
and because they shed new light upon a relatively neglected figure. The arguments that Perl is to be read as a satirist and not as a novelist; that, as a Galician, he is to be seen not in the context of the militant Haskalah of Czarist Russia but in that of the more moderate climate of the general Hapsburg culture; and that the "battle of the books" that he depicts is substantially the same struggle that a century later informs the key works of Bialik and Agnon--all these are, I think, valid and important contributions. The single essay on Mendele, on the other hand, seems incomplete and must be judged as unsuccessful. Kurzweil is principally concerned with disputing Brenner's and Kariv's estimations, certainly a legitimate critical task, but such ends in an epic writer of Mendele's breadth require a much more detailed and work-centered analysis than kurzweil presents. 10

Equally deserving of better readings than he gives them are Y. L. Gordon and Berditchevski. They are evidently judged to be artistically wanting, but it becomes obvious that Kurzweil handles more fully only those who fit into "the great tradition" that, like F. R. Leavis, he sets up. ${ }^{11}$ It is hard to escape the conclusion that there is much more to the Haskalah and its key literary representatives both in terms of content and technique than what Kurzweil tells us.

The Tragic Period

With the realization by the East European Jewish artistic elite that the ideals of Enlightenment humanism would not suffice as a new basis for Jewish existence, since the vague hopes for "progress" they had aroused proved illusory, the Haskalah declined and Hebrew literature enters a new phase, the "doubly tragic" one. The tragedy is twofold because at the same time when the aspirations of that elite, who lived "at the edge" in uncommon intensity, began to be turned away from the values of the Gentile world to inner Jewish ones, there came the shocking discovery that the necessary foundation for Jewish life, religious faith, had evaporated. This is the sensibility that Kurzweil sees animating Hebrew literature from the end of the nineteenth century through the first third of the twentieth, a period when he considers the literature to have achieved full esthetic consciousness of itself. It is on the painstaking explication of this sensibility as he finds it in its various expressions in Bialik, Brenner, Agnon and Tshernichovski that kurzweil concentrates his critical energies. 
There is a personal element here that cannot be ignored. The sensibility I have here described is very much a generational one, perhaps the Jewish analogue to the "lost generation" of American expatriates in Europe between the wars. In any case, as I have tried to show in earlier chapters, this sensibility certainly mirrors Kurzweil's own existential situation. The twin themes of "loss" of religious faith and the attempt at a "late return" to it are the literary coordinates of what he knew experientially, intuitively. That is why he poured so much of himself into ferreting out this experience as he saw it manifested in the literature of the period. His overall perception of the period as "tragic" is an inversion of the prevalent view of it as the period of national "revival", a view undoubtedly fostered by critics who themselves were products of the second and Third Aliyot.

If the literature of the Haskalah and the national
revival still accorded to the religious-traditional
message of our ancient literature a modern interpre-
tation; if the divine message was still capable of being
transmuted into some vision, some sublime modern secular
imperative--the latter generation is completely lacking
such befjef, and the place of the vision is taken by the
absurd.

Implicit here, the conventional terminology of a literature of "national revival" notwithstanding, is kurzweil's essential point about the real trajectory of modern Hebrew literature. It is the trajectory itself, the process of passing "from vision to the absurd" that claims his attention, not the beginning and terminal points. This is the same feature of his work in European literature. But here the treatment is copious and rooted in individual works. It represents the ripest fruit of Kurzweil's criticism. And its results are major revisions in the reading of all the important figures of this period of modern Hebrew literature. These I now note seriatim.

A. Feierberg.--Kurzweil considers that with Feierberg modern Hebrew literature arrives at its first authentic flowering. 13 This is not only because "the problem of the tradition" is central here, but because for the first time that problem is treated with a semblance of the objectivity needed to transform a work from a didactic tract into art. The positions of both Nahman and his father are presented with equal weight so that the question "Whither?" is allowed to stand in its full complexity and painfulness as the fundamental question of Jewish modernity. Kurzweil thus shows how Feierberg does not belong to the nineteenth century Haskalah, and that he is inadequately served when read either 
according to the canons of Ahad ha-Am's melioristic positivism or Berditchevski's "transvaluation of values", for the nationalistic concern of the former and existentialistic individualism of the latter are blended in Feierberg in a wholly new way. "His personal existence is dependent on the existence of the Jewish people and both of them depend for their ultimate consumation on the existence of Divine Providence."14 when these contingencies are laid open to question, as Feierberg forces them to be, then an entirely new itinerary of concerns comes into view. If Feierberg did not live to develop these concerns, Kurzweil sees them as the very ones that pre-occupy Feierberg's successors, especially Bialik. 15

B. Bialik.--The full force of Kurzweil's poetics and phenomenological method can be felt in his essays on Bialik. Until Kurzweil, Bialik was approached largely through the biographical and historical details surrounding his work. Lachower, for example, outdid anyone in the empirical accumulation of such facts but, though he admires the effort, Kurzweil saw plainly its inadequacy. The nature of these details: Bialik's involvement in the zionist movement, his relationship to Ahad ha-Am, the fact that his poetry begins in the late Haskalah, where the conflict is between religious tradition and enlightenment--has distorted and obscured the Eidos of Bialik as poet, and has fostered a view of him as the mouthpiece of the Jewish national renaissance, as a latter-day "chastising prophet". What is lacking, in Kurzweil's view, is an intuitive interpretation of what all these facts mean, one that seeks to penetrate to the sources of Bialik's poetic creativity and defines him in his own terms. ${ }^{16}$ It is to these ends that Kurzweil's work on Bialik is directed.

The ground for this is prepared by exposing the experiential roots that underly Bialik's oeuvre. ${ }^{17}$ Kurzweil does not say so here but it appears to me that it is the Diltheyan Erlebnis that is his focus. He comes to discern the unique poetic "I" that Bialik developed and, again without mentioning them, seems to lean on Fichte and Buber in emphasizing that this "I" needs to be understood not in isolation but in relational terms. In Bialik's case the key lines of relation are between the "I" and the world and between the "I" and Jewish religious tradition. It is the tension between and the shifts within these two inter-twined relationships that are the fulcrum of Bialik's poetry. The result is a perception of a Bialik who, his nationalistic posture notwithstanding, is at heart an intensely subjective, lyrical poet. The fissures he knows to exist in the connection between 
himself and the world and between himself and his ancestral tradition are spanned only in the act of poetic creation.

Such a perception, in turn, gives rise to new readings of certain key works that, compared to earlier ones, are devoid of any ideological ignis fatuus. Megilat ha'esh, for example, is shown to be not exceptional or peripheral to the Bialik corpus, as was commonly thought, but paradigmatic of it. Kurzweil accounts very well for the form of the work as a displacement onto myth of the painful dilemmas of Jewish modernity as Bialik himself felt them. ${ }^{18}$ Kurzweil shows the nature poems to be a further development of the process of poetic objectivation of the subjective. His discussion of "haBerekhah" contains some of the closest textual analysis to be found anywhere in his criticism. 19 "Metei midbar", given a major re-interpretation, is seen now not as the national allegory Fichmann made it out to be but as the extreme example of the dissonance between infinite nature and the finite, now starkly alienated "I". 20 The disjunctiveness between the silent language of the cosmos and the speech of poetic self-revelation is now apparent. Kurzweil comes to focus on the small group of poems written in 1910-11, what he calls the "personal poems", as the key to the entire Bialik corpus. Here the poetic "I" is in complete solitude, having left the world behind. There now can be no use of the ancestral past or nature as objective correlatives. All that is left is pure subjectivity as it is embodied in poetic language. But since, in the absence of a living religious faith, the road to the past is closed, and there is now no relationship to the external world, language carries no freight, discloses no Being. Language now conceals more than it reveals. In this situation resolution can come only with death or silence. The loss of faith in God thus brought Bialik to a loss of faith in the word, and Kurzweil notes the affinities between Bialik and the crisis in language as felt by Kraus. Bialik's perplexing poetic silence, the fact that he virtualiy ceased from writing poetry while at the height of his powers, is thus explained by Kurzweil more convincingly than by anyone before him. It is not due to any drying up of talent but is the natural result of his existential predicament. 21

We may, then, describe all Kurzweil's work on Bialik as a tracking of this predicament. In his final essay he comes to distinguish between the choices a Hebrew poet who faces them can make and those open to poets writing in other languages. Bialik, according to Kurzweil, when he reached the limits of his Hebrew linguistic medium, refused either to regress into the realm of 
esthetic banality or try to cross the chasm that lay before him and risk falling into the abyss of nihilism and madness, as did Hölderlin, Rimbaud, Mallarmé and Trakl. 22 For the authentic Hebrew poet, creating in the sacral language of Divine revelation, neither estheticism nor nihilism are possibilities; there is only silence. If modernism in literature means the emptying out of language in consonance with the emptying out of primordial certainty, then

the poetry of Bialik stands at the borders of this process. Not within it. It defends itself against it and tortures itself with its nightmarish visions. It is still rooted in a reality that is whole, healthy, and [is founded] on a hierarchy of values such a reality contains. It follows, then, that his poetry is an unceasing struggle with the possibilities of return in all its modifications, from the literal return to the "nest," to the Bet Midrash, to nature, to the reviving [Jewish] people, until the ultimate, ghastly conception of return--of the "I" to itself, to the bosom of night, to death. Thus does this poetry of genius enclose within it all the possible way-stations of the Jew and of modern man. The "I" of the poet embraces them all, but not any one of these yazrious possible solutions will work for the modern poet.

To be sure, Bialik emerges from Kurzweil's hands still as the uncrowned poet laureate of the Jewish people in the twentieth century, but the significance of his stature is now irrevocably altered. Kurzweil shows him to have a much more profound grasp of the modern Jewish situation than his mentor (who Kurzweil emphasizes was only his intellectual, not his experiential mentor), Ahad ha-Am. Bialik as no one else represents the tragic paradox of this situation but he does not resolve or transcend it. Such attempts at solution come only in the secular humanism of shlonski and Altermann, in the private mysticism of shin shalom and in the vision of a new Jewish reality in Greenberg.

The influence of Kurzweil's work on subsequent Bialik criticism is clear, ${ }^{24}$ but its flaws are no less apparent. Many key poems do not receive the same careful reading that Kurzweil gives to those he feels illustrate his case. Further, as Dan Miron has noted, it is possible to say that in emphasizing the personal aspect of Bialik, Kurzweil over-states the case and thereby misses the variegated polyphony that Miron feels may well be the truly distinctive feature of this oeuvre. ${ }^{25}$ Then again, it is disquieting to realize that even if it is poetry and not fiction that Kurzweil is dealing with in his treatment of Bialik, it makes no real difference to him. But this by now is a familiar objection. 
C. Brenner.--Brenner's thematics begin where Bialik leaves off. ${ }^{26}$ The absurdity of a Jewish existence bereft of religious faith is the point around which Kurzweil sees all Brenner's work turning. The contribution here is similar to that made with respect to Bialik: Brenner is effectively rescued from those who would use him as a spokesman for a self-congratulatory zionism or, as happened with Kafka, as a foil for psychological interpretations. In exposing the metaphysical issues in his fiction, Kurzweil must be granted an important role in establishing Brenner's modernism and thus stimulating many younger critics to take a new interest in him. Moreover, Kurzweil's various discussions of Brenner suggest a recognition that the formal and stylistic aspects are by no means deficient or disfunctional; the self-effacement of his anti-heroes is accompanied by a deliberate destruction of smooth speech and rhetorical patterns. 27

"Brenner's heroes never forgive God for not existing for them." 28 It is the implications of this insight that kurzweil pursues, and it is to the Nietzschean elements within it that he points rather than to those more commonly associated with Brenner, the Dostoevskian. Jewish reality divested of its religious foundations is "life in quotation marks", the antithesis of the full feral Leben that Nietzsche espoused. As much as Brenner and his heroes affirm, yearn for and are consumed with envy of the latter, to that extent do they flagellate themselves and other Jews for accepting the frigidity of the former. The erotic problem in Brenner, the "erotomania" of such autobiographical characters--one wonders why Kurzweil, who is seemingly so sensitive to language, calls them "heroes"--as Jeremiah Feierman or Yehezkel Hefetz is thus fully accounted for: to love requires belief in life lived without quotation marks, where the self can be transcended, if not by God then at least by woman. Where no such transcendence obtains, Eros is reduced to sex.

Kurzweil connects this attitude to the Jewish condition to that of Weininger, Kraus and Kafka. In all cases he sees not "Jewish self hate", as Theodor Lessing described it, but a repudiation of the contemporary Jewish life they saw around them that was satisfied to counterfeit itself in the phraseology of a banal secular nationalism. Implicit in all of them is an uncompromising refusal to lend themselves to such an absurd enterprise as well as a demand for a return to the sublimity and morality of the unsullied sacral past. This connection leads to one of the central conclusions of Kurzweil's criticism: 
The problem of a Jewish existence that had become absurd is the focal point of Brenner's writings. But the absurd in Jewish existence only serves to uncover the absurd condition in general, 29 of which other literatures bit by bit became conscious.

Brenner, therefore, is thematically as much an anticipation of modern fiction as is his Jewish contemporary Kafka.

We have, then, a pronounced concentration on the thanatopic elements in Kurzweil's reading of Brenner. Everywhere the focus is on the process of "breakdown and bereavement". Kurzweil's sense of personal involvement in this process is clear. It is probably not co-incidental that Brenner is the author he was working on at the time of his death in the summer of 1972 and that the last essay he wrote was entitled "Shekhol vekishalon--The Last Stop of Absurd Jewish Experience". It is this tendency toward pessimism that might account for Kurzweil's failure to deal with the affirmative element in Brenner, his paradoxical asseveration of life. This is an element kurzweil unquestionably sees, 30 but he does not, perhaps cannot, explain and relate it to the totality of Brenner's work. The discussion of Shekhol vekishalon seems especially truncated. There is no mention at all of the character Menahem. The motif of the home which, Kurzweil tells us, "is one of the most important elements for the understanding of the story, Brenner in particular and modern Hebrew literature in general," to which motif Kurzweil promises to return and "submit it to a meticulous examination, "31 receives scarcely more than two pages. still, the Brenner criticism that Kurzweil wrote can only be described as seminal.

D. Agnon.--If the result of Kurzweil's work on Agnon is a new view of him as the artistic consummation of modern Hebrew literature, it is also the consummation of Kurzweil's work as a critic. Though before Kurzweil Agnon was given his due by a few isolated critics of stature, such as Eliezer Meir Lipschutz, Dov Sadan and Gustav Krojanker, he was read by most as a weaver of naive pietistic and neoromantic folktales and as a writer with a distinctly religious world-view. Kurzweil demonstrated as had no one before him that the various surfaces of Agnon's unique narratives constitute a series of carefully wrought fictive masks and that underneath them is an artist of uncommon craftiness wrestling with the root problems of Jewish modernism. A full assessment of this contribution has been done by Barzel and there is no need here to reproduce its insightful details. ${ }^{32}$

Instead it is only necessary to make a number of observations about where Agnon fits in thematically to the total scheme of 
modern Hebrew literature as Kurzweil perceives it. Unlike Brenner Agnon"cannot make peace with the absurd as the basis for his epic world" 33 even though he is no less cognizant of its presence. In Agnon vision and absurdity are in equilibrium, and in the most exquisite way. The tensions between the Jewish past and present endow this fiction with an intrinsically bi-polar quality and it is just this dual focus on the "then" and the "now" that, Kurzweil feels, enables Agnon to treat Jewish reality with an objectivity unprecedented in modern Hebrew literature. The esthetic advance here is not only beyond Mendele and Feierberg but Kurzweil seems to imply it is beyond Bialik too. Whereas Bialik, who faced exactly the same tensions as Agnon, dealt with them out of the subjectivity of poetic utterance (a subjectivity which, as I have noted, assumed objective existence) Agnon's objectivity is the fruit of an epic distancing which captured the totality of life. ${ }^{34}$ It is this preference for the artistic presentation of the fullness of life that we can now see animates Kurzweil's proclivity to prose over poetry and his apprehension of the novel primarily in epic terms. Moreover, it is important to note that what Kurzweil sees in Agnon and what his criticism of him celebrates is the triumph of dynamic artistic creativity over the sterility that results from the dessication of religious faith. It is art that re-constitutes for Agnon the totality of life into its primordial unity, not religion ${ }^{35}$--this is the real reason why Agnon represents the organic culmination of the revolutionary process that is secular modern Hebrew literature.

Kurzweil's perception of what we may term the Hapsburg Empire aspect of Agnon must also be recognized as a vital element in the formation of his definitive interpretation. Here I have reference not only to the metaphysical and historical significance of the Empire, the Kaiser and the problems of authority and tradition, all of which are, I think, among the deepest insights. Rather I have in mind the sensitivity to language, style and technique that is in evidence more in the criticism of Agnon than of any other writer Kurzweil discusses, a sensitivity borne of Kurzweil's acquaintance with the deceptive "epic quietude" of stifter. Equipped with this sensitivity Kurzweil is able to pierce the veneer of Agnon's narrative and discern "no monolithic Agnon style but a unity of styles". ${ }^{36}$ It is this giving the formal aspect its due that enriches Kurzweil's criticism of Agnon immeasurably and saves the thematic conclusions it ultimately arrives at from being pure content analysis. 
Thus, if at the beginning of his work on Agnon Kurzweil is not deceived by the pietistic nature of some portions of the narrative and is able, as with stifter, to uncover it demonic depths, eventually he accounts for the plurality of styles in a much more extensive way. What Agnon presents more than anything else by these styles is a recapitulation of the sacral Jewish past; what he means by it is the same thing he means in his various presentations of Jewish time: an attempt to transcend the break between the past and the present by creating the possibility of a "new continuum", by implying the primacy of the timeless meta-historic over the finitiude of history. In other words, the sacral quality of much of Agnon's language is ultimately seen not so much as veil as the linguistic concretization of "late return" which, paradoxically, may yet succeed.

To be sure, we do not have here a manifestation of simple belief but rather the volitional decision to envision the "then" and the "now", the "there" and the "here" in acçgrdance with the categories immanent to the past itself.

In establishing this vision or, more correctly, in re-establishing it, Agnon affirms its triumph over the "absurd" and thus reaches the limits of the tragic period. We are brought very close to the new Jewish reality, which is poetically beheld in all its fullness only by Uri Zvi Greenberg.

Kurzweil's interpretation of Agnon has never been seriously challenged and may properly be seen as the basis from which all subsequent Agnon criticism proceeds. ${ }^{38}$ It is obvious that this interpretation is the result of both the metaphysical postulates Kurzweil brought to his reading as well as the critical methods he employed. This fact raises a number of questions about Kurzweil in particular and criticism in general. Why did he succeed so brilliantly with Agnon? Which were more decisive in enabling Kurzweil to open up Agnon as he did: the pre-suppositions about religion, art, Judaism, history and language? or the holistic reading of the individual work in relation to the hermeneutic of the total Agnon corpus? If we say that both sets of elements are involved, then the question becomes: can we isolate one from the other or are they necessarily related? What is, in fact, their relationship? Barzel, at the outset of his discussion, notes that

the critic was close to the author in terms of the primary spiritual experience of confronting a Jewish whole world in its values, faith and purpose caught up in the process of disintegration and the danger of destruction. 
Does this mean that a given writer requires a critic with corresponding values, receptors and even commitments in order to be read with some degree of reliability? Or is it simply that a given writer attracts such a critic? ${ }^{40}$ Or, conversely, that such a critic is naturally drawn to such a writer? The secret of great criticism seems as inscrutable as that of sublime artistic creation.

E. Tshernichovski.--These questions take on even more force when we consider Kurzweil's accomplishments with Tschernichovski. Here the distance between the critic and his subject is ostensibly as wide as it is narrow with respect to Agnon. Tshernichovski seemingly lies outside the thematic circle which Kurzweil circumscribes around modern Hebrew literature and, in fact, his identity as a Hebrew poet was for a long time very much open to question. yet Kurzweil must be seen as instrumental in showing that Tshernichovski is not to be read as the great "pagan", "Greek" or "Scythian" poet of "freedom and light" who wrote in modern Hebrew but rather as an integral part of the modern Hebrew literary enterprise or, more accurately, of a specific strand of that enterprise. ${ }^{41}$ The victory here is of art over ideology--both in the poet and in the critic. In affirming and illuminating the artistic truth of Tshernichovski's poetry as the object of his critical attention, Kurzweil's esthetic sensitivity prevails over his own ideological considerations, for Tshernichovski surely does not conform to all of Kurzweil's metaphysical postulates. ${ }^{42}$

At bottom here is an essential willingness to look for and accept the particular "intrinsic coherence" of Tshernichovski's work. In his first formulation of a schematic configuration of modern Hebrew literature Kurzweil observes that though the

creative, enchanting and prolific personality of saul Tshernichovski requires its own particular evaluation . . . [it nevertheless] hints to a certain extent at a second strain. . . in our literature. . . whose representatives continue the line of the Haskalah and.. bring out the anti-religious tenor until Judaism and its values are rejected.

Yet this movement "against the national purpose" is "a legitimate expression of the national secularization of our people in its ancestral land", 44 for it too is in search of wholeness and certainty that have been lost, but in a way different from those artists who accept the religious definition of the purpose and meaning of Jewish existence.

Throughout Kurzweil emphasizes that in understanding Tshernichovski the distinction must be made between the 
intellectual position from which he began and the artistic stances he assumed as his lyric developed. The former, without question, is the Haskalah didacticism of $Y$. L. Gordon blended with the Nietzschean vitalism of Berditchevski, and it is this position that is stamped on the early programmatic poems. But Tschernichovski is a poet, not a publicist or a philosopher, and as his art matures this dogmatism gives way to a more objective, less doctrinaire treatment of the Jewish past and tradition, as the king saul poems testify. ${ }^{45}$ It is not ideological consistency that one should look for in Tshernichovski but poetic categories, 46 the most important of which is the idyllic. For kurzweil the idyllic is not a genre but the "background" of all Tshernichovski's work, an esthetic posture of the same order as the tragic, though antithetical to it. The idyllic is, as we have seen, a main principle of Kurzweil's own poetics, and he applies it directly to Tshernichovski. ${ }^{4}$ It is thus the idyllic that enabled Tshernichovski to attain to a poetic "Anschauung" that brings together past and present, ancestral legend and reality, man and God, in such a way that it forces him to transcend his early tendentiousness against Jewish tradition. Such tendentiousness is but a cerebral construct, much more superficial than the idyllic which has experiential roots. 48 In this way Kurzweil forces attention on the artistic values of Tschernichovski's poetry, a contribution which has been acknowledged as having had "great influence on Hebrew criticism". 49

Beyond this Kurzweil discovers that Tshernichovski is no less engaged in the theme of "return" than Bialik, but in a completely different way. Tshernichovski's values, as well as his view of man and human freedom, derive not only from Judaism but from a universalistic humanism. His mature poetry, especially the two sonnet cycles, ponder the crisis of all western culture, and the return is to the archaic in all its forms, to the mythic human past in all its variety. This "mythological syncretism" is not, as is customarily thought, attained

out of a surfeit of healthiness and an abundance of vitalistic effervescence, but out of a deep suspicion of and discontent with the resources of the great culture of humanism, which progressively 5 increase the more we are dependent on and rooted in it.

History for Tshernichovski is not synonymous with progress and Kurzweil, as his treatment of the poet develops, probes the full significance of the "pagan" element. It is the numinous experience of ritual that Tshernichovski seeks to recover, and the 
consonance between this experience and the idyllic basis of his art indicates that at bottom that art is a profound search for the "lost unity" and that Tschernichovski is, though not in any formal sense, essentially a religious poet. Moreover, since all ritual is grounded in the concreteness of human history and society, Tshernichovski's language is of necessity anchored in this same concreteness. Kurzweil wishes to forestall any attempt to appropriate Tshernichovski as an estheticistic anticipation of poésie pure in Hebrew; there are no "flowers of evil" in his poetry just as this poetry is not "naive" in schiller's sense. 51

The culmination of this interpretation comes in the reading Kurzweil gives to the late masterpiece 'Ama dedahava. Here the two strands of the idyllic and the humanistic are seen as fused into a new perception of Jewish and human life. In thus showing how this work is both formally and thematically the cumulative creation of Tshernichovski's muse, Kurzweil barns the harvest of his approach, for the relationship of this complex work to the rest of the oeuvre is for the first time cogently demonstrated. 52 The achievement here is similar to that which Kurzweil attains with Agnon's Sefer hama'asim and Bialik's Megilat ha'esh. The irrevocable conclusions Kurzweil's criticism leads to are both a new definition of Tshernichovski's modernism and a recognition that this modernism nonetheless exists within the framework of the tragic and the Jewish.

These four pillars of modern Hebrew literature--Bialik, Brenner, Agnon and Tshernichovski--may be seen to constitute for Kurzweil the four major expressions of or responses to the Jewish condition as it exists in the tragic period. All other expressions of this period are derived out of them. That is why his sustained treatment of each of these four overshadows the discussion of other figures who belong here, which discussions are, in comparison, fragmentary and occasional. The impasse at which Bialik arrived is seen to have also been reached variously by Lamdan, Shlonski, Altermann, Shin Shalom and Uri zvi Greenberg, except in each case there is some movement beyond it. Greenberg's solution is so radical as to cause him to transcend completely the tragic dimension, as I shall shortly note. The previous three each go in a different direction from where Bialik left off before he chose silence; all write poetry that is personal but make their stand now on secular, relative values that are put forth in place of the absolute of religious certainty. ${ }^{53}$ whereas shlonski and Altermann both fasten on a progressive humanism without 
transcendence and on the powers of Eros, Shin Shalom descends to the depths of his poetic "I" and internalizes powers previously ascribed to God. Kurzweil feels in shin shalom a severe stress being placed on a sacral Hebrew language that is now being used in a wholly secular way. In his consideration of this poet he raises a question that is equally applicable to Shlonski and Altermann:

\begin{abstract}
To what extent is this conquest of sacral expression legitimate at all, and does it not alter the spirit of the Hebrew language? . . [This] process of the deification of the poetic "I" allows us to define the general problem: the legitimate limits of the transposition of a sacral linguistic system to the secular sphere. This is not only an intellectual, religious and moral question but a linguistic one, namely, is it possible that we are approaching the point beyond which we shall no more be dealing with a language that provides coverage through suitable meanings but, instead, poetry itself is in danger of turning into a rhetoric and a jargon which, like sacks that have become empty, contain that which is most opposed to the original significance of the metaphor, the image and the accouterments of wonder and the wondrous? . . This 4 is the question of questions of modern Hebrew poetry.
\end{abstract}

In prose Kurzweil finds the same process to be adumbrated by Gnessin, who otherwise displays a thematics similar to Brenner. 55 on the Tshernichovski axis, if we may so call it, belong schneour and Hazaz, but this is the most undeveloped region of Kurzweil's criticism of the tragic period. Schneour he dismisses as an inferior poet, 56 and Hazaz, whom he admires, holds only early interest for him. ${ }^{57}$ He does not deal at all with such important contemporaries as Fogel, Steinberg, Devorah Baron, Schoffmann and Peretz. We cannot gainsay him or any critic the right to deal with those whom he chooses to deal, 58 but at the same time when we equate volume and intensity of treatment with esthetic quality of the works treated, we see a sophisticated taste and a critical judgment with which it is hard to quarrel. Kurzweil did not seek to illuminate the obscure corners of modern Hebrew literature but to confront directly and penetrate its foremost facades. 59

The New Vision of Jewish Sovereignty: Uri zvi Greenberg

What Kurzweil did with Uri zvi Greenberg is essentially the same as what he did with Tshernichovski: a poet who had been read largely in ideological terms was now analyzed out of his own particular context. But the nature of that poetic context, as Kurzweil apprehended it, and its relationship to the totality of 
modern Hebrew literature, brought Kurzweil to define Greenberg's significance in a wholly new way.

The conventional view saw Greenberg as the poet of extreme Jewish nationalism as formulated by Jabotinsky's revision of zionist theory. Those who agreed with this revision fervently lauded Greenberg, while the more normative zionists bitterly condemned him, some even charging him with approximating a Jewish fascism of sorts. The value of his poetry was thus linked to whatever ideological assessment was made. Kurzweil, although he was not literally the first to do so, was the most vigorous champion of reading Greenberg without reference to any partisan political considerations. ${ }^{60}$ Rather, as with Bialik, Tshernichovski, Shlonski, Shin Shalom and Altermann, his focus is on the nature of the poetic Erlebnis that lies at the bottom of the poetry and gives rise to it.

Kurzweil sees Greenberg as providing a poetic solution to the deadend Bialik reached that had forced him into silence. It is a solution attained not by fastening on a secular substitute for the lost religious faith but, as with Agnon, in terms of that faith itself and the tradition that concretizes it in life. The solution is the offering of a daring affirmation of the "otherness" of the Jews among the nations and an accompanying apocalyptic vision of Jewish existence as a millenial category transcending time and history. This grasp of the unity of the Jewish past, present and future, unprecedented and without parallel in modern Hebrew poetry, was unattainable by Bialik and opens up a thematic field that is, in the modern period, completely new. The essential motif now is not the loss of faith but the re-acquisition of the power to imagine redemption. The national revival that was bruited about is now not a cliche but a real possibility, since it is founded on the intrinsically religious nature of the Jewish people, not on secular models derived from Europe nor on dubious illusions of inexorable progress fostered by western bourgeois liberal humanism. In short, Kurzweil finds in Greenberg the definitive answer to the fundamental question of modern Hebrew literature as Feierberg had first posed it--"Whither?" Inasmuch as it "Jeaves behind it from the outset the entire problematic of the Haskalah" as well as such historical postures as the waiting for the Messiah in the unredeemed Diaspora, Greenberg's poetry, in Kurzweil's perception, brings modern Hebrew literature to a new phase unmeasurable by the criteria and thematics of those phases that preceded it. 61 The notion of "late return" applies no longer, for the "synoptic vision" assures the re-acquisition of 
the certainty of the primordial vision. This is why, incidentally, Kurzweil can link Greenberg to so different a spirit as Buber:
Like Greenberg, Buber also shows a critical attitude to the manner in which our political dream has been realized. $\cdot$. Both of them reject the ${ }_{2}$ present as it is because it is seen as betrayal. . . 5
This, too, is why kurzweil can say that
Uri Zvi Greenberg seems to me the greatest figure in our poetry, not because of his views or because of his attitude to Jewish tradition is the most positive, but because. . . I find in them [his poems] the most concentrated, consummate and interesting expression of the intrinsic coherence of our destiny.

Again, Kurzweil is speaking in phenomenological terms here and he means that the content of Greenberg's vision of meta-history corresponds to the objective nature of Judaism and the Jewish people. One implication of this that Kurzweil pursues is that, in realizing his vision, Greenberg returns to and recreates the primal Jewish mythos. The dynamic is similar to that of Tshernichovski, except with Greenberg the myth that is re-asserted is not pagan but that of the sacred covenant of Sinai between the Jewish people and its God. In his various discussions of this re-mythification of Jewish existence, Kurzweil shows an interesting dialectic. Myth, he emphasizes, is in the last analysis irrational, and in his admonitions against scholem and all who would glorify sabbatianism we have already seen his antipathy to the mythic. In his analysis of Greenberg's mythic consciousness as a possible microcosm of the collective Jewish consciousness, Kurzweil seems to suggest that the poet does not so much return to chilahood as legitimize an immature, infantile regression. 64 Furthermore, the actualization of ancient myth in a modern situation totally different from antiquity presents grave dangers; it dichotomizes, for example, humanity into Jews and Gentiles in a way that eventually will subvert Jewish myth. ${ }^{65}$ Here Kurzweil's own humanistic leanings show through. At one point he argues that it may be precisely the rational elements in the Jewish spirit and Jewish history, and not the mythical ones, that can be shown to be the most influential and decisive ones. ${ }^{66}$ Against all this are Kurzweil's repeated indications, as the quotation at the head of this paragraph shows, 63 that the myth that Greenberg re-vivifies corresponds to living Jewish reality. It is not the

fruit of any ideology . . historical or political platform,. . not a fable or an esthetic fad or an 


\section{artistic game . .--myth for Greenberg is the reality of realities! The historic-mythic perception $\frac{i}{6} f$ for the poet absolute truth, not an experiment... .}

As his encounter with Greenberg deepens Kurzweil spends more and more time on the specifics of the poems. He examines the structure of such central images as "Sinai" and the "Blacksmith", and gets involved in formal matters to an extent only seen in the criticism of Bialik, Agnon and Tshernichovski. As with them the underlying unity of Greenberg's seemingly disparate works comes into focus. The perceptions of time, history and landscape are shown to be refractions of the essential mode of vision that animates the entire oeuvre, and over and over again Kurzweil stresses the uniqueness of this vision. He comes to the conclusion that in Greenberg the vision is so all-embracing that the universe reverts to its "seamless" form--the holy and the secular are undifferentiated and encompass beauty within them as in the beginning. In short, Greenberg represents the positive fulfillment of every one of Kurzweil's metaphysical postulates as well as the recrudescence of his esthetics. This leads Kurzweil finally to wonder whether Greenberg can even be considered a modern poet or whether he represents a return to the sacral poetry of pre-modern times. If the latter is the case and his poetry is dealt with through the canons of modern literary criticism, there are problems:

Such evaluation is methodologically speaking meta-literary and is properly the concern of [religious] faith. Appropriate here for the literary scholar is silence. Meta-literary magifestations . . are appraised through other criteria.

Now although Kurzweil's basic interpretation of Greenberg is of no less stature and importance than that of the other major figures, his linking this interpretation to a new fourth period of modern Hebrew literature must be seen as problematical. This is not because there is no one else besides Greenberg who belongs here; ${ }^{69}$ theoretically an historical category, no less than a biological genus, can exist even if no exemplification or species is available for classification within it. Rather, I think, the difficulty is philosophical: the fourth period as Kurzweil defines it is an ultimate one that leaves no room for future development, at least as far as I can see, and a literature, like life, develops within time. It has no other sphere of existence. But here we come upon what $I$ see as the real difficulty of Kurzweil's periodization: it is prescriptive, not descriptive. In designating Greenberg and his new vision as the legitimate heir 
of the tragic period, Kurzweil is asserting the primacy of the meta-historic over the historic and is, in effect, reading out of the modern Hebrew literary tradition that literature that issued out of the finite, secular historical context that chronologically followed the tragic period. Specifically, this is the literature produced after 1948 in the state of Israel. It is to Kurzweil's massive critique of such literature that I now turn.

\section{The Critique of Post-1948 Israeli Literature}

The crucial fact about all the poets and novelists whose works Kurzweil includes within the organon of modern Hebrew literature is that they were all born in the European Diaspora. This fact is crucial because of the relationship to the Hebrew language Kurzweil sees it implying. All the figures mentioned in this chapter thus far, in Kurzweil's view, of necessity received Hebrew in their formative years as a written language that existed only within the sphere of the synagogue and Bet Midrash, not as a spoken language utilized to communicate the trivialities of secular daily life. For them the spoken tongue was yiddish or some European vernacular. This, of course, cannot be true for the Sabra writers and those who, like Amichai, were born in Europe but came to Israel at an early age. And as with the Hebrew language itself, so with the sacred texts which are its principal expressions. From Wessely and Mapu down to Shlonski and Altermann all Hebrew artists legitimated their art as Hebrew creativity by recourse to the Bible, the Mishnah, the Midrash. Indeed, they had to deal with these sacred texts and the sacral sphere in which they are rooted even before they could deal with their own reality. This was an artistic legitimation, not a religious one. This fact of literary life does not obtain for sabra writers, for whom the language was ab initio "normalized" and for whom the sacred texts possess no authority of any kind, artistic, religious or even historical. For them the Hebrew they write and the works they write with it are inter-changeable with any other western language. 70 "The more the [Hebrew] language attains the status of a natural language, the more it becomes more colloquial, [the more] it loses its link to the original, sublime implications." 71

Here we have what I regard as the essence of the critique of Israeli literature Kurzweil developed early in his career and maintained steadfastly throughout it. This definition of the problem of Israeli literature as a linguistic one does not come 
until relatively late, but $I$ see it as the clarification of what Kurzweil was saying even in the late forties when he took on the "Palmach" writers. More than other criteria for judging the deficiencies of Israeli literature, criteria I shall presently discuss, it is the linguistic factor that, I feel, accounts for the consistent chip on Kurzweil's critical shoulder with respect to this literature. After all, Bialik, when he sensed the crisis of Hebrew language and Jewish being in the twentieth century, fell silent; Tshernichovski, Shlonski, Altermann and Shin Shalom maintained their muse by trying to go around the crisis, not by denying it; Brenner by wallowing in it; and Agnon and Greenberg, blessed with the miraculous gift of the tenth muse, transcended it. But these Sabra writers blithely put pen to paper with more proficiency to draw ink graphomanically from the pot than authentic poetic inspiration from the well-springs of the Jewish soul. It is important to note here that Kurzweil's critique of these writers is fueled not only by a condemnation of this proficiency but by an implicit yearning for such inspiration, by a genuine interest in and concern for the literary creativity of the sabra writers, an interest and concern he never abandoned in spite of his bitterness against them. We can say now, as the "Palmach" generation recedes to a distance of several decades, that if Kurzweil demanded much from it, he demanded more than it was capable of providing in the heady early years of statehood, when a Hebrew novel was a celebration of the new society in the making, and not a presentation of its totality with epic objectivity. In this respect the esthetic stance of Kurzweil the critic, who saw Agnon and Greenberg as the epitomes of the hermeneutic of modern Hebrew literature, was consistently antipodal to that of such young writers as the Moshe Shamir of 1948, the S. Yizhar or Natan Zach of 1958, or the Amos Oz or A. B. Yehoshua of 1968 who, whether they liked it or not, had to face a given Friday edition of onlyguess. Esthetic stance is without question the issue here, not the talent of these writers, for even in his most scathing criti-cisms Kurzweil always pointed out that native poetic or narrative abilities were in evidence.

Now, although when looked at as a whole Kurzweil's treatment--let us say rejection--of the post-1948 writers is all of one piece, a closer inspection reveals that it is not. By the middle sixties he himself recognized that the "Palmach" writers had been displaced by newer and younger ones, creators of what he called "contemporary Hebrew literature". As hard as he was on the 
former, he was even harder on the latter. In order to appreciate the nuances of this negativity, we ought to look at the different esthetic arguments he employed in each case.

The assessments of the efforts of the "Palmach" writers (Kurzweil never calls them by that name) that Kurzweil wrote in the latter half of the forties are of interest in a way very different from his criticism of, say, Bialik or Agnon. Important here is not the interpretive aspect of criticism but its judgmental function. These are, as I have said, assessments. It is the larger questions they ask--of the possibilities for an Israeli literature--that endows these particular essays with their value. Kurzweil is not concerned with the fine points of how their novels must be read; he is only zealous to demonstrate beyond doubt that any claims by or for a Mossinsohn, Shamir, Yizhar or Shaham that their work represents "the great Israeli novel" be exposed as arrant presumptiousness, as "snobby immaturity and inflated nothingness". If anything, it is poetry and not prose that has the better chance in the new society, for the subjective lyric is less in need of artistic distance and of the solid, clearly defined world that fiction demands. ${ }^{72}$ Yet Kurzweil was no more sparing of such younger poets as T. Carmi, who, he charged, were not writing Hebrew poetry at all but Hebrew imitations of English and American verse, though in time he came to accept Natan Zach and, especially, Daliah Ravikovitch. 73

Kurzweil's prognosis for Israeli prose was the antithesis of what the young writers and their followers wanted to hear. What animates the novel as a genre for Kurzweil is the dimension of time, the way in which it draws on the past of the society it reflects. "Any real work of fiction begins before the first line."74 The novel, he posits, flowers at the end, not at the beginning of a society's development and such flowering is inversely proportional to political upheaval. ${ }^{75}$ so as opposed to the European Diaspora, where the ripe and coherent world of the shtetl served as a foundation for Hebrew fiction, no such basis had yet crystallized in the new-born nation. The kibbutz and the kefar were too new to serve as the social contexts for any real epic, and the city in the European sense did not exist in the new state. What is available is the city of Jerusalem but Kurzweil fears that the secular Israeli writers would be unable to handle the religious freight with which this unique world is laden. ${ }^{76}$ Whereas the Diaspora writers had a deep understanding of the function of tradition in Jewish life, the Sabra writers, when they do not repudiate this tradition, know it only intellectually, not 
experientially. What is worse, the same is true of their relationship to European culture. ${ }^{77}$ All that the new Israeli fiction can achieve, then, is a shallow depiction of the present, and this establishes it not as fictive art but as mere reportage and journalism, what Kurzweil frequently calls "a literarization of life" and not literature. This is what Kurzweil means when he pronounces continuously that such novels as Shamir's Hu'halakh basadot or Yizhar's haHurshah bagiv'ah lack the "dimension of depth" and a "sense of proportion" that a relationship to Jewish time would give them, and hence they are flat, two-dimensional, confined to the present and, therefore, superficial. 78

These formidable artistic problems are compounded by others. First there is the collectivistic, herd-like posture of such prose. The perspective is that of first-person plural, the "Palmach" refrain of "ever we", and not the individuated narrative "I" that is necessary for true art. This is related to what Kurzweil often terms the "narcissistic sentimentality" of such narrative, a quality that he feels controverts the requirement in all good fiction for the narrator to stand back from his world and body it forth with objectivity. In doing this such a narrator will come to understand the esthetic value of compression of language and the subtleties of silence, as Agnon shows them. Kurzweil consistently advises the young writers to stay away from the novel and concentrate on the short story, which is a more suitable form for their lyrical effusiveness. It is easy to understand why Kurzweil, armed with such criteria, prefers Amichai the poet to Amichai the novelist ${ }^{79}$ and why he demolishes Yizhar's Yemei tsiklag. His stern judgment of it as not at all "the great Israeli novel" everyone had been waiting for but simply an overly long and stupendously boring expansion of a "Palmach" story remains one of his most controversial attempts to sabotage pretensions. ${ }^{80}$

In the light of all these limitations in both the would-be artists and their embryonic society, Kurzweil warned almost from the outset of his career against the dangers of even making the demand "give us the great Hebrew novel!" much less of hailing any work as such. Art, he cautions, is not created on demand but must grow organically from within. ${ }^{81}$ If the young writers will learn from Agnon and Hazaz how to link past and present organically and "the secret of silence", then Israeli fiction in time might flower.

We have only to decide if we truly intend to create something new, in which case what is needed is great 
patience, for the hour is not yet ripe for certain literary forms which appear on $1 y_{82}$ as exquisite fruits after centuries of a rich culture.

Throughout the two subsequent decades no Israeli novel appeared that made Kurzweil alter this prognosis. ${ }^{83}$ By the mid-sixties he senses that though technical standards have improved, the over-all artistic situation has declined drastically. ${ }^{84}$ Instead of moving towards the admittedly difficult goal of authentic Hebraic creativity, such figures as Shahar, Tammuz, Aharon Meged, Amichai, and their younger counterparts Amos $\mathrm{Oz}$ and A. B. Yehoshua (in his earliest efforts) have modishly embraced the "contemporary" modernism of post-World War II Europe. In other words, the anomic individualism and nihilistic tendency of French Existentialism have assured the entrenchment of Hebrew letters in the realm of the absurd. To be sure, the new Hebrew novel is not quite as preoccupied with surfaces as the French but, in comparison, the "Palmach" novel that was judged to be so superficial he now sees as positively profound. For there at least fiction had reference to the semblance of a world, however inchoate, and, more important, to a set of ideals, however inadequate. Now the younger writers have become disillusioned with the zionist vision no less than their forebears were with the traditional values of Diaspora; all that is left is a highly polished technical virtuosity that masks the emptiness beneath it. ${ }^{85}$ Kurzweil thus comes to repudiate completely one of the most widely read works of Israeli fiction perhaps since the founding of the state, Amos Oz's Mikha'el sheli. In one of his most spiteful and acrimonious essays kurzweil confesses to a total inability to grab hold of the work because there is no nexus whatsoever between it and anything outside it--author, society or reader. Its heroine, Hannah Gonen, he regards as more dangerous to Israel as a nation than all the Arab armies! 86

We can recognize here the conjunction of this judgment with Kurzweil's general unwillingness to accept all manifestations of literary modernism. I shall explore the significance of this unwillingness as well as of Kurzweil's critique of Israeli literature within the context of the assessment below of the totality of his criticism of modern Hebrew literature. We are left with the question: was Kurzweil unreservedly satisfied with any single work by an sabra writer? He himself at various points answers positively: the poetry of $\mathrm{Zach}$ (whose work he never really deals with ${ }^{87}$ ), Ravikovitch and Amichai, the early Yizhar (though not as fiction but as an example of another genre, heroic epic), Shamir's 
Bemo yadav, parts of Mossinsohn's Derekh gever and a few of the stories of Shahar and Tammuz--these Kurzweil cites as works he admires. ${ }^{88}$ In the short stories of A. B. Yehoshua he perceptively sees the first intimations of the kind of fiction he is looking for from Israeli writers. 89

But such a list strikes me as the proverbial damnation with faint praise. The reality is that for kurzweil, art, culture and man since World War II have been in decline, and post-1948 Israeli literature is but a mediocre, Levantine, relatively unexciting reflection of this process, and has contributed nothing to the development of modern Hebrew literature as he construes it. 90

\section{Summary Evaluation}

Kurzweil's criticism of European literature structurally resembles his criticism of Hebrew literature. And so with the same stroke he is able to show how modern Hebrew literature relates to the European tradition and how it is distinctive from it. The upshot of his unrelenting insistence on modern Hebrew literature as a rupture with the Jewish past is the insight which the following passage brilliantly conveys:

Modern Hebrew literature is qualitatively, as well as in its spiritual and social aspirations a part of world literature. Its significance [as such] cannot be diminished. . - by an order of retreat back into its narrow national boundaries. . . . It was necessary to recall the dialectical situation between continuity and revolt and to push the emphasis onto the new . . so as to break down the isolation [of] Jewish [literary scholarship] and to integrate it into the literary world of all cultures.

Since the hour of birth of modern Hebrew literature is the hour of the loss of simple religious faith, this literature overtly displays a new relationship to the very existence of the Jews. Jewish being possessed most distinctive qualities in that it was an existence without a land and without a living language. Therefore, this literature proclaims through its greatest representatives the existential crisis of modern man in general before this crisis became pervasive and reached full consciousness in the literary creations of other nations whose existence was more "protected" and secure socially, politically and culturally. In other words: self-consciousness as sich-Selbst-Verstandich-Sein, that is, to be secure about the certainty of one's own existence was for the Jew without religious faith something completely different than for the Englishman without Anglican faith or for a Frenchman living without the certainty of the Catholic faith. To the Frenchman, the Englishman, the German or the Russian his national existence in his land, state and culture remained [self-] evident. What, however, was left for the Jew in 
Diaspora among the Gentiles, after the loss of his faith?

This is the burning question in modern Hebrew literature. It turns into a bitter wail in its greatest artists. . . The seismic sensitivity of the [Hebrew] artist[s] is an anticipation of what is fated for the illustrious artists of the world as a whole as, in the wake of the traumas of the twentieth century, the illusory bastions of culture are devastated.

I cite this passage in all its length because, written as it was in the last months of his life, I see it as the central insight toward which Kurzweil, as a comparatist in the Goethean sense, strove throughout his career as a critic. If the dynamic of modernity is the passage "from vision to the absurd", then the Jewish condition, as reflected in modern Hebrew literature, is the harbinger of the human condition as reflected in modern European literatures, for the linguistic crisis that the Hebrew language undergoes, in this view, is the most severe one that any language can experience. Moreover, if we begin to view, as I have suggested is possible, the body of Kurzweil's Hebrew criticism as a kind of history of modern Hebrew literature from within, one governed by norms inherent in the literature itself and not biographical facts imposed on it from without, then we must grant that this criticism may indeed begin to meet Wellek's demand that

the problem of "nationality" and of the distinct contribution of the individual nations to the general literary process [be defined] with theoretical clarity [so that we are] able to analyze the exact way in which each natiogal literature enters into the European tradition.

From a disciplinary perspective Kurzweil's work would seem to bear out Brouwer's suggestion that comparative literature

must not over-look the small literatures; there are processes at work whigh have often in the past ended up in great literatures.

Within the Hebrew literary sphere itself Kurzweil's work, both in its theory and in its praxis, must be seen as a source of enrichment. The manner in which it dissociates modern Hebrew literature as literature from the assumptions and fortunes of the zionist movement and all its attendant ideologies must be recognized as among its most important accomplishments. Artistically Kurzweil, in spite of the contumely vented upon him for doing so, probably demanded more of modern Hebrew writers than had any critic before him. It is important that we recognize why this had to be: if modern Hebrew literature is going to remove itself from its unique sphere--the sacral--and exist in the secular sphere in 
which all other literatures are created, then it has to be judged by the most discriminating esthetic criteria of that sphere. ${ }^{94}$ on the other hand, Kurzweil never allows us to forget that this literature cannot ignore those criteria which come out of its own tradition. Thus, for example, the Israeli novelist (and critic) who would presume to create (or judge) an historical novel has to face both all the formidable problems the genre in general poses as well as those presented by the unique nature of the Jewish past. He must find a way to treat fictively an ancient society without rationalizing, historicizing or otherwise distorting its sacral nature, and he must be very careful that the sublime language of the Bible and the rabbinic periods does not get in his way and drown him out. 95 The same is true in the poetic treatment of Biblical motifs like the Akedah (the sacrifice of Isaac); here, too, the religious context in which the whole story moves must be taken into account. ${ }^{96}$

There is evidence that many of the younger writers respected and paid a great deal of attention to Kurzweil's strictures and in time came to accept them, whether consciously or not. Moshe Shamir in the fifties abandoned the "Palmach" story and essayed a return to the Jewish past in Melekh basar vadam, an attempt that Kurzweil welcomed and took seriously. ${ }^{97}$ Shahar, Amichai, Oz and Yehoshua made a similar movement not in terms of form but of setting as they all came to explore Jerusalem as the locale for their works. Others, however, whether they felt it or not, refused to be the recipients of the back of Kurzweil's critical hand. A common complaint--and, I would add, an understandable one from their point of view--was that he held out no real constructive possibilities for them to follow. T. Carmi put it well: when the developing writers try to learn from continental or American techniques, Kurzweil condemns them as Levantine imitators, and when they ignore the western literary tradition, they are condemned as Levantine provincials. ${ }^{98}$ Furthermore, transcendence and the Jewish past are really closed cases for them and, if the present alone is, in Kurzweil's view, an inadequate basis for narrative art, then he gives them nothing to work toward 99 except silence. The most eloquent response to this implication came from Amos $O z$ who answered Kurzweil at the Israeli-French literary dialogue in 1966. Oz refuses to cower in silence simply because it was his destiny not to have been born in the European Diaspora and to have had the experiences that foster the kind of Hebrew literary art kurzweil demands. "I refuse," he says, "to stand in a posture of abnegation" with a permanently crippling 
inferiority complex that the humility toward the Jewish past that Kurzweil calls for really means. Instead, $\mathrm{Oz}$ avers that, his recognition that he is artistically in a more difficult position than his forbears notwithstanding, he has no other way but to write and in no other language but modern Hebrew. 100

This inability to introject critically what the Sabras were doing indicates the weaknesses that lie at the heart of Kurzweil's approach to modern Hebrew literature. It bespeaks a fundamental and consistent inability to grasp the reality that the young Israeli writers perceived and to accord esthetic value to its representation in literature. This is as true of his reaction to Shamir's Hu'halakh basadot as it is of Yizhar's yemei tsiklag and oz's Mikha'el sheli. In all cases it is possible to say that, in spite of an acute analysis, he essentially mis-reads these novels. In the latter case, especially, his insensitivity to the novel as a psychological and not only a social instrument is responsible for the mis-reading, but this is an insensitivity familiar from the European criticism. In the final analysis, Kurzweil's treatment of post-1948 Israeli literature seems to be of the same order as Kariv's handling of modern Hebrew literature of earlier periods.

It is a truism that everything in life has its price. So, too, I would conclude, in literary criticism. No method or critical approach apprehends literature in its totality. Kurzweil's inability to accept the Israeli phase of modern Hebrew literature, like his inability to accept European literature after Broch, is the price he pays for what he can achieve with the "tragic" phase and pre-World war II works. What forces him to pay this price, we can now see, are the particular presuppositions and postulates about literature, language and the Jewish people to which he is committed. Kurzweil himself doubtlessly would not have seen it this way, in terms of a price, for he would hardly have thought he was missing out on anything; if anything at all is not to be overlooked it is the crisis of man as literature depicts it, for otherwise literature itself is irrelevant if not immoral.

But here I am constrained to say that the definition of this crisis as essentially one of religious faith, noble and even sublime as it may be, is, no matter how phenomenologically arrived at, an existential one and, therefore, unverifiable. So, too, in the Jewish context: what Kurzweil regards as absurd, viz. Jewish existence beyond belief in a living God and tradition, is not necessarily so for large numbers of Jews, just as the definition of "vision" as the timeless Divine covenant of sinai is not one 
that is unanimously accepted. In any case, to found a theology upon the ontological nature of the Jewish people and the Hebrew language is one thing; to found a body of literary criticism upon them is quite another. There are many who argue from more materialistic premises that there is no such thing as meta-history and that the Jewish people, like the rest of the human family, is simply a physical organism developing in history with its own biological, demographic, cultural and intellectual dynamics. ${ }^{101}$ In this perspective religious faith may be nothing more than one possible mode or even stage of the organism's life. Logically it seems to me no less possible to make this argument, and anyone who would approach modern Hebrew literature from these premises would indeed have to dismiss Kurzweil's work as, in Band's words, "ultimately destructive". ${ }^{102}$ But then the onus would be upon him to apply his own particular assumptions, norms and criteria, for criticism cannot take place without these. 103 such a critic, I think, would be hard put to match the comprehensiveness and coherence Kurzweil's criticism exhibits, not to mention its human passion and concern. 
CHAPTER VII

\section{BARUKH KURZWEIL: THE SENSIBILITY OF \\ WEIMAR GERMANY IN RAMAT GAN}

This inquiry now approaches its end. Throughout it, especially at the close of chapters four and six, lie scattered a series evaluative conclusions I believe can be drawn about kurzweil and the body of literary criticism he has left. If these conclusions are more an elaboration of some valid insights made by Kurzweil's most perceptive readers rather than purely original ones, that is because the primary need I see at this time is precisely to synthesize, clarify and develop those insights. It is only on this basis that future work on Kurzweil and modern Hebrew criticism can proceed, even if it may come to qualify or revise these findings.

This study has addressed itself in particular to two points about Kurzweil's criticism that have contributed to an imprecise understanding of it. First is the discrepancy between what I would describe as the form and the content of Kurzweil's criticism. The form is the relatively short essay or article in Ha'arets or some other newspaper or periodical, while the content of each such individual piece pre-supposes a familiarity with the total corpus and its unique assumptions. This self-reflexive quality places anyone who wishes to get to the bottom of any one instance of Kurzweil criticism at an immediate disadvantage: it forces him either to become a veritable kurzweil specialist or to run the risk of mis-apprehending that particular essay. In order to preclude both these alternatives, the above chapters have treated the entire Kurzweil corpus as one large mosaic; even though more than half of it is now available in ten volumes, I have sought to relate almost all the parts to the whole.

The second point behind the incorrect understanding of this criticism lies in the content itself: it is grounded in an intellectual tradition and a theory of literature that, to the extent they are even known in the American and Israeli literary worlds, have not fared too well there. That is why I have paid special attention to establishing and uncovering these linkages. without taking them into account, Kurzweil is very much a closed book. Briefly, I would summarize their implications as follows. 
I.

Literature is important principally as a discloser of truth about man, as a human revelation of the human spirit, as the only full, satisfactory and dynamic answer to what is judged the most fundamental and pressing of all questions since the waning of the sacral middle ages--what is man? Literature thus provides what neither philosophy, no matter how anthropologically oriented it may be (viz., Scheler), nor history nor any of the other humanistic and social sciences can ever tell us. Further, it furnishes us with more insight into reality than the natural sciences. This is because instead of breaking down reality and dissecting it or manipulating it as an inert object for human control, literature, because it is art, re-constitutes polysemous reality into a wholeness that relates man to the cosmos in a way that transcends the cartesian dualism of subject-object. In other words, literature, like all art, furnishes man with that fullness of being that is born of the dialogue between "I and Thou" as Buber developed it.

This, in turn, is because the act of literary creation is itself the transmutation into language of the encounter between the "I" of the literary artist and the "Thou" of his world (i.e., his society, his tradition). Dilthey's theory of art as Erlebnis is the operative one here, and I have emphasized, in line with Dilthey studies, that this is not an historical, biographical or psychological matter but an existential-phenomenological one. Iiterature is important because it alone, at its most sublime, can furnish wholeness of perception and certainty to man now that religious faith is no longer available, and it must be read to recover from it this vision, "Anschauung" in the Goethean sense, and not as an illustration of some arbitrarily defined zeitgeist or as a document of Geistesgeschichte.

Literary criticism thus partakes of the same process as literary creation, only it does so from the side of the discerning reader not of the literary artist. Criticism is primarily interpretation of the literary text and evaluation of it in the light of the total human situation of which that text is a part. Criticism aims at laying bare the Erlebnis of a work through the act of verstehen. Such a view has its roots in the hermeneutic theory of Schleiermacher, Dilthey and Heidegger and it has been developed in recent years by Gadamer. It sees the critic in a way very different from other approaches such as formalism, structuralism and New Criticism. I have brought to bear some evidence 
that at bottom this difference is an epistemological one. The latter approaches rest on an Aristotelian realism whereby the literary text is seen to exist as an objective entity susceptible to anatomization and analysis; hermeneutics as understood by Kurzweil and German critical theory rests on the mode of cognition developed by Husserl, whereby the literary text is not reified but perceived in total subjectivity, out of the "transcendental ego" of phenomenology. More than anything else, a literary work contains a human voice, and the task of the critic is to hear that voice and render it audible. Criticism, then, is as much an art as poesy or narrative, and any attempt to construe it as a science subverts it. The kind of hermeneutic interpretation Kurzweil espouses seeks after the subjectively--but not arbitrarily--defined truth of a work and renounces the problem of validation. Kurzweil is much closer to Hans-Georg Gadamer's wahrheit und Methode than to E. D. Hirsch Jr.'s Validity in Interpretation.

As a phenomenological critic, Kurzweil seeks to penetrate to the heart of a work, to reduce it to its undeniable essence. As a hermeneutician, he operates in terms of a cognitive and perceptual circle whereby what he regards as the essence of a work, its "intrinsic coherence", is related to even as it is determined by the essence of the total oeuvre of its creator, which essence in turn implies and is implied by the Eidos of the society and culture of which he is a part. Kurzweil reduced the problem of western culture to the problem of man or, more accurately, to the problem of a proper relationship between man and society. He posits a kind of spiritual Golden Age when religious faith and practice bespoke a sacral existence in which this relationship was in balance, and he sees modernity, beginning about the time of the Renaissance and intensifying with the Enlightenment, as a loss of faith in the living God and the consequent enfranchisement of man as the ultimate power, throwing the entire relationship out of balance. This process is commonly termed secularization but Kurzweil understands this in metaphysical, not sociological, terms. Its culmination has come in the twentieth century, "the last days of mankind", when the full absurdity and horror of man, living beyond good and evil, outside the relationship to any values be they of an absolute God or of a relativistic humanism, has manifested itself in two world wars and the imminent prospect of a final apocalypse.

Modern literature, regardless of its genre or language, of necessity reflects some aspect of this process. Kurzweil sees it all as one large metaphysical field and so is able to relate the 
various European traditions to it in spite of the fact that he recognizes the individual nature of each. In actuality, however, Kurzweil is not open to substantial areas of modern literature; his holism causes him to see the drama solely in terms of tragedy, where he follows Hegel more than Aristotle, and leads him away from the bulk of modern poetry. Essentially it is fiction that is his focus but even here he is primarily concerned with the French and German novel from Goethe to world war I.

Modern Hebrew literature is read in the very same way. This allows Kurzweil to account for the manner in which it is linked to the total field of modern literature as well as at the same time to point to its distinctive features. His work here represents a development of Klausner's ideas that secularism is the essential quality of modern Hebrew belles lettres--and that their terminus a quo is the Enlightenment of the late eighteenth century. Kurzweil determines that the absurdity of the human condition as depicted in the literature of modern Europe is presaged by the Jewish condition as modern Hebrew literature at about the turn of the century begins to present it. This is because the collapse of the humanistic ideals of the Haskalah, on top of the earlier disintegration of Jewish religious faith, makes the modern Jew a paradigm, if not a harbinger, of the metaphysical nakedness that would pervade all of Europe in the wake of World War I. Kurzweil's readings of Bialik, Brenner and Tshernichovski are explications of this idea; his interpretation of Agnon and Greenberg affirms the possibility that the dynamic of modernity in the present can be denied and transcended by envisioning a re-sacralized future worthy of the Jewish past; and his rejection of the post-1948 Sabra writers stems specifically from what he sees as their refusal to accept the meta-historical realm, their consequent denial of the ontological status of the Jewish people and their resultant embrace of a literary modernism bereft of all cultural values.

II.

This remarkably coherent mosaic of thought and criticism did not evolve in any particular stages over Kurzweil's thirty years as a critic. In reviewing this career we find no substantial revisions or dramatic reversals of position. Rather, the outline of the mosaic is already quite visible in the doctoral thesis of 1933, and the treatment of modern Hebrew literature that began after the encounter with Agnon's ore'ah natah lalun in 
1939-40 represents but an expansion, not a re-design, of the total structure. In the course of the years one does see a gradual refinement of the total picture; more and more pieces are put in as Kurzweil responds to new ideas in esthetic and critical theory in Europe and America, absorbing some of them and repudiating others. This is why it has made no sense to deal with the Kurzweil corpus developmentally.

Kurzweil's criticism invites analysis from a different perspective. In the course of discussion I have repeatedly pointed out that it coheres only inside the framework imposed by its creator. That is to say, it is most vulnerable outside the pre-suppositions and postulates on which it rests. Once we grant Kurzweil these I think it becomes quite difficult to deny that he has, as Y. Talmon has said of his views on Jewish nationalism, "an irrefutable and hermetically closed case". But no less significant is Talmon's subsequent comment:

\begin{abstract}
That is the strength of the "case" and that is its weakness, for life is not as logical as logic. Certainly we should believe, but what if we are unable to? And what if faith does not come by itself? It cannot be brought into being by any artificial means [or] by fiat.
\end{abstract}

As I have shown, in spite of all its claims at an analysis free of pre-suppositions, the phenomenological method has no reference to that which lies beyond what is grasped out of transcendental subjectivity. All Kurzweil's reading flows out of certain specific pre-suppositions about man, God, religion, the Jewish people and language, and he cannot free himself from these in his criticism. But the pre-suppositions themselves are certainly open to question.

Philosophically, Kurzweil can be seen to combine the legacy of German idealism with German existentialism. ${ }^{2}$ He appropriates and synthesizes various elements in the tradition that runs from Goethe through Nietzsche, Dilthey, Buber and Heidegger. The polarity between Geist and Leben, the central issue of Lebensphilosophie, is a fundamental Erlebnis out of which his criticism proceeds. Isaiah Tishbi, in an exchange with Kurzweil over the latter's handling of Gershom Scholem and Sabbatianism, comes to wonder "what is the meaning of the satanic quality that pervades Kurzweil's articles?" His observation tells us more about Kurzweil than he might have realized:

As an authority on demonology I can flatly say: the deepseated demonism is a basis for his life and work. It is this which has given rise to the bugaboo of making 
Judaism into demonology, and it is from $_{3}$ it that the many weeds that grow in his articles spring.

The demons that torment Kurzweil are the same ones he sees tormenting Faust and all his descendents: individualism, the insatiable demands of the "I" that now understands itself to be living in a universe devoid of an "Eternal Thou" or even a transitory one. There is a distinctly "Promethean" quality in Kurzweil himself, and Abramson has shown the connections between the "true critic" as Kurzweil defines him and the "great individual" of modern fiction that so enchants him. ${ }^{4}$ Indeed, an intensive reading of his writings suggests to me that Kurzweil the critic, in a subtle way, insinuates himself as a type of Nietzschean ubermensch. It is on this basis that we are really asked to trust his subjective judgments and to accept the violence of his engagement with life.

Kurzweil's criticism is superb when it is destructive . . . It is when he attempts to be constructive that he falls victim to the ${ }_{5}$ same wishful thinking which he so skillfully condemns.

Kurzweil is a Nietzschean in another sense too: in his understanding of what modernity is.

As the man who acts must, according to Goethe, be without a conscience, he must also be without knowledge; he forgets everything in order to be able to do something; he is unfair toward what lies behind and knows only one right, the right of what is now coming into being as the result of his own action.

Modernity in these words is not a matter of fashions, movements or manifestoes but, as de Man brilliantly shows, the antithesis to history. This, he feels, is what Nietzshe was trying to teach all along: that there is a fundamental opposition between history and life.

"Life" is conceived not just in biological but in temporal terms as the ability to forget whatever precedes a present situation. . . Modernity exists in the form of a desire to wipe out whatever came earlier in the hope of reaching at last a point that could be called a true present, a point of origin that marks a new departure. This combined interplay of a deliberate forgetting with an action that is also a new origin reaches the full power of the idea of modernity. Thus defined, modernity and history are diametrically opposed to each other in Nietzsche's text. Nor is there any doubt as to his commitment to modernity, the only way to reach the metahistorical realm in which the rhythm of one's existence coincides with that of the eternal return. 
This is exactly Kurzweil's perspective. It is this conception of modernity that explains why he defines the modern crisis as one of belief. For if modernity means forgetfulness, then "forgetfulness is the mother of denial", 8 a line Kurzweil quotes very often. For Kurzweil as a Jew history can and must be escaped not by forgetting it but by transcending it; the rhythm of one's Jewish existence coincides with that of the synoptic vision.

III.

As an intellectual of pre-world war II Central Europe, Kurzweil from a distance can be seen to bear general resemblances to three other "Goetheans" of that time and place--Georg Lukacs, Karl Kraus and Walter Benjamin. Like Lukacs, he structures his reading around an Absolute; but instead of dialectical materialism he weds existentialism to German Idealism. Like Kraus, he is an epigone, a stranger to twentieth century reality, imbued with the same sensibility and beset by the same obsessions.

I was born in the Hapsburg Empire, before the First World War. I write because most of the authors I have loved have already died, and because most of the authors I do not like are alive and continue to write. I write because when I was young I had the strength to hate bad books; now that I am old I am sick of hating bad books. But they are sent to my home, fill up my apartment, and are piled high over the good books which are being choked and which beg mercy from me because they do not want to die.

Like Kraus, Kurzweil

exposed an age which had lost all faith in absolute values and reminded his readers of ages in which life had not been totally subjugated to commercial purposes, but he did not attempt to show how man could introduce meaning into the modern world. Kraus's message was essentially one of despair. According to him, the world was facing its end.

What is true of Kurzweil is what Janik and Toulmin say of Kraus: "It is a central fact about Karl Kraus that the man and his work are unclassifiable."11 Throughout this study I have regarded Kurzweil more or less as a literary critic and referred to his work as literary criticism. This may not be incorrect, but it ought to be noted that this is a criticism that is sui generis, in which the boundaries of esthetic theory, textual explication, culturism and publicism freely intermingle. Kurzweil's singularity comes from the same soil and can be formulated in the same terms as walter Benjamin's: "Critique is concerned with the truth 
content of a work of art, the commentary with its subject matter."12 In this generation it is George steiner who most closely approximates this approach. In his impassioned espousal of the "old criticism", in his critique of structural linguistics and in such books as Language and Silence, The Death of Tragedy and In Bluebeard's Castle, Steiner adumbrates what Kurzweil is saying. 13

What really links Kurzweil with Kraus and Benjamin, however, is what Hannah Arendt describes as "the Jewish question". This she notes as a specific problem of the Jewish intellectual of German-speaking Central Europe before World War II, and one that has been forgotten

\begin{abstract}
although one still encounters it occasionally in the language of the older generation of German zionists whose thinking habits derive from the first decade of this century. Besides, it never was anything but the concern of the Jewish intelligentsia and had no significance for the majority of Central European Jewry. . . [But] no matter how insignificant this problem may appear to us in the face of what actually happened later, we cannot disregard it here, for neither Benjamin nor Kafka nor Karl Kraus can be understood without it. ${ }^{4}$
\end{abstract}

Nor, I would add, can Kurzweil. The "problem" as Arendt describes it has to do with the alienation of these Jewish intellectuals from the Jewish bourgeoisie whom they regarded as living in an "isolation from reality staged with all the devices of self-deception"; ${ }^{15}$ the "question" itself is one of finding authentic content for one's life as a Jew beyond religious faith. The only available options for such Jews were Zionism or Marxism; "both were escape routes from illusion into reality, from mendacity and self-deception to an honest existence". ${ }^{16}$ Both, we may say, supplied the "wholeness" and certainty that religion or metaphysics once did. Now unlike Gershom scholem, for example, or Lukács, who chose Zionism and Marxism respectively, neither Kraus, Benjamin or Kurzweil was able to accept wholeheartedly either of them. ${ }^{17}$ In this respect, I consider Kurzweil's relationship to zionism of the same order as Benjamin's to Marxism: there seems to be an apparent embrace but in actuality there is an ambivalence and a thoroughly selective, idiosyncratic appropriation of the ideology. Arendt points out that the "Jewish question" was accompanied by a corresponding crisis of language; the relationship to German as an alien tongue was as problematical as not writing at all. She notes the same despair in all these men:

The most clear-sighted among them were led by their personal conflicts to a much more general and more 
radical problem, namely, to questioning the relevance of the Western tradition as a whole. . . Walter Benjamin knew that the break in tradition and the loss of authority which occurred in his lifetime were irreparable, and he concluded that he had to discover new ways of dealing with the past.

So did Barukh Kurzweil. The essay "Self Hate in Jewish Literature", 19 where he argues that what appears as Jewish self-hate in Brenner, Weininger, Kafka and, above all, Kraus is really an inchoate longing for a higher reality, shows a revealing abundance of intuitive empathy. Hillel Weiss is quite correct in calling attention to the plethora of "meta" prefixes in Kurzweil's writing--"meta-historic", "meta-temporal", "meta-satirical", and his conclusion is noteworthy:

All these are testimony to Kurzweil's yearning for another reality. He tried to glimpse something beyond reality and above it, as a 2 partner in the tireless struggle of the great artists. 2

In spite of the facts that he was closer to Jewish sources and less "assimilated" than they ever were, that he professed halakhic observance and that he taught at a "religious" university, I have no hesitation in saying that Kurzweil at the core of his being has more in common with Kraus and Benjamin than with more ostensibly rooted "Jewish" figures. The trajectory of his life and thought is clearly "from vision to the absurd". If he lived like the narrator of Agnon's Sefer hama'asim, he died in a Brennerian nullity. 21

Nevertheless, having defined the European roots, I do not wish to deny or overlook the specifically Jewish roots to Kurzweil's criticism. The decisive difference about Kurzweil is that for him Jewish religious faith and tradition were never ruled out $\underline{a b}$ initio as potential well-springs of metaphysical certainty as they were by Kraus and Benjamin. All Kurzweil's struggles are within a particular Jewish context. In comparison with him, Kraus and Benjamin were indeed rootless cosmopolitans. But the Jewish nature of Kurzweil's work is ipso facto much harder to pin down. As Peter Salm has observed:

Studies dealing with literary theory call for a more international point of view than those dealing directly with literature. . . Poetic and aesthetic theories are justly expected to tranģend the special problems of nationality and language.

And the poetic principles of Kurzweil's criticism, as we have seen, derive directly out of European esthetics. 
Still I would argue, however speculatively, that there may be a number of Jewish ingredients subtly inter-mixed here. Kurzweil's steadfast refusal to concede the autonomy of the esthetic domain, more than it may be an affirmation of the Kantian ideal of the integration of the beautiful with the good and the true, may be an unwitting expression of the classical Jewish fear of the idolatrous possibilities of beauty, especially man-made beauty, when it is made an end in and of itself. 23 In the same way his attitude to the literary text, beyond its grounding in phenomenological hermeneutics, can be seen to have affinities with the attitude of the rabbis to the Biblical text. It was, after all, Buber's approach to the Biblical text that Kurzweil says first opened him up to the art of all reading. In its larger sense what Kurzweil ultimately gives us is an extended midrash on modernism, modern man and the modern Jew, a midrash which, like its rabbinic forbears, tells us more about its creator than about the text. Criticism in general has been called "a fiction on fiction", 24 and more than once has attention been called to the manner in which Kurzweil's assumes an independent existence, attached sometimes quite tenuously to the work on which it is based. ${ }^{25}$ The most theoretical question that this body of criticism stimulates is the same question that the prose of Agnon and the poetry of Greenberg raise: do they represent a groping toward a particularly Jewish esthetic? Can we even speak of such a thing? As far as criticism goes I have already noted that there is a correlation between the philosophical and epistemological approaches dominant in a culture and the prevailing critical tendencies. ${ }^{26}$ Anglo-American criticism generally is rooted in realism and empiricism and looks for analysis and validity; Continental criticism comes out of phenomenology and existentialism and strives after feeling and depth. Can we speak of a distinctly Hebrew criticism, one grounded in pre-suppositions and an epistemology indigenous to Judaism? ${ }^{27}$ The question is more easily raised than answered. In any case $I$ do not claim that Kurzweil's criticism, whose Continental nature is clear, signifies any answer. But it does force the question in a substantial way. 28

IV.

R. P. Blackmur has written:

The worst evil of fanatic falsification--of arrogant, irrationality and barbarism in all its forms--arises 
when a body of criticism is governed by an idee fixe, a really exaggerated heresy, when a notion of genuine but small scope is taken literally as of universal application. This is the body of tendentious criticism where, since something is assumed proved before the evidence is in, distortion, vitiation, and absolute assertion become supreme virtues. . . But even here, in this worst order of criticism, there is a taint of legitimacy. Once we reduce, in a man like Irving Babbitt, the magnitude of application of such notions as the inner check and the higher will, which were for Babbitt paramount--that is, when we determine the limits within which he really worked--then the massive erudition and acute observation with 29 which his work is packed become permanently available.

This seems to me, when applied to Kurzweil and when such key notions as secularism, the demonic, and primordial wholeness are substituted, to be what a final judgment about him from a minimalist position would sound like.

A maximalist one would go further. He would say, as I would like to, that the central issue of Kurzweil's work is hardly of "small scope". Kurzweil asks the large questions of literature and he therefore should not be called to account if he gives large answers. An encounter with his criticism, with all its limitations and inadequacies that $I$ have pointed out, is a unique engagement with the ultimate issues of literature and modernism, a disquieting induction to life and the utter earnestness of the human and the Jewish struggle. It is difficult to read in quite the same way after him. George steiner says of Lukács:
It is not the particular omission or persuasive insight that constitutes Lukács' essential quality. His great- ness is a matter of inner stance, of tone. Wherever we accede to this large enterprise of criticism and philo- sophic argument, the sense of a supreme seriousness, of a complete trust in $3^{\text {the }}$ life of the imagination and of thought, overwhelms.

With justice can the same be said of Barukh Kurzweil. If literary criticism is indeed a series of various frameworks and languages devised by critics and, therefore, the individual critic is only as good as the way he uses what he devises, then kurzweil must be judged a great one.

The Israeli critical scene today, in spite of the proliferation of technical prowess, conspicuously lacks a figure of Kurzweil's mien. It misses him and is all the poorer for his absence. To be sure his disciples attempt to continue his teaching but most of them are under no illusion that they can do this in quite the same way. What came together in Kurzweil was an induplicable blending of background, temperament and innate 
ability. In general, the scope of literary study in Israel seems much reduced now and Israeli critics appear to be content to work within it and answer smaller questions, albeit with proficiency. But when the time will come when this scope and these questions will not satisfy, when once again the big questions of modern literature, especially modern Hebrew literature, will come to the fore, Kurzweil's contribution will have to be dealt with. The ten volumes of his work, and more as they are re-claimed from the pages of fading newspapers and periodicals, will, I am certain, stand, indispensable and unavoidable to all who seek to understand what the word "modern" means. 
NOTES

\section{Note to Preface}

${ }^{1}$ Professor Henry Fischel in a letter to me (August 11, $1977)$ suggests that 'hukiyut penimit' "is in all probability a rendering of the German 'innere Gesetzmässigkeit', which is slightly more substantial than 'intrinsic coherence'. The original is a term of German Idealism, probably also of 19 th-century German romanticism...." 


\section{Notes to Chapter I}

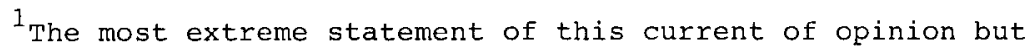
not unrepresentative of it, is Menahem Perry, "Mikhtav galui leProf. Barukh Kurzweil", Yedi'ot aharonot, Aug. 30, 1968. Perry concludes: "I maintain that you are incapable of performing a single interpretation of any Hebrew poem. . . ." The narrow assessment of Kurzweil as a "sociologist of literature" was expressed by Dr. Menaham Brinker in a radio discussion about Kurzweil ("Mesibah sifrutit", Israel Defense Forces Radio [Galei Zahal], May 30, 1976).

\section{${ }^{2}$ Arnold J. Band, Nostalgia and Nightmare: A study in the} Fiction of S. Y. Agnon (Berkeley and Los Angeles: University of California Press, 1968), p. ix. Something of a contradiction lies at the heart of this judgment: if Band sincerely believes that Kurzweil's work is "fructifying", it is hard to understand how he can regard it as "ultimately destructive".

${ }^{3}$ See Moshe Schwarcz, "Hanahot estetiot bemif'al habikoret shel Barukh Kurzweil", SBK, pp. 375-397 (also in Hagut yehudit nokhah hatarbut hakelalit (Tel Aviv: Schocken Publishing Co., 1976), pp. 165-195; Hillel Barzel, "Terumato shel Barukh Kurzweil leheker Shai "Agnon", SBK, pp. 74-92; "Kurzweil 'al haroman vehasipur haeiropeiyim", Moznayim XXXIX/1 (June, 1974), pp. 22-30; "Ahdut veribui bemishnato shel Barukh Kurzweil", Moznayim XXV/4-5 (Sept. - Oct., 1967), pp. 266-272; "haHatirah el lev hayetsirah darko shel Barukh Kurzweil bevikoret hasifrut", Yedi'ot aharonot, oct. 13, 1972; "'Agnon be'einei Kurzweil", Mevo'ot, VII (December 31, 19531, pp. 6 F; Yehudah Friedlander, "Humanist bedimdumei tarbut shoka'at", Ha'arets, September 7, 1973 (reprinted as preface to $M R^{2}$ ).

See also Ya'akov Abramson, "Sipurei Barukh Kurzweil vezikot hagomelin beineihem levein masotav", (Bar-Ilan University, unpublished master's dissertation, 1974). This work articulates the relationship of the three stories Kurzweil wrote to the larger body of his critical writings.

${ }^{4}$ see M. H. Abrams, "What's the Use of Theorizing about the Arts?" In Search of Literary Theory, ed. Morton W. Bloomfield (Ithaca and London: Cornell University Press, 1972), pp. 3-54, esp. pp. 39-49.

${ }^{5}$ See Alan Donagan, The Later Philosophy of R. G. collingwood (oxford at the clarendon Press, 1962), pp. $21 \mathrm{f}$.

${ }^{6}$. S. Crane, The Languages of Criticism and the Structures of Poetry (Toronto: University of Toronto Press, 1953), pp. $10 \mathrm{f}$.

${ }^{7}$ Ibid., p. 13 .

${ }^{8}$ Ezra Spicehandler, Encyclopedia Judaica, q.v. "Modern Hebrew Literature", vol. VIII, p. $175 \mathrm{~b}$.

9lit. "the tongue of sanctity". The name here gives the sacred a substantive quality.

${ }^{10}$ Spicehandler, p. $178 \mathrm{a}$.

$11_{A}$ good survey is Shalom Kremer, "Netivot bevikoret ha'ivrit 1920-1960", Me'asef, V-VI (1966), pp. 348-376. 
${ }^{12}$ R. Wellek and A. Warren, Theory of Literature, $3 r d$ ed., (New York: Harcourt, Brace \& World, 1956), pp. 52f.

$13_{\mathrm{H}, \mathrm{pp} .} 212 \mathrm{f}$.

14 For our purposes this is when Kurzweil's career as Hebrew literary critic begins. Technically, as I shall note in the next chapter, his involvement with literature goes back further, to his doctoral studies at the University of Frankfurt in the early thirties.

${ }^{15}$ The longest combined piece Kurzweil wrote is "Be'ayot yesod shel sifrutenu hahadashah", S, pp. 11-146. Of this, however, about a quarter (sections $1-6$ and section 8) appeared previously and separately.

16 Moshe Schwarcz, "Barukh Kurzweil kehogeh de'ot shel hayahadut", Ha'arets, June 13, 1975. (Re-printed in Hagut yehudit nokhah hatarbut hakelalit, pp. 196-224.)

$17 \mathrm{H}, \mathrm{p} .213$.

${ }^{18}$ See Joseph Strelka, prefact to Yearbook of Comparative Criticism, vol. 6: The Personality of the Critic (University Park and London: Pennsylvania State University Press, 1973), pp. viif. Strelka quotes Wellek's statement that "criticism is personal but it aims to discover a structure of determination in the object itself", but he reverses it to read: "Criticism aims to discover a structure of determination in the object itself, but it is nevertheless inescapably personal." Between these two formulations lies a philosophical difference that is crucial and that I shall have occasion to bring out. See also in the same volume, Murray Krieger, "The Critic as Person and as Persona", pp. 70-92.

${ }^{19}$ Richard E. Palmer, Hermeneutics: Interpretation Theory in Schleiermacher, Dilthey, Heidegger and Gadamer (Evanston: Northwestern University Press, 1969), p. 155.

${ }^{20}$ There are two facets of Kurzweil's work that I do not discuss here: his criticism of modern European literature and his own short-lived attempts at fiction. I judge both of these aspects to be of less interest to the general reader. In any case, the former is available largely in $\mathrm{MR}^{2}$ and haDrama haieropiit (1982) and the latter in $\mathrm{N}$. Kurzweil's reputation will always stand or fall with respect to what he did with modern Hebrew literature, and it is on that that this work focuses. 


\section{Notes to Chapter II}

\section{${ }^{1}$ Allan Janik and Stephen Toulmin, Wittgenstein's Vienna} (New York: Simon and Schuster, 1973), p. 27.

${ }^{2}$ George Lichtheim, Lukács (London: Fontana/Collins, 1970), p. 9. Lichtheim makes this statement with respect to Lukács whom he locates within this same tradition. The resemblances between Kurzweil and Lukacs are neither incidental nor insignificant.

${ }^{3}$ The key difference for our purposes is a philosophic one, which we may here describe as a difference between the idealistic tradition of metaphysics of the continent as against the development of empiricism and pragmatism in England and America. This difference, for example, informs kurzweil's critique of Ahad ha-Am (see S, pp. 190-224) and the epistemology of his criticism (see Chapter IV).

${ }^{4}$ Kurzweil himself never ceased pondering and pointing out the differences. Note his essays "Dioknah shel hayahadut hamesoratit beGermaniah", J, 266-290 (esp. $281 \mathrm{ff.}$ ), and "The Image of the Western Jew in Modern Hebrew Literature", Yearbook of the Leo Baeck Institute, 1961 (London), 170-189. Kurzweil says that German Jewry's primary relationship was to the synagogue and to the liturgy, as opposed to East European Jewry's emphasis on the Beit Midrash and Talmudic study ("He'arot leshirei Yehudah Amihai", Ha'arets, June 28, 1963).

${ }^{5}$ Basic biographical facts are found in the curriculum vita sheet attached to Kurzweil's doctoral thesis ("Lebenslauf"), G. Kressel, Leksikon hasifrut ha'ivrit bedorot ha'aharonim (Merhaviah: Sifriat PO'alim), II, $721 \mathrm{f.}$, and in Who's who in Israel (Tel Aviv: Bronfman and Cohen Publishers), p. 196. I am especially grateful to Mrs. Margot Kurzweil for confirming and supplementing many of these facts in personal discussion with me.

${ }^{6}$ This is the date and place that appear on the curriculum vita sheet attached to Kurzweil's doctoral thesis ("Lebenslauf"). The same information is found in the card-catalogue of Genazim, the Asher Barash Institute of Records of the Hebrew Writers' Association in Israel in Tel Aviv. The Hebrew birth-date indicated there is $11 \mathrm{Av}, 5667$.

${ }^{7}$ Gershom Schocken, "Yehudi, ish merkaz eiropa, shamran", SBK, p. 43. Kurzweil has a close relationship to the work of ali of these figures, as we shall see. Schocken overstates the case, I think, though, when he says "I have no doubt that had Kurzweil been born fifty years earlier, his name would be included among these bright lights of central European culture."

8 Encyclopedia Judaica, q.v. "Brno", vol. III. Good historical surveys of Czech Jewry are: Hans Kohn, "Before 1918 in the Historic Lands", The Jews of Czechoslovakia: Historical Studies and Surveys (Philadelphia and New York: The Jewish Publication society and the Society for the History of czechoslovak Jews, 1968), I, pp. 12-20 and Ruth Kestenberg-Gladstein, "The Jews Between Czechs and Germans in the Historic Lands, 1848-1918", ibid., p. 21-71.

9 Encyclopedia Judaica, q.v. "Moravia", vol. XII, p. 303 a. on the Hapsburg characteristics of Herzl and his Zionism see Janik and Toulmin, op. cit., pp. 58-61. 
${ }^{10} \mathrm{~A}$ similar view is advanced by Felix weltsch in his admittedly impressionistic character study of Czech Jewry. Weltsch writes: "I shall take as my thesis.. . that the distinctive characteristics of the Jews of Bohemia and Moravia may be attributed to a delicately balanced blending of romanticism and realism." ("Realism and Romanticism: Observations of the Jewish Intelligentsia of Bohemia and Moravia", The Jews of Czechoslovakia, op. cit., II, p. 44I.) The emphasis is Weltsch's.

11 "Yehudei. Tshekhiah umekoman besifrut", Ha'arets, June 9, 1944. Kurzweil later says that Moravian Jewry was more traditional and less assimilated than Bohemian, and he emphasizes that actually the two are quite different (letter to Ha'arets, "G. Mahler vehag hapesah", May 3, 1959).

12 of all these elements Kurzweil's relationship to secular zionism is the most problematical. But his admiration for Herzl, who he vastly admired over Ahad ha-Am is clear.

13 Kurzweil mentions both in his very personal remarks spoken on receiving the prestigious Bialik Prize in 1964, printed in Ha'arets, Jan. 17, 1964. Presumably, Kurzweil was named after his maternal grandfather.

14 Ibid.

${ }^{15}$ Interview with Haim Shoham, "Diokan shel hoker sifrut sihah "im prof. Barukh Kurzweil", transcript of a broadcast on Israel radio printed in Ha'arets, July 28, 1967.

${ }^{16}$ Mrs. Kurzweil indicates that though the Yeshiva at Bratislava (Pressburg) was much closer to home, it was ruled out, probably because its intellectual climate and attitude to secular studies were too narrow, in his father's opinion, to permit his son to develop there. We may, incidentally, note also that many of these biographical details about kurzweil were unknown to his contemporaries and caused them to draw erroneous conclusions about him. Shlomo Tsemah, for example, attributes the source of Kurzweil's polemical temperament to the fact that he "was born among the towns between Pressburg and Munkatsch (Mukachevo) and was nurtured on the ad hominem literature of polemic noted for its slanderous and embarrassing nature . . ", "haNilozim bema'agalotam", Behinot, VIII (Nisan, 5715, Mar.-April, 1955), 3-14, and re-printed in Sheti va'erev (Am Oved: Tel Aviv, 1959) pp. 109-135. Tsemah is correct in noting the extremist quality of Slovakian-Hungarian Jewry but, as we can see, that is not Kurzweil's milieu. The sources of kurzweil's contentiousness lie elsewhere.

17 Janik and Toulmin's thesis is just this: that the cultural and political corrosion of the late Hapsburg Empire was the pre-cursor of the crisis that was to engulf all of Western culture, "our own twentieth-century culture in its infancy" (p. 13). See also Barbara W. Tuchman, The Guns of August (New York: The Macmillan Co., 1962), which complements this view.

${ }^{18}$ See especially Agnon's Ore'ah natah lalun (Tel Aviv: Schocken, 1939), translated by Misha Louvish as A Guest for the Night (New York: Schocken Books, 1968), Chapters 1 and 7 , and Kurzweil's discussion of the novel in A, 50-68. See also A, p. 14 and $\mathrm{N}$, pp. $109 \mathrm{f}$.

19 "Yehudei Tshekhiah umekoman besifrut." see also $\mathrm{MR}^{2}$, pp. $85 \mathrm{f}$, and $393 \mathrm{f}$. 
${ }^{20}$ See "Dioknah shel hayahadut hamesoratit beGermaniah", where Kurzweil tried to combine honest nostalgia with poetic insight to re-create a picture of the Jewish Frankfurt he remembered. Though subjective, this sketch is nevertheless historically enlightening (even though Kurzweil recoiled against "objective historical truth").

21 For a short sketch see Dr. Eliezer Posen, "The Frankfurt Yeshiva", in the Rabbi Dr. Joseph Breuer Jubilee Volume (New York: Phillipp Feldheim, 1962), pp. 149-154.

22 Forty years later Kurzweil saw Hirsch's solution to the dilemma of Emancipation as an "anachronism"; "The notion of "Torah with derekh 'erets' [Torah with worldly learning] does not suit the changes that have come about in the scientific sphere, which in turn have altered the very approach to the relationship between science and religion." J, pp. 286-289.

23 Kurzweil wrote two important essays on him: "Yitshak Breuer", Ha'arets, Dec. 17, 1943, and "lezikhro shel Yitshak Breuer", Ha'arets, Nov. 1, 1946. Re-printed in L. pp. 117-130. See also the historical discussion by Ya'akov Levinger, "haTsiyoni halohem batsiyonut", SBK, pp. 151-168.

24 Besides Kurzweil's discussion of Hirsch in $J$, pp. 285-289, see his treatment in his three instructive essay-reviews of Rotenstreich's hamahashavah hayehudit ba'et hahadashah, Ha'arets, Jan. 11, 1946, Jan. 26, 1951, and Feb. 9, 1951. These are re-printed in $L$, pp. 41-60.

${ }^{25}$ Kurzweil says he heard Husserl lecture, though he does not say when or where. "haMetsi'ut hahadashah beshirah hamodernit", Feb. 16, 1962.

${ }^{26}$ Limburg a.d. Lahn (Druck der Limburger Vereinsdruckerei G M. b. H.), 1933, $114 \mathrm{pp}$. Two copies of this dissertation are extant. I am grateful to Mr. Ya'akov Abramson of Yad Kurzweil at Bar-Ilan University for making one available to me. In the "Lebenslauf" appended to the work Kurzweil lists his teachers: "Cornelius, v. Düring, Gelb, Gelzer, Gumbel, Heinemann, Kommerell, Naumann, Platzhoff, Riezler, Rheindorf, Schneider, Schultz, Tillich, weber and wertheimer."

Hans Cornelius and Franz schultz were the heads of the Aesthetics and German departments respectively at the University of Frankfurt. It was they who had rejected Walter Benjamin's thesis on the origin of German tragic drama in 1928 (see Gershom Scholem, "walter Benjamin", Leo Baeck Institute Yearbook, X (1965), p. 126). Cornelius has been described as "a passionate teacher . . . in many ways the opposite of the current image of a German university professor, and in strong opposition to most of his colleagues. . . . Cornelius never hesitated to confess openly his convictions and his despair about present-day civilization." Quoted from a letter of Friedrich Pollock in Martin Jay, The Dialectical Imagination: A History of The Frankfurt School and the Institute of Social Research, 1923-1950 (London: Heinemann Education Books, 1973), pp. 44 f. Paul Tillich is probably the figure most familiar to the American reader though it should be clear that he is only one of the many exponents of existentialism to which Kurzweil was exposed. Max Kommerell and Fritz Heinemann belong here, too. The former was identified with the George circle and "the hunger for wholeness" that poetry filled in Weimar Germany. See Peter Gay, Weimar Culture: The Outsider as Insider (New York and Evanston: Harper and Row, 1968), pp. 48-106 and Rene Wellek, Concepts of Criticism (New Haven and London: Yale 
University Press, 1963), pp. 64 f., 361 f. Heinemann was a student of Hermann Cohen and his important work is Neue Wege der Philosophie: Geist, Leben, Existenz (1929).

Adhémar Gelb and Max Wertheimer were professors of psychology, the latter being one of the founders of Gestalt theory. Matthias Gelzer was a professor of ancient history. Hermann Gumbel and Hans Naumann taught German philology. Naumann was a rather highly regarded scholar and is the subject of extensive discussion in Karl Korn's Lange Lehrzeit. Walter Platzhoff, Fedor Schneider and Kurt Rheindorf were professors of medieval and modern history. Kurt Riezler was honorary professor of the philosophy of history and later became Curator of the university. This information comes from both the archives of the Johann Wolfgang Goethe University at Frankfurt as well as the Kürchner Gelehrten Lexikon for the years 1928-1933. Neither source mentions the other two men Kurzweil names, $V$. Düring and weber, and I am unable to identify either with any precision. I am indebted to Professor Egon Schwarz of Washington University for assisting me in obtaining the information in the preceding paragraph.

27 This ordination entitled him to fill the liturgical and pastoral functions of a rabbi but was not the full semikha which empowered one to rule on questions of Jewish law. In any case it is doubtful if Kurzweil was interested in achieving that status. Note Zvi Kurzweil's statement about his brother that "he did not receive the title 'Rabbi"", "Barukh Kurzweil kemehanekh", SBK, p. 35 .

${ }^{28}$ on Horkheimer, who he says was heavily influenced by Cornelius, see Jay, op. cit., pp. $44 \mathrm{ff}$, and Eva G. Reichmann, "Max Horkheimer the Jew: Critical Theory and Beyond", the Leo Baeck Institute Yearbook, XIX (1974), pp. 181-195.

\footnotetext{
${ }^{29}$ zvi Kurzweil, op. cit., pp. $31 \mathrm{ff}$.
}

30 The important German language weekly published in Prague by the Bohemian District of the Zionist Organization Selbstwehr (Jan. 1, 1937) publicizes Buber's talk at Brno for Jan. 14 on the topic "Die ewigen Werte des Zionismus".

31 "haMoreh hagadol M. Buber", Ha'arets, Feb. 7, 1958, written on the occasion of Buber's eighteenth birthday. Re-printed in L, pp. 63-69. See p. 65 .

32 This is not merely my own conjecture; Mrs. Kurzweil is clear on this point.

33 Technically, therefore, Kurzweil did not arrive in palestine as a refugee. Nor, I should point out, did he go there to fulfill the zionist ideal of Aliyah," "to build and be re-built there".

$$
{ }^{34} \text { see the stories in } N \text {. }
$$

35 zur problematic des Religionsunterrichtes (Herausgegeben von Klub Politischer Zionisten in Brű́n: Brưnn, 1936), and Die Bedeutung der Thoragesetze für unsere Zeit (Druch von Markus Kral: Brinn, 1936).

${ }^{36}$ Yehoshua Barzilai (Folman), Ketavav ha'ivriyim shel haprof. Barukh Kurzweil, 5702-5722 [1942-1963] (Ramat Gan: 1963). The volumes of Selbstwehr available in the National Library at the Hebrew University in Jerusalem for the years Kurzweil was in Brno 
show three published articles: "Chanukahbetrachtungen", December 20, 1935; "Josef Kasteins Werke", February 14, 1936; and "Abschied", December 17, 1937. The latter is noted as a chapter from an unfinished novel "Die sterbende Gemeinde" and anticipates the story "haNesi'ah". Additionally there are in these issues of Selbstwehr many announcements and reports of several public lectures by Kurzweil. These were mostly related to Kurzweil's teaching role. See for example the issues of June 21 , and November 8, 1935; January 17, 24, October 8 and November 6, 1936. The only literary lecture indicated is one given by Kurzweil on February 18, 1937 entitled "Betrachtungen über Dichtung und Weltanschauung mit besonderer Berucksichtigung der Judischen Problematik) Anschliesend Leseproblem aus eigenen Werken". A brief report on this is found in the issue of February 25, 1937.

37 "Kavin lidemuto shel Martin Buber", Ha'arets, June 18, 1965. Reprinted in I, pp. 105-114.

38 Interview with Haim shoham. of this group the most well-known were to be Shenhar, who is regarded as a moderately important figure in Hebrew fiction; Politzer, who subsequently emigrated to the United states, and is known for his work on Kafka; and Spitzer, who had been associated with the schocken Publishing $\mathrm{Co}$. in Berlin and, upon his arrival in Jerusalem in 1932, served as Buber's assistant in the translation of the Bible. In 1939 spitzer founded "Tarshish" Publications, one of Israel's most esthetically discriminating book houses.

$$
{ }^{39} \text { See A, p. } 5 \text {. }
$$

40 Shoham. Kurzweil does note that these works did at the time have some impact on him, especially Feierberg, but obviously it was not enough to impel him to read as widely as deeply in modern Hebrew literature as he would now.

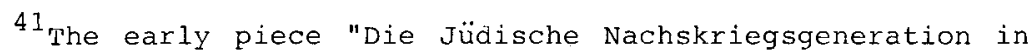
Agnon's Oreach Nata Lalun" (mimeographed, Jerusalem: P. Freund, 1941), was probably printed before Kurzweil began hearing the details of the Holocaust or had made his decision. From then on all Kurzweil's work is in Hebrew. It appears, though, that he relented in later years and published occasional articles in the Neue zuricher zeitung (see Bibliography).

${ }^{42}$ see preface to N. Note that the published story "bevet hakeneset", Moznayim, XXI (Tishri-Adar, 5706, 1945-46), pp. 187-194, was written in Hebrew.

${ }^{43}$ It should be noted that during the 1941-42 school year Kurzweil taught in the adult education program Bet Midrash Amami sponsored by the Association of Immigrants from Germany, Austria and Czechoslovakia in co-operation with Emet veEmunah Synagogue in Jerusalem. His courses focused mostly on the reading and interpretation of Agnon.

\footnotetext{
${ }^{44}$ zvi Kurzweil, op. cit., p. 32.
}

45 See "Bet hasefer utenu'at hano'ar", Luah Ha'arets, 5705

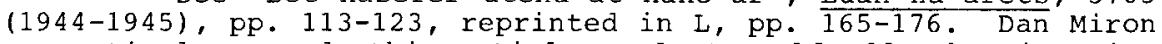
perceptively regards this article--and, I would add, the situation in Kurzweil's classroom at "Hugim" in those years--as an anticipation of Kurzweil's later critique of Israeli fiction and the Canaanite movement. See "Kavim lidemuto shel hamevaker Kurzweil", Ha'arets, Jan. 8, 1960. For a sensitive and revealing reminiscence of Kurzweil as a teacher at "Hugim" by a former student see 
the poet Natan Zach's "haMoreh lesifrut - leprof. Barukh Kurzweil leyovalo", Ha'arets, Aug. 18, 1967.

${ }^{46}$ See "Shylock veshasimpoziyon beveit habri'ut", Ha'arets, March 24, 1944 .

47 In 1947-48 Kurzweil was appointed to teach regularly in the school for Overseas students but the war conditions then prevailing made travel from Haifa to Jerusalem impossible. For a discussion of a later such lecture see T. Carmi, "hatikvah ha'aharonha shel hasifrut hatse'irah - beshulei hartsaah retsinit", 'Al hamishmar, July 14, 1950.

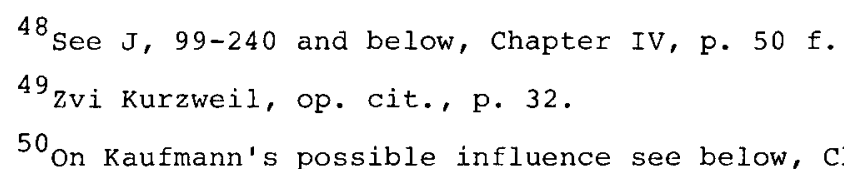
p. f. Schechter is a gifted and original educator who has written on a wide variety of cultural subjects, including the relationship between literature and values. See James S. Diamond, "Yosef Schechter: An Approach to 'Jewish Consciousness'", Reconstructionist, XxX/17 (December 25, 1964), pp. 17-24. The relationship to Shalom is less documentable but was unquestionably close. See, for example, Kurzweil's letter to Daniel Persky of 3 Shevat, 5715 in Genazim archives and the re-printing of selected passages of Kurzweil's shalom criticism in honor of the poet's seventieth birthday, Ha'arets, March 21, 1975.

${ }^{51}$ Kurzweil was recommended to Schocken by Agnon, who had read the early piece on Ore'ah natah Lalun and was sufficiently impressed by it to feel that Kurzweil deserved a wider audience (related by Gershom Schocken in radio discussion of Kurzweil, "mesibah sifrutit", on Galei Zahal [Israel Defense Forces Radio], May 30, 1976.)

52 zvi kurzweil says that when he docked as an immigrant at Haifa in 1950 he was regaled with the quotation of a critical point made by his brother in a recent essay in Ha'arets by a customs clerk (who had evidently recognized the similarity in family name) op. cit., SBK, p. 32. Moshe shamir, in his penetrating appraisal written the day after Kurzweil's death, notes that Kurzweil was a "continuing drama" and was read and discussed regularly by a whole generation. "Har ga'ash kavah", Ma'ariv. Aug. 25, 1972 .

53 Major reviews are: David Kena'ani, "'Agnon leshalish ulerevi'a", Masa' (Lamerhav), Dec. 3 and Dec. 17, 1953; Hillel Barzel, "'Agnon be'einei Kurzweil", Mevo'ot, VII (Dec. 31, 1953), pp. 6 f; Yitshak Shalev, "haFenomen Kurzweil", Ha'arets, July 8, 1955.

${ }^{54}$ See below, chapter VI, pp. 105-114, for the specifics of Kurzweil's critique of the "young" Israeli literature.

${ }^{55}$ Yosef Klausner, "Ketsat yoter zehirut uketsat pahot yehirut", Ha'arets, April 13, 1944.

${ }^{56}$ Ernst Simon, "haMevaker Barukh Kurzweil", Ha'arets, April 12, 1946.

57 Rabbi Binyamin (Yehoshu'a Radler-Feldman), "le'or bikoret hadishah ledugmah", Ha'arets, May 2, 1947. 
58 "Masot historiyot leYosef Klausner", Ha'arets, Jan. 12, 1945 , and see also "haPopulariyut hamesukenet", Ha'arets, December 29, 1944 (re-printed in L, pp. 205-209), which is essentially an attack on Klausner.

59"'Al hapulmus bevikoret", Ha'arets, June 7, 1946, and see below, Chapter V, p. 57.

60 "Anshei hapenim va'anashim min hahuts", May 16, 1947.

${ }^{61}$ See Davar, Jan. 7, 1948. Kurzweil always held up the fact that he helped award this prize to Yizhar as proof that he was not in principle hostile to Israeli literature. See his interview with Rachel Eitan, Ha'arets, April 15, 1966.

${ }^{62}$ See Ha'arets, May 21 and June 11, 1954.

${ }^{63}$ See zvi Kurzweil, op. cit., pp. 32 f. See also Harold Fisch, "Bar-Ilan University", Ariel: A Quarterly Review of the Arts and Sciences in Israel, 26 (Spring, 1970), pp. 53-61.

${ }^{64}$ Kurzweil had a close relationship with Bialoblotzky. In spite of their differences in background--Bialoblotzky was a product of Lithuanian Jewry--both shared an aversion to neo-mystical and other religious expressions which, because of their public visage, could be construed as exhibitionistic. See kurzweil's "Kavin lidemuto shel haga'on R. Shemuel Bialoblotsky", Ha'arets, Feb. 5, 1960. This essay gives the lie to those who claim Kurzweil failed to understand East European Jewry.

p. 35 .

${ }^{65}$ M.z. Kaddari, "Barukh Kurzweil bauniversitah", SBK,

${ }^{66}$ See "He'arot life'ulat hamo'etsah lehaskalah gevohah", Ha'arets, June 8,1960 , "Emet utsevi'ut bide'agah lehaskalah gevohah", Ha'arets, Nov. 2, 1961, and the two addresses on Bar-Ilan as a religious university reprinted in L, pp. 224-239. In his letter to Agnon congratulating him on receiving the Nobel Prize for Literature Kurzweil says he wishes to emphasize for the record that he had written his letter of testimony to the swedish Academy in Stockholm as a professor at Bar-Ilan on Bar-Ilan stationery, a fact he complains the press had ignored. See letter to Agnon, dated Wednesday, Parshat vaYera, 5727 [Fall, 1966] in Yad Agnon archives at the National Library, Hebrew University, Jerusalem.

$$
\begin{aligned}
& { }^{67} \text { Kaddari, op. cit., p. } 35 . \\
& { }^{68} \text { Interview with Yosef Lapid, Ma'ariv, Jan. 17, } 1964 .
\end{aligned}
$$

${ }^{69}$ See "Panim aherot - lediokano shel haprof. Barukh Kurzweil Z.L. kefi shemesartetim oto talmidav", Bikoret ufarshanut, VI (Dec. 1974), pp. 108-113; and Menahem Michelson, "haHed shehafakh lekol", Yedi'ot aharonot, Sept. 1, 1972.

70 An example: Pregnant women students who appeared for the final oral examination were generally sent home; Kurzweil feared they would exploit their condition by appealing for sympathy. But when one such student's husband showed up in her stead, Kurzweil was persuaded that no such motivations were in play. Accordingly, he went to the hospital and examined the student shortly after she had given birth. (Y. Friedlander, "Panim aherot"). 
${ }^{71}$ Ibid.

72 The reviews of substance are: Moshe Gil, "Sifrutenu hahadashah umashber hayahadut", Davar, Dec. 18, 1959; Boaz Evron, "Barukh Kurzweil - halohem livehirut hamahashavah", Ha'arets, Jan. 8, 1960; Moshe Dor, "Hemshekh o mahapekha? torat hasifrut leB. Kurzweil", Ma'ariv, Jan. 15, 1960; Gavriel Moked, "Sifrutenu be'einei Barukh Kurzweil", Lamerhav, April 11, 1960, and "Bikorto shel Barukh Kurzweil umigebaloteha", Lamerhav, May 27, 1960.

73 The reviews of value are: M. Bar-Ya'akov (Moshe Dor?), Ma'ariv, Dec. 16, 1960; and Dan Miron, "Bialik veTshernihovski le'or bikorto shel B. Kurzweil", Ha'arets, Feb. 24, 1961.

${ }^{74}$ Major reviews are: Hillel Barzel, "'Agnon umefarsho Kurzweil", Haboker, Feb. 8, 1963; Gavriel Moked, Ha'arets, March 1, 1963. We may note here that Kurzweil also edited an important collection of critical essays on Agnon in honor of the latter's seventieth birthday, Yuval Shai (Ramat Gan: Bar-Ilan University, 1958).

${ }^{75}$ See Kurzweil's denunciation of the awarding of the Bialik Prize to $S$. Yizhar for his controversial novel Yemei tsiklag: "'od lo nutkah hashalshelet (shoftim o 'askanim sifrutiyim?)", Ha'arets, Jan. 2, 1959; and see his subsequent exchange with Dov Sadan on the entire matter of literary prizes in Ha'arets, Jan. 16, 1959. Kurzweil says he initially had turned down the prize, and the repeated attempts to convince him to accept it caused him much anguish. Finally, he sought the halakhic opinion of his friend, Rabbi Kalman Schlesinger, who ruled that a rejection of the prize by Kurzweil would constitute a defamation of the Hebrew poet's memory (Interview with Yosef Lapid, op. cit.).

Jan. 17,1964 .

76 "Peras Bialik - nimukei hashofetim", Masa' (Lamerhav),

77 The text of the Rutgers lecture was printed as "'Al zeramin hadashim besifrut ha'ivrit hahadashah", Moznayim, XXV/4-5 (Sept.-Oct., 1967), pp. 257-265. For a synopsis and discussion of the J.T.S. lecture see Shlomo Kodesh "Panim aherot lador!" Hado'ar, XLV/8 (Jan. 1, 1965), pp. 131-133. A manuscript of the German lecture at Leo Baeck exists in the Institute's New York archive. For Kurzweil's own impressions and other details of his American visit, see Vera Levin, "Prof. Kurzweil martseh umitrashem be'ar(tsot) hab(erit)", Ha'arets, Jan. 15, 1965.

78 The only worthwhile review of $H$ is Yehudah Friedlander, "haRe'ut hafenomenologit bevikoret sifrutenu", Moznayim XXIV/2 (Tevet 5727, 1967), pp. 132-135.

${ }^{79}$ Reviews of value are: Re'uven Rabinovits, Ha'arets, oct. 17, 1969; Yosef Ben-Shlomo, "Milhamto shel Barukh Kurzweil besitra ahra", Masa' (Lamerhav), Nov. 28 and Dec. 5, 1969; Yosef Friedlander, "Barukh Kurzweil - hamevaker halohem", Gazit, XXVI (37)/1-8 (Apr.-Nov., 1969), pp. 191 f.; Gavriel Moked, "besa'ar ishim ve'arakhim", Yedi'ot aharonot, January 30, 1970.

${ }^{80}$ Interview with Rachel Eitan, op. cit. That pessimism was a trait espoused and admired early on by Kurzweil may be seen in "Kavim lidemuto shel Schopenhauer", Ha'arets, June 21, 1946 (L, pp. 154-162). See also Kurzweil's story "hasekhvi Ferdinand behatsar Frants Yosef" in $\mathrm{N}$. 
${ }^{81}$ See "Kelalat haberakhah shel hahagshamah hatsiyonit", Ha'arets, Oct. 10, 1969; "Tatspit mihuts litehum 'al matsavenu (hirhurim betom shenat TaSHaL)", Ha'arets, Sept. 30, 1970, (L, pp. 193-204).

\section{${ }^{82}$ For discussion of the terms of the conflict see below,} Chapter IV, pp. 51-59.

83 Thus Ha'arets, Ma'ariv and Davar of Aug. 25, 1972. The failure of these newspapers to report the facts of Kurzweil's death probably is explained by two reasons. They may have been showing sensitivity to the interests of the family and treated this as some other cases of suicide. Also, they may have judged the nature of Kurzweil's death to be too shocking and incongruous with his image as an observant Jew, for whom suicide is forbidden by halakhah. The only publication to print the full story was, predictably, Ha'olam hazeh, "haMevaker shekatal et 'atsmo", No. 1826 , August $\overline{30,1972}$.

Speculations as to why Kurzweil chose to take his own life, to the extent that this is a worthwhile endeavor, must, it seems to me, take into account two separate, but related, aspects of Kurzweil's inner life: his subjective psychological state at the time and his entire attitude to life as objectively expressed in his writings. Of the former, which is probably the decisive consideration, I know little and am unable to speak. An indication of it, however, can clearly be discerned in Uri zvi Greenberg's poignant account of his last meetings with Kurzweil in "Sheki'in", SBK, pp. 11-13. As for the latter, I must call attention to the thanatopic quality of Kurzweil's pessimism and his feeling that self-destruction is an inherent consequence of modernism as he understands it (see below, Chapter III). Barzel, in his review of $\mathrm{MR}^{2}$, suggestively points to a number of passages in it that are revealing (MR, $\mathrm{pp} .19$ and $94 \mathrm{f}$ ).

Janik and Toulmin (op. cit.) cite Durkheim's study of suicide which establishes that acts of individual self-destruction "which at first seem to express only his personal temperament, are really the supplement and prolongation of a social condition which they express externally" (quoted on p. 64). They link the high suicide rate in the Hapsburg Empire, including that of Weininger, to "the problems of identity and community that plagued Viennese society at every level" (ibid., p. 65). Kurzweil, as we shall see in the next chapters, sees this very problem, but he couches it in more specific terms. Speaking of Weininger's suicide, he says:

"Here we have the tragic reaction of a philosopher and a man of genius to the objectively absurd situation of the Jew and to the threat of the rule of the absurd over all human existence. only against the religious-metaphysical crisis in his world is it possible to understand the tragedy named Weininger. Karl Kraus with brilliant instinct. . eulogized him without mentioning him by name thus: 'This suicide was performed out of an attack of spiritual clarity.' And well does Werner Kraft sum up: 'Weininger had reasons, metaphysical and religious, to renounce life at the outset of a glorious life.' Both Kraus and Kraft observed the metaphysical religious significance of this suicide which was an alarm call to the profound religious-existential crisis of modern man and, in particular, of the modern Jew" ( $S$, p. 393; emphases mine, J.S.D.).

Are these words of Kurzweil a prescience that help explain not only Weininger's but also his own death as a private martyrdom to the forces of the absurd? I cannot but think so; more, "it is possible to say that to understand the meaning of death is identical with solving the problem of life" $\left(\mathrm{MR}^{2}, \mathrm{p} .198\right)$. For a further development of the notion of suicide as a conscious art transcending individual psychiatric factors see A. Alvarez, The 
Savage God: A Study of Suicide (London: Weidenfeld and Nicholson, 1971).

84 hanesi'ah received more reviews than any of Kurzweil's criticism published while he was alive, but the major critics did not touch it.

${ }^{85}$ Edited with an introduction by Moshe Schwarcz (Ramat Gan: B. Kurzweil Memorial Foundation, Bar-Ilan University, 1976). Subsequent to this writing, two collections of Kurzweil's essays have been published. The first brings together his writings on drama, haDramah haeiropiit: pirkei mehkar umasah [European Drama: Studies and Essays], Ya'akov Abramson and Hayim Shoham, eds. Afterword by Y. Abramson. (Ramat Gan: B. Kurzweil Memorial Foundation, Bar-Ilan University, 1979). The second book collects Kurzweil's writings on Israeli literature, Behipus hasifrut hayisra'elit: masot uma'amarim [In Search of Israeli Literature: Essays and Articles], Zvi Luz and Yedidiah Yitshaki, eds. (Ramat Gan: B. Kurzweil Memorial Foundation, Bar-Ilan University, 1982).

${ }^{86}$ Gershom Schocken, op. cit., sBK, p. 44.

87 Ibid. See also Shalom Kremer, "Netivot bevikoret ha'ivrit 1920-1960", Me'asef 5-6 (1966), p. 366 .

${ }^{88}$ some of the most acrid polemical essays convey this, particularly when the ad hominem attacks become ends in themselves and the assumed subject of the criticism gets away from Kurzweil. See, for example, "Behinot uvohanim shelo hitslihu", Ha'arets, June 27 and July 11, 1952; "haTarbut hamitkademet bevet ha'avot", Ha'arets, June 12, 1964; "Besof hama'arav - o ga'agu'im lama'arav?" Ha'arets, Feb. 10, 1967.

${ }^{89}$ Quoted in interview of same title with Rachel Eitan, op. cit. (see above n. 61). 
Notes to Chapter III

1'George Lichtheim, Lukács (London: Fontana/collins,

$2 \mathrm{~J}, \mathrm{P} .160$.

${ }^{3}$ See Hillel Barzel, "Ahdut veribui bemishnato shel Barukh Kurzweil", Moznayim, XXV/4 (Sept.-Oct., 1967), pp. 266-272; and "Kurzweil 'al haroman vehasipur haeiropeiyim", Moznayim, XXXIX/1 (June, 1974), pp. 22-30. For Schwarcz see SBK, pp. 375-397.

${ }^{4}$ see J, pp. xiij f. (\#24).

${ }^{5}$ see S, p. 204 .

${ }^{6} \mathrm{~J}, \mathrm{p} .40 \mathrm{ff}$.

${ }^{7}$ Bialik, Safiah. Indirectly Jean paul may here be an influence, too.

${ }^{8}$ See B, pp. 65-82; A, pp. 275-282; and H, p. 20 . See also $\mathrm{MR}^{2}$, p. $83 \mathrm{f}$. , where Kurzweil relates this to Proust.

${ }^{9}$ Erich Heller, The Disinherited Mind: Essays in Modern German Literature and Thought (New York: Farrar, Straus \& Cudahy, 1952), p. 65. Note the implication of this kind of perception for hermeneutical theory, especially the notion of "the hermeneutic circle". See below, pp. $56 \mathrm{ff}$.

${ }^{10}$ Huizinga and Burckhardt are, as we might expect, the historians kurzweil most reveres. See H, p. xiv.

${ }^{11}$ see "'Al hitpathutah shel hasifrut ha'ivrit hamodernit", Ha'arets, sept. 17, 1944. This early essay contains the seeds of much of Kurzweil's later writings.

${ }^{12}$ In this connection we may note another of Kurzweil's favorite words, "tehomi", which communicates this sense of the abyss. But I must confess to an inability to find any satisfactory English equivalent for it.

13 See $\mathrm{MR}^{2}$ ， pp. 49-56, 99-111; BT, pp. 106-113; H, pp. 291-302. The centrality of the terms "bedidut" (solitude) and "demamah" (silence) should now be apparent.

14 See "haBe'ayah haFaustit vehashpa'atah 'al ruah eiropah", Molad, III/17-18 (Aug.-Sept. 1949), pp. 315-324. See also "le'oro shel hayareah hakavush", Ha'arets, Aug. 1, 1969. Kurzweil never says so explicitly but his views allow us to infer that it was hardly an accident that Nazism, the full flower of demonic modernity, would invest its diabolical energies most in attempting to liquidate the Jews and Judaism, the epitomes of the sacred past.

${ }^{15}$ For Marxist critiques of Kurzweil's interpretation of Goethe see T. Ben-Moshe, "Faust uve'ayat hademoniyut - neged perush reaktsioni shel yetsirat Goethe", besha'ar, 91 (Dec. 8, 1949), and Avraham Nesher, "Neged hareaktsiah bevikoret hasifrutit", Basha'ar, Jan. 19, 1950.

${ }^{16}$ See $L$, pp. 100 and $109 \mathrm{f}$. Note that in this last essay on Buber (p. 107) Kurzweil makes the important point that Buber 
really cannot be understood apart from the German context of Lebensphilosophie as it developed in Dilthey, the George Kreis and Heidegger.

17 s, p. 377 .

18 "Hayesh 'od lesifrutenu diokan yehudi?" Ha'arets,

Sept. 28,1962 .

${ }^{19}$ See Quentin Lauer, phenomenology: Its Genesis and Prospect (New York: Harper \& Row, 1958), p. 10. Also, see below, pp. 59-67, for discussion of the relation of phenomenology to Kurzweil's critical theory.

20 Lawrence J. Silberstein, "History and Ideology: The Writings of Yehezkel Kaufmann" (Brandeis University: unpublished doctoral dissertation, 1972), p. 5 .

21 Ibid., pp. 143-153.

${ }^{22}$ Ibid., pp. 106, 161-164, 188 f., 193 f. Silberstein cites Robert Nisbet who notes that the "sacred" was one of the basic unit ideas of 19 th century sociological thought, viz., Fustel de Coulanges, his disciple Durkheim, Rudolph otto and Max Weber (p. 179). While Kurzweil never cites these figures, I have no doubt that, as a natural eclectic, he knew them and that they shaped his thinking.

23 one of the distinctive features of Husserlian phenomenology is its insistence that it is scientific and objective even as it is grounded solely in subjective consciousness. See Lauer, op. cit., Chapter 5, "The sense of objectivity", pp. 82-99. Kurzweil, too, partakes of this epistemology. See below, p. $62 \mathrm{f}$.

${ }^{24}$ Uri Zvi Greenberg, Rehovot hanahar, p. 37. Quoted in $H$, p. $35, \mathrm{~L}, \mathrm{p} .94$ and numerous other places.

${ }^{25}$ See H, pp. 45 ff., 86 , and J, p. 227 .

${ }^{26}$ See J, pp. 78 and vii (section 6), viii (sections 8, 9), and xiii-xiv (sections 24,25 ).

$27 \mathrm{~J}$, p. viii (section 8 ).

${ }^{28}$ Kurzweil quotes Breuer's statement that "Zionism did for the Jewish problem what Marxism did for the economic problem . . . In this respect zionism fulfilled a scientific function by placing the Jewish problem on the only basis on which it could be understood: on the ground of history" (L, p 119).

${ }^{29}$ Ibid.

${ }^{30} \mathrm{~L}, \mathrm{pp} .132 \mathrm{f}$.

${ }^{31} \mathrm{~J}, \mathrm{pp} .278$ and 253.

${ }^{32}$ In spite of his close relationship to Buber, Kurzweil did not identify in any way with Buber's dialogical zionism or with the Berit Shalom movement which advocated a bi-national state in Palestine. The slender written evidence there is on this matter suggests that Kurzweil's outlook on the Arab-Israeli conflict lay somewhere between realism and pessimism. In "Kelalat haberakhah shel hahagshamah hatsiyonit", Ha'arets, Oct. 10, 1969, he draws attention to the disparity between the two nationalisms: 
the Arab variety has deep roots in a religious ethos and mythos, while zionism, having formally cut the ties to the Jewish religious past, operates on 19 th century rational, humanistic, utopian ideals that deprive it of the adequate basis in irrational mythos it needs if it is to see the conflict through. "The establishment of a state amidst the living space of other nations means war [Kurzweil's emphasis] . . . Only anthropological foolishness mixed with idle provincialism could have assumed that it would be possible to set up a Jewish state without bloodshed."

${ }^{33}$ see I, p. 183 ; there are slight textual changes here from the original.

${ }^{34}$ see Kurzweil's remarks at the world Jewish Congress's Symposium on "hale'umiyut hayehudit bizemanenu", L, P. 244: "But he who affirms zionism--and all of us here do affirm it--. . . ." See also "Panim aherot - lediokano shel haProf. Barukh Kurzweil Z.I. kefi shemesartetim oto talmidav", Bikoret ufarshanut, VI (Dec., 1974), pp. 108-113. Kurzweil's special affection and respect for Israeli military officers is here recounted.

$$
\begin{aligned}
& { }^{35} \mathrm{~L}, \mathrm{p}, 130 . \\
& { }^{36} \mathrm{~L}, \mathrm{p}, 131 .
\end{aligned}
$$

${ }^{37}$ Boaz Evron finds the same contradiction in the last paragraph of Kurzweil's long introductory essay "Be'ayot yesod besifrutenu hahadashah" (S, p. 146). See "Barukh Kurzweil halohem livehirut hamahashavah", Ha'arets, Jan. 8, 1960.

${ }^{38}$ It is worth noting that the Hebrew word for life, "Hayim", is the plural form, which suggests that human existence is inherently multi-faceted and dialectical.

${ }^{39}$ See L, pp. 193-204. See also Kurzweil's remarks in an interview with Ge'ulah Cohen, Ma'ariv, Oct. 13, 1968, and also the satirical essay "miHuts litehum", Ha'arets, Aug. 23, 1968.

$$
\begin{aligned}
& { }^{40} \text { L, pp. } 203 \mathrm{f} . \\
& { }^{41} \text { S, p. } 144 \text {, and see pp. } 144-146 \text { passim. } \\
& { }^{42} \text { See A, pp. 394-399. }
\end{aligned}
$$

43 The idealistic nature and the ontological basis of "the meta-historic" as the touchstones of Kurzweil's Jewish world-view are what I think animate the disagreements implicit in the correspondence between him and David Ben-Gurion (see L, pp. 246-251). In this respect this disagreement is paradigmatic of the one that we shall see divides Kurzweil from the Sabra writers and critics and paves the way for mutual rejection and incomprehension.

44 "Yesodot humaniyim keshirat hahoveh", op. cit. Kurzweil did not recognize shlonsky until the late fifties. Prior to that time he had been very hard on him for his progressivist-Marxist political activity.

${ }^{45}$ See Kurzweil's response to a symposium on art and ideology "live'ayat hamegamatiyut vehahemshekhiyut basifrut", Mevo'ot, X (April 9, 1954).

${ }^{46}$ See René wellek, Concepts of Criticism (New Haven \& London: Yale Univ. Press, 1963), pp. 268-271. It is worth noting 
here Wellek's observation that: "In the Anglo-Saxon world, surprisingly enough, no such linguistic and stylistic criticism took hold. There the gulf between linguistics and literary criticism has widened deplorably." (p. 351)

${ }^{47}$ See Wilma A. Iggers, Karl Kraus: A Viennese Critic of the Twentieth Century (The Hague: Martinus Nijhoff, 1967), p. 26.

${ }^{48}$ See Palmer, Hermeneutics, pp. 124 f. Heidegger's key work in this connection is, of course, Sein und zeit, translated as Being and Time by John Macquarrie and Edward Robinson (London: SCM Press Ltd., 1962).

pp. 203-210.

${ }^{49}$ Quoted in Palmer, p. 153. See Being and Time,

${ }^{50}$ Palmer, p. 155.

51 on the way to Language, trans. Peter D. Hertz (N.Y.: Harper \& Row, 1971), p. 57. See also Schwarcz in SBK, p. 394.

52 This is not to imply that kurzweil accepted in toto Heidegger's solution to the problem "What is man?" or Buber's or anyone else's. See next chapter and also $\mathrm{MR}^{2}$ p. 365 .

${ }^{53}$ Schwarcz, SBK, p. 394.

54 The star of Redemption, trans. William W. Hallo (New York: Holt, Rinehart \& Winston, 1970-71), pp. $301 \mathrm{f}$.

${ }^{55}$ See "Teguvot aktualiyot 'al mishnat Frants Rosentsweig umashma'utan", L, pp. 131-139, where Kurzweil implicitly acknowledges the importance of Rosenzweig's thinking in shaping his esthetic posture toward Hebrew literature.

${ }^{56}$ See Schwarcz, SBK, p. 395.

$57 \mathrm{~J}, \mathrm{p} .50$.

$58 \mathrm{~J}, \mathrm{p} . \mathrm{xvii}$

${ }^{59} \mathrm{H}, \mathrm{p} .246$.

${ }^{60}$ Heller, op. cit., p. 206.

${ }^{61}$ See Ernst Simon, "hamevaker Barukh Kurzweil", Ha'arets, April 12, 1946. Simon is reacting to Kurzweil's piece "'Al takfidei habikoret", Ha'arets, Sept. 7, 1945.

${ }^{62}$ See Kurzweil's response to Ha'arets's editor Gershom schocken, "havahat mikibush hayareah ve'i-hanahat me'anshei haruah", Ha'arets, Aug. 15, 1969.

${ }^{63}$ See "Hovot halevavot hashetulim", Ha'arets, Jan. 2, and Jan. 31, 1969. Gershom schocken regard's Kurzweil's satirical response to the first moon landing, "le'oro shel hayareah hakavush", Ha'arets, Aug. 1, 1969, as an imitative variation of Kraus's Apocalypse (1908) and he opines that altogether "Kurzweil has learned too much" from Kraus ("Gershom Schocken meshiv", Ha'arets, August 15, 1969).

$$
\begin{aligned}
& { }^{64} \mathrm{~S}, \mathrm{pp} .388 \mathrm{f} . \\
& { }^{65} \text { Ibid. }
\end{aligned}
$$


${ }^{66}$ It is in such terms that kurzweil explains kraus's remarkable refusal to say or write anything against the Nazis. "This silence of the high priest of the German language and the keeper of its secrets is of the same order as the Jewish tragedy." (Ibid., p. 390). Kurzweil often quotes with reverence Kraus's statement that "Regarding Hitler nothing comes to mind."

${ }^{67} \mathrm{~S}, \mathrm{pp} .383 \mathrm{f}$. See also J, pp. $231 \mathrm{f}$.

${ }^{68} \mathrm{~L}, \mathrm{p} .215$.

${ }^{69}$ See Carl E. Schorske, Fin-de-Siècle Vienna Politics and Culture (New York: Alfred A. Knopf, 1980), especially essays I, pp. 3-23 and VI, pp. 279-321.

${ }^{70}$ See $\mathrm{MR}^{2}, \mathrm{pp}_{2} 189 \mathrm{f}$, written in 1954. See also $\mathrm{H}, \mathrm{pp}$. $356 \mathrm{ff} ; \mathrm{J}, \mathrm{p} .148 ; \mathrm{MR}^{2}$, pp. $393 \mathrm{ff} ; \mathrm{L}, \mathrm{p} .211$.

${ }^{71}$ Janik and Toulmin, op. cit., p. 116.

72 A, p. 14 .

$73^{\mathrm{J}}, \mathrm{p} . \mathrm{xvi}$

74 Ibid.

75 Bialik's key essay expressing the crisis of language is "Gilui vekisui belashon". This has been translated and annotated by Avraham Holtz, "The Explicit and the Allusive in Language", Literature East and West, XV/3 (1971?), pp. 498-508. Another translation is by Jacob Sloan, "Revealment and Concealment in Language", in Israel Cohen and B.Y. Michali, eds., An Anthology of Hebrew Essays (Tel Aviv: Institute for the Translation of Hebrew Literature and Massada publishing Co. Ltd., 1966), I, pp. 127-135. See also the translation of an important statement by Agnon, "The Holy Tongue as a Written Language", Ariel: A Quarterly Review of the Arts and Sciences in Israel 25 (Winter, 1969), pp. 19-24.

${ }^{76}$ Wellek, Concepts of Criticism, p. 207. 


\section{Notes to Chapter IV}

${ }^{1}$ See Martin Buber, "What is Man?", Between Man and Man, trans. Ronald Gregor Smith (N.P., The Macmillan Co., 1947), p. 119 and Kurzweil, "Bein antropologiah lesifrut", Ha'arets, April 9, 1971.

2 Buber, loc. cit.

3 "Bein antropologiah lesifrut."

${ }^{4}$ Ibid.

${ }^{5}$ Ibid.

${ }^{6} \mathrm{BT}$, p. 337. See pp. 335-338 for a lucid statement of this aspect of Kurzweil's poetics.

${ }^{7}$ Buber, op. cit., p. 203.

${ }^{8}$ Ibid., p. 205.

${ }^{9}$ See $\mathrm{MR}^{2}$, pp. 413-425, where Kurzweil explores "Erotic Romanticism and the cult of Eros" as it is reflected in the Bildungsroman.

10 See the two essays "Be'ayot hashirah hamodernit bitekufatenu", Ha'arets, Jan. 26, 1962, and "haMetsi'ut hahadashah beshirah hamodernit", Ha'aerts, Feb. 16, 1962.

${ }^{11}$ See $J$, p. 41 and $S$, p. 321. Kurzweil is sensitive to the importance of music in Thomas Mann and Hesse (see MR p. 300) and he asks that his own story haNesi'ah be read to the accompaniment of the middle movement of Mozart's K. 364 (Sinfonia Concertante in E Flat for Violin, Viola and orchestra). See N, p. 11. Kurzweil, incidentally, often expressed the wish that he could have been a conductor instead of a critic, since the interpretive nature of the conductor's role is more acknowledged and received with less rancor than the literary critic's. Regarding the plastic arts, Kurzweil is remarkably silent. He did paint, though, in more than a casual way, and in his lectures, apparently, spoke frequently of the relationship between painting and literature.

$12 \mathrm{MR}^{2}$, p. 302 .

${ }^{13}$ See Schwarcz, "Hanahot estetiot bemif'al habikortit shel Barukh Kurzweil", SBK, pp. 377 f.

${ }^{14}$ see $J$, pp. $40 \mathrm{ff}$.

${ }^{15}$ Ibid., p. 45 .

${ }^{16}$ Schwarcz, op. cit., pp. $381 \mathrm{ff}$.

17 These are the manifestations of artistic striving to which Schwarcz points, and he cites Bialik, U. Z. Greenberg and Agnon as respective examples. In the European context one thinks of the attempts of Proust to recapture lost time, of Joyce to re-create the "conscience of my race", and of Kafka to re-establish a relationship with the transcendent.

${ }^{18} \mathrm{~A}, \mathrm{p} .422$. Schwarcz finds affinities between Kurzweil's esthetic position here with that of Alois Halder (Kunst und Kult, 
1964), E. Grassi (Kunst und Mythos, 1957), and Rosenzweig ("the mythical element founded the realm of the beautiful for metaphysical theology"; The star of Redemption, p. 80). Following Gadamer, schwarcz traces the source for all this back to Schiller's fundamental distinction between "naive" and "sentimental" poetry, and he observes that Schiller's category of "the naive" was an inherently esthetic one that served to structure all reality in esthetic terms. See Schwarcz, op. cit., pp. 378-381.

$19 \mathrm{MR}^{2}$, pp. $455 \mathrm{f}$. These words refer to camus and are part of Kurzweil's explanation of why he considers camus and the entire tradition of "Latin French lucidity" started by Montaigne and the moralists to be inferior artistically to the Germans and the "neo-Byzantine" Russians who, he feels, are more naturally in touch with the irrational depths.

20 see the crucial essay "Shorashav hanafshiyim vehametafisiyim shel hayesod haidili", $S$, pp. 301-328, especially pp. $320 \mathrm{f}$. See also schwarcz, op. cit., pp. 386-389. For an opposing concept of the idyllic see Yosef Ha'efrati, haldiliah shel Tshernihovski (Merhaviah And Tel Aviv: Sifriat Po'alim, 1971), pp. 9 f.

$$
\begin{aligned}
& 21_{\mathrm{S}, \mathrm{p}} 301 . \\
& 22_{\mathrm{BT}}, \mathrm{p} \cdot 333 . \\
& 23_{\mathrm{MR}^{2}}, \mathrm{p} \cdot 38, \text { See also } \mathrm{A}, \mathrm{p} \cdot 278 . \\
& 24 \mathrm{MR}^{2}, \mathrm{p} \cdot 150 .
\end{aligned}
$$

25 "He'arot lederakh hadramah hagermanit", Ha'arets, March 29, 1972 .

${ }^{26}$ Friedrich Schiller, on the Aesthetic Education of Man in a Series of Letters, trans. with introduction by Reginald snell (New Haven: Yale University Press, 1969), 15th letter, p. 76, and 16th letter, p. 81. See also letters 11-14, pp. 60-75.

27 Kurt Müller-Vollmer, Towards a Phenomenological Theory of Literature: A study of wilhelm Dilthey's Poetik (The Hague: Mouton \& Co., 1963), p. 73.

28 Rene Wellek, A History of Modern Criticism (London, Jonathan Cape: 1965), IV, p. 322. Palmer further explains that in spite of its form as a singular noun, Erlebnis need not necessarily be confined to a single experience. Rather it is "a lived experience" that may be a series of events seen by the artist as a unit held together by a common meaning. (Hermeneutics: Interpretation Theory in Schleiermacher, Dilthey, Heidegger and Gadamer [Evanston: Northwestern University Press, 1969], p. $107)$. $140-145$.

$$
\begin{aligned}
& 29 \text { Wellek, History, IV, p. } 322 \text {. } \\
& { }^{30} \text { Palmer, op. cit., p. } 108 . \\
& { }^{31} \text { Milller-Vollmer, op. cit., pp. } 107 \mathrm{f} \text {. See also pp. } 94 \text { and }
\end{aligned}
$$$$
32 \text { Ibid., p. } 100 \text {. }
$$

${ }^{33}$ palmer, op. cit., p. 102. This grouping of Kant with Locke and Hume is questionable but it is Dilthey's. Palmer quotes 
his statement that "in the veins of the 'knowing subject' constructed by Locke, Hume and kant runs no real blood". (Ibid.)

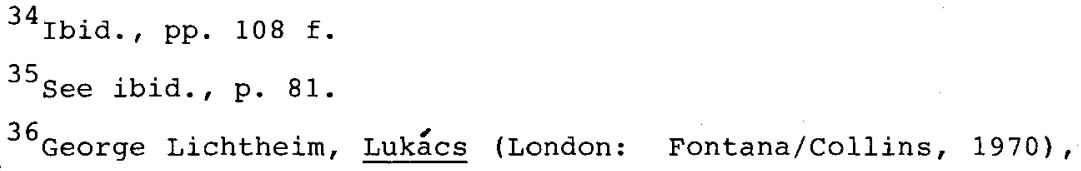

${ }^{39}$ Erich Heller, The Disinherited Mind: Essays in Modern German Literature and Thought (New York: Farrar, Straus and Cudahy, 1952), p. 14. Wellek confirms the particularly German nature of this vision when he speaks of "the German tradition of Ganzheit, Gestalt, wholeness, totality" in Concepts of Criticism (New Haven and London: Yale University Press, 1963), p. 67.

${ }^{40}$ Heller, op. cit., p. 17.

41 This is not a contradiction in terms. At its outset phenomenology, in its endeavor to establish itself as a rigorous science, rejected metaphysics as vigorously as did logical positivism. But Pivcevit notes: "Phenomenology, especially German phenomenology, in spite of its insistence on the neutrality of its method, shows a consistent tendency to develop in a metaphysical direction. Its whole approach to the problems of meaning and truth is very different from a positivist approach to these problems." Edo Pivcević, Husserl and Phenomenology (London: Hutchinson University Library, 1970), p. 152. Pivcevie cites Heidegger as an example of this, but the tendency can already be clearly discerned in Dilthey (see Palmer, Hermeneutics, p. 123, esp. n. 51). It is thus understandable that Kurzweil could embrace both metaphysics and phenomenology with no sense of contradiction.

$$
42 \mathrm{~J}, \mathrm{p} .161 .
$$

43 Paul de Man, "Literary History and Literary Modernity", In Search of Literary Theory, Morton W. Bloomfield, ed. (Ithaca and London: Cornell University Press, 1972), p. 267.

44 See, for example, Kurzweil's early essay on "haHoker Avraham Shalit", Ha'arets, Sept. 26, 1944. This is a discussion of Shalit's Hebrew translation Kurzweil considers a responsible and substantial model of scientific scholarship.

${ }^{45}$ See the eight essays in $J$, pp. 94-240, which include Kurzweil's intense discussion of Scholem's monumental study of the Sabbatian heresy, Shabetai zevi vehatenuah hashabetait biyemei hayav (Tel Aviv: Am Oved, 1957). Scholem himself never answered Kurzweil's onslaught but two of his colleagues did. See Isaiah Tisbi, "Divrei pulmus pesulot", Ha'arets, Aug. 2, 1957 and "Heker hademonologiah uma'asim demoniyim", Ha'arets, Sept. 20, 1957; Ya'akov Katz, "Historiah subyektivit uvikoret obyektivit", Ha'arets, May 28, 1965. The essays collected in J include Kurzweil's replies to Tishbi and Katz. The entire Kurzweil-Scholem debate is deserving of separate treatment. Still, my contention is that in placing it within a philosophical context as an epistemological problem and in evaluating it as 
such, as I shall, we perform one of the tasks most immediately necessary to understanding the disagreement.

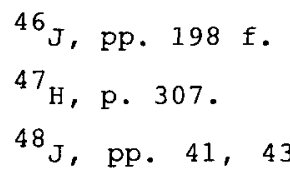
this. In an uncollected essay Kurzeil refers to three world-views each with its own set of values: the Judeo-Christian tradition, secular humanism and Marxism. Though he obviously prefers the first, Kurzweil admires the other two for the coherence they bring to human life and clearly affirms them over the Absurd as grounds for culture. See "Gevulot hahaba'ah hateatrait", Ha'arets, Jan. 20,1961 .

${ }^{49}$ Concepts of Criticism, p. 68. See J, p. 47 where Kurzweil quotes this passage. In the Theory of Literature (New York: Harcourt, Brace \& World, Inc. third ed. 1956), p. 156, Wellek says: "There is no structure outside norms and values. We cannot comprehend and analyze any work of art without reference to values. The very fact that I recognize a certain structure as a 'work of art' implies a judgment of value."

$50 \mathrm{~J}, \mathrm{p} .39$.

${ }^{51}$ see the "Akdamut milin" (Prolegomenon) to $\mathrm{J}, \mathrm{pp} . \mathrm{v}-\mathrm{vi} i \mathrm{i}$ (\#'s 2,3 and 4 ).

52 A, p. 388 .

53 "Gevulot hatragiyut vehahumanizm bemif'alo shel Goethe", Ha'arets, Sept. 14, 1966. Re-printed as preface to Two Tragedies of Goethe, trans. Y. Cahan (Tel Aviv: Schocken, 1967), p.x. See also A, p. 165 .

1971.

54"'Ekronot haparshanut hasifrutit", Ha'arets, July 16,

$55 \mathrm{~J}, \mathrm{pp} .47$ and 54 .

$56_{\mathrm{J}}$, pp. $47 \mathrm{f}$; "Mada' obyektivi veshiput subyektivi O kinus ugenizah be'einei Mati Meged", Ha'arets, Jan. 29, 1971. Emphasis is Kurzweil's.

$$
\begin{aligned}
& { }^{57} \mathrm{~J}, \mathrm{p} .48 . \\
& { }^{58} \text { Ibid., p. } 226 .
\end{aligned}
$$

59 "Luhot hadashim mitsiyon hahadashah o sulam 'arakhim hadash-verosho tehomah", Ha'arets, June 11, 1971.

${ }^{60} \mathrm{~J}$, p. 52. Emphasis is Kurzweil's. See also "Akdamut milin" J, p. v. (\#1).

${ }^{61} \mathrm{~J}$, pp. 33 f. see also "'Ekronot haparshanut hasifrutit". This point is made as early as Kurzweil's doctoral thesis: "Wir sind uns bewusst, das keine Art analytischen Verfahrens etwas Letztliches uber das Phanomen eines schöpferischen Prozesses asuzusagen vermag." ["We are conscious of the fact that there is no kind of analytical method which is capable of saying something definitive about the phenomenon of the creative process."] Die Bedeutung bürgerlicher und künstlerischer 


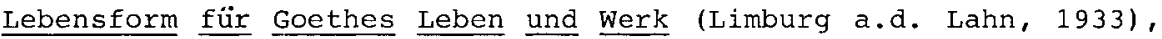
p. 11 .

${ }^{62}$ See the first chapter of both Quentin Lauer, Phenomenology: Its Genesis and Prospect (New York: Harper \& Row, 1958) and Piverevie, op. cit.

${ }^{6}$ Palmer, op. cit., pp. $114 \mathrm{f}$.
64 Ibid., p. 117.
${ }^{65}$ Lichtheim, op. cit., p. 15.
66 Müller-Vollmer, op. cit., p. 43 . See also pp. 20 ff.
67 See Müller -Vollmer, op. cit., Chapter 10, pp. 167-186. Ingarden's key work is Das literarische Kunstwerk (1931). See also John Fizer, "The Concept of Strata and Phases in Roman Ingarden's Theory of Literary Structure", Yearbook of Comparative Criticism, Joseph Strelka, ed., vol. 6: The Personality of the Critic (University Park and London: Pennsy lvania State University Press, 1973), pp. 10-39.

${ }^{68}$ Múller-Vollmer, op. cit., p. 81 .

${ }^{69}$ Ibid., pp. $178 \mathrm{f}$.

70 Ibid., p. 34 and see esp. n. 5. I do not wish to suggest that the last word on Dilthey has been said or that Muller-Vollmer has said it. A more recent study that clarifies much is Rudolf A. Makreel, Dilthey: Philosopher of the Human Studies (Princeton: Princeton University Press, 1975). Makreel maintains that, in his attempt to establish the phenomenological nature of Dilthey's poetic theory, "Müller-Vollmer ignores the problem of change in Dilthey's philosophy by not really dealing with any work written after $1900 "$ (p. 12).

${ }^{71} \mathrm{~J}$, p. 84 .

72"'Al hapulmus bevikuret", Ha'arets, June 7, 1946.

73"'Al takfidei habikoret", Ha'arets, Sept. 7, 1945.

${ }^{74}$ Interview with Rachel Eitan, Ha'arets, April 15, 1966.

${ }^{75} \mathrm{H}, \mathrm{p} .12$.

${ }^{76}$ see "Mekorot habikoret haotentit", Ha'arets, May 23,

1958.

77 Thomas Mann, "The Artist and Society", quoted in The Study of Literature: A Handbook of Critical Essays and Terms, $\mathrm{S}$. Barnet, M. Berman, W. Burto, eds. (Boston: Little, Brown \& Co., $1960)$, p. 253 . IV, p. 355 .

${ }^{78}$ Quoted in Rene Wellek, A History of Modern Criticism,

$$
\begin{aligned}
& { }^{79} \mathrm{~s}, \mathrm{p} .5 . \\
& { }^{80} \mathrm{H}, \mathrm{p} . \mathrm{xiii} .
\end{aligned}
$$

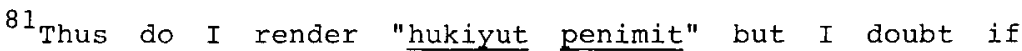
"coherence" catches the nuances of the inexorable and the 
centripetal that the Hebrew "hukiyut" conveys. See above p. 127, n. 1 .

$$
{ }^{82} \mathrm{BT}, \text { p. } 129 .
$$

$83_{\text {That }}$ is how Kurzweil is described by Hillel Barzel in Encyclopedia Judaica, Vol X, q.v. "Baruch Kurzweil".

${ }^{84}$ see Rene Wellek, Concepts of Criticism, pp. $351 \mathrm{f}$. , and Moshe Schwarcz, "Hanahot estetiot bemif'al habikoret shel Barukh Kurzweil", SBK, P. 392.

${ }^{85}$ In his attempt to draw "A Map of Contemporary Criticism in Europe", Wellek takes note of "the sense of the gulfs yawning between the different national traditions in spite of all the many attempts at building bridges--that is, of the tenacity with which the main European nations cling to their distinct critical traditions--and, even within one nation, the sense of the almost equally unbridgeable chasms that divide schools, ideologies, and individuals. . . . It is often very difficult to understand the terminology and assumptions of much foreign criticism if one starts with any kind of pre-conceptions and a vocabulary of one's own, as one inevitably does". Discriminations: Further Concepts of Criticism (New Haven and London: Yale University Press, 1970), pp. 345 f.

${ }^{86}$ Neal Oxenhandler, "Ontological Criticism in America and France", Modern Language Review, LV (1960), p. 18.

${ }^{87}$ See Palmer, op. cit., pp. 7, 160.

${ }^{88}$ oxenhandler, op. cit., p. 19.

${ }^{89}$ palmer, op. cit., p. 226.

90 Oxenhandler, op. cit., pp. $21 \mathrm{f}$.

${ }^{91}$ see Palmer, op cit., p. 159.

${ }^{92} \mathrm{~J}, \mathrm{p} . \mathrm{v}$ (section \#1).

${ }^{93}$ See Lauer, op cit., Chapters 1 and 3 .

${ }^{94}$ pivčević, op cit., p. 73.

${ }^{95}$ Palmer writes: "There is in Heidegger a new kind of objectivity, opposed to the objectivity of the natural sciences, of Dilthey, of the historical school, of modern metaphysics, and ultimately of modern technological thinking with all its pragmatism. It is the objectivity of allowing the thing that appears to be as it really is for us." (op. cit., p. 179)

${ }^{96}$ Lauer, op. cit., p. 53.

${ }^{97} \mathrm{~J}, \mathrm{p} .161$. In the light of this it is hard to regard the following evaluative generalization by Baruch Hochman as adequate: "Kurzweil is a passionate and an ideological reader, with axes to grind." (The Fiction of S. Y. Agnon [Ithaca and London: Cornell University Press, 1970], p. 195, n. 1.) As if there could be and Kurzweil could be expected to write criticism without "axes to grind". Such "axeless" criticism, were it possible, would be not only dull but impotent. Similarly, it should be clear why Band's curt dismissal of Kurzweil on the grounds of 
"neoimpressionism" and "flagrant subjectivism" misses the mark and misleads (Nostalgia and Nightmare: A Study in the Fiction of $S$. Y. Agnon [Berkeley and Los Angeles: University of California Press, 1968], p. ixl.

${ }^{98}$ Preface to $\mathrm{MR}^{2}$. This explains also the frequent use of the title "On Reading. . ." ("'Im keriat. . .").

${ }^{99}$ Preface to $\mathrm{MR}^{2}$.

$100_{\mathrm{BT}, \mathrm{p} .} 85$.

${ }^{101}$ Palmer, op. cit., p. 94 . See also pp. $76-81,87$ ff., $118-121$.

102 A, p. 141 .

103 See Hillel Barzel, "Terumato shel Barukh Kurzweil leheker Shai 'Agnon", SBK, pp. 85-87.

104 A, p. 64 .

105"'Ekronot haparshanut hasifrutit."

106 Ibid.

${ }^{107}$ See $M R^{2}$, p. 68 and "Ekronot haparshanut hasifrutit."

108 oxenhandler, op. cit., p. 23.

${ }^{109}$ Palmer, op. cit., p. 215.

${ }^{110}$ See Palmer, op. cit., p. 64 and his entire discussion of the debate over the nature and scope of hermeneutics between E. D. Hirsch, Jr. and Emilio Betti, who call for "validity in interpretation" and Gadamer, who calls for experiential depth. Palmer and $\mathrm{Hirsch}$ continue their debate in a special number on hermeneutics of The Journal of Religion, LV/3 (July, 1975), pp. 298-326.

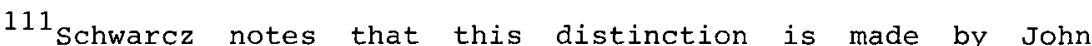
Hospers in Meaning and Truth in the Arts (1964), pp. $162 \mathrm{f}$. See Schwarcz, op. cit., p. 391 .

112 pivčević, op. cit., pp. 79-82. Herbert spiegelberg also concludes that solipsism remained a permanent threat to Husserl's philosophy (The Phenomenological Movement: A Historical Introduction [The Hague: Martinus Nijhoff, 1960], I, p. 88 .

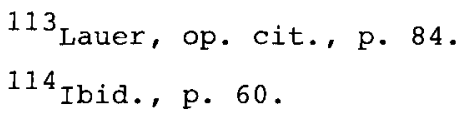




\section{Notes to Chapter V}

${ }^{1} \mathrm{~J}$, p. 22. See also "haFunktsiah shel hatekstim halo" kedoshim basipur hayisra'eli", Ha'arets, March 18, 1966.

2 "Ahdut veribui bemishnato shel Barukh Kurzweil", Moznayim, XXV/4-5 (Sept.-Oct. 1967), pp. $271 \mathrm{f}$.

$3_{F}$. Lachower, Toledot hasifrut ha'ivrit hahadashah (Tel Aviv: Dvir Co., 1928), I.

${ }^{4} \mathrm{~J}$. Klausner, Historiah shel hasifrut ha'ivrit hahadashah (Jerusalem: Achiasaf Publishing Co., 2nd Revised edition, 1952), I. This was originally written in 1930 .

${ }^{5}$ Avraham Sha'anan notes that Lachower believes the "new spirit" actually originated in 16 th century Italy but because he can find no artistically superior literary figure until Luzzatto he begins with him. See hasifrut ha'ivrit hahadashah lizerameiha (Tel Aviv: Massadah Publishing Co., 1962), I, p. 17. Sha'anan's discussion of the entire matter I am here concerned with is lucid and altogether insightful (see pp. 13-19).

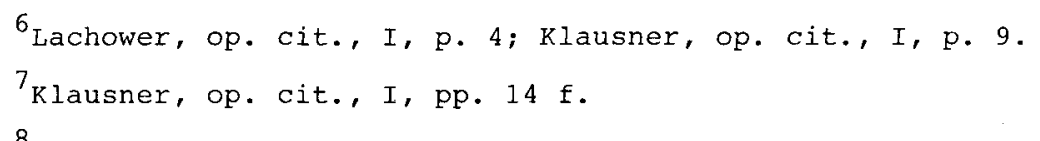

8 "Modern Hebrew Literature", Encyclopedia Judaica, VIII, p. 178 b. For a superior critique of all the extant histories of modern Hebrew literature in the light of the norms and practices of literary history see Avraham Holtz, "Prolegomenon to a Literary History of Modern Hebrew Literature", Literature East and West, XI/3 (Sept. 1967), pp. 259 ff.

9 Dov Sadan, "'al Sifrutenu", (1950), reprinted in Avnei bedek: 'al sifrutenue, masadah, ve'agapeha (Tel Aviv: haKibbutz hame' uha d, 1962) pp. $9-6 \overline{\text {. }}$

${ }^{10}$ See Dan Miron, "Penei habikoret beyisra'el", Ha'arets, Sept. 19,1958 .

${ }^{11}$ Gershom Scholem, "Mitzvah haba'ah ba'averah", Keneset, II (1937), pp. 347-392. English translation by Hillel Halkin as "Redemption Through Sin", in G. Scholem, The Messianic Idea in Judaism and Other Essays on Jewish Spirituality (New York: Schocken Books, 1971), pp. 78-141.

${ }^{12}$ See Hayim Nahman Schapira, Toledot hasifrut ha'ivrit hahadashah, second printing, 1967 (Tel Aviv: Massadah Publishing Co., 1940), pp. 27-37. This work was originally conceived as a 12 volume opus but Schapira was murdered by the Nazis in 1943. In his preface to the 1967 re-printing, Ben zion Benshalom says that Schapira had completed the manuscript of Volume 2 but it was destroyed. Schapira's terminology is most problematic. I have not attempted to find equivalents for such key concepts as "terraliyut" or "superliyut", but have instead given the general sense of his argument.

$$
{ }^{13} \text { Ibid. , pp. 43-49. }
$$

${ }^{14}$ Ibid., pp. $60 \mathrm{f}$. In general I find many similarities in critical method between schapira and Kurzweil in spite of the differences in outlook between them. Had he survived and 
continued his work in Israel, Schapira, I think, might have resembled kurzweil more than any other figure even though he was a literary historian rather than a critic.

$$
{ }^{15} \text { Ibid., pp. 58-62. }
$$

${ }^{16}$ Simon Halkin, Modern Hebrew Literature from the Enlightenment to the Birth of the State of Israel: Trends and Values, new edition, 1970 (New York: Schocken Books, 1950), pp. 11, 15, and $29-31$.

${ }^{17}$ Ibid., p. 33 and see epilogue, pp. 211-217. See also Halkin's Mavo lesifrut ha'ivrit, ed. Tsofiah Hillel (Jerusalem: mimeograph of Hebrew University, 1958).

${ }^{18}$ See Avraham Kariv, "haSifrut veha'am (1942), mishileshom ve'ad hena (Tel Aviv: M. Neumann Co., 1973), pp. 13-29\%

19 "hasifrut ha'ivrit hahadashah leA. Sha'anan", Ha'arets, April 8, 1963. Again, it is curious how kurzweil sees the discipline of criticism as scientific.

$$
\begin{aligned}
& 20 \text { "Sin'at 'atsmo besifrut hayehudit", S, pp. 112-128. } \\
& { }^{21} \text { See BT, pp. } x \text { and } 160 \mathrm{f} \text {. } \\
& { }^{22} \text { See "Darko shel A. Kariv beheker sifrutenu", Ha'arets, }
\end{aligned}
$$
July $29,1960$.

${ }^{23}$ Yitshak Bakon, "Brenner hamesaper be'einei habikoret", [introduction to] Yosef Hayim Brenner - mivhar ma'amarei bikoret, ed. Y Bakon (Tel Aviv: Am Oved Publishers Ltd., 1972), p. 32 .

${ }^{24}$ See "Darko shel A. Kariv beheker sifrutenu", op. cit.

${ }^{25}$ Shalom Kremer, "Netivot bevikoret ha'ivrit 1920-1960", Me'asef, 5-6 (1966), pp. 365-368. The first revision, in Kremer's view, was accomplished by Shlonski and his followers and was marked by a shift in emphasis--away from the values of collectivistic nationalism in favor of individualism.

$$
\begin{aligned}
& { }^{26} \text { Sha'anan, op. cit., I, p. } 15 . \\
& { }^{27} \text { S, p. 16. See entire discussion here, pp. 13-19. }
\end{aligned}
$$

28 So, too, Leon I. Yudkin, Escape into Siege: A Survey of Israeli Literature Today (London and Boston: Routledge and Kegan Paul, 1974), p. 7. See entire discussion pp. 1-18.

29 The key source for much of the following discussion is Kurzweil's long introductory essay, "Be'ayot yesod shel sifrutenu hahadashah", S, pp. 11-146, possibly his most important and certainly the quintessential single work. The core of the argument is in the first six sections, which were published first; section seven is a bridge passage to the expansion of the argument in sections eight through fourteen. But the structure of the latter seven sections follows those of the first six.

${ }^{30} \mathrm{H}, \mathrm{pp} .282 \mathrm{f}$.

${ }^{31}$ See "'Al hitpathutah shel hasifrut ha'ivrit hamodernit", Ha'arets, sept. 17, 1944, and S, p. 30 . 
32 Berlin, 1933. Hebrew translation by Leah Zagagi, haDat hayehudit bitekufat haemantsipatsiah (Jerusalem: Mosad Biali $\bar{k}$ and the Leo Baeck Institute, 1974).

${ }^{33}$ See, for example, Jacob Katz, Tradition and Crisis: Jewish Society at the End of the Middle Ages (New York: Schocken Books, 1961) and Michael A. Meyer, The Origins of the Modern Jew: Jewish Identity and European Culture in Germany, 1749-1824 (Detroit: Wayne State University Press, 1967).

${ }^{34}$ wiener, haDat hayehudit, op. cit., p. 55. pp. $61 \mathrm{ff}$.

${ }^{35}$ New York: Holt, Rinehart and Winston, 1968. See S,

${ }^{36}$ s, p. 92 .

${ }^{37}$ Ibid., pp. 96 f.

${ }^{38}$ Ibid., p. 100 .

${ }^{39}$ Ibid. , p. 104 .

40 Ibid., pp. $67-78$.

41 Ibid., pp. 108 f. The philosophical differential between contintental and American criticism shows through here. Note how Kurzweil talks in terms of the "totality" of reality, to which all details are sub-servient. Schapira, too, perceives by wholes; he simply disagrees with kurzweil on the nature of the Gestalt. Halkin, trained in America, proceeds quite differently. For a defense of Halkin against Kurzweil's charges see Isaiah Tishbi, "Divrei pulmus pesulot", Davar, August 2, 1957. Kurzweil's counter-attack came in "Al haetikah hasifrutit umada'it shel istenis", Davar, Sept. 6, 1957, and Tisbi's subsequent reply was "Heker hademonologiah uma'asim demoniyim", Davar, Sept. 20, 1957.

$$
\begin{aligned}
& 42 \mathrm{~s}, \text { pp. } 83,63, \text { and } 109 . \\
& 43 \text { Ibid., p. } 107 .
\end{aligned}
$$

44 In another place Kurzweil writes: "In what respect it [modern Hebrew literature] is a continuity is so clear as not to require emphasis. Rather, it is necessary and vital to call to mind the dialectical situation between continuity and revolt and to shift the emphasis to the new in modern [Hebrew] literature, to its revolutionary aspect. . ." (H, p. 304)

45 Toward the end of the essay "Be'ayot yesod" Kurzweil admits: "There is no period, no matter how dynamic and revolutionary, whose 'sudden' changes, as it were, were not fostered by the slow movements and the quiet shifts, invisible to the naked eye, of the static period preceding", and he bows in scholem's direction. But he still refuses to see Sabbatianism as anything more than a secondary cause (S, pp. 138 and 140). See also $\mathrm{S}$, p. 226 for the way the indirect influence of Nietzsche on modern Hebrew literature is validated. For discussion of the problems involved in determining influence see: Ihab Hassan, "The Problem of Influence in Literary History", Journal of Aesthetic and Art Criticism, XV (1955), pp. 66-76; Haskell Block, "The Concept of Influence in Comparative Literature", Yearbook of Comparative and General Literature, VII (1958), pp. 30-37; Claudio Guillen, "The Aesthetics of Influence Studies", proceedings of the Second 
Congress of the International Association of Comparative Literature, 1958 (Chapel Hill: University of North Carolina Press, 1959), PP. 175-192; and Anna Balakian "Influence and Literary Fortune", YCGL, XI (1962), pp. 24-31.

${ }^{46} \mathrm{~S}, \mathrm{pp} .19,21$.

47 Ibid., pp. 26-30; see also "hasifrut ha'ivrit hahadashah leA. Sha'anan", op. cit.

cit.

48"'Al hitpathutah shel hasifrut ha'ivrit hamodernit", op.

${ }^{49} \mathrm{~S}, \mathrm{pp} .31 \mathrm{f}$.

50"'Al motiv merkazi ehad besifrutenu hahadashah ('al motiv ha'avadon)", Ha'arets, August 31, 1951; see also S, p. 120 .

${ }^{51}$ See "hasifrut ha'ivrit hahadashah leA. Sha'anan", op. cit., and "Temihah mitokh i-havanah", Davar, oct. 16, 1959.

${ }^{52}$ see "'Al mobiv merkazi ehad besifrutenu hahadashah", op. cit., and $S$, pp. $36-40,141$.

${ }^{53}$ see "hasefer ha'ivri kenekhes ukeve'ayah", L, p. 233.

54 "Temihah mitokh i-havanah", op. cit.

$55 \mathrm{~J}$, p. ix.

${ }^{56} \mathrm{H}, \mathrm{p} . \mathrm{vi}$.

${ }^{57} \mathrm{~s}, \mathrm{p} .32$.

${ }^{58}$ Ibid., p. 37.

59 "haYesh derekh le'atsmaut tarbutit?" L, p. 177.

60 "'Al zeramim hadashim besifrut ha'ivrit hahadashah", Moznayim, XxV/4-5 (Sept.-Oct., 1967), pp. 257-265. Emphasis is Kurzweil's.

${ }^{61}$ see "hasifrut ha'ivrit hahadashah leA. Sha'anan", op. cit., and $S, p .30$.

$62 \mathrm{~S}, \mathrm{pp} \cdot 110-131$ and 141.
63 Ezra Spicehandler, revi

1961) 188 a. Spicehandler proposes $S$ in Judaism, $X / 2$ (Spring, "Modern Hebrew Literature", Encyclopedia Judaica, op. cit. Holtz arrives at an opinion of Kurzweil's periodization that is virtually identical with spicehandler and he, too, observes that it "falls short of encompassing the whole literature, and the last period is very limiting" ("Prolegomenon", op. cit., p. 264). 


\section{Notes to Chapter VI}

${ }^{1}$, p. xiil. This point should be applied also to his treatment of the course of the European novel in $\mathrm{MR}^{2}$.

2 Kurt Müller-Vollmer, Towards a Phenomenological Theory of Literature: A Study of Wilhelm Dilthey's Poetik (The Hague: Mouton \& Co., 1963), p. 179.

${ }^{3}$ See Rene Wellek, Concepts of Criticism (New Haven and London: Yale University Press, 1963), pp. 1-20.

${ }^{4}$ see J, pp. 68-95.

5 There is one essay on the first modern Hebrew play, a comedy from the Italian Renaissance period, Tsahut bedihuta dekidushin by Yehuda Somo. See "hamahazeh ha'ivri harishon", Ha'arets, August 23, 1946.

"On the "naive" and "militant" phases of the Haskalah, see

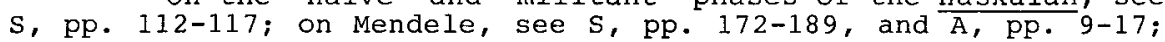
on Berditchevski, see S, pp. 241-250 and H, pp. 283-285.

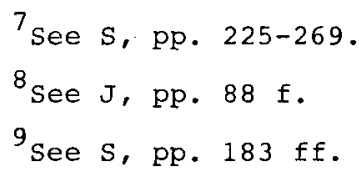

${ }^{10}$ For a further critique of Kurzweil's treatment of Mendele, see Menahem Brinker, "Olamo haepi shel hayotser", Masa', 75 (May 27, 1954), pp. 4, 8 .

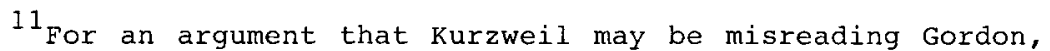
see Avraham Holtz, "Hirhurim 'al be'ayot yesod", Petahim, III (March, 1968), pp. 19-26. Holtz contends that Gordon does not idealize the non-Jew (as Kurzweil claims) and shows, using Gordon's letters, that the poet was not against Jewish religion per se (as Kurzweil makes him out to be) but against its petrification into a sterile orthodoxy.

$$
\begin{aligned}
& 12 \mathrm{H}, \mathrm{p} \text {. vii. } \\
& { }^{13} \text { see S, pp. 118-122 and 149-171. } \\
& 14 \text { Ibid., p. } 167 . \\
& \text { see S, pp. } 156 \mathrm{f}, 168-171 \text {, and BT, pp. 44-46. }
\end{aligned}
$$$$
{ }^{15} \text { on the thematic connections between Feierberg and Bialik, }
$$

${ }^{16}$ See BT, pp. 99-101. See also Kurzweil's discussions of Ya'akov Kapilowitz's (Yeshurun Keshet) work on Bialik "deDoro shel Bialik", Ha'arets, October 15, 1943, and of Lachower's "Bialik-hayav viyetsirotav", Ha'arets, Feb. 23 and March 9, 1945. 
${ }^{21}$ Ibid., pp. 99-147. See above p. 144, n. 75.

22 Ibid., p. 192 .

23 Ibid., p. xil. see also s, pp. 122-125.

24 See for example, Adi Tsemah, halavi hamistater.

25 see Miron's review of BT' "Bialik veTshernihovski le'or bikorto shel B. Kurzweil", Ha'arets, Feb. 24, 1961.

26 on Brenner, see $S$, pp. 131-138; 250-259, $337 \mathrm{f} ., 373 \mathrm{f}$, and $H, p p .271-318$.

27 see S, pp. $254,257 \mathrm{f} ., 337 \mathrm{f.}$, and H, pp. $315 \mathrm{f}$.

$28_{\mathrm{H}, \mathrm{P} .} 287$.

29 Ibid., pp. $305 \mathrm{f}$.

${ }^{30}$ see ibid., pp. $281 \mathrm{f}$. and $301 \mathrm{f}$.

31 Ibid., pp. $312 \mathrm{f}$.

32 "Terumato shel Barukh Kurzweil leheker Shai 'Agnon", SBK, pp. 74-82.

\section{${ }^{33}$ A, p. 313 .}

${ }^{34}$ see ibid., pp. 130-135, 336-339 and 9-17. "The great principle [is] that the Iyric does not present an objective world and does not admit of a separation between subject and object; its whole nature involves the destruction of the barrier between the "I" and the world in the art of creation" (H, pp. $110 \mathrm{f.}$.

${ }^{35}$ see A, pp. 346-352.

36 Ibid., p. 380, and see Kurzweil's discussion of "stylistic shifts as a response - . . to reality in Agnon's stories" (pp. 387-394).

${ }^{37} \mathrm{~S}, \mathrm{p} .144$, and see A, pp. 394-399.

38 After Kurzweil's death, Avraham Kariv attempted to argue against Kurzweil's casting Agnon in a "European" mould. See his "Parshanut mahti'ah", Molad, V/27 (Jan.-Feb., 1973), pp. 249-266; and "Interpretatisiah rabat eyal", Molad, VI/31 (April-June, 1974), pp. 108-121. Kariv, to my mind, is as unsuccessful in proposing a convincing alternative over-all reading of Agnon as is Band in Nostalgia and Nightmare: A study in the Fiction of $S$. $Y$. Agnon (The University of California Press: Berkeley and Los Angeles, 1968). Barzel neatly points out that Band has recourse to Kurzweil's interpretations as much as he tries to propose differing ones (op. cit., p. 89). The same is true of Baruch Hochman's The Fiction of S. Y. Agnon (Ithaca and London: Cornell University Press, 1970) and Robert Alter's "S. Y. Agnon: The Alphabet of Holiness", After the Tradition: Essays on Modern Jewish Writing (New York: E. P. Dutton \& Co., 1969), pp. 131-150. All three of these treatments of Agnon are largely derivative from Kurzweil; it is only Band who explicitly seeks to break away from him.

${ }^{39}$ op. cit., p. 74 
${ }^{40}$ Murray Krieger suggests just this. As examples, he gives Northrop Frye and his relationship to Blake and Georges Poulet's to Mallarmé. "Behind the vast structure in the Anatomy of Criticism we sense the profound commitment, personal and professional, that propelled his faithful study of Blake, Fearful symmetry. The further we go from Frye's system's center in Blake--to Shakespeare or to Milton, for example--the more we sense the imprint of Frye's vision at the expense of our previous sense of the poet himself. . . . If we feel comfortable with poulet on Mallarme (as we did with Frye on Blake), it is because he is at home there, his person--as he tells us--becoming one with his object. So he is being faithful to this poet because he can do so by being faithful to himself. It is when he moves off to objects less natural to him, less obviously a reflection of himself, that we feel the need to forego our former sense of the author if we are to accept the critic who has usurped his place" ("The Critic as Person and Persona", Yearbook of Comparative Criticism, Joseph P. Strelka, ed. (University Park and London: Pennsylvania State University Press, 1973), 6, pp. 83 f.

${ }^{41}$ see, for example, BT, pp. 237, 253,267, 277, and 289.

${ }^{42}$ Here the limits of these postulates, as least as I have determined them, become obvious, for kurzweil may be as close to Tshernichovski as he is to Agnon.

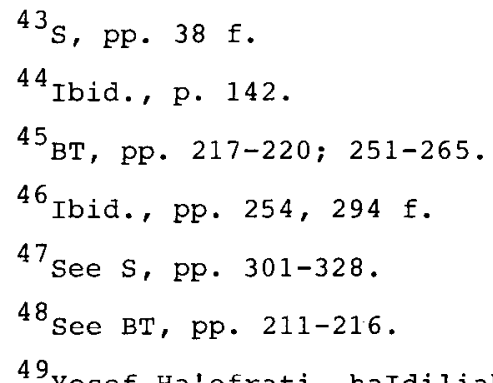

49 Yosef Ha'efrati, haIdiliah shel Tshernihovski (Merhaviah and Tel Aviv: Sifriat Po'alim, 1971), p. $\frac{\text {. }}{9}$

${ }^{50} \mathrm{BT}, \mathrm{p} .292$. See also pp. xii f.

${ }^{51}$ see ibid., pp. $322-334$.

52 Ibid., pp. 296-321.

${ }^{53}$ See H, pp. 105 ff., 114-116, 167-169, 225-234.

54 Ibid., p. 151 .

${ }^{55}$ Ibid., pp. 333-358.

${ }^{56}$ See the essay on Schneour's Luhot genuzim: "Milhamot Adonai vesefer hayashar be'einei $z$. Shneiur 0 'al ha'ofnah haarkhait", $\mathrm{Ha}^{\prime}$ arets, Dec. 15, 1950.

${ }^{57}$ On Hazaz, see especially the essays on Yaish, "haTetralogiah shel Hayim Hazaz", Ha'arets, April 30 and May 22, 1953. See also "Hayim Hazaz: reihayim shevurim", Ha'arets, August 28, 1942; "haYoshevet baganim leHayim Hazaz", Ha'arets, August 11, 1944; "Al yesod ruhani bekitvei Hazaz", beTerem, XI (65) (Nov. 15, 1947), pp. 23-25; and S, pp. 260-269. 
${ }^{58}$ In his preface to $\mathrm{H}$ Kurzweil observes that if a discussion of "the place of [various] important writers is lacking here, it certainly is not because of denigration. . . . The selection is not arbitrary but it is subjective" (p. xv).

${ }^{59}$ Abramson equates the fullness of Kurzweil's treatment of certain authors with another factor: "It is in just those instances where he had to break new critical ground as in the cases of Agnon and U. Z. Greenberg, . . . that his perception inclines toward dialectical [richness] and many sidedness." (Sipurei Barukh Kurzweil vezikot hagomelin beineihem levein masotav [Bar Ilan University, unpublished M.A. Thesis, 1974], p. 87).

${ }^{60}$ See Yehudah Friedlander, "Kavim behitpathut habikoret 'al shirat Uri Tsvi Greenberg", Y. Friedlander, ed., Uri Tsvi Greenberg: mivhar ma'amarei bikoret 'al yetsirato (Tel Aviv, Am Oved, 1974) pp. 7-34.

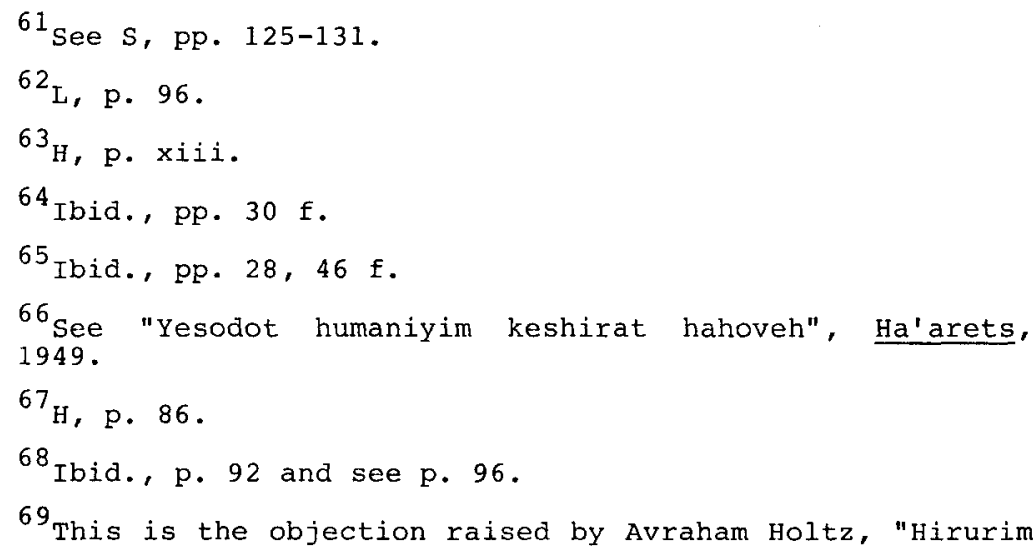
Feb. 4,1949 . 'al be'ayot yesod", op. cit. ' and Ezra Spicehandler, who, as noted fourth period unconvincing.

70 see "haFunktsiah shel hatekstim halo' kedoshim basipur hayisra'eli", Ha'arets, March 18, 1966. See also "Hayesh 'od lesifrutenu diokan yehudi?" Ha'arets, Sept. 28, 1962.

71 "Be'ayot hayetsirah hasifrut(it) beyisra'el", Moznayim, XXIII/2 (July, 1966), p. 127 .

${ }^{72} \mathrm{All}$ the themes and parts of this entire argument are announced in Kurzweil's first attempt to tackle Mossinsohn, "hasipurim ha'arets yisra'eliyim leyigal Mosinzon", Ha'arets, sept. 25, 1946. It is repeated in full or in part in all subsequent discussions of the sabra writers.

${ }^{73}$ In "'Im keri'at shirim hadashim", Ha'arets, June 22 , 1956, Kurzweil holds up the works of three younger poets, Yonah David, Shlomo Shenhad and Adar Kesari as examples of what he likes. This was often noted as one of his biggest critical gaffes, especially by the major figures among the younger poets. See Natan Zach, "Hulshato shel haDr. Kurzweil leshirah", Lamerhav, June 29, 1956. Kurzweil's two essays on Ravikovitch are "Shireiha shel Daliah Ravikovits", Ha'arets, Dec. 25, 1959, and "Shirei Daliah Ravikovits-ahad hagiluyim hahashuvim beyoter beshiratenu hatse'irah", Ha'arets, Jan. 29, 1965. 
74 "'Al 'efsharuyot hasipur ha'eretsyisra'eli", Ha'arets, May $23,1947$.

${ }^{75}$ See "leDerekh hasifrut ha'ivrit be'eser hashanim ha'aharonot", Ha'arets, April 25, 1958.

76"'Al 'efsharuyot hasipur ha'eretsyisra'eli", op. cit.

$77_{\mathrm{H}, \mathrm{p} .} 405$.

78 "'Al 'efsharuyot hasipur ha'eretsyisra'eli", Ha'arets, April 4, 1947. See also H, pp. 380-402.

${ }^{79}$ See "Sipurei Yehudah Amihai", Ha'arets, April 21, 1961; "He'arot leshirei Yehudah Amihai", Ha'arets, June 28, 1963; "Shirah otobiografit baMidbar hagadol", Ha'arets, July 12, 1963; "He'arot leLo me'akshav lo mikan le Y. Amihai", Ha'arets, Sept. 6 and $13,196 \overline{3}$.

${ }^{80}$ See H, Pp. 416-442 and also 403-415.

${ }^{81}$ Kurzweil early concentrated his attacks not on the writers but on the publishers for printing what should never have gone beyond manuscript. See "sefarim hadashim umoleihem", Ha'arets, April 7, 1944.

82 "Al efsharuyot hasipur ha'eretsyisra'eli", op. cit., May 23, 1947 .

${ }^{83}$ See H, p. 415, n. 15 .

${ }^{84}$ For interim assessments see: "Nos'im hadashim basipur hayisra'eli", Ha'arets, July 20, 1956; "leDerekh hasifrut ha'ivrit be'eser hashanim ha'aharonot", op. cit.; "Me'ever lekhol ha'arakhim ('al he'eder hush haproportsiah"), Ha'arets, May 15 and May 22, 1959; "'Al zeramim hadashim besifrut ha'ivrit hahadashah", Moznayim, XXV/4-5 (Sept.-Oct., 1967), pp. 257-265 (originally delivered as a lecture at Rutgers University in the fall of 1964).

${ }^{85}$ See "hasipur hayisr'eli beshanim ha'aharonot", Ha'arets, March 4, 1966.

${ }^{86}$ See "hasusah haapokaliptit tsohelet betraklin hasipur hayisra'eli o 'ergat hakisufim shel yisra'el ha'ovedet linesikhim unesikhot", Ha'arets, May 31, 1968. See also the discussion in the review of Tammuz's "Besof hama'arav - o ga'agu'im lama'arav?" Ha'arets, Feb. 10, 1967. In rejecting Mikha'el sheli as completely as he did, Kurzweil may possibly be settling a score with $\mathrm{Oz}$ for his reply to him at the French-Israeli literary dialogue. See below, n. 100 .

${ }^{87}$ See "haMuzah insah et meshorer-hakets Netan'el", Ha'arets, July 4, 1958. This is a parody of one of $\mathrm{Zach}$ 's poems instead of a critical discussion, by which Kurzweil means he feels the poem is not worth the effort to understand.

${ }^{88}$ See H, p. 386 and the interview with Rachel Eitan, Ha'arets, April 15, 1966.

${ }^{89}$ See "Mekoman shel sipurei Avraham B. Yehoshu'a", Ha'arets, August $30,1968$.

${ }^{90}$ I do not discuss here Kurzweil's famous essay on the 'Canaanite' movement (S, pp. 270-300). While this is of historic 
importance as the first attempt to examine the cultural significance of this movement, the essay's argument, I think, derives its cogency from the larger view of Israeli and modern Hebrew literature that I have focused on here.

$91_{H}, \mathrm{pp} .304$ f. Kurzweil here is referring specifically to Brenner but it is obvious that his point applies to all the major figures of the tragic period as I have noted them.

${ }^{92} \mathrm{R}$. Wellek and A. Warren, Theory of Literature, $3 \mathrm{rd}$ edition (New York: Harcourt, Brace and World, 1956), pp. $52 \mathrm{f}$. See above, Chapter I, p. 4. See also A. Holtz, "Prolegomenon to a Literary History of Modern Hebrew Literature", Literature East and West, XI/3 (Sept, 1967), pp. 268-271.

$93 \mathrm{~J}$. H. Brouwer, "The Relation Between Frisian Literature and other Literatures", Proceedings of the IIIrd Congress of the International Comparative Literature Association - Utrecht - 1961 (Gravenhage: Mouton \& Co., 1962), p. 297.

${ }^{94} \mathrm{~L}, \mathrm{p} .219$.

95 "He'arot live'ayot haroman hahistori ha'ivri", Davar, April 22, 1959.

96 "Nose' ha'akedah besifrut hahadashah", Davar, oct. 2, 1959. Kurzweil here cites Kierkegaard's Fear and Trembling and Greenberg's "belayl gashum biYerushalayim" as examples of what he means, Gilboa's "Yitshak" as an example of what he does not.

97 See "Melekh basar vadam lemoshe Shamir", Ha'arets, June 18,1954 . See also H, pp. 411 f.

98 "haTikvah ha'aharonah shel hasifrut hatse'irah beshulei hartsaah retsinit", 'Al hamishmar, July 14, 1950.

${ }^{99}$ See Hanokh Bartov, "'od bahurenu Kurzweil hai!" Masa', 24 (July 24, 1952).

100 Response to Kurzweil, Moznayim, XXIII/2 (July, 1966), pp. $133 \mathrm{f}$.

${ }^{101}$ see, for example, Ben-Gurion, L, pp. 246-248. See above, p. $142, \mathrm{n} .43$.

${ }^{102}$ A. Band, op. cit., p. ix. Band means something quite different in this judgment; he is bothered by what he feels is Kurzweil's violation of the autonomy of the literary work.

103 A very similar point is made in his excellent review of S by Boaz Evron, "Barukh Kurzweil - halohem livehirut hamahashavah", Ha'arets, January 9, 1960. 


\section{Notes to Chapter VII}

${ }^{1}$ Response to Kurzweil's paper in the symposium "haLe'umiyut hayehudit bizemanenu", (Jerusalem: World Jewish Congress, 1961), p. 34 .

${ }^{2}$ See Kurzweil's discussion of the collection of philosophical essays presented to S. H. Bergmann Hagut, L, pp. 140-147. See also Moshe Schwarcz, Hagut yehudit nokhah hatarbut hakelalit (Tel Aviv: Schocken Publishing Co., 1976), pp. 196-201.

3"Heker hademonologiah uma'asim demoniyim", Davar, Sept. 20, 1957.

${ }^{4}$ Ya'akov Abramson, "Sipurei Barukh Kurzweil vezikot hagomelin beineihem levein masotav", (Ramat Gan: unpublished M.A. Thesis, Bar-Ilan University, 1974), pp. 83-87.

${ }^{5}$ Ezra Spicehandler, review of $S$, Judaism, $x / 2$ (Spring, $1961)$, p. 188 .

${ }^{6}$. Nietzsche, "Vom Nutzen und Nachteil der Historie fur das Leben", Unzeitgemässe Betrachtungen, II, Karl Schlechta, ed., Werke 1 (Munich: 1954), p. 216, quoted in Paul de Man, "Literary History and Literary Modernity", Morton w. Bloomfield, ed., In Search of Literary Theory (Ithaca and London: Cornell University Press, 1972), p. 245 .

${ }^{7}$ de Man, op. cit., pp. 243, $245 \mathrm{f}$.

${ }^{8}$ Uri Zvi Greenberg, Rehovot hanahar, (Jerusalem and Tel Aviv: Schocken Publishing Co., 1953).

9 "hasusah haapokaliptit tsohelet betraklin hasipur hayisra'eli o 'ergat hakisufim shel yisra'el ha'ovedet linesikhim unesikhot", Ha'arets, May 31, 1968. Of Kraus, Wilma A. Iggers writes: "Apart from a few isolated instances, Kraus objected very much to the literary movements which continued to spring up throughout his lifetime and was proud to be one of the despised Epigonen." Karl Kraus: A Viennese Critic of the Twentieth Century (The Hague: Martinus Nijhoff, 1967), p. 27.

${ }^{10}$ Iggers, op. cit., p. 228.

$11_{A}$. Janik and S. Toulmin, Wittgenstein's Vienna (New York: Simon and Schuster, 1973), p. 80.

${ }^{12}$ Quoted from Benjamin's Goethe's Elective Affinities in Hannah Arendt's introduction to Illuminations, Hannah Arendt, ed., Harry Zohn, trans. (London: Jonathan Cape, 1970), p. 4.

13 In Tolstoy or Dostoevsky: An Essay in the old Criticism (New York: Alfred A. Knopf, 1959), Steiner writes: "The old criticism is engendered by admiration. It sometimes steps back from the text to look upon moral purpose. It thinks of literature as existing not in isolation but as central to the play of historical and political energies. Above all, the old criticism is philosophic in range and temper" (p. 6). In the preface to Extra-Territorial: Papers on Literature and the Language Revolution (New York: Atheneum, 1971), Steiner directs American criticism to the very sources from which Kurzweil's springs: "I have in mind the phenomenological tradition of Dilthey and Husserl with its stress on the historicity of speech acts, on the time 
boundedness and mutations of even the most elemental of semantic modes. I am thinking of the investigations into language by Heidegger, of Paul Ricoeur's De l'Interpretation, and of the whole hermeneutic approach now so lively in France, Italy and Germany. - . Cut off from these philosophic traditions, contemptuous of the uncertainties and transcendental intimations which they enact, the new linguistics, with its declared meta-mathematical ideals, runs the risk of a powerful triviality. . . The peremptory naivete of a good deal of transformational generative work makes impossible any real access to language when it is in a condition of maximal concentration, when, as Heidegger says, language is total being. . . . It is not in transformation grammars, however, but in hermeneutics, in the Sprachphilosophie of Walter Benjamin with its un-ashamed roots in Kabbalistic thought, that the implications of Babel are grasped" (pp. $x$ f.).

14 Hannah Arendt, introduction to walter Benjamin's Illuminations, op. cit., pp. $29 \mathrm{f}$.

$$
\begin{aligned}
& 15 \text { Ibid., p. } 32 . \\
& { }^{16} \text { Ibid. , p. } 34 .
\end{aligned}
$$

17 In this connection see scholem's two letters to Benjamin of Feb. 20, 1930 and March 30, 1931 in Devarim bego (Tel Aviv: Am Oved Publishers, Ltd., 1976), pp. 146-151. See also Scholem's insightful paper "Walter Benjamin", Leo Baeck Institute Yearbook, X (1965), pp. 117-136.

$$
\begin{aligned}
& { }^{18} \text { Arendt, op. cit., pp. } 37 \mathrm{f} . \\
& { }^{19} \mathrm{~s}, \mathrm{pp} .331-401 . \\
& 20 \text { "hayesod hatragi bemishnato shel Barukh Kurzweil", }
\end{aligned}
$$
Yedi'ot aharonot, Sept. 22, 1972.

${ }^{21}$ The resemblances here to the life and death of such more apparently marginal German Jews as Weininger, Toller and Stefan Zweig cannot be entirely co-incidental. See the treatment of these figures in Solomon Liptzin, Germany's Stepchildren (Philadelphia: The Jewish Publication Society, 1944).

22 Three Modes of Criticism: The Literary Theories of Scherer, walzel and Staiger (Cleveland: Case western Reserve University Press, 1968), p. 1.

${ }^{23}$ For a discussion of this issue with important bibliographical material, see steven s. Schwarzschild, "The Legal Foundation of Jewish Aesthetics", "The Journal of Aesthetic Education, IX/1 (January, 1975), pp. 29-42.

24 See John Caviglia, Flaubert and Leopoldo Alas: An Essay in Comparative Anatomy (unpublished doctoral thesis, Indiana University, 1970), p. 2

${ }^{25}$ See S. Alonim's review of $\mathrm{MR}^{1}$ "Bikoret-hai hanose et 'atsmo", Ha'arets, Jan. 8, 1954.

${ }^{26}$ See above, Chapter IV, pp. $60 f$.

${ }^{27}$ Northrop Frye suggests that criticism must derive its social context from what he calls the "myth of concern" of a society or a people, that "magic circle drawn around a culture; 
- . literature develops historically within a limited orbit of language, reference, allusion, beliefs, transmitted and shared tradition". ("The Critical Path: An Essay on the Social context of Literary Criticism", Morton w. Bloomfield, ed., In Search of Literary Theory, op. cit., p. 105). Kurzweil's criticism would be very close to a reading of literature from out of what he sees as the Jewish myth of concern. The implicit influence of Tillich on Frye is clear here, but it may also in a less conscious way have permeated Kurzweil.

${ }^{28}$ I do not deal with the possibility of holding up Kurzweil as an example of the "German-Jewish symbiosis" that some scholars frequently discuss. Kurzweil himself had great reservations about this concept (see J, pp. 279-281), and its value as a cultural or literary indicator seems to me to be too problematical to be of any use.

29 "A Critic's Job of Work", quoted from Language as Gesture (1935) in Morris Weitz, ed., Problems in Aesthetics: An Introductory Book of Readings (London: The Macmillan Co., second edition, 1970), p. 802 .

${ }^{30}$ Preface to Georg Lukács, Realism in our Time: Literature and the Class struggle (New York: Harper and Row, 1964), p. 15. 


\section{BIBLIOGRAPHY}

I. The Writings of Barukh Kurzweil Listed Chronologically

The following list was derived largely, but not exclusively, from the bibliography of Kurzweil's writings up to the end of the year 1963 prepared by Y. Barzilai (Folman), Ketavav ha'ivriyim shel haprof. Barukh Kurzweil [The Hebrew writings of Prof. Barukh Kurzweil], Ramat Gan: Histadrut hastudentim shel universitat Bar Ilan, 1963, mimeo, as well as from the bibliographical material at the Asher Barash Institute of Records (Genazim) at the Hebrew Writers' House (Bet hasofer) in Tel Aviv. In that it unites both these sources and, more importantly, corrects the many errors in them, especially in the former, this list can certainly be said to be a full and accurate and, therefore, serviceable one. It does not, however, purport to be the definitive enumeration of everything that Kurzweil wrote. That task shall presumably be realized by the Barukh Kurzweil Memorial Foundation (Yad Kurzweil) at Bar-Ilan University.

a) Volumes of Collected Essays and Articles:

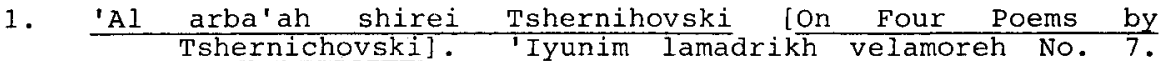
Jerusalem: Hamahlakah le'aliyat yeladim veno'ar, 5702 (1942). Re-printed in BT.

2. Masekhet haroman: shenei mahzorei masot 'al Shemuel Yosef 'Agnon ve'al toledot haroman haeiropi [The course of the Novel: Two Series of Essays on $S . X$. Agnon and on The History of the European Novel]. Tel Aviv: Schocken Publishing Co., 1953 .

3. Sifrutenu hahadashah - hemshekh o mahapekha? [Our Modern Iiterature--A Continuity or A Revolt?]. Jerusalem and Tel Aviv: Schocken Publishing Co., 1959. Third enlarged edition, 1971.

4. Bialik veTshernihovski - mehkarim beshiratam [Bialik And Tshernichovski - studies In Their Poetry ]. Jerusalem and Tel Aviv: Schocken Publishing Co., 1960. Fourth enlarged edition, 1971.

5. Masot 'al sipurei Shai 'Agnon [Essays on The Fiction of S. Y. Agnon]. Jerusalem and Tel Aviv: Schocken Publishing Co., 1963. Fourth enlarged edition, 1975.

6. Bein hazon levein ha'absurdi - perakim laderekh sifrutenu bame'ah ha'esrim [Between Vision And The Absurd - Essays on The Development of our Literature In The Twentieth Century]. Jerusalem and Tel Aviv: Schocken Publishing Co., 1966. Second enlarged edition, 1973.

7. Bema'avak 'al 'erkei hayahadut IIn The Struggle For Jewish Values]. Jerusalem and Tel Aviv: Schocken Publishing Co., 1969 . 
8. havesi'ah vesipurim aherim [The Journey And Other stories]. Tel Aviv: Am Oved Publishers Ltd., 1972.

9. Masekhet haroman vehasipur haeiropi [The Course of The Novel and European Fiction]. Edited with an introduction by Y. Friedlander. Jerusalem and Tel Aviv: Schocken Publishing Co., 1973.

10. leNokhah hamevukhah haruhanit shel dorenu - pirkei hagut uvikoret [Facing The spiritual Perplexity of Our Time]. Edited with an introduction by Moshe Schwarcz. Ramat Gan: B. Kurzweil Memorial Foundation, Bar-Ilan University, 1976.

11. haDramah haeiropiit: pirkei mehkar umasah [European Drama: Studies and Essaysl. Ya'akov Abramson and Hayim Shoham, eds. Afterword by Y. Abramson. Ramat Gan: B. Kurzweil Memorial Foundation, Bar-Ilan University, 1979.

12. Behipus hasifrut hayisra'elit: masot uma'amarim [In search of Israeli Literature: Essays and Articles] Zvi Luz $^{2}$ and Yedidiah Yitshaki, eds. Ramat Gan: B. Kurzweil Memorial Foundation, Bar-Ilan University, 1982.

b) Studies, Essays and Articles:

1. Die Bedeutung bürgerlicher und künstlerischer Lebensform für Goethes Leben und Werk dargestellt am Faust 1. Teil. Limburg a.d. Lahn: Druck der Limburger vereinsdruckerei, G.M. b. H., 1933. 114 pp.

2. "Chanukahbetrachtungen". Selbstwehr, December 20, 1935, pp. $6 f$.

3. "Josef Kasteins Werke". Selbstwehr, February 14, 1936, p. 6.

4. Die Bedeutung der Thoragesetze für unsere zeit. Brünn: Druck von Markus Kral, 1936. 11 pp. An address at the General Assembly of the Brno Jewish Burial Society.

5. Zur Problematik des Religionsunterrichtes. Brünn: Herausgegeben vom Klub politischer Zionisten in Brünn, 1936 . $47 \mathrm{pp}$.

6. "Abschied". Selbstwehr, December 17, 1937, pp. 7f. A chapter from an unfinished novel Die sterbende Gemeinde.

7. Die Jüdische Nachkriegsgeneration in Agnons "Oreach Nata Lalun". Jerusalem: P. Freund, 1941. Mimeographed, $28 \mathrm{pp}$.

8. "Shai 'Agnon: elu ve'elu" ["S. Y. Agnon's These And Those"]. Ha'arets, January 30, 1942. Re-printed in MR and in $A$.

9. "Bein kokhav vedeshe' - ('al sefaro shel Yitshak Shenberg)" ["On Yitshak Shenberg's Between The Star And The Lawn"]. Ha'arets, March 13, 1942 .

10. "Pat sheleimah leshai 'Agnon" ["S. Y. Agnon's 'A Whole Loaf'"]. Gazit, IV (7-13) (January - June, 1942, pp. 145-147. Re-printed in $M R^{1}$ and in $A$. 
11. "Sedarim (seder sipurim)" ["'Sequences' (A story Cycle)"]. Ha'arets, May 8 and June 26, 1942.

12. "Hayim Hazaz: reihayim shevurim" ["Haim Hazaz's Broken Millstones"] Ha'arets, August 28, 1942 .

13. "'Me'erets el erets (sipurim me'et Y. Shenberg)" ["'From Country to Country' (Stories by $Y$. Shenberg)"] . Ha'arets, January $22,1943$.

14. "Shevu'at emunim leshai 'Agnon" ["S. Y. Agnon's 'Betrothed"]. Ha'arets, June 4, 1943. Re-printed in $M R$ and in $A$.

15. "haRav M. A. 'Ami'el lenevukhei hatekufah ('al sefaro lenevukei hatekufah)" ["Rabbi M. A. Amiel's Book On the Perplexities of Our Time"]. Ha'arets, August $20, \frac{1943}{194}$

16. "Kisufim-roman IiYehudah Burla" ["Yearnings - Yehudah Burla's Novel"]. Ha'arets, September 3, 1943.

17. "beDoro shel Bialik" ["In the Generation of Bialik"]. Ha'arets, October 15, 1943. Critique of Ya'akov Kapilewicz's (Yeshurun Keshet) first volume of essays on Bialik.

18. "Ohel Ya'akov ('al sefaro shel S. Asaf)" ["The Tent of Jacob (On S. Assaf's Book)"]. Ha'arets, November 12, 1943.

19. "Yitshak Breuer" ["Isaac Breuer"]. Ha'arets, December 17, 1943. Re-printed in L.

20. "ha'Adonit veharokhel leshai 'Agnon" ["S. Y. Agnon's 'The Lady and the Pedlar'"]. Ha'arets, January 17, 1944. Re-printed in $M R^{1}$ and in $A$.

21. "beSa'ar ('al hame'asef be'arikhat Fikhman)" ["In The storm On an Anthology Edited by Fichmann)"]. Ha'arets, February 11, 1944.

22. "Reshimot leva'ayat ha'adam bekitvei Balzac" ["Notes on the Problems of Man in Balzac" $]_{2}$ Ha'arets, March 10, 1944. Re-printed in $M R^{1}$ and in $M R^{2}$.

23. "Shylock vehasimpoziyon beveit habri'ut" ['Shylock' and the Symposium in the Sanitorium']. Ha'arets, March 24, 1944. Review of a discussion of Ari Even-Zahav's Shylock The Jew of Venice.

24. "Sefarim hadashim umoleihem" [New Books and Their Publishers"]. Ha'arets, April 7, 1944.

25. "Yehudei Tshekhiah umekoman besifrut" ["The Jews of Czechoslovakia and Their Place in Literature"]. Ha'arets, June 9, 1944. Written to commemorate Max Brod's 60 th birthday.

26. "Yosef hamashbir leThomas Mann" ["Thomas Mann's Joseph The Provider"j. Ha'arets, June 23, 1944. Re-printed in MR and in $M R^{2}$.

27. "Alei higayon ('al sefaro shel Yitshak Shenberg)" ["On Yitshak Shenberg's Book To The sound of the Harp"] . Ha'arets, July 28,1944 . 
28. "haYoshevet baganim leHayim Hazaz" ["Hayim Hazaz's She That Dwells in the Gardens"]. Ha'arets, August 11, 1944 .

29. "'Al hitpathutah shel hasifrut ha'ivrit hamodernit" ["On The Development of Modern Hebrew Literature"]. Ha'arets, September 17,1944 .

30. "Bet hasefer utenu'at hano'ar" ["The School and the Youth Movement"]. Luah Ha'arets, 5705 (1944/45), pp. 113-123. Re-printed in $\mathrm{L}$.

31. "haHoker Avraham Shalit" ["Avraham Shalit The Scholar"]. Ha'arets, September 26, 1944. Discussion of Shalit's translation into Hebrew of Josephus' Antiquities.

32. "Gog uMagog leMartin Buber" ["Martin Buber's Gog and Magog"]. Ha'arets, November 24,1944 . Re-printed in L.

33. "hapopulariyut hamesukenet" ["A Dangerous Popularity"]. Ha'arets, December 29, 1944. Re-printed in L.

34. "Masot historiyot leYosef Klausner" ["Historical Essays by Joseph Klausner"]. Ha'arets, January $12,1945$.

35. "Bialik - hayav viyetsirotav leF. Lahover" ["F. Lachower's Bialik - His Life and Works"]. Ha'arets, February 23 and March 9, 1945 .

36. "Frants Kafka ('al sefaro Amerika)" ["On Franz Kafka's Amerikg"]. Ha'arets, March 22, 1945. Re-printed in MR and $\mathrm{MR}^{2}$.

37. "Hareka' haidili beshirei Tshernihovski" ["The Idyllic Background in Tshernichovski's Poetry"]. Ha'arets, March 27, 1945. Re-printed in BT.

38. "Hagut" ["Reflections"]. Ha'arets, May 25, 1945. Review of an anthology on Jewish thought for S. H. Bergmann. Re-printed in $\mathrm{L}$.

39. "No'arei hamelekh Henry harevi'i lal sefaro shel Heinrich Mann betirgumah shel Laya Goldberg)" ["On Die Jugend des Konigs Henri Quatre by Heinrich Mann as translated by Leah Goldberg"]. Ha'arets, June 1, 1945.

40. "'Al hasipur haavtobiografi" ["On the Autobiographical Story"]. Ha'arets, July 6, 1945. Discussion of article by $S$. Vilnay "Approaches to Autobiography in the Period of the Enlightenment."

41. "hasipur haavtobiografi etsel Bialik uBrenner" ["The Autobiographical Story in Bialik and Brenner"]. Ha'arets, July 20 and August 3, 1945.

42. "'Einayim 'atsumot lesh. Kadari" ["Eyes Shut by s. Kadari"]. Ha'arets, August $17,1945$.

43. "Yamin yedabru leYitshak Shenberg" ["Yitshak Shenberg's Days Will Speak"]. Ha'arets, August 31, 1945.

44. "Al takfidei habikoret" ["On The Functions of Criticism"]. Ha'arets, September 7, 1945. 
45. "'Al nisayon lefilosofiah shel hahasidut" ["On an Attempt at a Philosophy of Hasidism"]. Ha'arets, November 2, 1945. A review of Buber's In The Garden of Hasidism. Re-printed in $\mathrm{L}$.

46. "Temol shilshom leShai 'Agnon" ["S. Y. Agnon's Yesteryear"]. Ha'arets, November 16,1945 . Reprinted in $\mathrm{MR}^{1}$ and in $A$.

47. "haMahashavah hayehudit ba'et hahadashah" "Jewish Thought in Modern Times". Ha'arets, January 11, 1946. Discussion of Natan Rotenstreich's book of the same title. Re-printed in L.

48. "haMesaper Yehoshu'a Bar-Yosef" ["The Novelist Yehoshua Bar-Yosef"] . Ha'arets, January 25, 1946.

49. "bevet hakeneset" ["In the Synagogue"]. Moznayim, 21 (Tishri-Adar, 5706, 1945/46), pp. 187-194. Re-printed in $\mathrm{N}$.

50. "'Al Balak, hakelev hademoni betemol shilshom leshai 'Agnon" ["On Balak, the Demonic Dog in $S$. Y. Agnon's Yesteryear"]. Ha'arets, February 8, 1946. Re-printed in $M R$ and in $A$.

51. "'Al hasipur hahevrati ha'ivri" ["On the Hebrew Novel of Society"]. Hla'arets, February 22, 1946. On S. Y. Agnon's The Bridal Canopy. Re-printed under somewhat different title in MR and in $\mathrm{A}$.

52. "Sipurim meyutarim" ["Superfluous Stories"] Ha'arets, March 29, 1946.

53. "haSipur hahevrati etsel Balzac" ["The Social Novel in Balzac"]. Ha'arets, April 15, 1946. Re-printed under somewhat different title in $\mathrm{MR}^{1}$ and in $\mathrm{MR}^{2}$.

54. "Be'ayat hadorot besipurei Shai 'Agnon" ["The Problem of the Generations in the Fiction of S. Y. Agnon"]. Ha'arets, May 17, 1946. Re-printed in $\mathrm{MR}^{1}$ and in $\mathrm{A}$.

55. "'Al hapulmus bevikoret" ["On Polemic in Criticism"]. Ha'arets, June 7, 1946.

56. "Kavim lidemuto shel Schopenhauer" ["Towards a Profile of Schopenhauer"]. Ha'arets, June 21,1946 . Re-printed in I.

57. "Baderekh legar'in hamasoret o gilui ha'emdah hashelishit" ["On the Way to 'The Kernel of Tradition' or Outlining the Third Position"]. Ha'arets, July 26, 1946. On Buber's Moses. Re-printed in L.

58. "haMahazeh ha'ivri harishon" ["The First Hebrew Drama"]. Ha'arets, August 23, 1946. On Yehudah Somo's "An Eloquent Marriage Farce".

59. "haSipurim ha'erets yisra'eliyim leYigal Mosinzon" ["The Erets-Yisrael stories of Yigal Mossinsohn"]. Ha'arets, September 25,1946 .

60. "lezikhro shel Yitshak Breuer" ["In Memory of Isaac Breuer"]. Ha'arets, November 1, 1946. Re-printed in L. 
61. "Tikun" ["A Correction"]. Ha'arets, November 14, 1946. A correction of some typographical errors in preceding article.

62. "haMashber baroman hahevrati" ["The crisis in the social Noyel"]. Ha'grets, November 15, 1946. Re-printed in $M R^{1}$ and in $\mathrm{MR}^{2}$.

63. "Sipurei Prosper Mérimée be'ivrit" ["The Stories of Prosper Mérimée in Hebrew"]. Ha'arets, December 13, 1946. Re-printed in $M R^{2}$.

64. "Al shenei yesodot nafshiyim biyetsirato shel Bialik" ["On Two Existential Foundations of Bialik's Work"]. Keneset, ed. Y. Cahan, F. Lachower, Z. Woislawski. Tel Aviv: Dvir, 1946, pp. 30-40. Re-printed in BT.

65. "Hermann Hesse - hatan peras Nobel" ["Hermann Hesse - Nobel Prize Laureate"]. Ha'arets, January 24, 1947. Re-printed in $M R^{1}$ and in $\mathrm{MR}^{2}$.

66. "Mishakei peninei hazekhukhit leH. Hesse" ["H. Hesse's Das Glasperlenspiel" . Ha'arets, February 14, $19 \overline{47 .}$ Re-printed in $M R^{1}$ and in $\mathrm{MR}^{2}$.

67. "Pandre hagibor lez. Shneiur" ["z. Schneour's Hero Pandre"]. Ha'arets, February 21, 1947.

68. "'Al efshauyot hasipur ha'eretsyisra'eli" ["On the Possibilities for the Erets-Yisraeli Story."] Ha'arets, April 4 and May 23, 1947.

69. "le'or kivtsei-masoret hadashim" ["Looking at some New Anthologies"]. Ha'arets, April 18, 1947. Critique of some recent collections of critical essays.

70. "Anshei hapenim va'anashim min hahuts" ["Insiders and outsiders"]. Ha'arets, May 16, 1947.

71. "haHurshah asher bagiv'ah leYizhar" ["Yizhar's 'The Grove on The Hill'"]. Ha'arets, May 30, 1947.

72. "Sipurim eksotiyim ('al sipurav shel E. A. Poe)" ["Exotic Tales (On E. A. Poe's Stories)"]. Ha'arets, July 18, 1947. Re-printed in $\mathrm{MR}^{2}$.

73. "Balzac be'einei S. Zweig" ["Balzac Through the Eyes of S. Zweig"]. Ha'arets, July 25, 1947.

74. "haHefkerut basipur ha'ivri" ["The Chaos in Hebrew Fiction"]. Ha'arets, August 22, 1947.

75. "Mordecai ze'ev Feierberg". Ha'arets, September 14, 1947. $\mathrm{Re}$-printed in $\mathrm{S}$.

76. "Me'az umikedem leYitshak Shenberg" ["Yitshak Shenberg's Once Upon A Time"]. Ha'arets, October 5, 1947.

77. "He'arot linefashot metot leGogol" ["Notes on Gogol's Dead Souls"]. Ha'arets, October 31, 1947. Discussion of Shenberg's Hebrew translation. Re-printed in $\mathrm{MR}^{\mathrm{I}}$ and in $\mathrm{MR}^{2}$. 
78. "Al yesod ruhani bekitvei Hazaz" ["On a Spiritual Element in Hazaz's Writings"]. beTerem, $11(65)$ (November 15, 1947), pp. 23-25.

79. "'Al hatragi" ["On The Tragic"]. Ha'arets, November 21 , 1947 .

80. "haYesod hamoderni bedon kishot" ["The Modern Element in Don Quixote"]. Ha'arets, December 26, 1947. Written to commemorate the 400 th anniyersary of Cervantes' birth. Re-printed in $\mathrm{MR}^{1}$ and in $\mathrm{MR}^{2}$.

81. "hanahot ruhaniyot shel sifrutenu hahadashah ('al hadatiut vehahiloniut besifrutenu hahadashah" ["Spiritual Pre-suppositions of our Modern Literature (on Religiousness and Secularism in our Modern Literature")]. 'Alei 'Ayin, The Salman Schocken Jubilee Volume, [ed. not given]. Jerusalem: [Schocken?], 5708-5712 (1946-1950), pp. 407-432. Re-printed in $S$ (first six sections), pp. 11-40. Also re-printed in Mahashavot vede'ot, ed. Y. Becker and S. Spann, Tel Aviv: Yavneh, 1954, pp. 249-271.

82. "hatidush bemered ha'ivrim hahadashim ('al helkah shel sifrutenu hahadashah biyetsirat tenu'at hakena'aniyim)" ["The Novum in the Revolt of the 'Young Hebrews' (On the Role of our Modern Literature in the creation of the 'Canaanite' Movement)"]. beTerem, 14 (68) (January 1, $1948)$, pp. 13-15.

83. "Leket sihot vehanhagot sheI R. Nahman miBraslav" ["A Selection of Talks and practices of $R$. Nahman of Bratslav"]. Ha'arets, January 9, 1948. Review of work by Yosef Weiss.

84. "haYesod haromanti bekitvei Feierberg" ["The Romantic Element in Feierberg's Writings"]. Ha'arets, January 30, 1948. Re-printed in $S$.

85. "live'ayah hadatit shel Feierberg" ["On Feierberg's Religious Problem"]. Ha'arets, February 20, 1948. Re-printed in $\mathrm{S}$.

86. "lemahut 'olamah haruhani shel hatragediah" ["On The Nature of the Spiritual World of Tragedy"]. Ha'arets, March 12,1948 .

87. "Doktor Faustus leThomas Mann" ["Thomas Mann's Dr. Faustus"]. Ha'arets, March 26, 1948. Re-printed in $\mathrm{MR}^{1}$ and in $\mathrm{MR}^{2}$.

88. "Pereidah mehatarbut haburganit" [A Farewell to Bourgeois Culture"l. Ha'arets, April 23 and 29, 1948. More on Dr. Faustus and on Alfred Weber's Abschied von der bisherigen Geschichte. Re-printed in $\mathrm{MR}^{1}$ and in $\mathrm{MR}^{2}$.

89. "Demut ha'ezrah besifrut ha'olamit" ["The Image of the Bourgeois Hero in World Literature"] . Ha'arets, May 21, 1948. Re-printed in $\mathrm{MR}^{1}$ and in $\mathrm{MR}^{2}$.

90. "ke'Esev hasadeh ('al sefaro shel Taviv)" [As Grass In The Field (On Taviv's Book)"]. beTerem, 12 (79) (June 15, $\overline{1948)}$, pp. 23-25. 
91. "live'ayat haparshanut shel kitvei Kafka" ["On the Problem of the Interpretation of Kafka's ${ }_{1}$ Writings"] Ha'arets, $^{2}$ June 25,1948 . Re-printed in $M R^{1}$ and in $M R^{2}$.

92. "ha'Ezrah besipurei stifter uBalzac" ["The Bourgeois Hero in the Fiction of Stifter and Balzac"].2 Ha'arets, August 6,1948 . Re-printed in $\mathrm{MR}^{1}$ and in $\mathrm{MR}^{2}$.

93. "He'arot levehayah he'akov lemishor leshai 'Agnon" ["Notes on S. Y. Agnon's 'Änd The Crooked Shall Be Made Straight" "]. Ha'arets, August 13, 1948. Re-printed in $M R$ and in $A$.

94. "Ra'ayon habehirah beshirat Bialik" ["The Idea of Chosenness in Bialik's Poetry"]. beTerem, 15-16 (82-83) (August 15, 1948), pp. 37-41.

95. "Penei hasipur ha'ivri hahadash le'an?" ["Whither the New Hebrew Fiction?"]. Ha'arets, September 3 and September 17, 1948. Review of Shamir's He walked In The Fields and Mossinsohn's who Said He Was Black?

96. "Hakdamah lesefer hama'asim" ["Introduction to (Agnon's) The Book of Deeds"]. Ha'arets, October 3, 1948. Re-printed in $\mathrm{MR}^{1}$ and in $\mathrm{A}$.

97. "Hitkadmut veriaktsiah bevikoret" ["Progress and Reaction in Criticism"]. Ha'arets, November 5, 1948.

98. "ha'Ezrah 'erev hamashber (Lemahut haroman 'al saf hame'ah ha'esrim)" ["The Bourgeois Hero on the Eve of the Crisis (On the Nature of the Novel at the outset of the Twentieth Century)"]. 2a'arets, January 7, 1949. Re-printed in $\mathrm{MR}^{1}$ and in $\mathrm{MR}^{2}$.

99. "Yesodot humaniyim keshirat hahoveh" ["Humanistic Elements in Contemporary Poetry"]. Ha'arets, February 4, 1949.

100. "Galileo hakavul lemax Brod" ["Max Brod's Galileo In Captivity"]. Ha'arets, March 18, 1949. Re-printed in

101. "He'arot letil Eulenspiegel lech. De Coster" ["Notes on C. De Coster's Till Eulenspiegel"]. Ha'arets, April 13, 1949. Review of Shlonsky's Hebrew translation. Re-printed in $\mathrm{MR}^{1}$ and in $\mathrm{MR}^{2}$.

102. "Narkizm sentimentali o 'itsuv omanuti?" ["Narcissistic Sentimentality or Artistic Depiction?"]. Ha'arets, May 27, 1949. Review of Mossinsohn's In The Plains of The Negev.

103. "Boser snobisti ve'efes menupah" [A Snobby Immaturity and an Inflated Vacuum"]. Ha'arets, July 1, 1949. Critique of Natan Shaham's Corn and Lead.

104. "haBe'ayah hafaustit vehashpa'atah 'al ruah eiropah" ["The Faustian Problem and its Influence on the European Spirit"]. Molad, III(17-18) (August-September, 1949), pp. $315-324$.

105. "Demut hamelekh Sha'ul beshirat Tshernihovski" ["The Image of King Saul in Tshernichovski's Poetry"]. Dorot, I (8-9) (November 10 and 17,1949 ). Re-printed in BT. 
106. "Hazut ha'avadon vehage'ulah beshirei U. Ts. Greenberg" ["The Vision of Loss and Redemption in the poems of U. Z . Greenberg"]. Ha'arets, January 6, 1950. Re-printed in $\mathrm{H}$.

107. "haYe'ud ha'ishi vehamitos beshirei U. Ts. Greenberg" ["Private Mission and Mythos in the poems of U. Z. Greenberg"]. Ha'arets, February 24, 1950. Re-printed in $\mathrm{H}$.

108. "haToda'ah hahistorit beshirei Yitshak Lamdan" ["Historical Consciousness in the Poems of Yitshak Lamdan"]. Molad, IV (Tishri-Adar, 5710, Oct. 1949-March 1950), pp. $\overline{56-59}$. Re-printed in $\mathrm{H}$.

109. "He'arot lasipur kishrei kesharim" ["Notes to (Agnon's) Story 'Knots'"]. Ha'arets, March $31,1950$.

110. "ha'olam be'aspaklariah shel hamitos hale'umi l'al sefer hafitrug veha'emunah le'Uri Tsvi Greenberg)" ["The World Through the Mirror of the National Mythos (On U. Z. Greenberg's The Book of Inditement and Faith)"]. Ha'arets, March 31, 1950. Re-printed in $\mathrm{H}$.

111. "haPetihah beore'ah natah lalun" ["The Opening To A Guest For The Night"]. Ha'arets, June 23, 1950. Re-printed in MR and in $A$.

112. "Nose' hamafteah beore'ah natah lalun leshai 'Agnon" ["The Theme of the Key in S. Y. Agnon's A Guest For the Night"]. Ha'arets, July 14, 1950. Re-printed in MR and in $A$.

113. "Nose' hamafteah besipurei 'Agnon" ["The Theme of the Key in Agnon's stories"]. Ha'arets, July 21, 1950. Re-printed in $M R^{1}$ and in $A$.

114. "leve'ayat bikoret hatarbut beshirei Tshernihovski" ["On the Problem of the Critique of Culture in Tshernichovski's Poems"]. Ha'arets, August 4, 1950. Written to commemorate the 75 th anniversary of the poet's birth. Re-printed in BT.

115. "He'arot limegilat ha'esh leBialik" ["Notes on Bialik's The Scroll of Fire"]. Ha'arets, september $20,19 \overline{50 .}$ Re-printed in BT with different title.

116. "haNigud bein haye'ud levein haeiros bimegilat ha'esh" ["The Contrast Between Mission and Eros in The Scroll of Fire"]. Ha'arets, October 13, 1950. Re-printed in BT.

117. "hapitaron haparadoksali biMegilat ha'esh" ["The Paradoxical Resolution to The Scroll of Fire"]. Ha'arets, October 27, 1950. Re-printed in BT.

118. "Holot hazahav leVinyamin Tammuz" ["Benjamin Tammuz's Golden Sands"]. Ha'arets, November 24, 1950.

119. "Milhamot Adonai veSefer hayashar be'einei $Z$. Schneiur o 'al ha' Ofnah haarkhait" "The Wars of the Lord and the Book of Yashar In the Eyes of $\mathrm{z}$. Schneour or on the Fad of Archaism"]. Ha'arets, December 15, 1950. On Z. Schneour's Hidden Tablets. 
120. "hakotviyut bemif'alo hasifruti shel Shai 'Agnon" ["Polarity in the Literary Work of S. Y. Agnon"]. Ha'arets, December 22, 1950. Written to mafk Agnon's receiving the Bialik Prize. Re-printed in MR and in $A$.

121. "Nisayon filosofi lehavhir et hayahas shebein hayahadut levein hashe'elot hakiyumiyot shel yisra'e]" ["An Attempt to Clarify the Philosophic Relationship Between Judaism and the Existential Questions of the Jewish People"]. Ha'arets, January 25, 1951. Discussion of volume two of Rotenstreich's Jewish Thought in Modern Times. Re-printed in $\mathrm{L}$.

122. "He'arot mesakmot leHamahashavah hayehudit be'et hahadashah" ["Summary Notes on Jewish Thought in Modern Times"]. Ha'arets, February 9, 1951. Continuation of the preceding article. Re-printed in $\mathrm{L}$.

123. "He'arot le'Ido ve'Enam le'Agnon" ["Notes on Agnon's Edo and Enam"]. Ha'arets, April 20 and 26, 1951. Re-printed in $\mathrm{MR}^{+}$and in $\mathrm{A}$.

124. "haTrilogiah hatsefatit liYehoshu'a Bar-Yosef" ["Yehoshu'a Bar-Yosef's safed trilogy"]. Ha'arets, June 29, 1951.

125. "He'arot lemahut haroman harusi beme'ah halg" ["Notes on the Nature of the Russian Novel in the 19th Century"] . Ha'arets, July 13, 1951. Re-printed in $\mathrm{MR}^{1}$ and in $\mathrm{MR}^{2}$.

126. "'Al motiv merkazi ehad besifrutenu hahadashah ('al motiv ha'avadon)" ["On a Central Motif in our Modern Literature (On The Motif of Loss)"]. Ha'arets, August 24 and August 31, 1951 .

127. "Im (keri'at?) shirei Rehovot hanahar shel Uri Tsvi Greenberg" ["On (Reading?) U. Z. Greenberg's The Streets of the River"]. Ha'arets, September 7, 1951. Re-printed with different title in $H$.

128. "'Od 'al shirei sefer Rehovot hanahar shel Uri Tsvi Greenberg" ["More on U. Z. Greenberg's The streets of the River"]. Ha'arets, September 21, 1951. Re-printed in $\mathrm{H}$.

129. "hamusag realizm bivehinat kriterion omanuti" ["The Concept of 'Realism' as an Artistic Criterion"]. Ha'arets, September 30 and October 9, 1951. Re-printed in MR and in $\mathrm{MR}^{2}$.

130. "He'arot lanivhar leThomas Mann" ["Notes on Thomas Mann's The Holy Sinner"]. Ha'arets, November 23, 1951. Re-printed in $\mathrm{MR}^{1}$ and in $\mathrm{MR}^{2}$.

131. "'olamo haepi shel Mendele" ["Mendele's Epic World"]. Ha'arets, January 4, 1952. Re-printed in $\mathrm{S}$.

132. "Al mahut harealizm bekitvei Mendele" ["On the Nature of Realism in Mendele's Works"]. Ha'arets, January 18, 1952. Re-printed in $\mathrm{S}$.

133. "Shorashav hanafshiyim vehametafisiyim shel hayesod haidili" ["The Existential and Metaphysical Roots of the Idyllic"]. Molad, VIII (45) (January, 1952), pp. 160-171. Re-printed in $\mathrm{s}$. 
134. "haEpikah ha'Agnonic keshalav hadash betoledot hasipur ha'ivri" ["The Agnonic Epic as a New Stage in the History of Hebrew Fiction"]. Ha'arets, February 1, 1952. Re-printed in $M^{2}$ and in $A$.

135. "Teiologizatsiah mefukpeket shel haeiros (he'arot lekets hame'ora' leGraham Greene" ["A Spurious Theologization of Eros (Notes on Graham Greene's The End of the Affair)"], Ha'arets, March 28, 1952. Re-printed in MR and in $\mathrm{MR}^{2}$.

136. "Lemashma'ut hamusagim ge'ulah vetsedek beshirei Bialik" ["On the Meaning of the Terms 'Redemption' and 'Righteousness' in Bialik's Poems"]. Ha'arets, April 15, 1952. Re-printed in BT.

137. "Erets lelo eloah" ["A Land Without God"]. Ha'arets, April 25, 1952. Review of novel on the Holocaust by A. B. Kraus written in Czech, Zeme Bez Boha.

138. "Sha'ul leMax Zweig" ["Max Zweig's Saul"]. Ha'arets, May 16, 1952 .

139. "Behinot uvohanim shelo hitslihu" ["Unsuccessful Scrutinies and Scrutinizers"]. Ha'arets, June 27 and July 11 , 1952. Critique of new literary periodical Behinot. 140. "Stendhal"
in $\mathrm{MR}^{2}$.

141. "haAni hagadol uve'ayat hahamonim bekitvei stendhal" ["The Aggrandized Individual and the Problem of the Masses in the Works of Stendhal"]. 2 $\mathrm{Ha}^{\prime a r e t s}$, August 29, 1952. Re-printed in $\mathrm{MR}^{1}$ and in $\mathrm{MR}^{2}$.

142. "haReka' hanafshi shel kitvei Stendhal" ["The Inner Background of Stendhal's Works"]. Ha'arets, September 19, 1952. Re-printed in $\mathrm{MR}^{\mathrm{I}}$ and in $\overline{\mathrm{MR}^{2}}$.

143. "Mahutah umekoroteha shel tenu'at ha'ivrim hastse'irim (kena'anim)" ["The Nature And Origins of the 'Young Hebrews' (Canaanite movement)"]. Luah Ha'arets, 5713 $(1952-53)$, pp. 107-129. Re-printed in S.

144. "ha'Uvdah habjlti efsharit ('al ha'ivrim hatse'irim)" ["The Impossible Fact (on The Young Hebrews)"]. Ha'arets, October 24,1952 .

145. "'Ad henah leshai 'Agnon" ["S. Y. Agnon's Until Now"] . Ha'arets, December 12, 1952. Re-printed in MR and in A.

146. "Dor lelo malbushim ulelo sefarim" ["A Generation without Clothes or Books"]. Ha'arets, January 9, 1953. More on Agnon's 'Ad henah. Re-printed in $M R^{1}$ and in $A$.

147. "hashirah hapersonalit leBialik" ["Bialik's Personal Poetry"]. Ha'arets, February 27, 1953. Re-printed under different title in BT.

148. "haAni vehahevrah bemahazotav shel Ibsen" ["The Individua] and Society in Ibsen's Plays"]. Ha'arets, March 30 , 1953. 
149. "haTetralogiah shel Hayim Hazaz" ["Haim Hazaz's Tetrology"]. Ha'arets, April 30 and May 22, 1953. On the novel Yaish.

150. "hasifrut bisedeh hafker lehipusei tohu aharei 'arakhin" ["Literature's Fruitless Search for Values"]. Ha'arets, June 26, 1953. On Isaiah Rabinovitch's Yetser viyetsirah.

151. "Sheloshah ne'umim 'al hayahadut lem. Buber" ["Three Speeches on Judaism by M. Buber"]. Ha'arets, July 10, 1953. Re-printed in L.

152. "Teshuvah lehithamkuto shel M. Buber" ["A Reply to M. Buber's Evasion"]. Ha'arets, August 7, 1953. Letter to the editor answering Buber's comments on the preceding article.

153. "'olam hayetsirah ha'omanutit o misdar abiri lemusar hiloni" ["The world of Artistic Creation or a Knightly order for Secular Morality"]. Ha'arets, August 14, 1953. On G. Scholem's Reshit hakabalah and on Isaiah Rabinovitch's response to Kurzweil's article of June $26,1953$.

154. "Kavim lidemuto shel Tolstoi" ["Towards A Profile of Tolstoy"]. Ha'arets, September 9, 1953. Re-printed in $\mathrm{MR}^{2}$.

155. "'Al shenei motivim rashiyim be'ama dedahava leTshernihovski" ["On Two Main Motifs in Tshernichovski's The Golden People"]. Luah Ha'arets, 5714 (1953-54), pp. 141-160. Written to mark the 10 th anniversary of the poet's death. Re-printed in $\mathrm{BT}^{\mathrm{T}}$.

156. "Herut ha'adam beshirat Tshernihovski" ["The Freedom of Man in Tshernichovski's Poetry"]. Karmelit, ed. Shin Shalom and S. Kremer, 5714 (1953), pp. 23-39. Remprinted in BT.

157. "He'arot lemahut diokano shel hasipur hayisra'eli" ["Notes on the Nature of the Image of Israeli Fiction"]. Ha'arets, November 27, 1953. On Shamir, Mossinsohn, Taviv, Yizhar, A. Sha'anan and S. Nitsan.

158. "Nofim tarbutiyim vetoda'tiyim besipur hayisra'eli" ["Vistas of Culture and Consciousness in Israeli Fiction"] . Ha'arets, December 11,1953 . Re-printed in $\mathrm{H}$.

159. "Omanut hasipur o literarizatsiah shel hahayim?" ["Fictive Art or the Literarization of Life?"]. Ha'arets, January 1, 1954. On the "Sabra" writers. Re-printed in $\mathrm{H}$.

160. "ha'Olam beaspeklariah shel tamid anahnu" ["The World from the Perspective of 'Ever We'"]. Ha'arets, January 21, 1954 .

161. Letters to editor, Mevo'ot, VIII (January 31, 1954), p. 2 and IX (February 28, 1954), p. 2. Response to Hillel Barzel's review of $\mathrm{MR}^{1}$.

162. "Me'ein sikum beinayim ('al be'ayat hahemshekhiut besifrutenu hahadashah)" ["An Interim Summary (On the Problem of 
Continuity in our Modern Literature)"]. Ha'arets, February 26, 1954. Re-printed in $\mathrm{H}$.

163. "live'ayat hamegamatiyut vehahemshekhiyut basifrut" ["On the Problem of Tendentiousness and Continuity in Literature"]. Mevo'ot, X (April 9, 1954). Remarks on Shlonski, Shamir and v. z. Greenberg; part of a symposium on didacticism in criticism.

164. "Milhamto shel Honi hame'agel" ["Honi the Circle-Maker's Battle"]. Hatsofeh, April 23, 1954. A Reply to Gideon Katznelson. See also issue of April 27, 1954 for more on this.

165. "Melekh basar vadam leMoshe Shamir" ["Moshe Shamir's Ring of Flesh and Blood"]. Ha'arets, June 18, 1954.

166. "50 Shanah liyetsirato shel shai 'Agnon" ["50 years of Agnon's Works"]. Ha'arets, June 25, 1954.

167. "'Al motiv hashivah vehamavet beshirah hapersonalit leBialik" ["On the Motif of Return and Death in Bialik's Personal Poetry"]. Molad, XII (72) (July, 1954), pp. 274-287. Re-printed in BT.

168. Letter to editor, Mevo'ot XIV (September 21, 1954). A reply to Tuviah Rubner's critique of Kurzweil's view of modern Hebrew literature in preceding issue (XIII).

169. "He'arot lemahut haroman beme'ah ha'esrim" ["Notes on the Nature of the Novel in the 20 th Century"]. Ha'arets, September 27, 1954. Re-printed in $\mathrm{MR}^{2}$.

170. "haYahadut kegilui ratson-hayim hale'umi-habiologi (he'arot bikoret letorat hahemshekhiyut shel Ahad ha'Am)" ["Judaism as the Disclosure of a National-Biological Will-To-Live (A Critique of the Evolutionary Notions of Ahad ha-Am)"]. Luah Ha'arets, 5715 (1954-55), pp. 144-170. Re-printed in S. Also re-printed in Perakim bayahadut, eds. Jacob Petuchowski and Ezra Spichandler. Jerusalem and Cincinnati: M. Newman Publishing Ltd. and Hebrew Union College Press, n.d. [1963?].

171. "'Al shirei hateva' shel H. N. Bialik" ["On the Nature Poems of H. N. Bialik"]. Karmelit, ed. Shin Shalom, 5715 (1954-55), pp. 253-267. Re-printed with different title in BT.

172. "Shirei hateva' leBialik besiman gilgulei hitgabshut hayahas ani- 'olam" ["The Nature Poems of Bialik as an Indicator of Shifts in the Concretization of the Relationship Between the 'I' and 'the World'"]. Zemanim lesifrut (Hatsofeh?), September 27, 1954. Re-printed in BT.

173. "Mivhan 'elyon--usetiyah metsa'eret" ["'The Supreme Test' and a Regrettable Distortion"]. Ha'arets, November 12, 1954. Answer to an article by David Ben-Gurion in Davar, October 15, 1954.

174. "lemahut shirato shel Greenberg" ["On the Nature of Greenberg's Poetry"]. Ha'arets, December 24, 1954 . Re-printed in $\mathrm{H}$. 
175. "hatselilah letokh tehomot ha'ani ('al shirat Shin Shalom)" ["The Descent into the Depths of the 'I' (On Shin Shalom's Poetry)"]. Moznayim, XXIV (March, 1955), pp. 87-101. Re-printed in $\mathrm{H}$.

176. "Ahavat haherut o sin'at hadat hayehudit?" ["Love of Freedom or Hatred of Judaism?"]. Ha'arets, March 11, 1955.

177. "He'arot leothello" ["Notes on Othello"] . Ha'arets, April 6, 1955.

178. Letter to the editor, Ha'arets, April 22, 1955. Critique of article by Yitshak Shalev on Hebrew literature in Ha'arets of April 1, 1955.

179. "haYesh vehanir'eh beothello" ["Appearance and Reality in othello"]. Ha'arets, April 29, 1955.

180. "leMahut bikorti 'et torat Ahad ha'Am" ["On the Nature of My Critique of Ahad ha-Am"]. Ha'arets, July 1, 1955. Response to Y. E. Heller's critique of Kurzweil's essay on Ahad ha-Am. The same article appears also in Hado'ar, XXXV (\#32) (July 1, 1955), pp. $623 \mathrm{f}$.

181. "Viduyim mefukpakim shel gibor mefukpak bitekufah mefukpeket ('al sefaro ha'aharon shel Thomas Mann shehigi'a ligevurot" ["The spurious confessions of a Spurious Hero in a Spurious Time (on Thomas Mann's Recent Book at his 80 th Birthday)"]. Ha'arets, July 15, 1955. On The Confessions of Felix Krull. Re-printed in $\mathrm{MR}^{2}$.

182. "lezikhro shel Thomas Mann" ["In Memory of Thomas Mann"]. Ha'arets, August 26,1955 . Re-printed in $\mathrm{MR}^{2}$.

183. "haEpikan bitekufah pegumah bema'avak 'im hazeman (he'arot lepi shenayim leshai 'Agnon" ["The Epic Artist's struggle with Time in an Impaired Age (Notes on S. Y. Agnon's 'Twofold'"]. Karmelit, ed. Shin Shalom, 5716 (1955-56), pp. 159-187.

184. "Teguvot aktualiyot 'al mishnat Frants Rosenzweig umashma'utan" ["Some Salient Reactions to Franz Rosenzweig's Thought and Their Implications"]. Ha'arets, March 26, 1956. Re-printed in L.

185. "He'arot leRichard hashelishi (hahistoriah hageluyah vehanisteret umashma'ut hamotiv hevel havalim etsel shakespeare" ["Notes on Richard III (History Real and Apparent and the Significance of the 'Vanity of Vanities' Theme in Shakespeare"]. Ha'arets, May 25, 1956. Re-printed in Bamah, IV (57) (5720), pp. 35-4l.

186. "'Im keri'at shirim hadashim" ["On Reading some New Poems"]. Ha'arets, June 22, 1956. On Yonah David, Shlomo Shenhad and Adar Kesari.

187. "Nos'im hadashim basipur hayisra'eli" ["New Topics in Israeli Fiction"]. Ha'arets, July 20, 1956. On David Shahar's 'Al hahalomot, etc.

188. "Gishushim leha'amakat hamemad haepi" ["Gropings toward a Deepening of the Epic Dimension"]. Ha'arets, August 10, 1956. Continuation of the preceding article. 
189. "Emunah o demonologiah bekitvei $F$. Kafka" ["Belief or Demonology in F. Kafka's Works"]. Ha'arets, September 5, , 1956. Re-printed in $M R^{2}$.

190. "Kal Iiheyot mokhiah umoreh hador" ["It's So Easy to be the Generation's Castigator and Teacher"]. Ha'arets, March 1, 1957. On Yitshak Shalev's Kol 'Anot.

191. "Bein Brenner, Weininger vekafka" ["Brenner, Weininger and Kafka Compared"]. Ha'arets, April 15, 1957. Re-printed in $S$ and in $H$.

192. "Bituyim shekedai lehizaher mehem" ["Expressions worth Approaching Cautiously"]. Ha'arets, May 10, 1957. Strictures on an article by Boskovitch, Ha'arets music critic.

193. "haYesh derekh le'atsmaut tarbutit?" ["Is There a way to Cultural Independence?"]. Ha'arets, May 24, 1957. An address to an assembly of graduates of Haifa's Reali school. Re-printed in L.

194. "Shorashei hasin'ah hayehudit ha'atsmit" ["The Roots of Jewish Self-Hate"]. Ha'arets, June 4, 1957. Re-printed in $S$ (pp. $344 \mathrm{ff}$., section 6 ).

195. "haHiloniyut shel sifrutenu hahadashah" ["The Secularism of Our Modern Literature"]. Ha'arets, July 12, 1957. Re-printed in S (pp. $42 \mathrm{ff.}$, section 8).

196. "Bein hapel'i vehagalui" ["Between the wondrous and the Apparent"]. Ha'arets, August 16, 1957. On a book by Pinhas Pelli, 'Al Tilah.

197. "He'arot leferek meroman hadash lesamekh Yizhar" ["Notes on a Chapter of a New Novel by S. Yizhar"]. Ha'arets, August 30,1957 . Discussion of one chapter of Yemei tsiklag that had been printed in advance in Molad.

198. "'Al haetikah hasifrutit umada'it shel istenis ('al ma'amaro shel Tishbi Darkei pulmus pesulot)". ["On the Literary and Scientific Ethics of an Esthete (On Tishbi's Article 'An Improper Polemic')"j. Davar, September 6, 1957.

199. "He'arot leshabtai Tsevi shel Gershom Scholem" ["Notes on Gershom Scholem's Shabtai Tsvi"]. Ha'arets, September 25 and October 25, 1957. Re-printed in J.

200. "Gan na'ul levinyamin Tammuz" ["Benjamin Tammuz's The Sealed Garden"]. Ha'arets, November 22, 1957.

201. "'Al shetei tekhunot shel Pinhas Hurgin Z. L." ["On Two Qualities of the Late Pinhas Churgin"]. Ha'arets, January 5,1958 .

202. "Hashpa'ato shel Nietzsche 'al hasifrut ha'ivrit" ["The Influence of Nietzsche on Hebrew Literature"]. Ha'arets, January 17,1958 . Re-printed in S, pp. 225-232. Note: this article and the four of January 24, 31, February 14 and 21 are all re-printed in $S$ in five respective sections under the general title "haHashpa'ah shel filosofiat hahayim 'al hasifrut ha'ivrit bitehilat hame'ah he'esrim" ["The Influence of 
Lebensphilosophie on Hebrew Literature at the Beginning of the 20th century"].

203."Motiv ha'elilut hahadashah" ["The Motif of Neo-Paganism"]. Ha'arets, January 24, 1958. Re-printed in S, pp. 232-241.

204."be'Ashemat hasefarim veruhot hasefarim mishenot dor vador" ["The Guilt of Books and the spirit of Books From Time Immemorial (?)"]. Ha'arets, January 31, 1958. Re-printed in $S$, pp. $24 \overline{1-250 .}$

205. "haMoreh hagadol M. Buber" ["The Great Teacher M. Buber"]. Ha'arets, February 7, 1958. Re-printed in L.

206."haNehiyah le'olam hazar, lehayim beli merkhaot kefulot" ["The Lure of the outside world, of Life without Quotation Marks"]. Ha'arets, February 14, 1958. Re-printed in S, pp. 250-259.

207."Hisuf omanti shel hahayim beli mahseh" ["The Artistic Unveiling of Unsheltered Existence"]. Ha'arets, February 21,1958 . Re-printed in $\mathrm{S}, \mathrm{pp} .260-269$.

208."Sin'at 'atsmo besifrut hayehudit (Kraus, Kafka, Brenner vehayahadut)" ["Self-Hate In Jewish Literature (Kraus, Kafka, Brenner and Judaism)"]. Molad, XVI (116) (March 1958), pp. 112-128. Re-printed in S, (pp. 361-379?).

209. "He'arot le'Ir hayonah shel Natan Altermann" ["Notes on Nathan Altermann's The City of the Dove"]. Ha'arets, April 4 and April 10, 1958. Re-printed in $\mathrm{H}$.

210."leDerekh hasifrut ha'ivrit be'eser hashanim ha'aharonot" ["On the course of Hebrew Literature in the Past Decade"]. Ha'arets, April 25 and May 2, 1958. Written to mark Israel's loth anniversary.

211."hasefarim hahashuvim beyoter" ["The Most Important Books"]. Ma'ariv, May 2, 1958. Part of a symposium in connection with Israel's 10th anniversary.

212."Mekorot habikoret haotentit" ["The Sources of Authentic Criticism"]. Ha'arets, May 23, 1958. A dispute with Ephraim Urbach.

213.Preface to S, Tammuz, 5718 (June-July, 1958).

214."haMuzah insah et meshorer-hakets Netan'el" ["The Muse Has Raped the poet of the Apocalypse Nathaniel"]. Ha'arets, July 4, 1958. A parody of a poem by Natan Zach.

215."haEpikan 'Agnon utekufato" L"The Epic Artist Agnon and His Age"] . Ha'arets, August 1, 1958. Written to mark

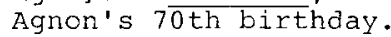

216."He'arot lakesher shebein hayetsirah ha'omanutit va'ani ma'amin dati" ["Notes on the Connection between the work of Art and the (Artist's) Religious Credo"]. Sheluhot, Av, 5818 (August, 1958). Written or published to mark Agnon's 70 th birthday. Re-printed in Ma'ariv, February 21,1975 . 
217. "ha'Akhzavah hagedolah ('al Yemei tsiklag lesamekh Yizhar)" ["The Great Disappointment (On S. Yizhar's The Days of Ziklag)"]. Davar, August 22, 1958. Re-printed in H.

218. "keHazut eimat hamavet" ["Like the Vision of the Fear of Death"]. Davar, August 29, 1958. More on Yemei tsiklag. Re-printed in $\mathrm{H}$.

219. "He'arot lemahutah shel hashirah vehaprozah hamodernit" ["Notes on the Nature of Modern Poetry and Prose"]. Davar, September 14, November 28 and December 5, 1958.

220. "Havayat yom hakipurim bekitvei 'Agnon" ["The Day of Atonement Experience in Agnon's Works"]. Ha'arets, September 28,1958 . Re-printed in $A$.

221. Letter to editor, Davar, September 27, 1958. A reply to Matti Meged.

222. "haYofi vehanisgav shel hayahadut etsel 'Agnon" ["The Beauty and the Sublimity of Judaism in Agnon"]. Davar, October 24, 1958. Re-printed in A.

223. Preface to Yuval Shai: ma'amarim likhevod Shemuel Yosef 'Agnon behagi'a leseivah beyom Tet beAv, TasHIaH [A Jubilee Gift: Essays in Honor of $S$. Y. Agnon for His Seventieth Birthday on the Ninth of Av, 5718], ed. B. Kurzweil. Ramat Gan: Bar Ilan University, 1958.

224. "'Al nose' hayetsiah beshiluvo 'im nose' hashivah besipurei "Agnon" ["On the Inter-relationship of the Themes of Departure and Return in Agnon's Fiction"]. Yuval Shai, ed. B. Kurzweil, pp. 131-157. Re-printed in A.

225. "haMevukhah haruhanit shel dorenu" ["The spiritual Perplexity of our Time"]. Lecture given at Hillel House, Jerusalem, November 16, 1958. Re-printed in I.

226. "'od lo nutkah hashalshelet (shoftim o 'askanim sifrutiyim?)" ["The Chain is Still Unbroken (Judges or Literary Entrepreneurs?)"]. Ha'arets, January 2, 1959. An objection to awarding the Bialik prize to Yizhar for Yemei tsiklag.

227. "Matun, matun--gabaim lefanekha" ["Careful, Careful-The Sextons Are Around"]. Ha'arets, January 16, 1959. An answer to Dov Sadan's response to the preceding article.

228. "Zur gegenwartigen literarischen Situation in Israel". Neue züricher Zeitung, January 25, 1959.

229. "haotobiografiah shel Pinhas Sadeh" ["The Autobiography of Pinhas Sadeh"]. Ha'arets, January 30, 1959. Critique of haHayim kemashal.

230. "He'arot live'ayot haroman hahistori ha'ivri" ["Notes on the Problems of the Hebrew Historical Novel"]. Davar, April 22, 1959 .

231. "He'der hush haproportsiah" ["A Lack of the Sense of Proportion"]. Ha'arets, April 22 and April 24, 1959. On fiction by Shahar, Shamir, etc. 
232. "G. Mahler vehag hapesah" ["G. Mahler and the Festival of Passover"]. Ha'arets, May 3, 1959. A brief note on an article by Robert weltch on Mahler.

233. "Me'ever lekhol ha'arakhim ('al he'eder hush haproportsiah)" ["Beyond All Values (On the Lack of a Sense of Proportion)"]. Ha'arets, May 15 and May 22, 1959. Review of several new works of fiction by Yehudah Ezrahi, etc.

234. "haNo'ar vehasifrut ha'ivrit" ["Young People and Hebrew Literature"]. Davar, May 22, 1959. Answer to a symposium on why young Israelis read less Hebrew literature than European and American.

235. "besiman hakarikaturah shel haidealim (siyum devarim 'al he'der hush haproportsiah)" ["The Mark of a Caricature of Ideals (Concluding Discussion of 'A Lack of the Sense of Proportion')"]. Ha'arets, June 19, 1959.

236. "hacondition Humaine beshirah hapersonalit leNatan Altermann" ["The Condition Humaine in the Personal Poetry of Natan Altermann"]. A portion printed in Davar, July 31, 1959. Full essay in Me'asef, I (1960), pp. 101-125. Re-printed in $\mathrm{H}$.

237. "haMahaza'i vehamesaper Friedrich Dürxenmatt" ["The Playwright and Novelist Friedrich Dürrenmatt"]. Ha'arets, october 2, 1959 .

238. "Nose' ha'akedah besifrut hahadashah (mitokh hirhurim 'al gilgulei hamotivim hamikra'iyim besifrutenu)" ["The Binding (of Isaac) Theme in Modern (Hebrew) Literature (From 'Reflections on the Metamorphosis of Biblical Motifs in our Literature')"]. Davar, October 2, 1959.

239. "Temihah mitokh i-havanah" ["Astonishment Arising from a Misunderstanding"] . Davar, October 16, 1959. A reply to $M$. Asaf's article taking exception to the preceding essay.

240. "Samkhut habikoret umigdal hashen shel hamadal" ["The Authority of Criticisin and the Ivory Tower of Science"]. Ha'arets, November 6, 1959.

241. Letter to the editor, Ha'arets, November 10, 1959. A complaint on election preparations in Ramat Gan.

242. "Pisgat ha'itsuv haepi vehashelemut ha'omanutit" ["The Pinnacle of Epic Presentation and Artistic Perfection"]. Ha'arets, November 27, 1959. Observations on the publication of the new edition of Agnon's collected works.

243. "hatanakh yarad ledargat kirkas" ["Making a Circus of the Bible"]. Ha'arets, November 30, 1959. Reply to a survey of opinion on the Biblical Quiz.

244. "beHipus aharei ha'ahdut ha'avudah" ["In search of the Lost Unity"]. Ha'arets, December 11, 1959. Paper read at symposium on Agnon in Tel Aviv, November 29, 1959. Re-printed in A.

245. "Shireiha shel Daliah Ravikovits" ["The Poems of Daliah Ravikovitch"]. Ha'arets, December 25, 1959. 
246. "Kavim lidemuto shel haga'on R. Shemuel Bialoblotski" ["Towards a Profile of the Late Rabbi Shmue] Bialoblotzky"]. Ha'arets, February 5, 1960.

247. "Mekomah shel shirat Shlonski besifrutenu hahadashah" ["The Place of Shlonski's Poetry in Our Modern Literature']. 'Al hamishmar, March 4, 1960. Re-printed in $\mathrm{H}$.

248. "Hazut hamavet veharat 'olam beshirei Avraham Shlonski (leyovalo hashishim)" ["The Vision of Death and the Birth of the World in Avraham Shlonski's Poems lon His 60 th Birthday)"]. Ha'arets, March 11, 1960. Re-printed in $\mathrm{H}$.

249. "hamesaper vahamasai Albert Camus" ["The Novelist and Essayist Albert Camus"]. Ha'arets, April 11, 1960. Re-printed in $M R^{2}$.

250. "hasefer ha'ivri kenekhes ukeve'ayah" ["The Hebrew Book as Resource and as Dilemma"]. Davar, April 11, 1960. Re-printed in $\mathrm{L}$.

251. "Shinuyim bitefisat hametsi'ut vehazeman baroman hame'ah ha'esrim" ["Changes in the Conception of Reality and Time in the Twentieth Century Novel"]. Davar, May 27, 1960. Re-printed in $\mathrm{MR}^{2}$.

252. "He'arot life'ulat hamo'etsah lehaskalah gevovah" ["Notes on the Activities of the Commission on Higher Education"]. Ha'arets, June 8, 1960. Contra the Hebrew University.

253. "Omanut hasipur kibe'ayah" ["The Art of Fiction as a Problem"]. Davar, June 10, 1960. Re-printed in $\mathrm{MR}^{2}$.

254. "haGibor besipurei Kafka uMusil" ["The Hero in the Fiction of Kafka and Musil"]. Davar, June 24, 1960. Re-printed in $\mathrm{MR}^{2}$.

255. "Hit'orerut datit o rikud shedim misaviv laBesht" ["Religious Revival or Dance of Demons around the Ba'al Shem Tov?"] Ha'arets, July 8, 1960 .

256. "haGibor bivehinat Ish lelo tekhunot" ["The Hero as a Man Withoyt Qualities"]. Davar, July 15, 1960. Re-printed in $\mathrm{MR}^{2}$.

257. "hagibor besipurei Hermann Broch" ["The Hero in the Fiction of Hermann Broch"]. Davar, July 29, 1960. Re-printed in $\mathrm{MR}^{2}$.

258. "Darko shel A. Kariv beheker sifrutenu" ["A. Kariv's Method in Hebrew Literature Scholarship"]. Ha'arets, July 29, 1960 .

259. "haMesaper bedimdumim bein shenei "olamot" ["The Novelist in the Twilight between Two Worlds"]. Ha'arets, September 21,1960 . On Yitshak shenhar. Re-printed in $\mathrm{H}$.

260. "haMeshutaf leshirei Bialik veTshernihovski" ["The Commonality in the Poetry of Bialik and Tshernichovski"]. Davar, september 21, 1960. Re-printed as the preface to BT with slight changes. 
261. "mikets hayamim umikets haderakhim" ["From the End of Time and the Ends of the Compass"]. Ha'arets, January 6 , 1961. On Shirei kele', a collection of poetry by "Almoni".

262. "Gevulot hahaba'ah hateatrait" ["The Limits of Theatrica]. Expression"]. Ha'arets, January 20, 1961. On Dürrenmatt's "The Marriage of Mr. Mississippi".

263. "be'Ikvot peleitat peh me'alefet" ["In the Wake of an Instructive siip of the Tongue"]. Ha'arets, February 13, 1961. Reaction to some remarks by Moshe Dayan on demonstrations and intellectuals.

264. "Ya'akov Horovits--hamesaper veha'orekh (bimelo'ot 10 shishim)" ("Yakov Horowitz--Novelist and Literary Editor (On His 60th Birthaay)"]. Ha'arets, February 17, 1961.

265. "Shofet bet hamishpat ha'elyon kevalshan" ["The Supreme court Justice as Philologist"]. Ha'arets, March 5, 1961. Letter to editor on conduct of Justice Hayim Cohen.

266. "hakiyum hayehudi besipurei Kafka" ["Jewish Existence in Kafka's Fiction"]. Ha'arets, March 31, 1961. Re-printed in $\mathrm{MR}^{2}$.

267. "haLe'umiyut hayehudit bizemanenu" ["Jewish Nationalism in our Time"]. Jerusalem: World Jewish Congress, 1961, pp. 15-17. Text of a paper read at a symposium on this subject. Re-printed in $L$.

268. "Sipurei Yehudah Amihai" ["The Stories of Yehudah Amichai"]. Davar, April 21, 1961 .

269. "Iyov ve'efsharuyot hatragediah hatankhit" ["Job and the Possibilities of Biblical Tragedy"]. 'Iyun, XII/3-4, (July, 1961), pp. 143-157. Re-printed in J.

270. "Mahut hamodernizm besipurei Uri Nisan Gnessin" ["The Nature of Modernism in the Stories of Uri Nissan Gnessin"]. Ha'arets, September 24,1961 . Re-printed in $\mathrm{H}$.

271. "Mashber hahaba'ah haleshonit besipurei Gnessin" ["The Crisjs of Linguistic Expression in Gnessin's Stories"]. Ha'arets, October 1, 1961. Re-printed in H.

272. "Tokhniyot radio o diesot shel pitputim akademayim?" ["Radio Programs or Pablum of Academic Poppycock?"]. Ha'arets, October 13, 1961. Letter contra the verbiage of sociologists on the radio.

273. "Emet utsevi'ut bide'agah Iehaskalah gevohah" ["Truth and Hypocrisy in the concern for Higher Education"]. Ha'arets, November 2, 1961. Contra Hebrew University: a response to article on higher education in Israel by Eli Eyal.

274. "Sipurei Ingeborg Bachmann - 'al matsav hasipur hagermani" ["The Fiction of Ingeborg Bachmann - on the status of German Fiction"]. November 24, 1961. Re-printed in $\mathrm{MR}^{2}$. 
275. "Yisra'eliyim kemesaprim germaniyim" ["Israelis as German Novelists"]. Ha'arets, December 8, 1961. On Y. Klein's Ka'asher yanus ish mipnei ha'ari.

276. "M. Buber - hatan peras Bialik (kirvah mitokh merhak be'olamo)" ["M. Buber - Bialik Prize Laureate (An Approach from Afar)"]. Ha'arets, December 22, 1961. Re-printed in L.

277. "Be'ayot hashirah hamodernit bitekufatenu" ["The Problems of Modern Poetry in Our Time"]. Ha'arets, January 26 , 1962 .

278. "haMetsi'ut hahadashah beshirah hamodernit" ["The New Reality in Modern Poetry"]. Ha'arets, February 16, 1962.

279. "Yahadut Germaniah be'einei Naomi Fraenkel ('al hahelek hasheni shel hasefer Sha'ul veYohanah)" ["German Jewry through the Eyes of Naomi Fraenkel ion Part Two of Saul and Johanna)"]. Ha'arets, March 30, 1962.

280. "Tenudot be'itsuv hadiokan ha'atsmi beshirei Bialik" ["Shifts in the Representation of the self in Bialik's Poems"]. Ha'arets, April 18, 1962. Re-printed in BT.

281. "Yerushalayim besipurei 'Agnon" ["Jerusalem in Agnon's Fiction"]. Ha'arets, June 7, 1962. Re-printed in A.

282. "Hanahot yesod behinukh yehudi" ["Basic Premises in Jewish Education"]. Paper read at a symposium sponsored by the Cultural Affairs Committee of the World Jewish Congress on April 18, 1962. Printed in Gesher: Quarterly Review of the Nation's Problems, VIII/1-2 (30-31) (June 1962), pp. 18-23. Re-printed in. $J$.

283. "Mifgan bekiut umiktsaf intelektualj" ["A Show of Erudition and Intellectual Froth"]. Ha'arets, June 29, 1962. Critique of Dan Miron's Arba'panim besifrut ha'ivrit bat yameinu.

284. "Mehkar sifruti o ornamentikah yad'anit?" ["Literary Scholarship or Intellectual Frippery?"]. Ha'arets, July 6, 1962. More on the Miron book.

285. "Sipur beinayim epi aharei ha'akedah ('al ha'Esh veha'etsim leshai 'Agnon)" ["An Interim Epic Tale after the Akedah ion S. Y. Agnon's The Fire and the Wood)" ]. Ha'arets, July 27, 1962. Re-printed in A.

286. "Sefer takhlit hama'asim" ["The Book of Ultimate Deeds"]. Ha'arets, August 3, 1962. More on ha'Esh veha'etsim. Re-printed in $A$.

287. "Im moto shel Hermann Hesse" ["On the Death of Hermagn Hesse"]. Ha'arets, August 17, 1962. Re-printed in MR ${ }^{2}$.

288. "Hayesh 'od lesifrutenu diokan yehudi?" ["Does Our (Modern Hebrew) Literature Still Have a Jewish Cast?"]. Ha'arets, September 28, 1962.

289. Preface to A. Tishri, 5723 (October, 1962). 
290. "He'arot lesefer hai ro'i leshin shalom" ["Notes on shin shalom's The Book of the Living one who Sees Me"]. Ha'arets, December 14, 1962 .

291. "Sifrutenu hahadashah besefer-kis germani" ["Our Modern (Hebrew) Literature in a German Paperback"]. Ha'arets, January 18, 1963. Critique of Peninah Naveh's German outline of modern Hebrew literature.

292. "Buber kefarshano shel Kafka" ["Buber as an Interpreter of Kafka"]. Ha'arets, February 8, 1963. Re-printed in $M R^{2}$.

293. "ha'Adam vehahevrah biyetsirato shel F. Kafka" ["Man and Society in Kafka's Works"]. Ha'arets, March 22, 1963. Re-printed in $\mathrm{MR}^{2}$.

294. "haSifrut ha'ivrit hahadashah leA. Sha'anan" ["A. Sha'anan's (View of) Modern Hebrew Literature"]. Ha'arets, April 8, 1963. Discussion of hasifrut ha'ivrit hahadashah lizerameiha.

295. "Pulhan hatsabariyut hino bitui galuti muvhak" ["'The cult of the Sabra' - A Typical Diaspora Manifestation"]. Ma'ariv, April 14, 1963. Part of a symposium on the Sabra at fifteen years of Israeli independence.

296. "besiman shel narkizm" ["Under the Sign of Narcissism"]. Ha'arets, May 24, 1963. Review of Kaniuk's hayored lema'alah.

297. "Sinai - hanokhekhut hanitshit beshirei Uri Tsvi Greenberg" ["Sinai - The Eternal Presence in the Poems of Uri zvi Greenberg"]. Ha'arets, May 28, 1963. Re-printed in H.

298. "He'arot leshirei Yehudah Amihai" ["Notes on the Poems of Yehudah Amichai"]. Ha'arets, June 28, 1963.

299. "Shirah otobiografit baMidbar hagadol" ["Autobiographical Poetry--In the Great Desert"]. Ha'arets, July 12, 1963. More on Amichai's poetry.

300. "He'arot lishenei perakim mitokh sipurei "Agnon" ["Notes on Two Chapters of Agnon's Novels"]. Ha'arets, July 26, 1963. On the opening of Sipur pashut. Re-printed in $A$.

301. "He'arot leLo me'akhshav 10 mikan le Y. Amihai" ["Notes on y. Amichai's Not of This Time, Not of This Place"]. Ha'arets, september 6 and September 13, 1963 .

302. "leve'ayat haparshanut shel kitvei 'Agnon (he'arot lasipur haNerot) " ["On the Problem of the Interpretation of Agnon (Notes on 'The Candles')"]. Ha'arets, September 18, 1963. Re-printed in A.

303. "haNof beshirei David Rokeah" ["The Landscape in the Poems of David Rokeah"]. Ha'arets, December 6, 1963. Hebrew translation of an article written in German for the Neue Züricher Zeitung (n.d.) in the wake of an edition of Rokeah's poetry published in Europe with both Hebrew original and German translation. 
304. "Tsurah ufulhan beshirat Tshernihovski" ["Form and Cult in Tshernichovski's Poetry"]. Davar, January 10, 1964. Re-printed in BT.

305. "'Od arukah haderekh lefanenu lilemod linehog beruho shel Bialik" ["We Have a Long Way to Go to Emulate the Spirit of Bialik"]. Remarks delivered upon receiving the Bialik Prize on January 12, 1964. Printed in Ha'arets, January 17, 1964 .

306. "Bialik veKafka" ["Bialik and Kafka"]. 'Al hamishmar, January $17,1964$.

307. "Mahut hasevel vehahayim besipurei Y. H. Brenner" ["The Nature of Suffering and of Life in the Fiction of Y. H. Brenner"]. Davar, March 27, 1964. Re-printed in $\mathrm{H}$ (Sections $1-3$, pp. 271-283).

308. "IiShe'elot hahinukh hayehudi". ["On the Questions of Jewish Education"]. Prozdor, VIII (Nisan-Iyar, 5724), p. 80 . Letter to editor replying to article by Gershom scholem in Elul, 5723 issue.

309. "haHitmotetut hadatit vetsivyon haeros besipurei Y. H. Brenner" ["Religious Collapse and the Nature of Eros in Y. H. Brenner's Fiction"]. Davar, April 30, 1964 . Re-printed in $\mathrm{H}$ (section 4, pp. 283-291).

310. "Merkaz ruhani o merkaz kalkali?" ["An Intellectual or an Economic Center?"]. Ha'arets, April 30, 1964. Contra the Hebrew University.

311. "He'arot lemahut hanofim beshirei U. TS. Greenberg" ["Notes on the Nature of the Landscapes in the Poems of $U . Z$. Greenberg"]. Ha'arets, May 15, 1964. Re-printed in H.

312. "haEros vezik hatikvah besipurei Brenner" ["Eros and the Spark of Hope in Brenner's Fiction"]. Davar, May 15, 1964. Re-printed in $\mathrm{H}$ (sections 5, 6, pp. 291-302).

313. "hatarbut hamitkademet bevet ha'avot" ["'Progressive Culture' in the Ancestral Home"]. Ha'arets, June 12, 1964. Critique of a symposium on "The Writer and the Past" run by the Hebrew University and the Foreign Ministry.

314. "haMetah bein hashir vehademamah biyetsirato shel Bialik" ["The Tension between the Poem and Silence in Bialik's Work"]. Ha'arets, July 10, 1964. Re-printed in BT.

315. "Yisra'el vehatefutsot" ["Israel and the Diaspora"]. Remarks delivered at World Plenary of the World Jewish Congress (summer, 1964?). Printed under title "hashe'elah hagoralit" ["The Fateful Question"] in Gesher: Quarterly keview of the Nation's Problems, $x / 4$ (41), (Tevet, 5725; December, 1964), pp. 27-31. Re-printed in $\mathrm{J}$.

316. "He'arot lamatsav sifrutenu besha'ah zu" ["Notes on the Current Situation of Our Literature"]. Ha'arets, September 6, 1964 .

317. "Al ye'udah shel universitah datit" ["On the Mission of a Religious University"]. Lecture to Board of Trustees, Bar-Ilan University, in New York, November, 1964. Re-printed in $\mathrm{L}$. 
318. "haHistoriah kemakor shirato shel Uri Tsvi Greenberg" ["History as the Source of Uri Zvi Greenberg's Poetry"]. Moznayim, Xx/1 (December, 1964), pp. 3-11. Re-printed in $\mathrm{H}$.

319. "Shirei Daliah Ravikovits - ahad hagiluyim hahashuvim beyoter beshiratenu hatse'irah" ["The poems of Daliah Ravikovitch - One of the Most Important Discoveries in our Young Poetry"]. Ha'arets, January 29, 1965.

320. "Kavim lemif'alo hasifruti shel Max Frisch" ["A Sketch of the Literary Endeavors of Max Frisch"]. Ha'arets, April 2, 1965. Re-printed in $\mathrm{MR}^{2}$.

321. "I-hanahat shebehistoriah umada'ei hayahadut" ["History, Judaic Studies and Their Discontents"]. Ha'arets, April 16, 1965. Re-printed in J.

322. "Erkei hayahadut bire'i hador" ["The Values of Judaism in the Mirror of our Generation"]. Ha'arets, April 30 , 1965. Remarks at a symposium sponsored by Hebrew Writers Association, April, 1965. Re-printed in $J$ and also in Daf, XXVI (June, 1965), pp. $3 \mathrm{ff}$.

323. "Al gevulot samkhuyoteiha shel hahistoriah" ["On the Limits of the Authority of History"]. Ha'arets, May 14, 1965 . Re-printed in $\mathrm{J}$.

324. "Hirhurim shel kore' halutsinatori" ["The Meditations of an Hallucinatory Reader"]. Ha'arets, May 28, 1965. Response to Ya'akov Katz's article "Historiah subyektivit uvikoret obyektivit". Re-printed in J.

325. "Kavim lidemuto shel Martin Buber Z. L." "[Towards a Sketch of the Late Martin Buber"]. Ha'arets, June 18, 1965. Re-printed in $\mathrm{L}$.

326. "Al mashma'ut hayafeh beshirei Uri Tsvi Greenberg" ["On the Meaning of the Beautiful in the Poems of Uri Zvi Greenberg"]. Ha'arets, July 30, 1965. Re-printed in H.

327. "Dioknah shel hayahadut hamesoratit beGermaniah" ["The Image of Traditional Jewry in Germany"]. Paper read at memorial for Aaron Barth. Printed in Ha'arets, September 26, 1965. Re-printed in J.

328. "haHata'im lo nishtanu, gadlu rak hamemadim (gavrah nehitutam shel anshei haruah bifnei anshei hatekhnikah)" ["The Sins are the Same but Their Dimensions Are Larger (On the Increased Debasement of the Intellectuals by the Technocrats)"]. Ma'ariv, september 26, 1965.

329. "Al mashma'ut hapele' beshirat shin shalom - berakhah leyovalo hashishim" ["On the Meaning of wonder in shin Shalom's Poetry - Greetings on His 60th Birthday"]. Moznayim, XX/6 (43) (May, 1965), pp. 449-454. Re-printed in $\mathrm{H}$.

330. "hasipur hayisra'eli beshanim ha'aharonot" [" Israeli Fiction in Recent Years"]. Ha'arets, March 4, 1966.

331. "haFunktsiah shel hatekstim halo' kedoshim basipur hayisra'eli" ["The Function of the Non-Holy Texts in Israeli Fiction"]. Ha'arets, March 18, 1966. 
332. "Satirah umetsi'ut basipur hayisra'eli" ["Satire And Reality in Israeli Fiction"]. Ha'arets, April 4, 1966.

333. "Beitsah shel kolombos shenoldah beyom tov" ["The Egg of Columbus that Was Laid on the Holiday"]. Ha'arets, April 22, 1966. Polemical essay against Ephraim Urbach.

334. "Be'ayot hayetsirah hasifrut(it) beyisra'el" ["The Problems of Literary creation in Israel"]. Moznayim, XXIII/2 (46) (July, 1966), pp. 126-129. Originally read at Israeli-French literary dialogue sponsored by the Hebrew Writers Association, (n.à.).

335. "Bein hazon levein haabsurdi" ["Between Vision and the Absurd"]. Ha'arets, August 19, 1966. Re-printed as preface to $\mathrm{H}$.

336. "Gevulot hatragiyut vehahumanizm bemif'alo shel Goethe" ["The Limits of the Tragic and Humanism in Goethe's Work"]. Ha'arets, September 14, 1966. Re-printed as first part of preface to Goethe's shetei tragediot [Two Tragedies], trans. Ya'akov Kahan. Tel Aviv: Schocken Publishing Co., 1967.

337. "haHafnamah vehashetikah bekitvei Goethe" ["Inwardness and Silence in Goethe's Writings"]. Ha'arets, September 23, 1966. Re-printed as second part of preface to shetei tragediot, trans. Kahan (see preceding).

338. "Tenudot betefisat diokan hamesaper bekitvei Shai 'Agnon ["Shifts in the Conception of the Image of the Narrator in $S$. Y. Agnon's Writings"]. Ha'arets, December 2, 1966. Re-printed in A.

339. "Besof hama'arav - o ga'agu'im lama'arav?" ["In the Far West - or Longings for the West?"]. Ha'arets, Febru$\overline{\operatorname{ary}} 10,1967$. Review of Binyamin Tammuz's novel.

340. "Peri megadim megehinom" ["Luscious Fruit from Hell"]. Ha'arets, February 17, 1967. Contra Israeli writers who attended a Bergen Belsen seminar, especially against the Meged brothers.

341. "Al hato'elet ve'al hanezek shel mada'ei hayahadut" ["On the Use and Abuse of Judaic Studies"]. Ha'arets, April 24, 1967. Re-printed in $J$ under different title, pp. $184-197$.

342. "hale'umiyut hahilonit mahlifah et haapologetikah" ["Secular Nationalism Replaces Apologetics"]. Ha'arets, June 25. 1967. Re-printed in J, pp. 197-206.

343. "Pluralizm haanormaliyut kiyesod kiyum hayehudi" ["The Pluralism of Abnormality as the Basis for Jewish Existence"]. Ha'arets, June 30, 1967. Re-printed in J, pp. 206-213.

344. "Shetei hareshuyot shebesipurei Yitshak Shenhar" ["The Two Domains in the Stories of Yitshak Shenhar"]. Ha'arets, July 7, 1967. Written to mark the tenth anniversary of Shenhar's death.

345. Preface to the third edition of BT. Elul, 5727 (August, $1967)$. 
346. "Temurot bahazut ha'eimim shel hamal'akh hehadash- o hatahanah ha'aharonah shel mada'ei hayahadut" ["Shifts in the Dreadful Apparition of the Angelus Novus or the Last Stop for Judaic Studies"]. Ha'arets, October 4, 1967. Re-printed in $J$, pp. 213-340.

347. "Al zeramim hadashim besifrut ha'ivrit hahadashah" ["On New Currents in Modern Hebrew Literature"]. Moznayim, $\mathrm{XXV} / 4-5$ (September-october, 1967), pp. 257-2 $\overline{65}$. Text of a lecture delivered at Rutgers University, Fall, 1964.

348. "Strindberg - mefales derekh leteatron zemanenu" ["Strindberg - Harbinger of the contemporary Theater"]. Ha'arets, December 29, 1967. On The Father.

349. "Ha'arakhah sifrutit ve'olam ha'arakhim" ["Literary Evaluation and the World of Values"]. Ha'arets, March 1, and March 8, 1968. Re-printed in Karmelit, 14/15 (5729), pp. 53-65. Also re-printed in $\mathrm{J}$.

350. "He'arot lemahut hasatirah" ["Notes on the Nature of Satire"]. Ha'arets, April 12, 1968. Re-printed in $J$ as part 1 of series of essays on the satire of Yosef Perl.

351. "haBukh bema'avako 'im hasefarim" ["The 'Book' in Its Struggle with The Books"]. Ha'arets, April 30, 1968. Re-printed in $J$ as part 2 of essay on perl.

352. "Nosa'i hasatirah ha'ikariyim beMegaleh temirin" ["The Main subjects for satire in Revealing the Hidden"]. Ha'arets, May 24, 1968. Re-printed in J as part 3 of essay on Perl.

353. "hasusah haapokaliptit tsohelet betraklin hasipur hayisra'eli o 'ergat hakisufim shel yisra'el ha'ovedet linesikhim unesikhot" ["The Apolcalyptic Mare Neighs in the Parlor of Israeli Fiction or the Longing of Working (Class) Israel for Princes and Princesses"]. Ha'arets, May 31 , 1968. On Amos Oz's Mikha'el sheli.

354. "miHuts litehum" ["From the Margin"]. Ha'arets, August 23, 1968. Two satirical pieces on some events at the Western WaIl.

355. "Mekoman shel sipurei Avraham B. Yehoshu'a" ["The Place of Avraham B. Yehoshua's Stories"]. Ha'arets, August 30, 1968. On Mul haye'arot.

356. "hametsi'ut hahadashah beDon Quixote lecervantes" ["The New Reality in Cervantes' Don Quixgte"]. Ha'arets, September 22,1968 . Re-printed in $\mathrm{MR}^{2}$.

357. "milenchen 'ad leshirim le'il'il" ["From 'Lenchen' to the Poems to 'Il'il"]. Ha'arets, December $6,1968$. Re-printed in BT.

358. "Hovot halevavot hashetulim" ["The Duties of the Transplanted Heart"]. Ha'arets, January 2 and January $31,1969$. satire on technology.

359. "'Al satirah, herut, dogmah, progres, Sokrates ve'od zutot" ["On Satire, Freedom, Dogma, Progress, Socrates and other Trifles"]. Ha'arets, February 14, 1969. Reply to 
a reader's letter by Hanan Reich, Ha'arets, February 7, 1969 .

360. "Akdamut-milin" ["Prolegomenon"]. Ha'arets, June 20, 1969. Re-printed as preface to $\mathrm{J}$.

361. "le'Oro shel hayareah hakavush" ["By the Light of the Conquered Moon"]. Ha'arets, August 1, 1969. Part of a series of intellectuals' comments on the first walk on the moon.

362. "haNahat mikibush hayareah ve'i-hanahat me'anshei haruah" ["The Satisfaction with the Moon Conquest and the Dissatisfaction with the Intellectuals"]. Ha'arets, August 15, 1969. Reply to Gershom Schocken's comments in Ha'arets, August 8, 1969.

363. "lemahut haotobiografiah mehame'ah hal8 'ad litehilat hame'ah ha'esrim" ["On the Nature of Autobiography from the $18 \mathrm{th}$ Century to the Beginning of the 20th century"]. Ha'arets, September 12, 1969. Re-printed in $\mathrm{MR}^{2}$ as part 1 of "'Al sheloshah sipurei hitbagrut mireshit hame'ah ha'esrim" ["On Three Novels of Maturation of the Early 20th Century"].

364. "Kelalat haberakhah shel hahagshamah hatsiyonit" ["The Cursed Blessing of Zionist Fulfillment"]. Ha'arets, October 10, 1969. Discussion of Shabtai Tevet's work on the Six Day War.

365. "haYahadut hadatit einah Mafdal" ["Religious Judaism Does Not Equal the National Religious Party"]. Ha'arets, October 17, 1969. Response to M. H. Shapiro's comments in recent interview in $\mathrm{Ha}$ 'arets.

366. "hasefer ba'idan hatekhnologi" ["The Book in the Technological Age"]. Ha'arets, December 5, 1969. Re-printed in I.

367. "Al hapornografiah" ["On Pornography"]. Ha'arets, January 9, 1970. Part of a symposium, conducted by Ha'arets.

368. "R. Alter nose'a derekh Kisalon IiYerushalayim" ["R. Alter Travels to Jerusalem Through Stupidville"]. Ha'arets, January 23, 1970. Reply to letter of Robert Alter in Ha'arets, January 14,1970 .

369. Preface, Bikoret ufarshanut, I (March, 1970), p. 5.

370. "Shihrur lema'an mimush ha'atsmut" ["Liberation for the Sake of Self-Realization"] and "Romantikah erotit ufulhan haeiros" ["Erotic Romanticism and the cult of Eros"]. Bikoret ufarshaqut, I (March, 1970), pp. 7-20. Re-printed in $\mathrm{MR}^{2}$ as parts 2 and 3 of "Al sheloshah sipurei hitbagrut mireshit hame'ah ha'esrim" ["On Three Novels of Maturation of the Early 20 th Century"].

371. "Tenudot signoniyot kehe'anut ukiteguvah 'al etgar hametsi'ut besipurei 'Agnon" ["Stylistic Shifts as a Response and a Reaction to the challenge of Reality in Agnon's Stories"]. Ha'arets, March 20, 1970. Re-printed in A. 
372. "Avraham Shlonski - meshorer ha'olam hamasaki" ["Avraham Shlonski - Poet of the World of Disguises"]. Ha'arets, March 27, 1970. Written to mark the poet's seventieth birthday. Re-printed in $\mathrm{H}$.

373. "ha'omanut kemiklat aharon ukinekamah (he'arot limif'alo shel Flaubert)" ["Art as a Last Refuge and as a Revenge (Notes on the Work of Elaubert)"]. Ha'arets, April 20, 1970. Re-printed in $\mathrm{MR}^{2}$.

374. "lezekher R. Rabinovits" ["In Memory of R. Rabinovitz"]. Davar, August 7, 1970 .

375. "Tatspit mihuts litehum 'al matsavenu (hirhurim betom shenat TaSHaL)" ["A View from the Margin of Our situation (Reflections at the End of the Year 5730)"]. Ha'arets, September 30,1970 . Re-printed in L.

376. "mada" obyektivi veshiput subyektivi o kinus ugenizah be'einei Mati Meged" ["Objective Science and subjective Judgment or Mati Meged's Principles of Anthological Selection"]. Hla'arets, January 29, 1971.

377. "Heshbono ha'omanuti ha'aharon shel Shemuel Yosef 'Agnon" [S. y. Agnon's Final Artistic Reckoning"]. Ha'arets, March 12 and March 19, 1971. On Shirah. Re-printed in A.

378. "Bein antropologiah lesifrut" ["Between Anthropology and Isiterature"]. Ha'arets, ApriI 9, 1971.

379. "Luhot hadashim mitsiyon hahadashah o sulam 'arakhim hadash verosho tehomah" ["New Tablets from a Renewed zion or a New - and Perverted - Scale of Values"]. Ha'arets, June 11, 1971.

380. "'Ekronot haparshanut hasifrutit" ["The Principles of Literary Interpretation"]. Ha'arets, July 16, 1971.

381. "hasekhvi Ferdinand behatsar Frants Yosef" ["Ferdinand the Rooster at Franz Josef's Court"], trans. Shemuel Gilai. Ha'arets, september 19, 1971. Re-printed in N.

382. "He'arot lederekh hadramah hagermanit" ["Notes on the course of German Drama"]. Ha'arets, March 29, 1972.

383. "Sipurei Brenner keantitsipatsiah shel be'ayat hasipur hamoderni beme'ah ha'esrim" ["Brenner's Fiction as an Anticipation of the Problem of Modern Fiction in the Twentieth Century"]. Ha'arets, April 21, 1972. Expanded and re-printed in Bikoret ufarshanut, II-III (October, 1972), pp. 5-10. Also re-printed in $\mathrm{H}$.

384. "Universitah datit uzemanenu" ["A Religious University and our Time"]. Remarks at commencement exercises of Bar Ilan University (June, 1972?). Printed in Ha'arets, July 7,1972 . Re-printed in L.

385. "Mazon dieteti lamehashvim" ["Dietary Nourishment for Computers"]. Ha'arets, July 14, 1972. Contra the use of the computer in literary study.

386. Letter to the editor of literary supplement, Davar, July 21, 1972. A note on the links between Agnon's Shirah and 
Shin Shalom's Sonnets and the failure of critics to recognize him as the first to see these links.

387. "Shekhol vekhishalon - hatahanah ha'aharonah shel kiyum yehudi absurdi" ["Breakdown and Bereavement - The Last Stop for an Absurd Jewish Existence"]. 'Iyunim lezikhro shel N. Ginton, IV (1972), pp. 48-55. Re-printed in H.

II. Articles by Kurzweil translated into English

1. "The New 'Canaanites' in Israel", trans. Theodore Friedman. Judaism, II/1 (January, 1953), pp. 2-15. Hebrew original in Luah Ha'arets, 5713 (1952-53), pp. 107-129.

2. "The Young Hebrews", trans. Mordecai Nurock. The Jewish spectator, XVIII/7 (September, 1953), pp. $\frac{\text { 21-29. A }}{\text { A }}$ shortened version of the preceding.

3. "Shin Shalom's Exploration in the Depths of the I", trans. Chaim Rabin. Sifrut, I (1955), pp. 1-3. Re-printed as introduction to Shalom's on Ben Pele', trans. Victor Reichert and Moses Zalesky. Jerusalem: Youth and Hehalutz Department of the zionist Organization, 1963. Hebrew original in Moznayim, XXIV (March, 1955), pp. 87-101.

4. "Judaism - The Group Will to Survive? A Critique of Ahad Ha-Amism", trans. Herbert Weiner. Judaism, IV/3 (Summer, 1955), pp. 209-224. Hebrew original in Iuah Ha'arets, $5715(1954-55)$, pp. 144-170.

5. "Notes on Hebrew Literature: 1948-1958", (trans. not given). Judaism, VII/2 (Spring, 1958), pp. 121-129 and VII/3 (Summer, 1958), pp. 267-275. Hebrew original in Ha'arets, April 25 and May 2, 1958.

6. "The Image of the Western Jew in Modern Hebrew Literature", (trans. not given). Leo Baeck Yearbook, VI(1961), pp. 170-189. London, Jerusalem, New York: The Leo Baeck Institute and East and West Iibrary. Hebrew original unknown.

7. "Is There Such a Thing as Biblical Tragedy?" trans. M. Z. Frank. An Anthology of Hebrew Essays, ed. I. Cohen and B. Y. Michali. Tel Aviv: Institute for the Translation of Hebrew Literature and Massada Publishing Co., 1966, pp. 97-116. Hebrew original in 'Iyun, XII/3-4 (July, 1961), pp. 143-157.

8. "An Appraisal of The Stories of Avraham B. Yehoshua", (trans. not given). Ariel: A Quarterly Review of the Arts and Sciences in Israel, No. 22 (Spring, 1968). Also printed in Iiterature East And West, XIV/I (1970), pp. 60-72. Hebrew original in Ha'arets, August 30,1968 . 
III. Material About Kurzweil

a) Articles And Studies Cited:

1. Abramson, Ya'akov. "Sipurei Barukh Kurzweil vezikot hagomelin beineihem levein masotav" ["Barukh Kurzweil's Stories and the Common Links between Them and His Essays"]. Bar-Ilan University. Unpublished master's dissertation, 1974 .

2. Alonim, S. "Bikoret-hai hanose' et 'atsmo" ["A Self-Sustaining Criticism"]. Ha'arets, January 8, 1954. A review of $M R^{1}$.

3. Alter, uri (Robert). "hatekhnologiah - tofa'ah du-mashma'it" ["Technology - A Two-Sided Phenomenon"]. Ha'arets, January 14, 1970. A letter in response to kurzweil's essay of December 5, 1969, "haSefer ba'idan hatekhnologi".

4. Asaf, Mikha'el. "Faronim, kena'anim A vekena'anim B" ["Pharoahnites, Canaanites 'A' and Canaanites 'B'"]. Davar, October 3, 1952 .

5. Bakon, Yitshak. "Brenner hamesaper be'einei habikoret" ["Brenner the Novelist in the Eyes of the Critics"]. Introduction to Yosef Hayim Brenner - mivhar ma'amarei bikoret [Yosef Hayim Brenner - A Selection of Critical Essays], ed. Y. Bakon. Tel Aviv: Am Oved Publishers Ltd., 1972, pp. 7-36.

6. Bartov, Hanokh. "'od bahurenu Kurzweil hai!" ["Our Boy Kurzweil still Lives!"]. Mas'a, 24 (July 24, 1952), p. 1 .

7. Barukh, Miri. "Nesi'ato shel Karl Bok" ["Karl Bok's Journey"]. Davar, November 3, 1972. On N.

8. Bar-Ya'akov, M. (Moshe Dor?). Review of BT. Ma'ariv, December $16,1960$.

9. Barzel, Hillel. "'Agnon be'einei Kurzweil" ["Agnon through Kurzweil's Eyes"]. Mevo'ot, VII (December 31, 1953), pp. $6 \mathrm{f}$. Review of $M \mathrm{R}^{\mathrm{T}}$.

10. - "besh'arei yetsirah - bikoret" ["At the Gates of Creation - Criticism"]. Moznayim, XI/1 (Aug.-Sept., 1960), pp. 257 f.

11. "Agnon umefarsho Kurzweil" ["Agnon and His Interpreter Kurzweil"]. Haboker, February 8, 1963. Review of $A$.

12. "Kurzweil kefarshano shel Bialik" ["Kurzweil as an Interpreter of Bialik"]. Haboker, January 17, 1964. On Kurzweil's receiving the Bialik Prize.

13.

"Ahdut veribui bemishnato shel Barukh Kurzweil" ["Unity and Diversity in the Theory of Barukh Kurzweil"]. Moznayim, XXV/4-5 (Sept.-Oct., 1967), pp. $266-272$.

14. - "Barukh Kurzweil". Encyclopedia Judaica, Vol. X. 
15.

"haHatirah el lev hayetsirah - darko shel Barukh Kurzweil bevikoret hasifrut". ["Penetration to the Heart of the Work - Barukh Kurzweil's Method in Literary Criticism"]. Yedi'ot aharonot, October 13, 1972.

16.

"Kurzweil 'al haroman vehasipur haeiropeiyim" ["Kurzweil on the European Novel and Fiction"]. Moznayim, XXXIX/1 (June, 1974), pp. 22-30. Review of $\mathrm{MR}^{2}$.

17.

"Terumato shel Barukh Kurzweil leheker Shai 'Agnon" "Barukh Kurzweil's Contribution to Agnon Criticism"]. SBK, pp. 74-92.

18. Ben-Ezer, Ehud. "Sipurei Barukh Kurzweil" ["The Stories of Barukh Kurzweil"]. 'Al hamishmar, November 10, 1972. On $\mathrm{N}$.

19. Ben-Moshe, T. "Faust uve'ayat hademoniyut - neged perush reaktsioni shel yetsirat Goethe" ["Faust and the problemi of the Demonic - Against A Reactionary Interpretation of Goethe's Work"]. besha'ar, 91 (December 8, 1949).

20. Ben-Shlomo, Yosef. "Milhamto shel Barukh Kurzweil besitra ahra" ["Barukh Kurzweil's Fight with the Devil"]. Lamerhav, November 28 and December 5, 1969. On J.

21. Binyamin, Rabbi (Yehoshu'a Radler-Feldman). "le'or bikoret hadishah ledugmah" ["In the Light of a Very Model of Modern Criticism"]. Ha'arets, May 2, 1947.

22. Brinker, Menahem. "'olamo haepi shel hayotser" ["The Epic World of the Artist"]. Masa' 75 (May 27, 1954), p. 4.

23. Bronovski, Yoram. "Goethe - katnut ugedolot" ["Goethe - The Little Things and the Big"]. Lamerhav, March 8, 1968.

24. Carmi, T. "hatikvah ha'aharonah shel hasifrut hatse'irah beshulei hartsaah retsinit" ["The Last Hope of a Budding Literature - Notes on a Most Serious Lecture"]. 'Al hamishmar, July 14, 1950.

25. Cohen, Yisra'el. "Retsifutah shel sifrutenu" ["The Continuity of Our Literature"]. Me'asef, III (5723), pp. 82-92. Re-printed in his Aspaklariyot, [Mirrors], Ramat Gan: Massadah Publishing Co., 1968, pp. $9-20$.

26. Dor, Moshe. "Hemshekh o mahapekha? torat hasifrut leB. Kurzweil" ["Continuity or Revolt? B. Kurzweil's Theory of Literature"]. Ma'ariv, January 15, 1960. On S.

27. Eldad, Yisra'el. "Goethe, Hitler veThomas Mann (she'elah leDr. B. Kurzweil)" ["Goethe, Hitler and Thomas Mann (A Question to Dr. B. Kurzweil)"]. Sulam, VII/5-6 (Elul, 5715 - Tishri 5716), pp. 25 f.

28. Even, Yosef. "Shitato habikortit shel B. Kurzweil" ["B. Kurzweil's Critical Methodology"]. Lamerhav, May 13 and May 20, 1966.

29. Evron, Boaz. "Barukh Kurzweil - halohem livehirut hamahashavah" ["Barukh Kurzweil - Fighter for Intellectual Clarity"]. Ha'arets, January 8, 1960. Review of S. 
30. Faians, Efrat. "Sha'ashu'ei siporet shal mevaker gadol" ["The Fictional Frolics of a Great Critic"]. Ma'ariv, December 29,1972 . Review of $\mathrm{N}$.

31. Fisch, Harold. "Portrait of a Critic". Jerusalem Post, September 1, 1972.

32. Friedlander, Yehudah. "haRe'ut hafenomenologit bevikoret sifrutenu" ["The Phenomenological Perspective in the Criticism of our Literature"]. Moznayim, XXIV/2 (January, 1967), pp. 132-135.

33. "halolem 'al herut haruah" ["The Fighter for Intellectual Liberty"]. Yedi'ot aharonot, September 1, 1972 .

34. "hashivah hame'uheret el ha'atsmiyut ha'avidah" ["The Late Return to the Lost Self"]. Ha'arets, November 10,1972 . On $\mathrm{N}$.

35. "Humanist bedimdumei tarbut shoka'at" ["The Humanist in the Twilight of a Decfining Culture"]. Ha'arets, September 7, 1973. on $\mathrm{MR}^{2}$. Re-printed as preface to $\mathrm{MR}^{2}$.

36. Friedlander, Yosef. "Barukh Kurzweil - hamevaker halohem" ["Barukh Kurzweil - The Fighting Critic"]. Gazit, (37) XXVI/1-8 (April-November, 1969), pp. $191 \mathrm{f}$.

37. Gil, Moshe. "Sifrutenu hahadashah umashber hayahadut" ["Our New Literature and the Crisis of Judaism"]. Davar, December 18,1959 . Review of $\mathrm{S}$.

38. Gorman-orian, Yehuait. "Bein eros levein etos" ["Between Eros and Ethos"]. Lamerhav, December 16, 1966. (Masa', No. 52). Review of $\mathrm{H}$.

39. Greenberg, Uri Zvi. "Sheki'in" ["Secret Memories"]. SBK, pp. $11-13$.

40. Helier, Yosef Eliahu. "Ahad ha'Am vedoro" ["Ahad ha- Am and His Generation"]. Hado'ar, XXXV/20 (March 18, 1955), pp. $379 \mathrm{f}$.

41. Holtz, Avraham. "Hirhurim 'al be'ayot yesod" ["Reflections on Some Fundamental Problems"]. Petahim, No. III (March 18, 1968), pp. 19-26.

42. Kaddari, M. Z. "Barukh Kurzweil bauniversitah" ["Barukh Kurzweil at the University"]. SBK, pp. $35 \mathrm{f}$.

43. Kariv, Avraham. "Parshanut mahti'ah" ["Misleading Interpretation"]. Molad, V, No. 27 (January-February, 1973), pp. $249-266$.

44.

"Interpretatsiah rabat eyal" ["A Strenuous Interpretation"]. Molad, VI, No. 31 (April-June, 1974), pp. $108-121$.

45. Katz, Ya'akov. "Historiah subyektivit uvikoret obyektivit" ["Subjective History and Objective criticism"]. Ha'arets, May 28, 1965 . 
46. Katz, Sarah. "Shilton hatarnegol ba'olam" ["The Rule of the Rooster in the World"]. Davar, September 29, 1972. On N.

47. "Masekhet shel yetsirah uvikoret" ["A Tome of Creativity and Criticism"]. Ma'ariv, March 1, 1974. On $M R^{2}$.

48. Kena'ani David. "'Agnon leshalish ulerevi'a" ["Agnon by a I'hird or a Quarter"]. Lamerhav, December 3 and December 17, 1953 (Masa', No. 62 and No. 63). Review of MR.

49. Klausner, Yosef. "Ketsat yoter zehirut uketsat pahot yehirut" ["A Little Less Carelessness and a Little More Humility"]. Ha'arets, April 13, 1944.

50. Kodesh, Shlomo. "Panim aherot lador!" ["Another Face to the Generation!"]. Hado'ar, XLV/8 (January 1, 1965), pp. 131-133.

51. Kremer, Shalom. "Netivot bevikoret ha'ivrit 1920-1960" ["Currents in Hebrew Criticism 1920-1960"]. Me'asef, V-VI (1966), pp. 348-376.

52. Kurzweil, zvi. "Barukh kurzweil kamehanekh" ["Barukh Kurzweil as Educator"]. Hed hahinukh, No. 8 (November 9, 1972), pp. 14-16. Re-printed in SBK, pp. $31-34$.

53. Landau, Dov. "Hanesi'ah bitehomot hazeman" ["Journey into the Depths of Time"]. Bikoret ufarshanut, Nos. 4-5 (March, 1974), pp. 86-88. On N.

54. Leor, Dan. "Ke'esh bo'eret be'atsmotav - Prof. Barukh Kurzweil sheloshim lifetirato" ["Like a Fire Burning in His Bones - A Month Since Prof. Barukh Kurzweil's Passing"]. Ha'arets, October 6, 1972.

55. Levin, vera. "Prof. Kurzweil martseh umitrashem be'ar(tsot) hab(erit)" ["Prof. Kurzweil Lectures and Gathers Impressions in the united States"]. Ha'arets, January $15,1965$.

56. Lipshitz, Aryeh. "Mahashavah vesipur beLuah Ha'arets 5713" ["Fiction and Thought in Luah Ha'arets 5713"]. Davar, October 31, 1952 .

57. Litai, A. (Aharon Rabinovitz). "Mifneh beha'arakhat hasifrut ha'ivrit hahadashah" ["A Turning Point in the Evaluation of Modern Hebrew Literature"]. Ha'arets, November 28, 1947 .

58. Mann, Yitshak. "Mar Barukh Kurzweil vesifrutenu hatse'irah" ["Mr. Barukh Kurzweil and our Young Literature"]. 'A] hamishmar, July 22, 1949.

59.

"Hatkafah vehashmatsah shehitslihu" ["A Successful Slanderous Attack"]. Masa', No. 24 (July 24, 1952), p. 2 .

60. Malkhin, Ya'akov. "Hitnaphut efsit usnobizm rakuv" ["Insignificant Puffiness and Rotten Snobism"]. 'Al hamishmar, July $8,1949$. 
61. Marani, David. "Neobarbarizm?" ["Neobarbarism?"]. Ha'arets, October 29,1948 .

62. Meged, Aharon. "levikoret 'atsmenu ulevikoret hasifrut" ["Toward a Criticism of Ourselves and of Literature"]. Masa', No. 1 (July 19, 1951).

63. Michali, B. Y. "'Al habikoret ha'orevet" ["Criticism as Ambush"]. Davar, March 5, 1954.

64. Michelson, Menahem. "haHed shehafakh lekol" ["The Echo which Became a Swell"]. Yedi'ot aharonot, September 1, 1972.

65. Miron, Dan. "Penei habikoret beyisra'el" ["The Face of Criticism in lsrael"]. Ha'arets, September 17, 1958.

66. _._. "Kavim lidemuto shel hamevaker Kurzweil" ["Toward a Profile of Kurzweil the Critic"]. Ha'arets, January 8, 1960 .

67. "Bialik vel'shernihovski le'or bikorto shel $B$. Kurzweil" ["Bialik and Tshernichovski in the Light of $\mathrm{B}$. Kurzweil's Criticism"]. Ha'arets, February 24, 1961.

68. Moked, Gavriel. "Diokeno shel mevaker vatik" ["A Profile of a Venerable critic"]. Yedi'ot aharonot, June 5, 1959.

69. "Sifrutenu be'einej Barukh Kurzweil" ["Our I,iterature in the Eyes of Barukh Kurzweil"l. Lamerhav, April 11, 1960. On S.

70. "Bikorto shel Barukh Kurzweil umigebaloteha" ["Barukh Kurzweil's Criticism and its Limitations"]. Lamerhav, May 27, 1960. More on S.

71. "Masot 'al sipurei 'Agnon shel Barukh Kurzweil" ["Barukh Kurzweil's Essays on Agnon's Stories"]. Ha'arets, March 1, 1963. On A.

72. "besa'ar ishim ve'arakhim" ["In the storm over People and Values"]. Yedi'ot aharonot, January 30 , 1970. On J.

73. "Barukh Kurzweil vehasifrut hatse'irah - shanah lemoto" ["Barukh Kurzweil and the Recent Literature - A Year Since His Death"]. Yedi'ot aharonot, September 7, 1973.

74. Nesher, Avrahān. "Neged hareaktsiah bevikoret hasifrutit" ["Against Reaction in Literary Criticism"]. Basha'ar, January 19, 1950 .

75. Oren, Yosef. "Kurzweil kesatirikon" ["Kurzweil as a Satirist"]. Yedi'ot aharonot, December 1, 1972. On N.

76. Perry, Menahem. "Mikhtav galui leprof. Barukh Kurzweil" ["An Open letter to Prof. Barukh Kurzweil"]. Yedi'ot aharonot, August 30, 1968.

77. Rabinovits, Re'uven. "beMa'avak 'al 'erkei hayahadut leBarukh Kurzweil" ["Barukh Kurzweil's In the Struggle for Jewish Values"]. Ha'arets, october 17, 1969. Review of J. 
78. Ram, B. "hasignon veharehilut" ["On Style and Gossip"]. 'Al hamishmar, July 4, 1952.

79. Reich, Hanan. "haprofesor halo'eg leprogres" ["The professor Who Scorns 'Progress'"]. Ha'arets, February 7, 1969. A letter in response to Kurzweil's articles in Ha'arets on January 2 and January $31,1969$.

80. Rubin, Tsilah. "Roman umevakro" ["A Novel and its Critic"]. 'Al hamishmar, October 12, 1948.

81. Sadan, Dov. "Matun, matun" ["Careful, Careful"]. Ha'arets, January $16,1959$.

82. Sandbank, Shim'on. "'Al tahbir veapokalipsiyut" ["On Composition and Apocalyptism"]. Lamerhav, July 4, 1969.

83. Schocken, Gershom. "Mahashavot 'al yovalo" "Thoughts on His Jubilee"]. Ha'arets, July 28, 1967.

84. - "Anshei ruah vehanehitah 'al hayareah" ["Intellectuals and the Landing on the Moon"]. Ha'arets, August 8,1969 .

85.

"Gershom Schocken meshiv" ["Gershorn Schocken Repplies"]. Ha'arets, August 15, 1969.

86.

"Devarim bemo'adon Milo" - Prof. Barukh Kurzweil sheloshim lifetirato" ["Remarks at the Milo' Club Thirty Days Since Prof. Barukh Kurzweil's Passing"]. Ha'arets, October 6, 1972. (Re-printed in SBK, pp. 42-46 as "Yehudi, ish merkaz eiropa, shamran" ["A Jewish Conservative from Central Europe"].)

87.

Schwarcz, Moshe. "hasar shene'evak 'al gahelet ha'esh ha'aharonah" ["The Noble Battler for the Last Flaming Ember"]. Ha'arets, September 1, 1972. (Re-printed in SBK, pp. 37-41 as "Barukh Kurzweil, ha'ish umif'alo" ["Barukh Kurzweil - The Man and His Work"].)

88 .

"Hanahot estetiot bemif'al habikoret shel Barukh Kurzweil" ["Esthetic Assumptions in the Criticism of Barukh Kurzweil"]. SBK, pp. 375-397. (Re-printed in M. Schwarcz, Hagut yehudit nokhah hatarbut hakelalit [Jewish Thought Confronts General Culture] (Tel Aviv: schocken Publishing Co., 1976), pp. 165-195.)

89.

"Barukh kurzweil kehogeh de'ot shel hayahadut" T"Barukh Kurzweil as a Jewish Thinker"]. Ha'arets, June 13, 1975. (Re-printed in Hagut yehudit nokhah hatarbut hakelalit, pp. 196-224.

90. Sha'anan, Avraham. "Bein mevaker lehistorion - beshiv'ah lemoto shel. Barukh Kurzweil" ["Between Critic and Historian - One Week Since Barukh Kurzweil's Death"]. Davar, september 1, 1972.

91. Shalev, Yitshak. "haFenomen Kurzweil" ["The Phenomenon Named kurzweil"]. Ha'arets, July 8, 1955. Or: MR .

92. Shamir, Moshe. "Keneset hareaktsiah shel sifrutenu" ("The Reactionary Element in our Literature"]. Masa', No. 11 (December 13, 1951). 
93. "Har ga'ash kavah" ["A Volcano Goes out"].
Mariv, August 25, 1972.

94. Shavit, Uzi. "He'arot lehaNesi'ah leBarukh Kurzweil" ["Notes on Barukh Kurzweil's The Journey"]. Bikoret ufarshanut, No. 6 (December, $1 9 7 4 \longdiv { \text { , pp. 99-107. } }$

95. Simon, Ernst. "haMevaker Barukh Kurzweil" ["The Critic Barukh Kurzweil"]. Ha'arets, April 12, 1946.

96. Spicehandler, Ezra. Review of $S$. Judaism, $X / 2$ (Spring, 1961), pp. 183-189.

97. _L_ Modern Hebrew Literature". Encyclopedia Judaica. Vol. VIII.

98. Talpaz, Gideon. "Al sipurei Barukh Kurzweil" l"On the Stories of Barukh Kurzweil"]. Moznayim, XXXV/5-6 (October-November, 1972), pp. 418-420. On $\mathrm{N}$.

99. Tishbi, Isaiah. "Divrei pulmus pesulot" ["An Improper Polemic"]. Davar, August 2, 1957. A reply to Kurzweil's article "haHiloniyut shel sifrutenu hahadashah" in Ha'arets, July 12, 1957.

100. "Heker hademonologiah uma'asim demoniyin" ["The Study of Demons and Demonic Deeds"]. Davar, September 20, 1957. A reply to Kurzweil's article 'Al haetikah hasifrutit umada'it shel istenis" in Davar, September 6, 1957.

101. Tsemah, Shlomo. "haNilozim bema'agalotam" ["Careless in Their Paths"]. Behinot, No. 8 (March-April, 1955), pp. 3-14. (Re-printed in $\mathrm{S}$. Tsemah, Sheti va'erev [Warp and Woof] (Tel Aviv: Am oved Publishers Ltd, 1959), pp. 109-135.)

102. Weiss, Hillel. "haYesod hatragi bemishnato shel Barukh Kurzweil" ["The Tragic Element in the Theory of Barukh Kurzwejl"]. Yedi'ot aharonot, September 22, 1972 .

103. "Kurzweil ke'ish tsava" ["Kurzweil As combatant"]. Davar, September 14, 1973.

104. "Tahalikhei hahurban shel tarbut hama'arav" ["The Dynamics of the Destruction of Western Culture"]. Davar, May 10, 1974. Review of $\mathrm{MR}^{2}$.

105. Yaffe, A. B. "Viduyav shel Dr. Kurzwej.l" ["The Confessions of Dr. Kurzweil."]. 'Al hamishmar, January 19, 1951.

106. Yizhar, S. "'Al snob ve'al..." ["on a snob and ..."]. Ha'arets, August 5, 1949.

107. Zach, Natan. Letter to the editor. Mevo'ot, No. 11 (May 18, $1954)$, p. 2 .

108. "Hulshato shel haDr. Kurzweil leshirah" ["Dr. Kurzweil's Weakness in Poetry"]. Iamerhav, June 29, 1956 .

109. "hamoreh lesifrut - leprof. Barukh Kurzwejl leyovalo" ["The Teacher of Literature - For Prof. Barukh 
Kurzweil on his Sixtieth Birthday"]. Ha'arets, August 18,1967 .

b) Interviews And Pertinent News Stories:

110. "Peras Bialik 5723 leprof. Kurzweil 'al sefaro Bialik veTshernihovski" ["Bialik Prize for 5723 to Prof. Kurzweil for his Book Bialik and Tshernichovski"]. Davar, January $10,1964$.

111. "Peras Bialik - nimukei hashofetim" ["The Bialik Prize - The Judges' Conclusions"]. Masa' (Lamerhav), January 17, 1964.

112. "Al meyu'ashim 'alizim ve'al adonim mesuyamim" ["On 'Happy Despairers' and 'Certain Gentlemen'"]. Interview with Yosef Lapid. Ma'ariv, January $17,1964$.

113. "Prof. B. Kurzweil: 'i-haratson lehodot bemigebalot molid et haziyuf" ["Prof. B. Kurzweil: Refusal to Acknowledge Limitations Engenders Phoniness"]. Interview with Rachel Eitan. Ha'arets, April 15, 1966.

114. "Diokan shel hoker sifrut - sihah 'im Prof. Barukh Kurzweil" ["Profile of a Literary Critic - A conversation with Prof. Barukh Kurzweil"]. Interview with Hayim Shoham. Ha'arets, July 28, 1967. (Transcript of broadcast interview on Israel radio marking Kurzweil's 6oth birthday.)

115. "Ha'im gam hasifrut shelanu amrah aharai?" ["Has Our Iiterature Also Said 'After Me'?"]. Interview with Ge'ulah Cohen. Ma'ariv, October 13, 1968.

116. "Bekinun yashir - diokano shel mevaker sifrut - 'im Prof. Barukh Kurzweil" ["Telling It Straight - Profile of a Literary Critic - With Prof. Barukh Kurzweil"]. Pen'ai, No. 1 (May, 1971), pp. 21-26. Interview with Y. Pik and I. Ya'oz-Kest.

117. "haMevaker shekatal et 'atsmo" ["The critic Who Killed Himself"]. Ha'olam hazeh, No. 1826 (August 30, 1972).

118. "Panim aherot - lediokano shel haprof. Barukh Kurzweil Z. L. kefi shemesartetim oto talmidav" ["Many Faces - A Profile of the Late Prof. Barukh Kurzweil as sketched by His Students"]. Participants: H. Barzel, Y. Friedlander, Z. Luz, G. Ramraz-Rauch, H. Shoham. Bikoret ufarshanut, No. 6 (December, 1974), pp. 108-113.

119. "Mesibah sifrutit" ["A Literary Gathering"]. Discussion of Kurzweil by Menahem Brinker and Hillel weiss. Galei Zahal (Israel Defense Forces Radio), May 30, 1976.

c) Other Articles:

120. Altermann, Natan. "Al kamah 'ir'urim shel B. Kurzweil" ["On Some Impugnations by B. Kurzweil"]. Ha'arets, June 10, 1955 . 
121.

"liteguvah 'al ma'amarei Barukh Kurzweil" ["In Reaction to Barukh Kurzweil's Articles"J. Davar, April 14, 1958. Response to Kurzweil's review of 'Ir hayonah in Ha'arets, April 4 and April 10, 1958.

122. Arnon, Yohanan. "haMif'al vehayetsirah" ["The Enterprise and the Work"]. Ha'arets, July 18, 1975. Review of SBK.

123. Ashani, Y. "Bein mevaker liyetsirah - kor'im kotevim 'al Yemei tsiklag" ["Between the Critic and the Work Readers Write about The Days of Ziklag"]. Davar, october 3, 1958 .

124. Ben-Dov, A. "Dr. Kurzweil mekales" ["Dr. Kurzweil Praises"]. Ma'avak, No. 98 (March 12, 1954).

125. Brinker, Menahem. "hasifrut ve'olam ha'avot" ["Literature and the Ancestral World"]. Masa', No. 76 (June 3, $1954)$, p. 5 .

126. Brown, M. "He'arot levikorto shel Kurzweil" ["Notes on Kurzweil's Criticsm"]. Lamerhav, January 13, 1967. On H.

127. Buber, Martin. "le'Inyan Gog uMagog" ["On the Matter of Gog and Magog"]. Ha'arets, December 8, 1944. Response to Kurzweil's article in Ha'arets, November $24,1944$.

128.

"lema'amaro shel Dr. Barukh Kurzweil" ["On Dr. Barukh Kurzweil's Article"]. Ha'arets, August 7, 1953. Response to Kurzweil's article in Ha'arets, July 10,1953 .

129. Dor, Moshe. "Lifnei bet-din shel matah" ["Before the Earthly Court"]. 'Al hamishmar, May 7, 1965.

130. Doron, Daniel. "lefulmus 'al bikorto shel Barukh Kurzweil" ["On the Controversy about Barukh Kurzweil's Criticism"]. Ha'arets, August 19, 1949.

131. Evron, B. "Luah Ha'arets 5715". Ha'arets, September 27 , 1954. On Kurzweil's essay on Ahad ha-Am.

132. Goren, Ya'akov. "Bein mevaker liyetsirah - kor'im kotevim 'al Yemei tsiklag" ["Between the Critic and the Work Readers Write about The Days of Ziklag"]. Davar, October 3, 1958 .

133. Greenberg, Uri Zvi. "miMa'alot bema'amakim" ["F'rom Soaring in the Depths"]. Ha'arets, July 28, 1967. Six chapters of verse for Kurzweil's 60 th birthday.

134. Ha'efrati, Yosef. "He'arot lemivhar hama'amarim 'al shirat Altermann" ["Notes on a Selection of Articles on Altermann's Poetry"]. Siman keri'ah, No. 1 (September, 1972), pp. 329-335.

135. Herzberg, Avraham (Arthur). "Ma'avako shel Barukh Kurzweil" ["Barukh Kurzweil's struggle"]. Ha'arets, October 22, 1976 .

136. Horovits, Ya'akov. "ha'Olam vehayahadut nusah Kurzwej.1" ["Judaism and the world According to Kurzweil"]. Davar, October 13, 1972 . 
137. Katznelson, Gid'on. "Bein Kurzweil leHoni hame'agel" ["Between Kurzweil and Honi the Circle-Maker"]. Ha'arets, April 2, 1954 .

138. Kurzweil, zvi. "He'arot lema'avako shel Barukh Kurzweil" ["Comments on 'Barukh Kurzweil's Struggle'"]. Ha'arets, November 12, 1976. Response to Herzberg's article in Ha'arets, October $22,1976$.

139. Lazar, David. "Yevusam lo" ["May He Enjoy It"]. Ma'ariv, February 24, 1967. Response to Kurzweil's article in Ha'arets, February 17, 1967.

140. Levinger, Ya'akov. "He'arot leferush 'al Pat shelemah" ["Comments on an Interpretation of 'A whole Loaf'"]. le'Agnon shai, ed. D. Sadan and E. Urbach. Jerusalem. 1959. pp. 179-183.

141.

"Tragediah shel mevaker dagul" ["The Tragedy of a Distinguished Critic"]. Yedi'ot aharonot, September 10, 1976.

142. Lichtenbaum, Yosef. "haMeshorer U. N. Gressin umevakro" ["The Artist U. N. Gnessin and his Critic"]. Moznayim, XIV (December, 1961), pp. 16-19.

143. Lindenbaum, Shalom. Review of SBK. Yedi'ot aharonot, August 22, 1975.

144. Margalit, Dan. "Universitah miflagtit" ["A Politicized University"]. Herut, May 18, 1962.

145. Meged, Matti. "hamitos sheshemo Barukh Kurzweil" ["The Myth Named Barukh Kurzweil"]. Lamerhav, September 5, 1958.

146. Miron, Dan. "He'arot le'Agadat sheloshah ve'arba'ah liBialik" ["Notes on Bialik's A Tale of Three and Four"]. Bailik antologiah, ed. G. Shaked. Jerusalem, 1974. pp. 373-399.

147. Oren, Yosef. "haportsim hozrim biteshuvah" ["The Attackers Repent"]. Ha'arets, May 11, 1973.

148. Rabinovitch, Isaiah. "'Al bikoret ve'al mevaker" ["On Criticism and a critic"]. Davar, September 25, 1953. Response to Kurzweil's articles in Ha'arets of June 26, 1953 and August 14, 1953.

149. Rosen, Ya'akov. "Bein mevaker liyetsirah - kor'im kotevim 'al Yemei tsiklag" ["Between the Critic and the Work Readers Write about The Days of Ziklag"]. Davar, October 3, 1958 .

150. Rubner, Tuvyah. Letter to the editor. Mevo'ot, No. 13 (August 6, 1954), p. 2 .

151. Sadan, Dov. "Al Yosef Hayim Brenner" ["On Yosef Hayim Brenner"]. Molad, XIX (June, 1961), pp. 298 ff.

152. Schocken, Gershom. "hasarat mikhshol" ["Removal of a Stumbling Block"]. Ha'arets, October 24, 1975. 
153. Schweid, Eliezer. "beMeitsar hare'iah hatragit" ["In the straitness of the Tragic Vision"]. Ma'ariv. August 27, 1976. Review of I.

154. Sha'anan, Avraham. "Hago shel hoker sifrut ('al Barukh Kurzweil bimelo'ot 10 60 shanah)" ["A Literary Critic's Celebration (On Barukh Kurzweil at 60)"]. Davar, August 18, 1967.

155. Shalev, Yitshak. "Bikoret o ruah ra'ah?" ["Criticism or I11-Temper?"]. Davar, March 22, 1957.

156. Shalom, shin. "'od 'al Shirah vehasonetot" ["More on Shirah and The Sonnets"]. Davar, August 18, 1972.

157. Sharf, Bat-Sheva. "Mikhtav galui leprof. Kurzweil" ["An Open Letter to Prof. Kurzweil"]. Davar, January 19, 1962.

158. Struzinski, Aryeh. "Bein mevaker liyetsirah - Kor'im kotevim 'al Yemei tsiklag" ["Between the Critic and the Work Readers Write about The Days of Ziklag"]. Davar, October 3, 1958.

159. Tochner, Meshulam. "leHeker yetsirato shel Shai 'Agnon" ["On the Criticism of $S$. Y. Agnon's Work"]. Molad, XI (November-December, 1953), pp. 268-284.

160 . - "Teguvat hayotser 'al heker yetsirato - Shai 'Agnon umefarshav" ["The Reaction of the Artist to the Criticism of His Work - S. Y. Agnon and His Interpreters"]. Molad, XXI (September-October, 1963), pp. $409-421$.

161. Weiner, Herbert. $91 / 2$ Mystics: The Kabbala Today. New York: Collier Books, 1969. See pp. 82-84 on Kurzweil on scholem.

162. Yaffe, A. B. "Barukh Kurzweil (ma'amar lezikhro)" ["Barukh Kurzweil (A Memorial Essay)']. 'Al hamishmar, September 1,1972 .

163. Yardeni, Galiah. "Mish'al 'al hasifrut ha'ivrit be'eser shanim ha'aharonot" ["Questionnaixe on Hebrew Literature of the Last Ten Years"]. Lamerhav, April 23, 1958.

IV. Other Sources

1. Agnon, S. Y. "The Holy Tongue as a Written Language", trans. unknown. Ariel: A Quarterly Review of the Arts and Sciences in Israel, No. 25 (Winter, 1969), pp. 19-24.

2. A Guest for the Night, trans. Misha Louvish. New York: Schocken Books, 1968.

3. Alter, Robert. After the Tradition: Essays on Modern Jewish Writing. New York: E. P. Dutton \& Co., 1969.

4. Alvarez, A. The Savage God: A Study of Suicide. London: Weidenfeld and Nicholson, 1971. 
5. Band, Arnold J. Nostalgia and Nightmare: A Study in the Fiction of S. Y. Agnon. Berkeley and Los Angeles: University of California Press, 1968.

6. Criticism: The Major Texts, ed. Walter Jackson Bate. New York: Harcourt, Brace \& Co., 1952.

7. Benjamin, Walter. Illuminations, trans. Harry zohn; ed. and introd. by Hannah Arendt. London: Jonathan Cape, 1970.

8. Berger, Peter. The Sacred Canopy: Elements of a SociologiCal Theory of Religion. Garden City, N.Y.: Anchor Books, Doubleday and Co., 1969.

9. I and Luckmann, Thomas. The Social construction of Reality: A Treatise in the Sociology of Knowledge. Garden City, N.Y.: Anchor Books, Doubleday and Co., 1966 .

10. Bialik, H. N. "The Explicit and the Allusive in Language", trans. Avraham Holtz. Literature East and West, XV/3 [n.d., 1971?], pp. 498-508.

11. Blackmur, R. P. "A Critic's Job of Work", in Problens in Aesthetics: An Introductory Book of Readings, ed. Morris Weitz. 2nd ed., London: The Macmillan Co., 1970 .

12. In Search of Literary Theory, ed. Morton w. Bloomfield. Ithaca and London: Corneli university Press, 1972.

13. Bradley, A. C. "Hegel's Theory of Tragedy". In Problems In Aesthetics: An Introductory Book of Readings, ed. Morris Weitz, 2nd ed. London: The Macmillan Co., 1970.

14. Breslin, Charles. "Philosophy or Philology: Auerbach and Aesthetic Historicism". The Journal of the History of Ideas, XXII/3 (July-september, 1961), pp. 369-381.

15. Breuer, Isaac. Concepts of Judajsm, ed. Jacob S. Levinger. Jerusalem: Israel Universities Press, 1974.

16. Brouwer, J. H. "The Relation between Frisjan Literature and other Iiteratures". In Proceedings of the IIIrd Congress of the International Comparative Literature Association - Utrecht - 1961. Gravenhage: Mouton and Co., 1962, pp. 290-297.

17. Buber, Martin. Between Man and Man, trans. Ronald Gregor Smith. New York: The Macmillan Co., 1947.

18. - I and Thou, trans. Ronald Gregor Smith. New York: Scribner's, 1958 .

19. Caviglia, John. "Flaubert and Leopoldo Alas: An Essay in Comparative Anatomy". Indiana University, unpublished doctoral dissertation, 1970.

20. Crane, R. S. The Languages of Criticism and the Structure of poetry. Toronto: University of Toronto Press, 1953.

21. Donagan, Alan. The Later Philosophy of R. G. Collingwood. Oxford: Clarendon Press, 1962. 
22. Fisch, Harold. "Shinui ha'arakhim bevikoret hasifrutit" ["The Transvaluation of Values in Literary Criticism"]. In $\mathrm{SBK}, \mathrm{pp} \cdot 128-138$.

23.

"Bar-Ilan University". Ariel: A Quarterly Review of the Arts and Sciences in Israel, No. 26 (Spring, 1970), pp. 53-61.

24. Fleischmann, Ya'akov. "hasafah bivekhinat ruah obyektivit etsel Humboldt" ["Language as 'objective spirit' in Humboldt"]. In SBK, pp. 213-219.

25. Friedlander, Yehudah. "Kavim behitpathut habikoret 'al shirat Uri Tsvi Greenberg" ["The Contours of the Development of the Criticism of the poetry of Uri zvi Greenberg"]. In Uri T'svi Greenberg - mivhar ma'amarei bikoret 'al yetsirato [Uri ZVi Greenberg - A selection of Critical Essays on His Work], ed. Y. Friedlander. Tel Aviv: Am Oved Publishing Co., 1974, pp. 7-34.

26. Gadamer, Hans-Georg. Truth and Method, trans. Garrett Barden and John Cumming. New York: The Seabury Press, 1975.

27. Gay, Peter. The Enlightenment - An Interpretation: The Rise of Modern Paganism. New York: Alfred A. Knopf, 1967.

28. Weimar Culture: The Outsider as Insider. New York and Evanston: Harper \& Row, 1968.

29. European Literary Theory and Practice: From Existential phenomenology to structuralism, ed. Vernon w. Gras. New York: A Delta Book, Dell Publishing Co., 1973.

30. Ha'efrati, Yosef. haIdiliah shel Tshernihovski [The Idyll In Tshernichovski]. Merhaviah and Tel Aviv: Sifriat Po'alim, 1971 .

31. Halkin, Simon. Modern Hebrew Literature from the Enlightenment to the Birth of the State of Israel: Trends and Values. New York: Schocken Books, 1950. New Edition $\overline{1970 .}$

32. Martin Heidegger. on the way to Language, trans. Peter $D$. Hertz. New York: Harper and Row, 1971 .

33. ___ Being and Time, trans. John MacQuarrie and Edward Robinson. London: SCM Press Ltd. , 1962.

34. Heller, Erich. The Disinherited Mind: Essays in Modern German Literature and Thought. n.p.: Penguin Books, 1961 .

35. Hirsch, E. D., Jr. Validity in Interpretation. New Haven and London: Yale University Press, 1967.

36. "Current Issues in Theory of Interpretation". The Journal of Religion, LV/3 (July, 1975), pp. 298-312.

37. Hochman, Baruch. The Fiction of S. Y. Agnon. Ithaca and London: Corneli University Press, 1970 .

38. Holtz, Avraham. "Prolegomenon to a Literary History of Nodern Hebrew Literature". Literature East and West, XI/3 (September, 1967), pp. 253-270. 
39. Hosillos, Lucilla V. "Filipino Literature: Its Emergence and Quest for National Identity". In proceedings of the IVth Congress of the International comparative Literature Association - Fribourg - 1964, ed. Francois Jost. The Hague and Paris: Mouton and Co., 1966, II, p. 1377.

40. Hrushovski, Binyamin. "Al tehumei mada' hasifrut". ["On the Parameters of the science of Literature"]. hasifrut, I/1 (Spring, 1968), pp. 1-10.

41. Iggers, Wilma A. Karl Kraus: A Viennese Critic of the Twentieth Century. The Hague: Martinus Nijhoff, 1967.

42. Janik, Allan and Toulmin, Stephen. Wittgenstein's Vienna. New York: Simon and Schuster, $197 \overline{73}$

43. Jay, Martin. The Dialectical Imagination: A History of the Frankfurt School and the Institute of Social Research, 1923-1950. London: Heinemann Educational Books, 1973 .

44. The Jews of Czechoslovakia: Historical studies and surveys. 2 Vols. Philadelphia and New York: The Jewish Publication Society of America and The Society for the History of Czechoslovak Jews, 1968 and 1971 .

45. Kahn, Shalom J. "Uri Zvi Greenberg - Poet of Kingship". Ariel: A Quarterly Review of the Arts and Sciences in Israel, No. $13(1966)$, pp. 35-52.

46. Kaminsky, Jack. Hegel on Art: An Interpretation of Hegel's Aesthetics. New York: State University of New York, 1962 .

47. Kardos, Bela Talbot. "Wholeness: A Synthesis of Individualism, Patriotism (Not Nationalism) and Universalism (Not Cosmopolitanism): Three Criteria of Literary Greatness". In Proceedings of the IVth Corgress of the International Comparative Iiterature Association Fribourg - 1964 , ed. Francois Jost. The Hague and Paris; Mouton and Co., 1966, II, pp. 667-674.

48. Kariv, Avraham. mishileshom ve'ad hena. Tel Aviv: $M$. Newmann, 1973.

49. Katz, Jacob. Tradition and Crisis: Jewish Society at the End of the Middle Ages. New York: Schocken Books, 1961 .

50. Klausner, Joseph. Mavo kelali [General Introduction], in vol. I of his Historiah shel hasifrut ha'ivrit hahadashah [History of Modern Hebrew Literature]. 2nd rev. ed. Jerusalem: Achiasaf Publishing House, 1930 , pp. $1-11$.

51. Kraft, werner. "'Eser shanim lifetirato shel Karl Kraus" ["Ten Years Since Karl Kraus's Death"]. Ha'arets, June $7,1946$.

52. Kressel, G. Leksikon hasifrut ha'ivrit bedorot ha'aharonim [Cyclopedia of Modern Hebrew Literature] . 2 Vols. Merhaviah: Sifriat Po'alim, 1967 .

53. Krieger, Murray. The New Apologists for Poetry. Minneapolis: The university of Minnesota Press, 1956. 
54. Lachower, F. Miyemei tsemihat hasifrut hahadashah beItaliah 'ad sheki'at hahaskalah bama'arav [From the Growth of the New Literature in Italy Until the Decline of the Haskalah in the West], Vol. I of his Toledot hasifrut ha'ivrit hahadashah [History of Modern Hebrew Literature]. Tel Aviv: Dvir Co., 1928.

55. Lauer, Quentin. Phenomenology: Its Genesis and Prospect. New York: Harper and Row, 1958.

56. Levinger, Ya'akov. "hatsiyoni halohem batsiyonut" "The Anti-Zionist Zionist". In SBK, pp. 151-168.

57. Lichtheim, George. Lukács. Fontana Modern Masters Series, ed. Frank Kermode. London: Fontana/Collins, 1970.

58. Liptzin, Solomon. Germany's Stepchildren. Philadelphia: The Jewish Publication Society of America, 1944.

59. Lukács, Georg. Realism in our Time: Literature and the class struggle, ed. and preface by George steiner. New York and Evanston: Harper and Row, 1964.

60. Makreel, Rudolph A. Dilthey: Philosopher of the Human Stuaies. Princeton: Princeton University Press, 1975.

61. Meyer, Michael A. The orj.gins of the Modern Jew: Jewish Identity and European Culture in Germany, 1749-1824. Detroit: Wayne state University Press, 1967.

62. Müller-vollmer, Kurt. Towards a Phenomenological Theory of Literature: A study of wilhelm Dilthey's Poetik. The Hague: Moutor and Co., 1963.

63. Oxenhandler, Neal. "Ontological Criticism in America and France". Modern Language Review, LV (1960), pp. 17-23.

64. Palmer, Richard E. Hermeneutics: Interpretation rheory in Schleiermacher, Dilthey, Heidegger and Gadanier. Evanston: Northwestern University Press, 1969.

65. "Toward a Postmodern Interpretive Self-Awareness". The Journal of Religion, LV/3 (July, 1975), pp. 313-326.

66. Pivćević, Edo. Husserl and Phenomenology. London: Hutchinson tiniversity tibrary, 1970.

67. Posen, Eliezer. "The Frankfurt Yeshiva". In Rabbi Dr. Joseph Breuer Jubilee Volume, ed. Leo Jung. New York: Phillipp Feldheim, 1962, pp. 149-154.

68. Reichmann, Eva G. "Max Horkheimer the Jew: Critical Theory and Beyond". In Leo Baeck Institute Yearbook, XIX (1974), pp. 181-195.

69. Rosenzweig, Franz. The Star of Redemption, trans. William W. Hallo. New York: Holt, Rinehart and Winston, 1970-71.

70. Rotenstreich, Nathan. Jewish Philosophy in Modern Times from Mendelsohn to Rosenzweig. New York: Holt, Rinehart and Winston, 1968 .

71. Sadan, Dov (Dov Shtok). "Masat mav'o" ["Introductory Essay"]. In his Avnei bedek: 'al sifrutenu, masadah, 
ve'agapeha [Touchstones: on our Literature, Its Founding and Branches]. Tel Aviv: hakibbutz hame'uhad Publishing House, 1962, pp. 9-66.

72. Salm, Peter. Three Modes of Criticism: The Literary Theories of Scherer, Walzel, and Staiger. Cleveland: Case-Western Reserve University Press, 1968.

73. Schapira, Hayim Nahman. Toledot hasifrut ha'ivrit hahadashah [The History of Modern Hebrew Literature]. Tel Aviv: Massadah Publishing Co., 1940. Re-printed 1967.

74. Schiller, Friedrich. On the Aesthetic Education of Man in a Series of Letters, trans. with intro. by Reginald snell. New Haven: Yale University Press, 1954.

75. Naive and Sentimental poetry and on the sublime: Two Essays, trans. with intro. by Julian A. Elias. New York: Frederick Ungar Publishing Co., 1966.

76. Scholem, Gershom. "Walter Benjamin". In Leo Baeck Institute Yearbook, X (1965), pp. 117-136. Re-printed in: On Jews and Judaism in Crisis: Selected Essays, ed. Werner J. Dannhauser. New York: Schocken Books, 1976.

77. Schorske, Carl E. Fin-De-Siècle Vienna Politics and Culture. New York: Alfred A. Knopf, 1980.

78. Schwarcz, Moshe. Hagut yehudit nokhah hatarbut hakelalit [Jewish Thought Confronts General Culture]. Tel Aviv: schocken Publishing Co., 1976.

79. Schwarzschild, Steven S. "The Legal Foundation of Jewish Aesthetics". The Journal of Aesthetic Education, IX/1

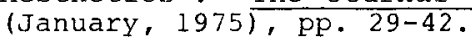

80. Sha'anan, Avraham. hasifrut ha'ivrit hahadashah lizerameiha [Currents in Modern Hebrew Literature]. 3 Vols. Tel Aviv: Massadah Publishing Co., 1962 .

81. Shaked, Gershon. "The Double Confrontation of Renascent Literature". Literature East and West, XIV/1 (n.d. 1970?), pp. 1-26. Re-printed in ArieI: A Quarterly Review of the Arts and Sciences in Israel, No. 22 (Spring, 1968), pp. 41-62.

82. Sharf, Andrew. "Statements, Generalisations and Karl Popper's Historicism". In SBK, pp. xxix-xli.

83. Silberstein, Lawrence Jay. "History and Ideology: The Writings of Yehezkel Kaufmann". Brandeis University, unpublished doctoral dissertation, 1971.

84. Spiegelberg, Herbert. The Phenomenological Movement: A Historical Introduction. 2 Vols. The Hague: Martinus Nijhoff, 1960.

85. Steiner, George. The Death of Tragedy. New York: Alfred A. Knopf, 1961 .

86. - Language and Silence:

Essays 1958-1966. London: Faber and Faber, 1958-1967. 
87. Extra-Territorial: Papers on Literature and the Language Revolution. New York: Atheneum, 1971.

88. - Tolstoy or Dostoevsky: An Essay in the old Criticism. New York: Alfred A. Knopf, 1959.

89. Strelka, Joseph P., ed. The Personality of the Critic. Yearbook of Comparative Criticism, Vol. 6. University Park, Penna. and London: Pennsylvania state University Press, 1973.

90. The Study of Literature: A Handbook of Critical Essays and Terms, ed. S. Barnet, M. Berman, W. Burto. Boston: Little, Brown and Co., 1960.

91. Todorov, Tzvetan. Qu'est-ce Que Le Structuralisme? Paris: Editions due seuil, 1968.

92. Tuchman, Barbara $W$. The Guns of August. New York: Macmilian Co., 1962 .

93. Wellek, René. Concepts of Criticism. New Haven and London: Yale University Press, 1963.

94. New $\frac{\text { Discriminations: Further Concepts of Criticism. }}{\text { Yale University Press, } 1970 .}$

95. - The Romantic Age, Vol. II of his A History of Modern Criticism. London: Jonathan Cape, $\overline{1955 .}$

96. - The Latter 19th Century, Vol. IV of his A History Of Modern Criticism. London: Jonathan Cape, $1 \overline{965}$.

97. and Warren, Austin. Theory of Literature. 3rd Edition. New York: Harcourt, Brace and World, 1956.

98. Wiener, Max. haDat hayehudit bitekufat haemantsipatsiah, trans. Leah Zagagi; introd. Yehoshu'a Amir. Jerusalem: Mosad Bialik and the Leo Baeck Institute, 1974.

99. Yudkin, Leon I. Escape into Siege: A Survey of Israeli Literature Today. London and Boston: Routledge and Kegan Paul, 1974 .

V. Letters

There are two collections of letters written by Kurzweil to which I had access.

The first is the letter archive at Bet hasofer (the Hebrew Writers' House) in Tel Aviv. Contained here are about a score of letters to such literary and intellectual figures as Yosef Arikha, M. Avi-Shaul, Asher Barash, K. A. Bertini, Avraham Kariv, B. Y. Michali, Daniel Persky, Zvi Woislawski and others. These letters are somewhat useful for documenting some biographical details. Their chief value is the light they shed on Kurzweil's inner life, especially his anger at the way in which his critical pronouncements were understood and his anguish at his sense of isolation from the Israeli literary establishment.

The same is true of the several letters from Kurzweil to S. Y. Agnon that are extant in the Agnon archive (Yad 'Agnon) at 
the National and University Library at the Hebrew University in Jerusalem. From these we get an idea of what his relationship to Agnon meant to Kurzweil in personal terms. There is much expression in this correspondence of his frustrations both as a writer and as a critic.

Both collections of letters, however, shed little, if any, light on Kurzweil's critical philosophy and I have chosen not to deal here with their contents or the issues they raise. 

Abramovitz, Shalom Ya'akov, 84, $88,89,96,156 \mathrm{n} 6, \mathrm{n} 10$

Abrams, M. H., $128 \mathrm{n} 4$

Abramson, Ya'akov, $128 \mathrm{n} 3$, $159 \mathrm{n} 59$

Agnon, S. Y., 1, 35, 41, 64, $82,95-98,100,106,108$, $124,135 \mathrm{n} 51,136 \mathrm{n} 66$, $137 \mathrm{n} 74,157 \mathrm{n} 38$

Ahad ha-Am, see Ginsberg, Asher Altermann, Natan, 93, 100, 101, 106

Amichai, Yehudah, 108, 112, 160 n79

Arendt, Hannah, 122

Auerbach, Erich, 57, 65

Bachelard, Gaston, 65

Bakon, Yitshak, 75

Band, Arnold J., 1, 7, 8, 114 , $128 \mathrm{n} 2,157 \mathrm{n} 38,161 \mathrm{n} 102$

Bar-Ilan University, 20, 21,54

Barzel, Hillel, 2, 28, 70, 95, $97,128 \mathrm{n} 3,138 \mathrm{n} 83$

Ben-Gurion, David, 142 n43, $161 \mathrm{n} 101$

Benjamin, walter, 36, 121-123, 132 n 26

Berditchevski, M. Y., 78, 82, $88,91,99,156 \mathrm{n} 6$

Bialik, H. N., $41,44,60,63$, $64,75,82,84,91-93,96$, $100,106,144 \mathrm{n} 75,156 \mathrm{n} 16$

Bialoblotzky, Shemuel, 20 , $136 \mathrm{n} 64$

Blackmur, R. P., 124

Brenner, Y. H., 39, 75, 82, 89, $94-95,100,106$

Brever, Solomon, 11, 12, 13

Breuer, Yitshak, 32, 33, 34, 80, $132 \mathrm{n} 23,141 \mathrm{n} 28$

Brinker, Menahem, $128 \mathrm{n} 1$

Brouwer, J. H., 111

Buber, Martin, 13, 14, 15, 16, $17,28,30,36,43,44$,

$47,103,133$ n30 n31, $134 \mathrm{n} 38,140 \mathrm{nl6}, 141 \mathrm{n} 32$, 143 n52

Camus, Albert, 146 n19

Carmi, T., 107, 112, $135 \mathrm{n} 47$

Crane, R. S., 2, 3

Dilthey, Wilhelm, 31, 36, 47, $48,49,55,56,57$, $140 \mathrm{n} 16,149 \mathrm{n} 70,162 \mathrm{n} 13$
Don Quixote, 88

Feierberg, M. 2., 41, 82, 84, $90-91,96,134 \mathrm{n} 40$, $156 \mathrm{n} 15$

Flaubert, Gustave, 65

Friedlander, Yehudah, 2, 25, $63,128 \mathrm{n} 3$

Frye, Northrop, 158 n40, $163 \mathrm{n} 27$

Gadamer, Hans-Georg, 57, 65, $66,117,151$ nI10

George, Stefan, 13, 45, 140 n16

Ginsberg, Asher (Ahad ha-Am), $16,22,34,80,91,93$, $130 \mathrm{n} 3,131 \mathrm{n} 12$

Goethe, Johann Wolfgang von, 49 Gordon, Y. L., 88, 89, 99, $156 \mathrm{n} 11$

Greenberg, Uri Zvi, 32, 35, 41, $82,93,97,101-105,106$, $124,138 \mathrm{n} 83$

Halkin, Simon, 4, 73, 76, 79, $154 \mathrm{n} 41$

Hazaz, Hayim, 82, 101, 108 , $158 \quad n 57$

Heidegger, Martin, 36, 37, 43, $48,57,62,83,140 \mathrm{n} 16$, $143 \mathrm{n} 52,150 \mathrm{n} 95,162 \mathrm{n} 13$

Herz], Theodore, 10, 32, $131 \mathrm{n} 12$

Hirsch, E. D. Jr., 117 , $151 \mathrm{n} 110$

Hirsch, Samson Raphae1, 12, 32, $132 \mathrm{n} 22$

Hochman, Baruch, $150 \mathrm{n} 97$, 157 n38

Holtz, Avraham, $144 \mathrm{n} 75$, $152 \mathrm{n} 8,155 \mathrm{n} 63,156 \mathrm{n} 11$, 159 n69

Hrushovsky, Benjamin, 24, 54

Huizinga, J., $78,140 \mathrm{n} 10$

Husserl, Edmund, 10, 31, 37, $48,50,55,56,62,66$, $67,132 \mathrm{n} 25,162 \mathrm{n} 13$

Ingarden, Roman, 56, 57, 65, $149 \quad n 67$

Janik, Allan (with Stephen Toulmin), 40, $130 \mathrm{n} 9$, 131 n17, 138 n83 
Kafka, Franz, 10, 39, 75, 94, 95,134 n38

Kant, Immanuel, 43, 45, 48, 79, $146 \quad \mathrm{n} 33$

Kapilowitz, Ya'akov (Yeshurun Keshet), 4, $156 \mathrm{n} 16$

Kariv, Avraham, 4, 73, 74, 75, $89,113,157$ n38

Kaufmann, Yehezkel, 17, 31

Kayser, Wolfgang, 57

Keshet, Yeshurun, see Kapilowitz, Ya'akov

Klausner, Joseph, 4, 17, 19, $70,71,72,73,76,77$, $80,84,85,118$

Kommere11, Max, 65, 132 n26

Kraus, karl, $10,36,38,39$, $40,41,44,75,92,94$, $121,122,123,144 \mathrm{n} 66$, $162 n 9$

Kremer, Shalom, 75, $128 \mathrm{n} 11$

Krieger, Murray, 7, 129 nl8, 158 n 40

Kurzweil, Barukh

attempts at fiction, 15 , 16,25

as child of Hapsburg Empire, 10，40，121

collections of essays published, 19,21 , $22,23,59$; posthumously published, 25

credo as a Jew, 32

death of, 24,138 n83

early responses to, 19

as outsider, 19, 20, 26, 58-59

pessimism of, $30,31,39$, $40,41,58$

phenomenological elements in thought of, 31,36

view of Hebrew language, $37,38,39$

and Agnon, 15, 16, 22

and Bialik, 16

and Bikoret ufarshanut, 24

and Buber, $1 \overline{4-17}$

and $\mathrm{Ha}$ 'arets, 18

and Hasifrut, $24,54,57$

and Hebrew University, 16 , 17

and Israeli critics, 54, 58

and Marxist critics, 55

and other arts, $145 \mathrm{n} 11$

and zionism, $24,32-35$

on Agnon, 29, 95-98

on Arab-Israej.i conflict, 141 n 32

on Bialik, 60, 91-93

on Brenner, 94-95, 100, 106

on Feierberg, 90-91 on Greenberg, 23, 29, $101-104$

on Haskalah, 88-89

on modern Hebrew literature, 110-111

periodization of, 104-105

on "Palmach" writers, $106-108$

on Sabra writers, 82-83, $85,105-110,113$

on Tschernichovski, 98-100

criticism of development of, 118 epistemology of, 49 , $50,51,61,62$, $141 \mathrm{n} 23$

form and content of, 115

personal element in, $90,97,98,113$

as phenomenological hermeneutics, $55,56,57,65$, $66,67,117$

as Midrash, 124

range of, 5,6

statements of method, $5,7,59,63$, $64,66,148$ n61

subjectivity of, 1 , $66,67,150 \mathrm{n} 97$, $159 \mathrm{n} 58$

temper of, 24,57 , $139 n 88$

critique of formalism, 53

critique of Scholem, 23 , $50,51,119,147$ n45, $154 \quad n 45$

critique of scientific method, $50,53,54$

Kurzwei1, Zvi, 135 n52, 136 n63

Lachower, F., 70, 71, 73, 76, $77,84,85,91,156 \mathrm{n} 16$

Lichtheim, George, $130 \mathrm{n} 2$

Lukács, Georg, 121, 122, 125, $130 \mathrm{n} 2$

Man, Paul de, 50, 120

Mann, Thomas, 58 .

Mendele, Mokher Sefarim, see Abramovitz, Shalom Ya'akov Miron, Dan, 93, 134 n45

Mossinsohn, Yig'al, 107, 110, 159 n72

Nietzsche, Friedrich, 59, 94 , 99,120 
Oxenhandler, Neal, 60,61

Oz, Amos, 106, 109, 112, 113, $160 \mathrm{n} 86$

Palmer, Richard, 48, 56, $146 \mathrm{n} 28,150 \mathrm{n} 95,151 \mathrm{n} 110$

Perl, Yosef, 87, 88, 89

Poulet, Georges, 65, 158 n40

Rabbi Binyamin, see Radler-Feldman Yehoshu'a

Radler-Feldman, Yehoshu'a (Rabbi Binyamin), 19, $20,135 \mathrm{n} 57$

Ravikovitch, Daliah, 107, 109, $159 \mathrm{n} 73$

Richards, I. A. , 48, 60

Ricoeur, Paul, 163 n13

Rosenzweig, Franz, 13, 32, 33, $36,37,39,83,143$ n55

Rotenstreich, Natan, 17, 78, $132 \mathrm{n} 24$

Sadan, Dov, 71, 72, 74, 75, 76, 95,137 n75

Sartre, Jean-Paul, 65

Schapira, H. N. , 72, 73, 76, $79,85,152 \mathrm{n} 14,154 \mathrm{n} 41$

Schechter, Yosef, 17,134 n50

Scheler, Max, 28, 43, 51

Schiller, Friedrich, 46, 47, $48,79,100$

Schleiermacher, Friedrich, 63, 64

Schneour, Zalman, 83, 101 , $158 \mathrm{n} 56$

Schocken, Gershom, 26, 130 n7, $135 \mathrm{n} 51,143 \mathrm{n} 63$

Schocken, Zalman, 18, 135 n51

Scholem, Gershom, 50, 51, 72, $76,78,79,80,147 \mathrm{n} 45$, $154 \mathrm{n} 45,163 \mathrm{n} 17$

Schopenhauer, Arthur, 46 , $137 \cap 80$

Schorske, Carl, 40, 144 n69

Schwarcz, Moshe, 2, 28, 45, $128 \mathrm{n} 3,129 \mathrm{n} 16,145 \mathrm{n} 18$, $151 \mathrm{n} 111$

Sha'anan, Avraham, 76, 80, $152 \mathrm{n} 5$

Shalom, shin, 17, 93, 100, 101, $106,135 \mathrm{n} 50$

Shamir, Moshe, 106, 107, 108, $109,110,112,113$, $135 \quad \mathrm{n} 52$

Shlonski, Avraham, 93, 100, $101,106,142 \mathrm{n} 44$

Simon, Ernst, $19,57,143 n 61$

Spicehandler, Ezra, 71, 85, $155 n 63$

Spiegelberg, Herbert, 151 n112
Staiger, Emil, 57, 65

Steinberg, Ya'akov, 82, 101

Steiner, George, 121,122 , $162 \mathrm{n} 13$

Steinmann, Eliezer, 4

Stifter, Adelbert, 10, 96, 97

Strelka, Joseph, 7, 129 n18

Tishbi, Isaiah, 119, 147 n45

Tschernichovski, Saul, 64, 82 , 98--100, 106

Tsemah, Shlomo, 4, 131 n 16

Weininger, otto, 39, 75, 94, $138 \mathrm{n} 83,163 \mathrm{n} 21$

Wellek, Rene, 4, 41, 48, 52, $111,129 \mathrm{n} 18,142 \mathrm{n} 46$, $147 \mathrm{n} 39,148 \mathrm{n} 49,150 \mathrm{n} 85$

Weltsch, Felix, 131 n10

Wiener, Max, 78

woislawski, zvi, 4

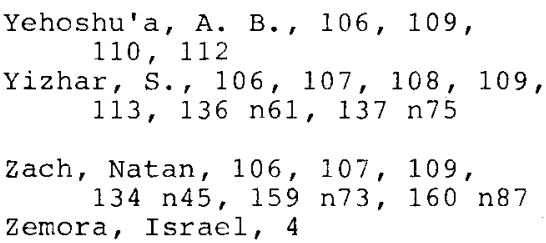

Yehoshu'a, A. B., 106, 109, 110,112

Yizhar, S., 106, 107, 108, 109, $113,136 \mathrm{n} 61,137 \mathrm{n} 75$

Zach, Natan, 106, 107, 109, $134 \mathrm{n} 45,159 \mathrm{n} 73,160 \mathrm{n} 87$

zemora, Israel, 4 



\section{INDEX OF SUBJECTS}

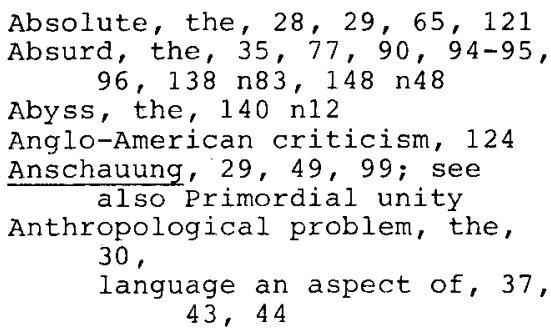

Art

as communication, 44

entropy of $45,64,84$

Austro-Hungarian Empire see Hapsburg Empire

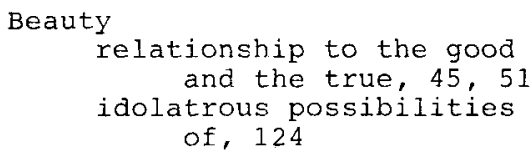

Geistesgeschichte

Kurzweil's rejection of, 55,57

Gestalt approach to criticism, $48,56,64,65$

Hapsburg Empire, 9, 10, 11, 40, 96,121

suicide in, $138 \mathrm{n} 83$

Haskalah, 70, 71, 72, 73, 77, $78,79,83,84,85,87$, $88-89,90,98,99$
Hebrew language

crisis in 20 th c., 111

raping of, 84

sacral nature of, 37,38 , $93,101,105$

Hermeneutic circle, 63, 64, 140 n9

Hermeneutic nature of criticism, 49, 63, 64; see also Phenomenology

Historicism, 50

Humanism, 30, 36

in Kurzweil, 103

Idyliic, the

as source for art, 46

in 'Tschernichovsky's poetry, 99, 100

Immanent coherence, 59; see also Intrinsic coherence

Independence of the critic, 58

Individualism, 29, 30, 120

Intrinsic coherence, 59, 63, $65,127 \mathrm{nl}, 149 \mathrm{n} 81$

of Tschernichovski's work, 98

of Greenberg's work, 103

Irrational, the

as source for artistic creativity, 46

Israeli criticism, 52, 54, 125

"Jewish question", the, 122

Language

as answer to the anthropological question, 43,44

as discloser of Being, 37 crisis of in 20 th $\mathrm{C} ., 40$, 41

George Steiner on, $162 \mathrm{n} 13$

Late return, $84,90,102$

in Agnon, 96

in Tschernichovski, 99

Lebensphilosophie, 22, 37, 47, $88,119,140$ n16

Literary creativity, 46,47

Marxism, 341 n28, 148 n48

Marxist critiques of Kurzweil, $140 \mathrm{n} 15$ 
Metahistorical approach to Judaism, 12, 32, 35 as reflected in Hebrew language, 37,38

in Greenberg's poetry, 102-103

Metaphysics, 27

Mode of existence of literary

work, 6I; see also

ontological status

Modernity, 29-30, 65, 120

defined by Kurzweil, 77, $78,154 \mathrm{r} 45$

defined by scholem, 72

and Nazism, 140 n 14

Modern Hebrew literature

characteristics of $, 3,4$

periodizations of, 71,77 , $85,104,105,155 \mathrm{n} 63$

as an indicator of literary norms, 110-111

revisions in understanding of, $75,76,83$, $153 \mathrm{n} 25$

relationship to European tradition, 4

European beginnings of, 81

two broad streams discerned in by Kurzweil, 82

Monism, critical, 65, 124, 125

Moravia, 10; see also Czech Jewry

Myth, 78, 103, 104, $163 \mathrm{n} 27$

"New continuum", 35, 85

in Agnon, 97

in Greenberg, 102-104

see also Metahistorical approach

New criticism, $60,61,64,83$

Objectivity, 150 n95; see also subjectivity

ontological status of work of art, 49

see also Mode of existence
Sabbatian movement, $72,73,78$, $79,80,154 \mathrm{n} 45$

Sacred, the, 77,82

Greenberg's poetry as embodiment of, 104

in art, 69; see also Hebrew language

Secularism, 70, $71,76,80$ in art, 69 secularization, 29

Secular humanism, $148 \mathrm{n} 48$

in Altermann and Shlonski, 100,101

in Tschernichovski, 99 , 100;

see also Humanism

Self-hate, Jewish, 39, 74, 94

Shiva me'uheret, 30 ; see also Late return

Sprachphilosophie, 36; see also Language

Subjectivity, $50,141 \mathrm{n} 23$

of criticism, 62,63

of Kurzweil's criticism, $66,67,159 \mathrm{n} 58$

suicide, $30,138^{\prime} \mathrm{n} 83$

Thanatos, 30, 95; see also Absurà

Values, 51, 52, $148 \mathrm{n} 48, \mathrm{n} 49$

Verstehen, 56

Vision, 90,147 n39 primal of childhood, 45

see also Anschauung, Primordial unity

Zeitgeist, 87

Zionism, 32-35, 122

Phenomenology, 56, 66-67,

$147 \mathrm{n} 4 \mathrm{l}$

in criticism, 60-61

in Kurzweil's criticism, 50

Primordial unity

childhood as source of, $28-29$

in Agnon, 96

in Greenberg, 102-104

in Tschernichovski, 100 